US Army Corps

of Engineers ${ }_{\circledast}$

Engineer Research and

Development Center

Classical and Innovative Methods of Fatigue and Fracture Repairs in Navigation Steel Structures

Christine M. Lozano and Guillermo A. Riveros

April 2021 
The U.S. Army Engineer Research and Development Center (ERDC) solves the nation's toughest engineering and environmental challenges. ERDC develops innovative solutions in civil and military engineering, geospatial sciences, water resources, and environmental sciences for the Army, the Department of Defense, civilian agencies, and our nation's public good. Find out more at www.erdc.usace.army.mil.

To search for other technical reports published by ERDC, visit the ERDC online library at https://erdclibrary.on.worldcat.org/discovery. 


\section{Classical and Innovative Methods of Fatigue and Fracture Repairs in Navigation Steel Structures}

Christine M. Lozano and Guillermo A. Riveros

Information Technology Laboratory

U.S. Army Engineer Research and Development Center

3909 Halls Ferry Road

Vicksburg, MS 39180-6199

Final report

Approved for public release; distribution is unlimited.

Prepared for U.S. Army Corps of Engineers

Washington, DC 20314-1000

Under Work Unit 8D8G7F A1100- CFRP for Repairs 


\section{Abstract}

Most of the hydraulic steel structures (HSS) in the U.S. have reached or have past their design life, which leads to unsatisfactory performance. Welded connections with low fatigue resistance, poor weld quality, unanticipated structural behavior, or unexpected loading due to the deterioration of the design boundary conditions are the causes of fatigue cracking. The purpose of this report is to identify and evaluate the traditional and new methods used for fatigue and fracture repairs in navigation steel structures to restore their load carrying capacity and fatigue and fracture resistance. The final objective was to generate a guidance report comprising of recommended and more efficient repair methods for the different fatigue limit states observed in navigation steel structures.

DISCLAIMER: The contents of this report are not to be used for advertising, publication, or promotional purposes. Citation of trade names does not constitute an official endorsement or approval of the use of such commercial products. All product names and trademarks cited are the property of their respective owners. The findings of this report are not to be construed as an official Department of the Army position unless so designated by other authorized documents. 


\section{Contents}

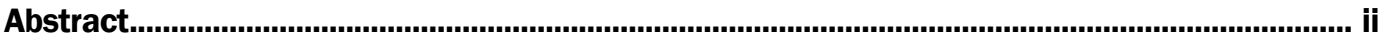

Figures and Tables............................................................................................................................................

Preface ..................................................................................................................................... vifi

1 Introduction............................................................................................................................... 1

1.1 Objectives.................................................................................................... 1

1.2 Research significance and Army benefits ..................................................... 2

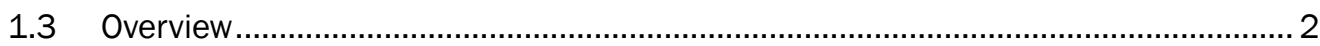

2 Fatigue and Fracture Theory ........................................................................................... 4

2.1 Modes of fracture ..................................................................................................... 5

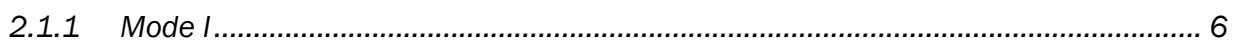

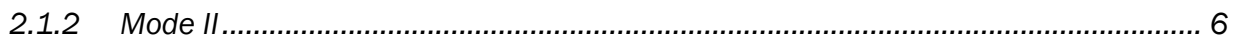

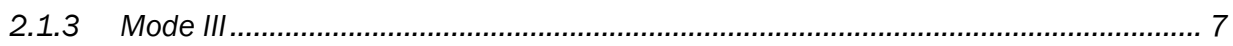

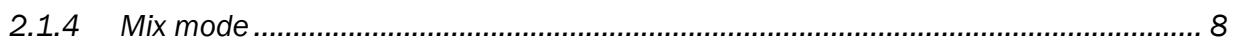

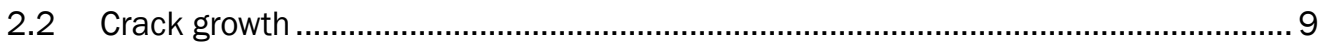

2.2.1 Griffiths energy release rate ............................................................................ 10

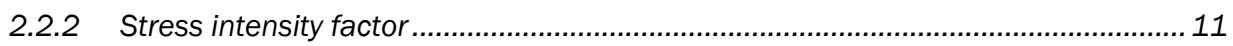

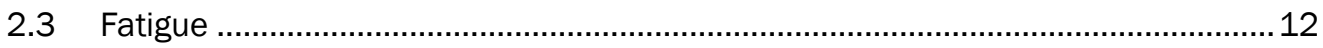

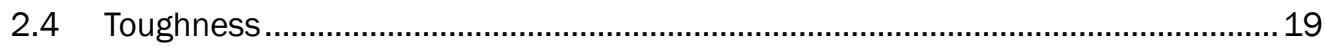

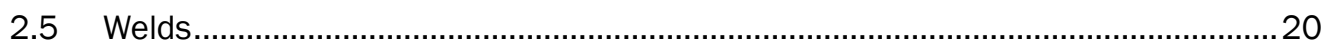

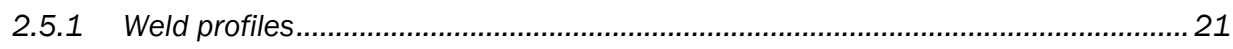

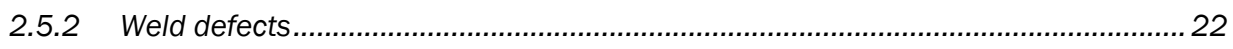

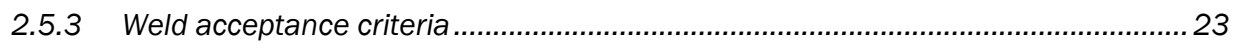

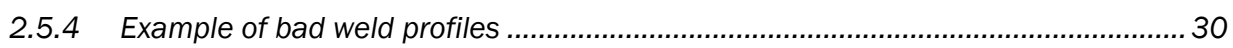

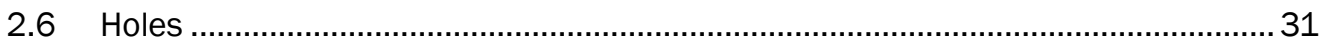

3 A Guide to a Fitness-For-Purpose Report .........................................................................33

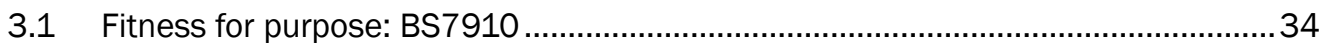

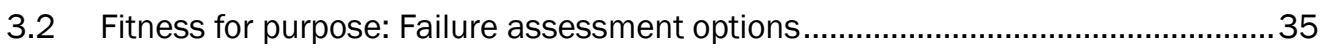

3.3 Fitness for purpose: Variables ......................................................................... 38

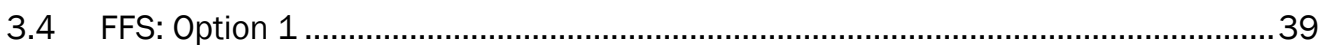

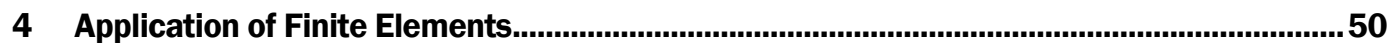

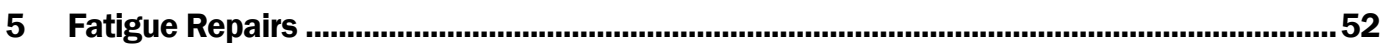

5.1 Crack detection techniques ........................................................................... 52

5.2 Current crack repair and retrofit methods ...................................................... 58

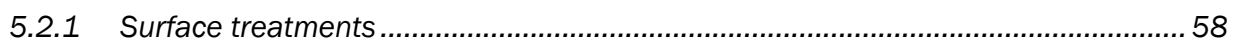

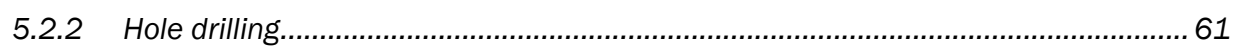

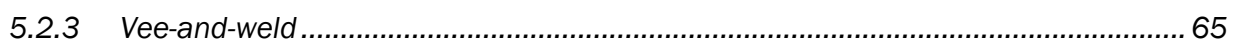

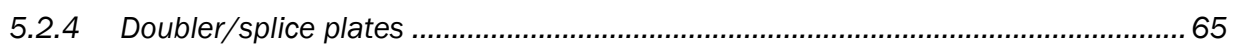

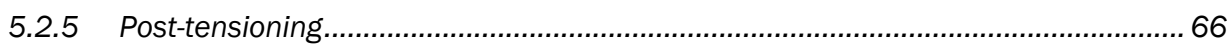




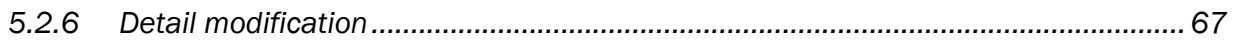

5.3 Underwater crack repair and retrofit methods ....................................................69

5.4 Innovative crack repair and retrofit research and methodologies............................69

5.4.1 Fiber Reinforced Polymer (FRP) ...................................................................... 70

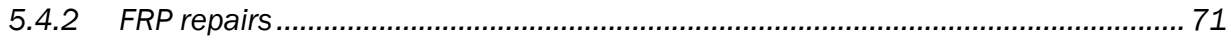

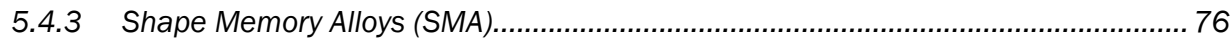

5.5 Comparison of repair and retrofit methodologies ................................................ 77

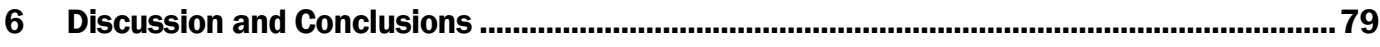

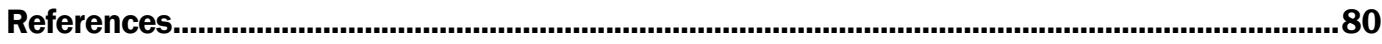

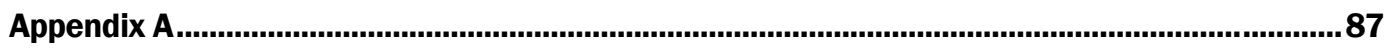

Appendix B...........................................................................................................................107

Acronyms .................................................................................................................................. 126

\section{Report Documentation Page}




\section{Figures and Tables}

\section{Figures}

Figure 1. Atom bonds breaking due to an external load, P.

Figure 2. The three fracture modes: a) Mode I, b) Mode II, and c) Mode III (Anderson 2005)

Figure 3. Mode II, plane of displacement.

Figure 4. Mode III, plane of displacement. ................................................................................... 8

Figure 5. Examples of mixed mode cracks on a miter gate's pintle socket and front flange

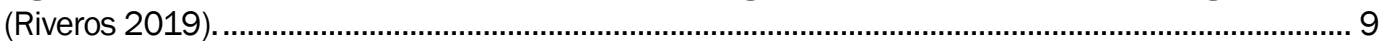

Figure 6. Crack at welded connection (Old Hickory Lock and Dam) .............................................. 10

Figure 7. Different energy states during fracture. ……………..................................................... 11

Figure 8. Energy accumulation over time. .................................................................................... 13

Figure 9. Fracture stages................................................................................................ 13

Figure 10. Paris Law derivation from plot. ................................................................................... 15

Figure 11. Example: Paris Law.............................................................................................. 15

Figure 12. Example: Fatigue Resistance Equation. .................................................................. 17

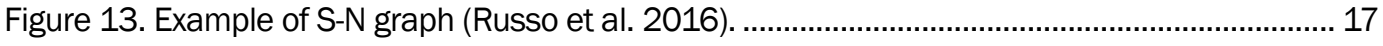

Figure 14. Example: S-N Curve (Thompson and Shephard). ........................................................ 18

Figure 15. Impact Test; conservation of energy. ………................................................................. 20

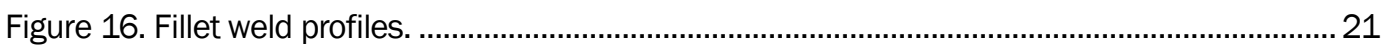

Figure 17. Groove weld profiles. .......................................................................................... 22

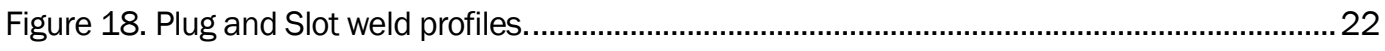

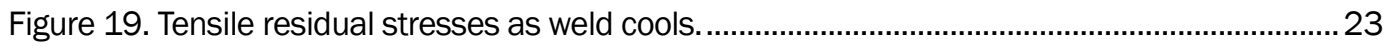

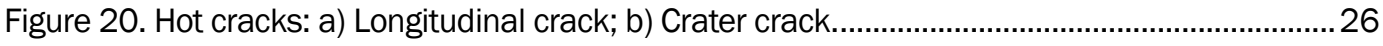

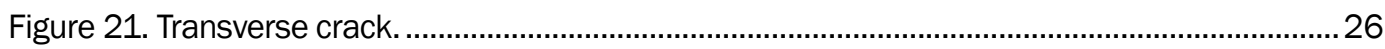

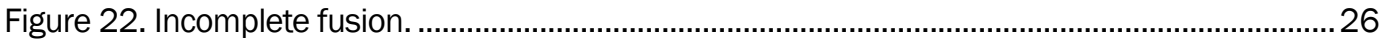

Figure 23. Example of weld bead with incomplete fusion (John 2014).......................................... 26

Figure 24. a) Cratering at the end of a weld b) Radial cracking within a crater. .............................. 27

Figure 25. Example of an undercut profile. ............................................................................. 28

Figure 26. Examples of porosity: a) distributed porosity b) surface porosity c) wormholes............... 29

Figure 27. Examples of a) satisfactory b) passable and c) unacceptable weld profiles.................... 31

Figure 28. Poor lock and dam weld profile with crack (Old Hickory Lock and Dam)....................... 31

Figure 29. a) Stress flow and stress concentrations around a smooth hole. b) Stress flow

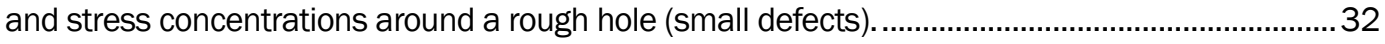

Figure 30. Crack at a riveted connection hole detail (USACE 2009). ...........................................32

Figure 31. Failure Assessment Diagram (FAD) Option 1, Continuous and Discontinuous

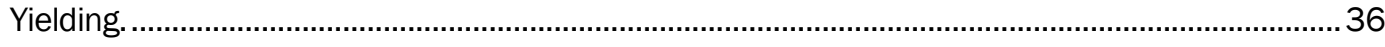

Figure 32. Option selection flowchart. ................................................................................... 37

Figure 33. Continuous and discontinuous yielding stress-strain.........................................................37 
Figure 34. Edge crack geometric dimensions.......................................................................... 42

Figure 35. Center crack geometric dimensions. ..................................................................... 43

Figure 36. Welded joint geometries for local stress concentration factor (BSI 7910:2013

+A1:2015 2015) ................................................................................................................... 45

Figure 37. Typical structural analysis a) 1D structural analysis b) 2D structural analysis c)

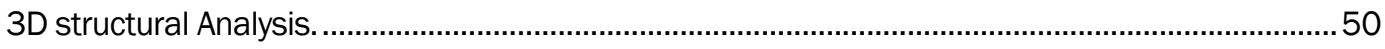

Figure 38. a) Global tainter valve model with location of high stress b) tainter valve high stress results c) CFRP repairs (Riveros 2018)................................................................................. 51

Figure 39. Dye-penetrant inspection process. .........................................................................53

Figure 40. Magnetic particle inspection. ............................................................................. 53

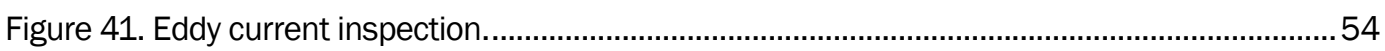

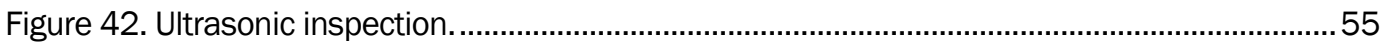

Figure 43. Time-of-flight diffraction inspection......................................................................... 55

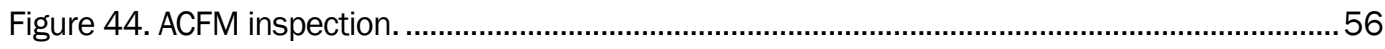

Figure 45. Weld surface finish a) no finish b) ground finish. ............................................................ 58

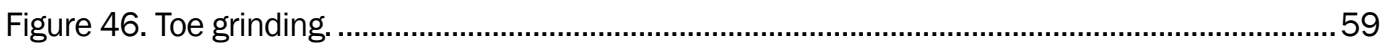

Figure 47. Full-profile grinding. ............................................................................................. 59

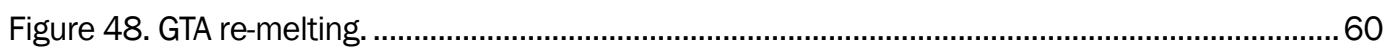

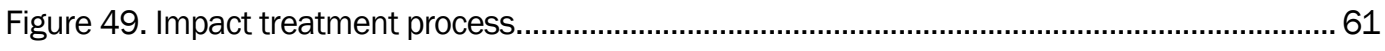

Figure 50. Hole drilling stress distributions: 1) Mode I; 2) Mode I; 3) Mixed mode..........................63

Figure 51. Mixed mode crack and angle.................................................................................. 64

Figure 52. Hole placement: a) hole placement not acceptable; b) acceptable hole

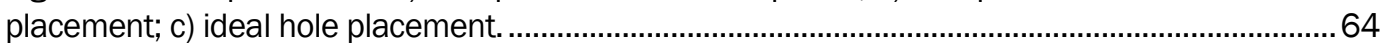

Figure 53. Vee-and-weld method............................................................................................. 65

Figure 54. Doubler/splice plate repair. .......................................................................................6

Figure 55. a) Stresses under load; b) stresses with post-tension applied........................................67

Figure 56. Detail modification: a) original detail; b) detail modification (lower stress

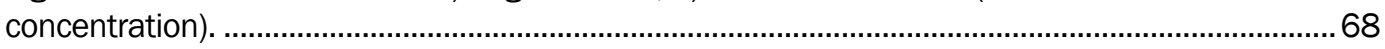

Figure 57. Detail modification repair: a) cracked section (detail category D); b) tack welded

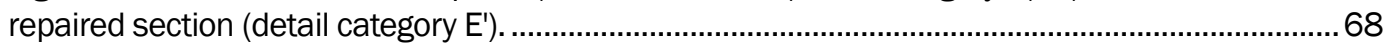

Figure 58. Underwater welding: a) set weld; b) dry underwater welding/hyperbaric chamber welding.

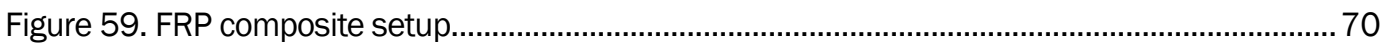

Figure 60. Composite layouts: a) uni-directional; b) bi-directional; c) quad-directional...................... 70

Figure 61. a) Fatigue crack of tainter valve beam; b) CFRP patch repairs for fatigue crack in tainter valve steel beam (Riveros 2018)................................................................................

Figure 62. Pre-stressed CFRP retrofit a) Slack/unstressed CFRP; b) Pre-stressed CFRP (Ghafoori et al. 2016)............................................................................................................ 72

Figure 63. CFRP patch layer configuration. ............................................................................... 73

Figure 64. Large-scale experiment (Mahmoud 2018). .................................................................

Figure 65. CFRP repairs on Pickwick Lock and Dam Tainter Valve................................................. 75

Figure 66. CFRP repair on Old Hickory Lock and Dam front flange...............................................75

Figure 67. Stress shift due to pre-stress retrofit (Ghafoori et al. 2018; Ghafoori 2016)................... 76 
Figure 68. SMA microstructure and method of deformation recovery (Lagoudas 2008).

\section{Tables}

Table 1. Different literature $C \& m$ values and cycles to critical crack failure.................................. 19

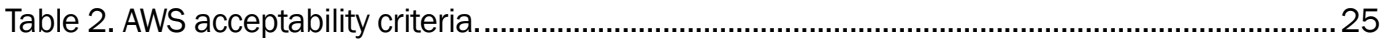

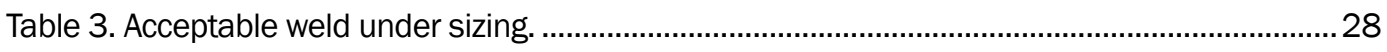

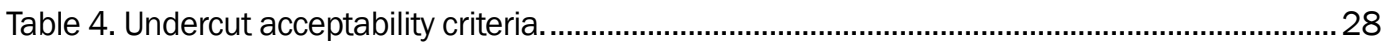

Table 5. Porosity acceptability limits.......................................................................................... 30

Table 6. Values for factors $\mathrm{v}$ and $\mathrm{w}$ used in calculating the stress concentration factor $\mathrm{Mk}$ (BSI 7910:2013 +A1:2015 2015) ................................................................................................. 46

Table 7. Factor of Safety based on failure consequence and section redundancy (BSI

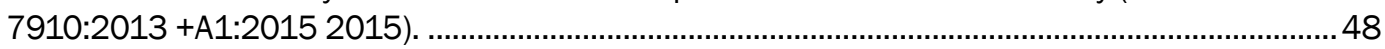

Table 8. Steel fracture toughness and Paris Law constants based on environment. .......................48

Table 9. Advantages and disadvantages of most common crack inspection methods.....................57

Table 10. Material properties of steel and common FRP (Sonnenscheina 2016).......................... 71

Table 11. Common advantages and disadvantages of different FRP (Sonnenscheina

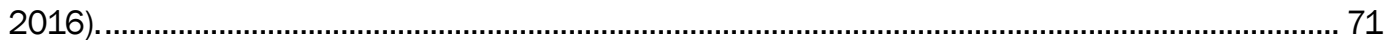

Table 12. Comparison of different repair and retrofit methodologies. ........................................... 78 


\section{Preface}

This study was conducted for the U.S. Army Corps of Engineers

Headquarters under the Navigation System Research Program, U.S. Army Engineer Research and Development Center (ERDC), Project HB52B1, "Methods to Repair Fatigue-Induced Cracks Using Fiber-Reinforced Polymers." The Technical Monitor was Mr. Charles E. Wiggins, Technical Director, Coastal Hydraulics Laboratory, ERDC.

At the time of publication, Dr. Jeffrey Hensley was Chief of the Computational Analysis Branch, ERDC-Information Technology Laboratory (ITL); Dr. Jerrell R. Ballard, Jr. was Chief of the Computational Science and Engineering Division, ERDC-ITL; and Dr. Robert Wallace was the Technical Director for ERDC-ITL. The Deputy Director of ERDC-ITL was Ms. Patti S. Duett and the Director was Dr. David A. Horner.

The Commander of ERDC was COL Teresa A. Schlosser and the Director was Dr. David W. Pittman. 


\section{Introduction}

The U.S. Army Corps of Engineers (USACE) has the maintenance and operational responsibility for hydraulic steel structures (HSS); HSS consist primarily of lock and spillway gates, bulkheads, and other closure structures (USACE 2009). The majority of the HSS in the U.S. have reached or are past their design life, which leads to unsatisfactory performance of these structures (Dexter et al. 2007). Most of the failures of HSS are due to fatigue cracking. Welded connections with low fatigue resistance (Markland Lock, and Greenup), poor weld quality, unanticipated structural behavior, or unexpected loading due to the deterioration of the design boundary conditions (Riveros 2009) are the causes of fatigue cracking. The poor performance has led to miter gate investigations and repairs. In the most severe cases, there was at least one catastrophic failure of a bulkhead system that nearly resulted in loss of life (Coffeeville Lock, maintenance stop-logs, 1994) (USACE 2009). At least three other cases have required complete replacement of lock gates (Melvin Price Lock, Upper Mississippi River Lock 27, and The Dalles) (USACE 2009). Maintenance and repair of fatigue and fracture failures represent a major Operations and Maintenance expenditure for the Corps.

\subsection{Objectives}

The purpose of this report is to identify and evaluate the traditional and new methods used for fatigue and fracture repairs in navigation steel structures to restore their load carrying capacity and fatigue and fracture resistance. The final objective was to generate a guidance report comprising of recommended and more efficient repair methods for the different limit states observed in navigation steel structures. To reach the objectives, this technical report (TR) includes five major thrusts: (1) provide an overview of fatigue and fracture; (2) offer guidance on a fitnessfor-purpose assessment; (3) demonstrate the use of finite element analysis in evaluating fatigue cracks and failures; (4) present, compare, and contrast the different common practice fatigue methodologies; (5) introduce new research for mitigating or repairing fatigue cracks. 


\subsection{Research significance and Army benefits}

USACE requires that hydraulic steel structures with fracture critical members (FCM) whose failure would result in probable loss of life be inspected to ensure structural integrity (USACE 2009). Recent history has demonstrated that the commonly used repair methods have not been as effective as expected and have required periodic repairs (Riveros 2018). Many repairs fail because HSS fatigue cracks are developed under tension and shear loads, while the most common repair techniques were developed for pure tension loading. This TR will provide information and guidance on analyzing fatigue and critical crack length as well as providing the best combination of repairs based on the boundary conditions and loading causing crack initiation, growth, and propagation. This information will help improve and expand the current knowledge of fatigue cracking and crack growth, improving the reliability of the structural system for fatigue and fracture.

\subsection{Overview}

This TR provides information and guidance on implementation of the five major thrusts. The Corps utilizes fitness-for-purpose reports to assess the results of an inspection and determine the critical crack length through fatigue and fracture theory. Finite element analysis is helpful in analyzing complex connections, loading, and displacement boundary conditions and verifying the results of the fitness-for-purpose. Comparing each methodology requires the methods to be evaluated and compared on their effectiveness due to load and displacement boundary conditions. Introducing new research expands the current knowledgebase to improve the methods used by the Corps for mitigating fatigue cracking.

The current state-of-practice repair methods can be split into seven methods. The following list gives an overview of the common and new fatigue and fracture repairs:

1. Surface treatments
a. Grinding
b. Re-melting
c. Impact treatments

2. Hole drilling

3. Vee-and-weld 
4. Adding doubler/splice plates

5. Post-tensioning

6. Modifying the detail

7. Carbon fiber reinforced polymer (CFRP) patch

8. Pre-stressed CFRP retrofit

9. Shape Memory Alloy 


\section{Fatigue and Fracture Theory}

A basic understanding of the fundamentals of fatigue and fracture mechanics is useful in analyzing failures and implementing repairs. Fracture mechanics is a method of characterizing the fracture behavior in structural parameters, stress, and flaw size (Barsom 1987). Fracture mechanics can quantitatively describe the relationship between stresses, material toughness, and flaw size to increase the reliability of structural designs.

The concepts of fracture mechanics were used in the World War II era to predict the failure of brittle steel materials in boat hulls. Since then, linear elastic fracture mechanics (LEFM) has been increasingly used to predict brittle fracture of high-strength low-toughness materials because most fractures in these materials occur in the linear elastic regime (Anderson 2005).

The rate of change of an existing crack, the load magnitude at which a crack will grow, and crack growth direction are determined using fracture mechanics principles. Fatigue is related to fracture because it is a timedependent crack growth mechanism.

Fracture is the cracking or breaking of a material due to the accumulation of energy in the form of tensile and/or shear stresses. A crack can occur in all materials, given sufficient external energy (via loads/stresses) is input into the material system. Figure 1 shows how external loads can cause and grow fractures/cracks at the atomic level. Fracture is susceptible to the material's fabrication environment (such as fabrication heat, weld type, and weld heat), material conditions, and type of material (Anderson 2005; Barsom 1987; Dexter 2004). 
Figure 1. Atom bonds breaking due to an external load, P.

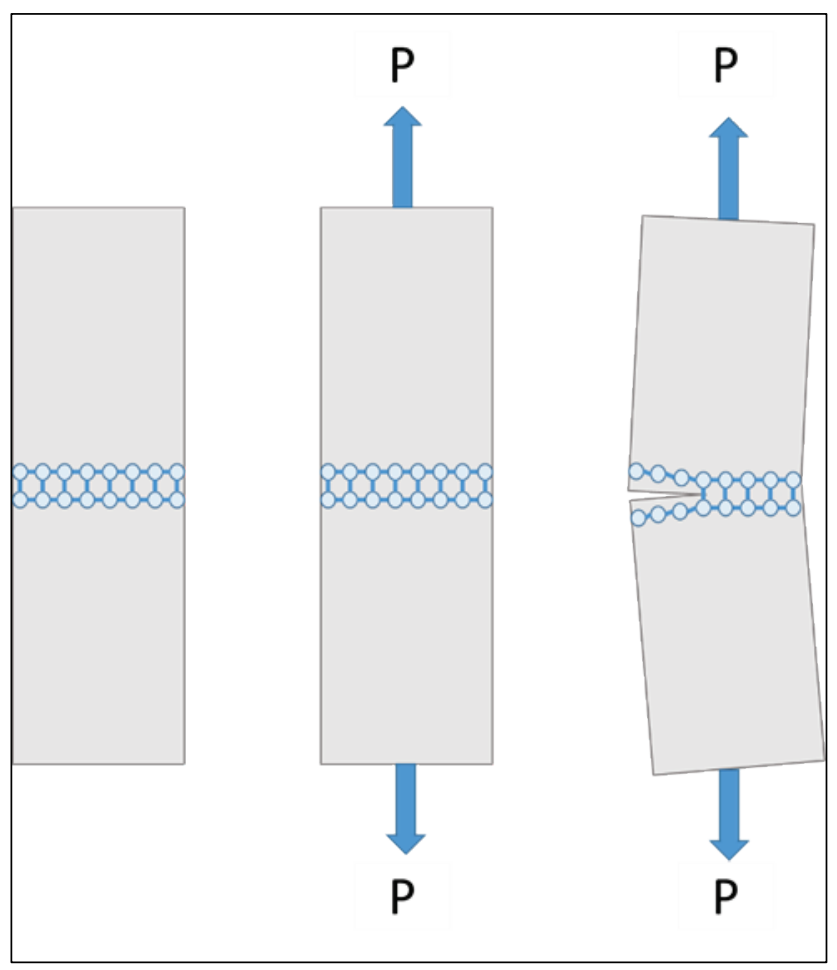

\subsection{Modes of fracture}

There are three principal modes of fracture, which are Mode I (opening mode), Mode II (sliding mode), and Mode III (tearing mode). The differences between these modes of fracture are in the type of relative displacement between the surfaces of a crack (Figure 2). When there are two or more types of fracture modes occurring at the same time, the state of fracture is known as mixed mode. 
Figure 2. The three fracture modes: a) Mode I, b) Mode II, and c) Mode III (Anderson 2005).

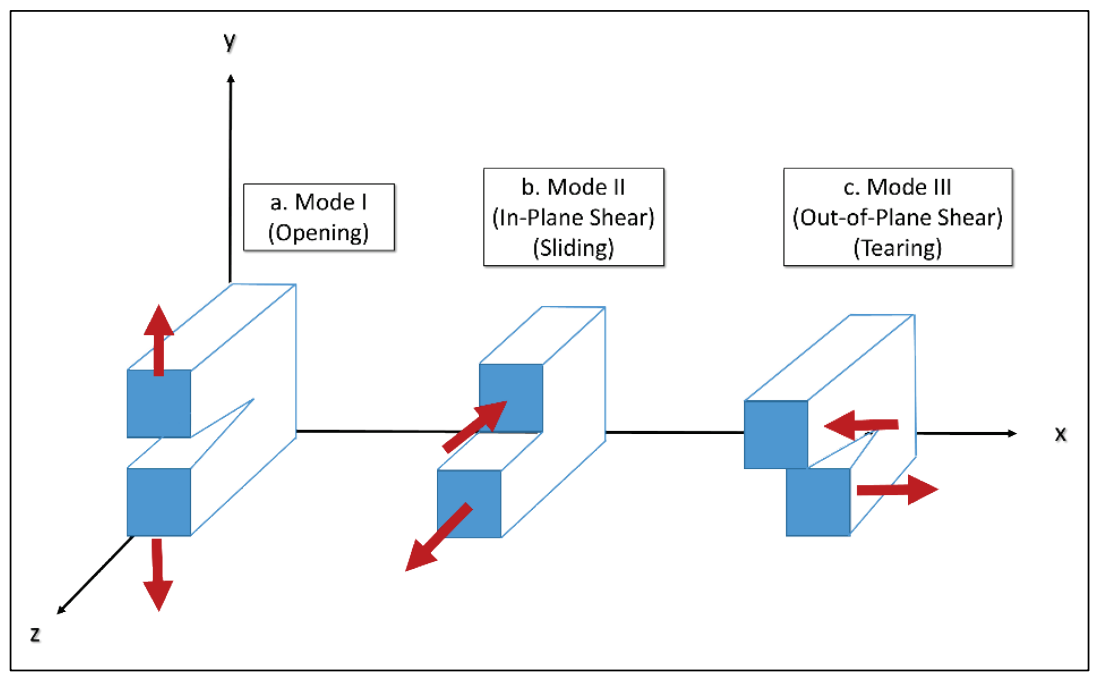

\subsubsection{Mode I}

In the opening mode, the instantaneous displacement of two crack surfaces is in opposite directions and perpendicular to the crack surface as shown in Figure 2. Direct tension and flexural action usually cause structural failure in this mode.

\subsubsection{Mode II}

Figure 3 shows the sliding or in-plane-shear mode; the instantaneous movement of the crack surfaces is in perpendicular, opposite direction but in the plane of the crack surface. In-plane shear forces or principal stresses, at a 30 to 60-degree angle, cause Mode II cracking (Figure 3). The $\mathrm{x}-\mathrm{y}$ plane is the plane of symmetry (in-plane). Cracking occurs with respect to plane $\mathrm{x}-\mathrm{z}$ (Figure 3 ). 
Figure 3. Mode II, plane of displacement.

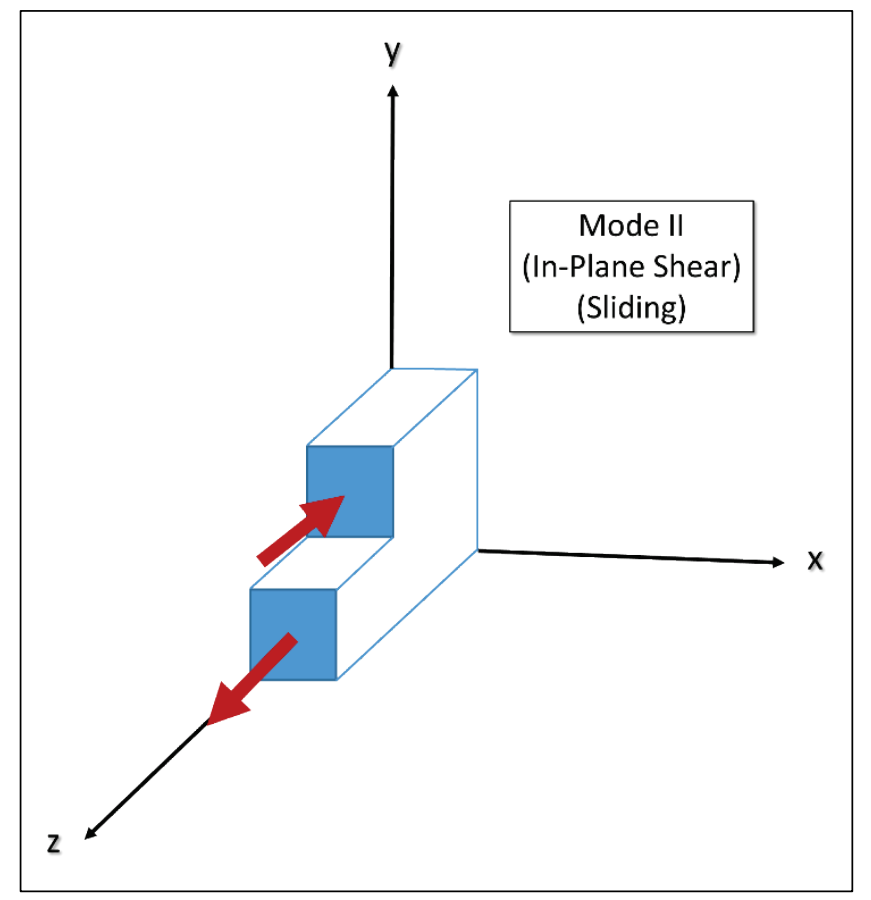

\subsubsection{Mode III}

Figure 4 shows Mode III; the tearing mode. This mode experiences instantaneous opposing and out of plane movement of the two crack surfaces (along the $\mathrm{x}-\mathrm{z}$ plane). The Mode III crack growth is antisymmetric with respect to both planes $x-y$ and $x-z$. Torsion loading causes this mode of fracture. 
Figure 4. Mode III, plane of displacement.

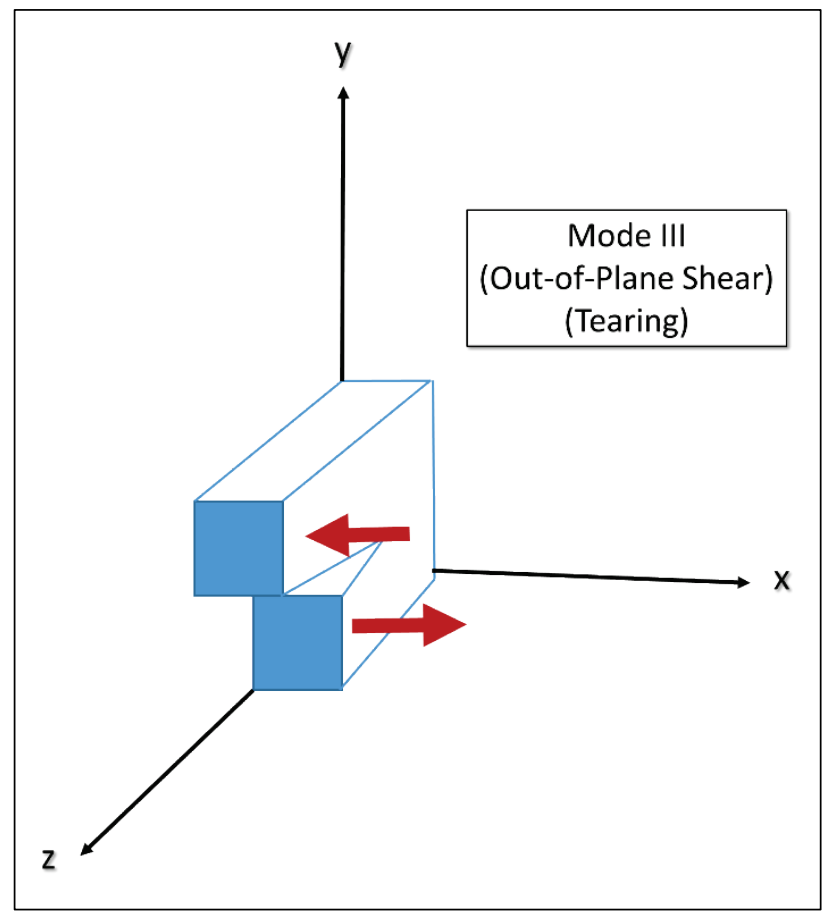

\subsubsection{Mix mode}

A mixed mode crack is a crack that initiates and propagates due to multiple fracture modes (Quian 1996; Patel and Pandey 1981). Due to shear forces, mixed mode cracks grow at an angle, typically between 30 to 60 degrees (Patel and Pandey 1981). Mixed mode can also be identified by a change in direction of the crack propagation (Quian 1996). Figure 5 shows two mixed mode cracks due to tension and torsion stresses induced through diagonal relaxation. 
Figure 5. Examples of mixed mode cracks on a miter gate's pintle socket and front flange (Riveros 2019).

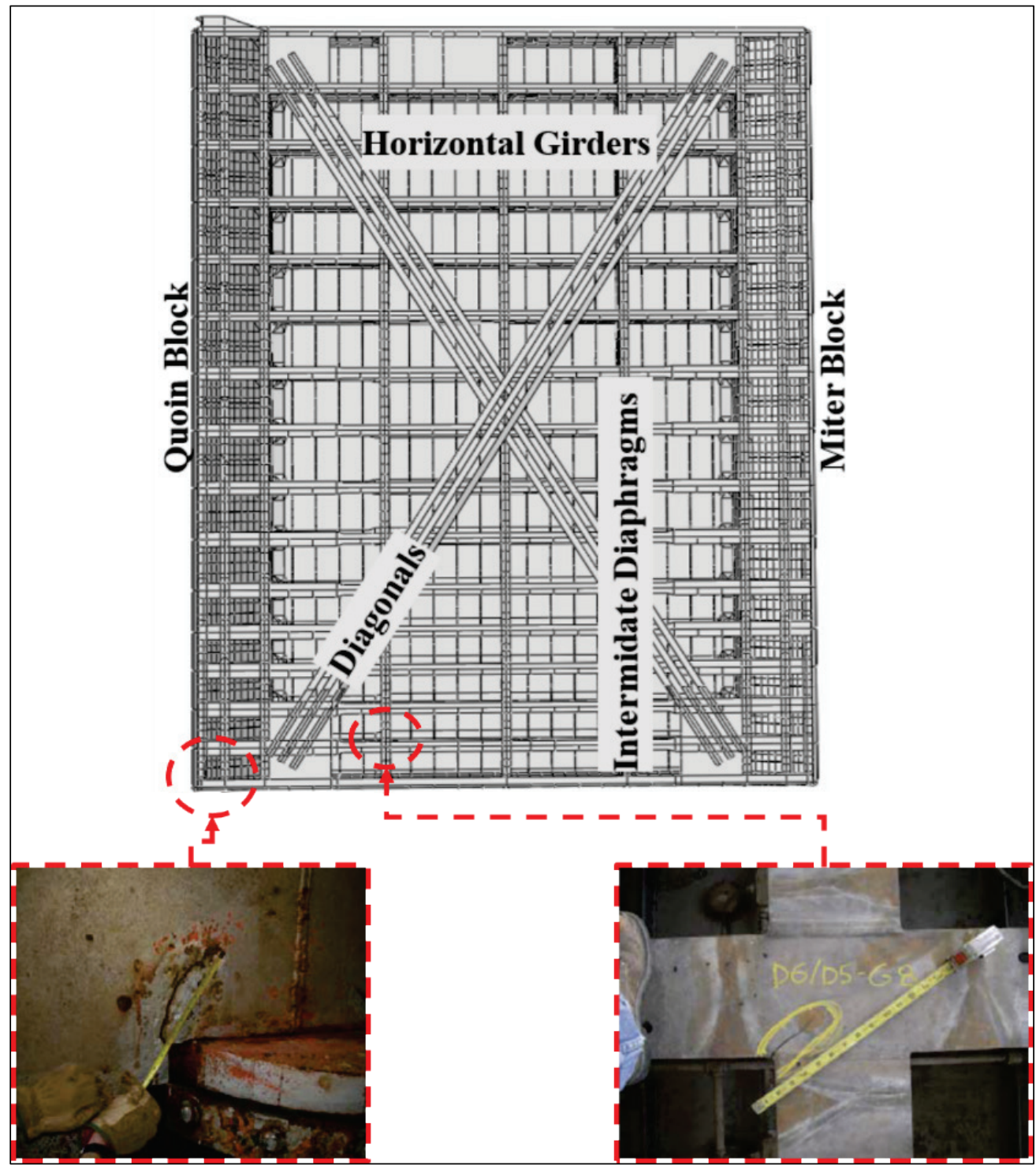

\subsection{Crack growth}

Cracks begin and propagate in areas where there are high stress concentrations. If the high stresses are higher than the atoms' cohesive energy, they will initiate a crack (Anderson 2005). Common areas of high stress concentrations in HSS are welded connections (Figure 6) or rough edges in details such as coped holes (Dexter et al. 2007). Once a crack has initiated further applied stresses it will cause the crack to propagate. A crack's propagation rate is determined by factors such as the applied stress value, crack size, and environment. 
Figure 6. Crack at welded connection (Old Hickory Lock and Dam).

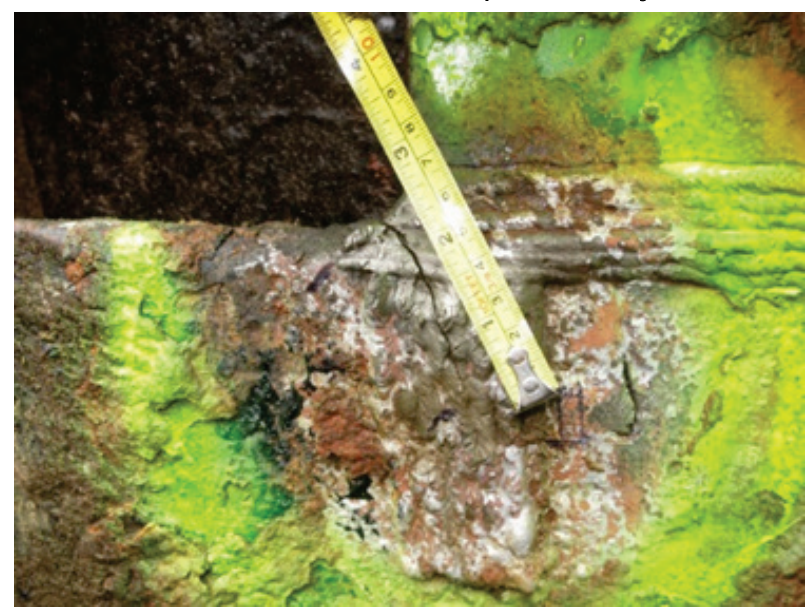

Two common fatigue and fracture approaches for evaluating crack propagation, crack growth rate, and crack size are Griffiths Energy Balance and the Stress Intensity Factor (K). Griffiths energy release rate theory is based on energy instead of local stress while the stress intensity factor's basis is the local stress. Both methods can be correlated to one another and can be used to evaluate fatigue (Anderson 2005).

\subsubsection{Griffiths energy release rate}

The Griffith's approach describes crack near-stresses and displacements using energy. The principles of conservation of energy are the foundation for Griffith's theory. The law of conservation of energy states the following (Anderson 2005):

1. Energy cannot be created or destroyed

2. Energy can change its form (i.e. potential energy to kinetic energy), but the total amount of energy does not change

Attraction forces, known as the surface bond energy, hold atoms together at equilibrium. The surface bond energy is a material property and varies from material to material; experimental results yield surface bond energy values. When a system of atoms, as seen in Figure 7, experiences tensile energy, the atoms are no longer in a state of equilibrium (minimum potential energy). As more energy is added to the system, the energy within the system of atoms reaches the capacity of the surface bond. Once the surface bond energy is surpassed, the atoms must release the excess energy to return to a state of equilibrium. The excess energy is released as 
the atoms separate/fracture and move apart, until the separated atoms reach a new state of equilibrium (stop moving).

Figure 7. Different energy states during fracture.

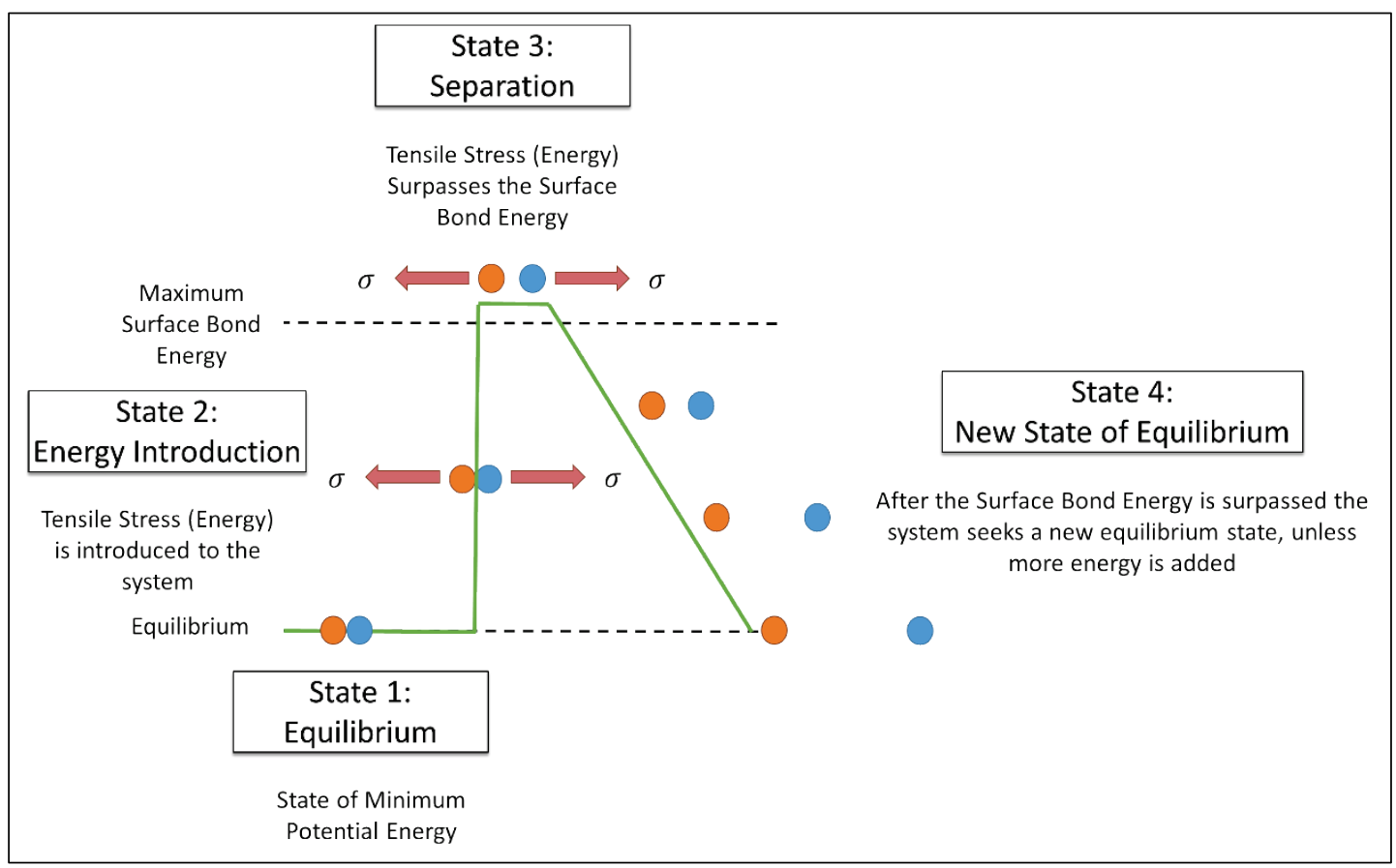

Griffith derived the following equation to describe the stresses and displacements at the crack tip (fracture area):

$$
G=\frac{\sigma^{2} \pi a}{E}
$$

$G$ is the energy release rate, $\sigma$ is the applied external stress, $a$ is the crack length, and $E$ is the modulus of elasticity of the material. Therefore, if the applied stress $\sigma$ (demand) is greater than the surface bond stress (capacity) the material will fracture

\subsubsection{Stress intensity factor}

The stress intensity factor is a single constant, $\mathrm{K}$, related to the energy release rate, and is used to describe the stresses and displacements at the crack tip. The stress intensity factor equation is:

$$
K=\varphi \sigma \sqrt{\pi a}
$$


$K$ is the stress intensity factor; $\varphi$ stands for a combination of geometric, size, and crack location dependent factors; $\sigma$ is the externally applied stress; and $a$ is the crack length. The stress intensity factor is dependent on the type/mode of stress felt at the crack tip and maybe an equivalent combination of different stress types' intensity factors (Anderson 2005).

The stress intensity factor's relationship to the energy release rate can be seen in the following equations:

$$
\begin{gathered}
K=\varphi \sigma \sqrt{\pi a} \\
G=\frac{K^{2}}{E}
\end{gathered}
$$

Within the linear elastic zone, before the material begins to yield, the relationship between the energy release rate approach and the stress intensity approach is equivalent. The stress intensity factor approach is a simpler way of describing/quantifying the stresses and displacements at the crack tip.

\subsection{Fatigue}

Fatigue is a time-dependent mechanism for crack initiation and growth; a function of repeatedly applied stresses over time. The critical stress of a material is the stress at which fracture will occur. Figure 8 demonstrates how energy, E, that is below the material's fracture capacity accumulates over time until the material's critical fracture capacity is reached. The phenomena of energy accumulation over time is known as fatigue induced fracture since the material fractures once its capacity is reached. Some materials, such as steel, have a certain stress limit below which fatigue will not occur. Fatigue is strongly dependent on the material or environmental conditions at the time of fabrication and operation. Different environmental factors can reduce the surface bond energy, which accelerates fatigueinduced fracture (Anderson 2005; Barsom 1987; Dexter 2004). 
Figure 8. Energy accumulation over time.

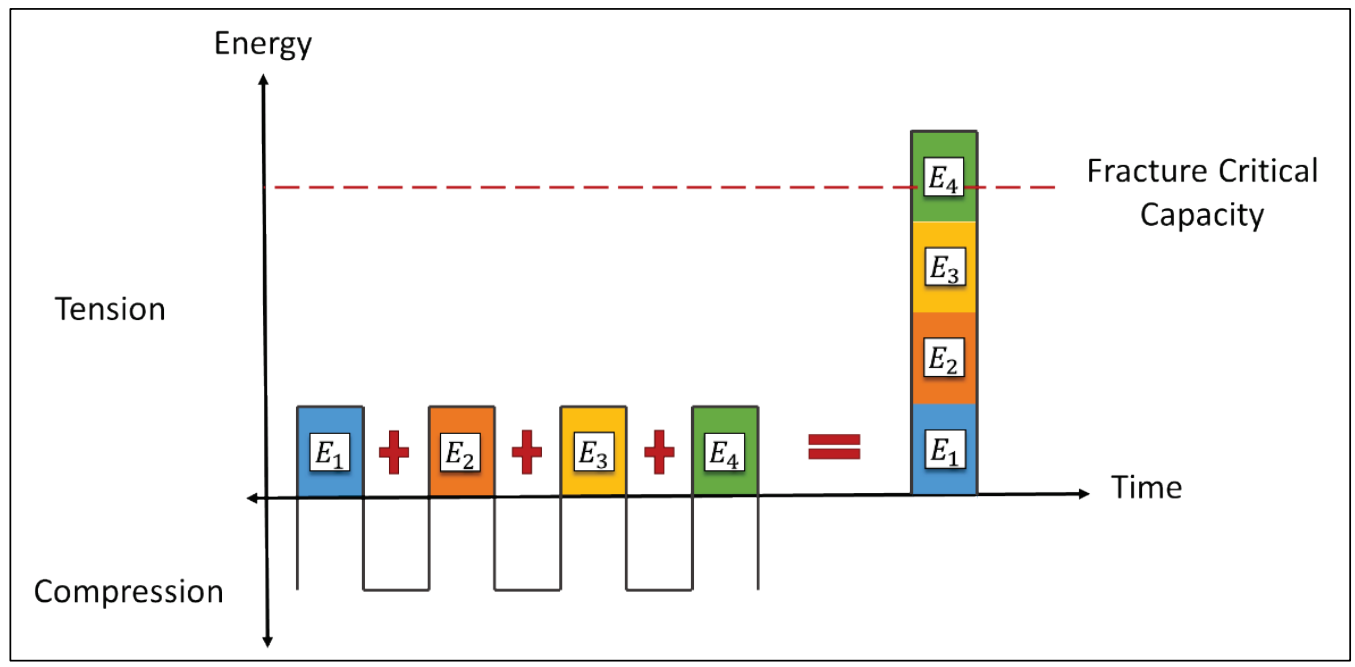

The basis for fatigue crack growth, whether using the stress intensity factor $(K)$ or energy release rate $(G)$, is capacity and demand. Figure 9 shows two capacities of a material, fracture threshold, when a crack initiates, $\left(K_{t h}\right.$ or $\left.G_{t h}\right)$ and the fracture toughness, when a crack reaches a length of exponential growth, $\left(K_{c}\right.$ or $\left.G_{c}\right)$. A crack will not initiate if the demand is less than the fracture threshold (Stage I in Figure 9). However, if the demand is greater than the fracture toughness, the material will, almost instantly, fracture (Stage III in Figure 9). The crack will propagate linearly when the demand is between the fracture threshold and the fracture toughness (Stage II in Figure 9) (Anderson 2005).

Figure 9. Fracture stages.

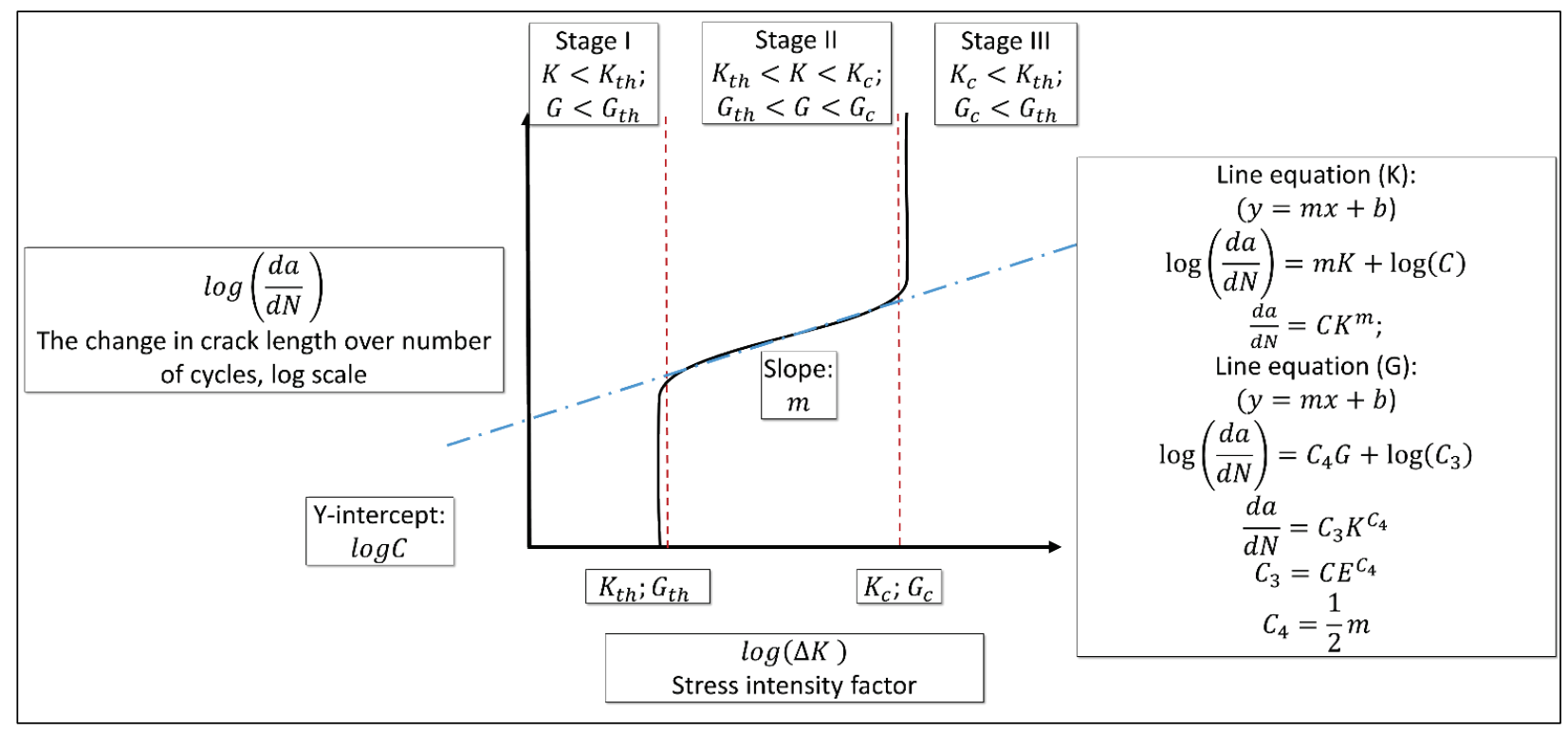


The two most common methods of determining the number of cycles for crack propagation are Paris Law and S-N curves. Paris Law utilizes the stress intensity threshold, $K_{t h}$, and critical stress intensity, $K_{c}$, factors as the capacities and $K$ as the demand. The S-N curves use only the threshold stress range, $(\Delta F)_{t h}$, as the capacity for crack initiation and propagation.

Paris Law is a numerical method used for crack propagation during Stage II. The simplified method of Paris Law does not describe Stage I or III because of the non-linear behavior of the crack growth at these stages. A crack initiates when the demand, $K$, is greater than the capacity $K_{t h}$. Once a crack has initiated, Paris Law utilizes the stress intensity factor, $K$, and material constants, $C$ and $m$, to determine the number of cycles, $N$, to propagate a crack a certain distance, $a$, see Equation 5 .

$$
\frac{d a}{d N}=C \Delta K^{m}
$$

The number of cycles is determined by taking the integral of the Paris Law equation from an initial crack size, $a_{i}$, to a final crack size, $a_{f}$, Equation 6 (Anderson 2005).

$$
N=\int_{a_{f}}^{a_{i}} \frac{d a}{C K^{m}}
$$

Figure 10 shows the typical behavior of crack initiation and propagation along with how Paris Law was derived from a data plot. Figure 11 gives an example of how to calculate number of cycles to the critical crack length using Paris Law. 
Figure 10. Paris Law derivation from plot.

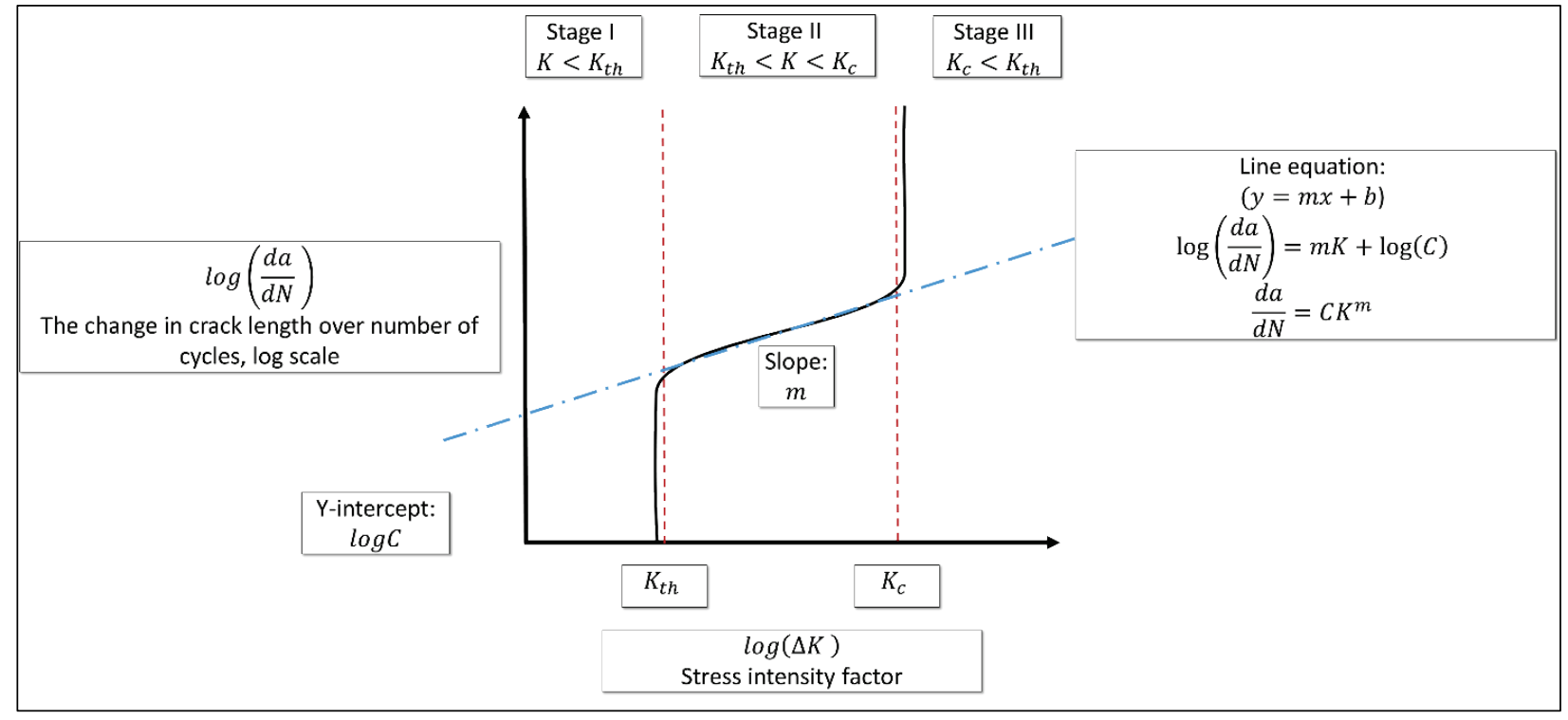

Figure 11. Example: Paris Law.

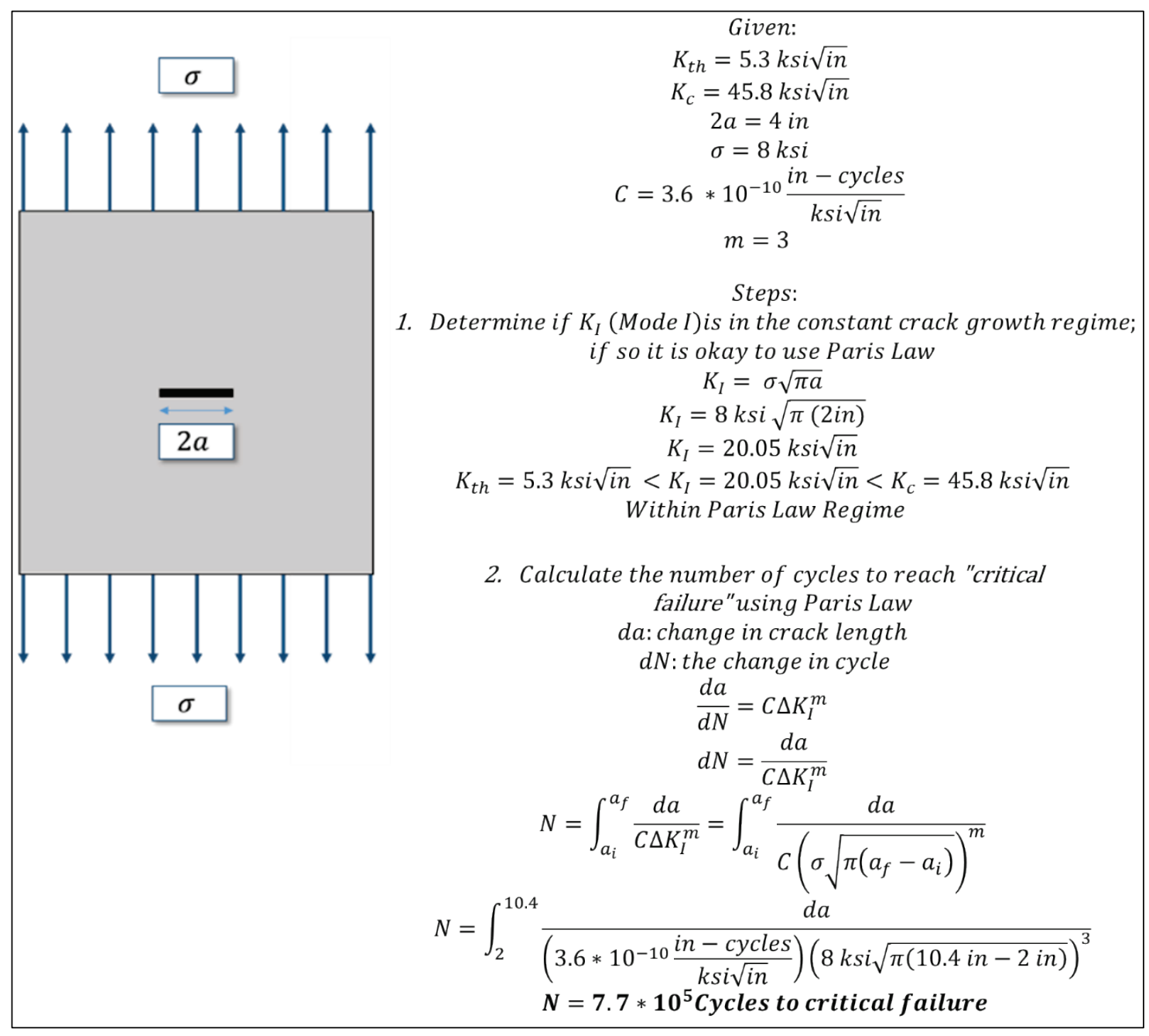


The basis of the S-N curve method is experimentally derived graphs and equations (Russo et al. 2016). The American Association of State Highway and Transportation Officials (AASHTO) has classified different section details into fatigue detail categories based on the experimental data. The fatigue category details give a designer the fatigue threshold, $(\Delta F)_{t h}$, and the experimentally derived constant $A$ (Russo et al. 2016; Grubb 2015; AASHTO 2011), Equation 7. "Design and evaluation of steel bridges for fatigue and fracture" by the Federal Highway Association (FHA) gives the full derivation for the constant $A$ (Russo et al. 2016). With these two values, a designer can then use an S-N graph (Figure 13) or Equation 7 to determine the number of cycles to initiate a crack at a given stress range. Figure 12 gives an example of how the number of cycles to critical failure are found using Equation 7. On the S-N graph any point below the S-N line will not lead to fatigue failure, while anything at or above the line will induce fatigue failure (Russo et al. 2016; AASHTO 2011; Grubb 2015) (Figure 14). Figure 14 gives an example of how to utilize the AASHTO Load and Resistance Factor Design (LRFD) Detail Categories and S-N curve to determine the number of cycles to critical failure at a given stress.

$$
\text { when } A=\frac{(W Y \sqrt{\pi a})^{-3}}{C}: \quad N=\frac{A}{\sigma^{3}}
$$


Figure 12. Example: Fatigue Resistance Equation.

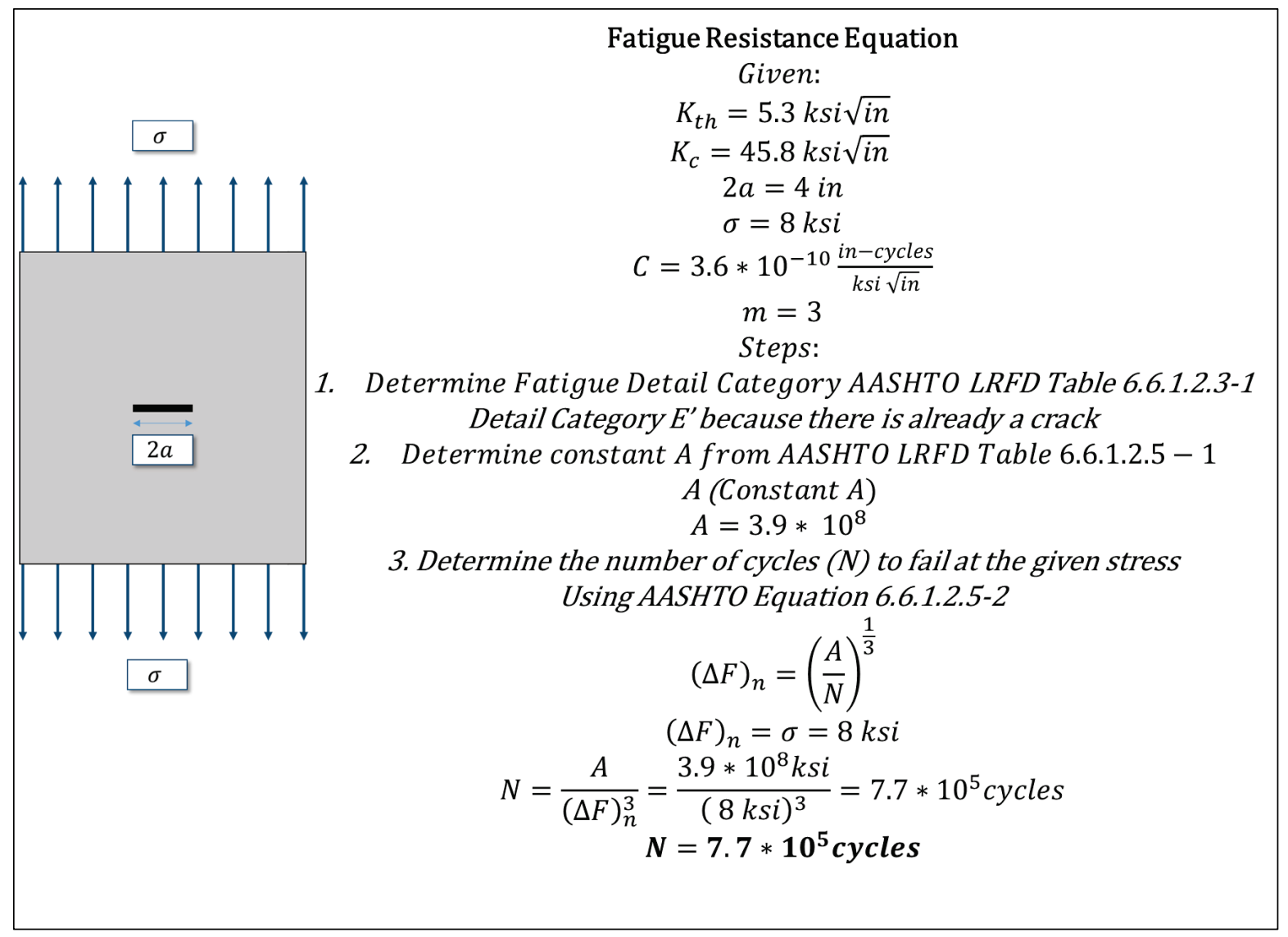

Figure 13. Example of S-N graph (Russo et al. 2016).

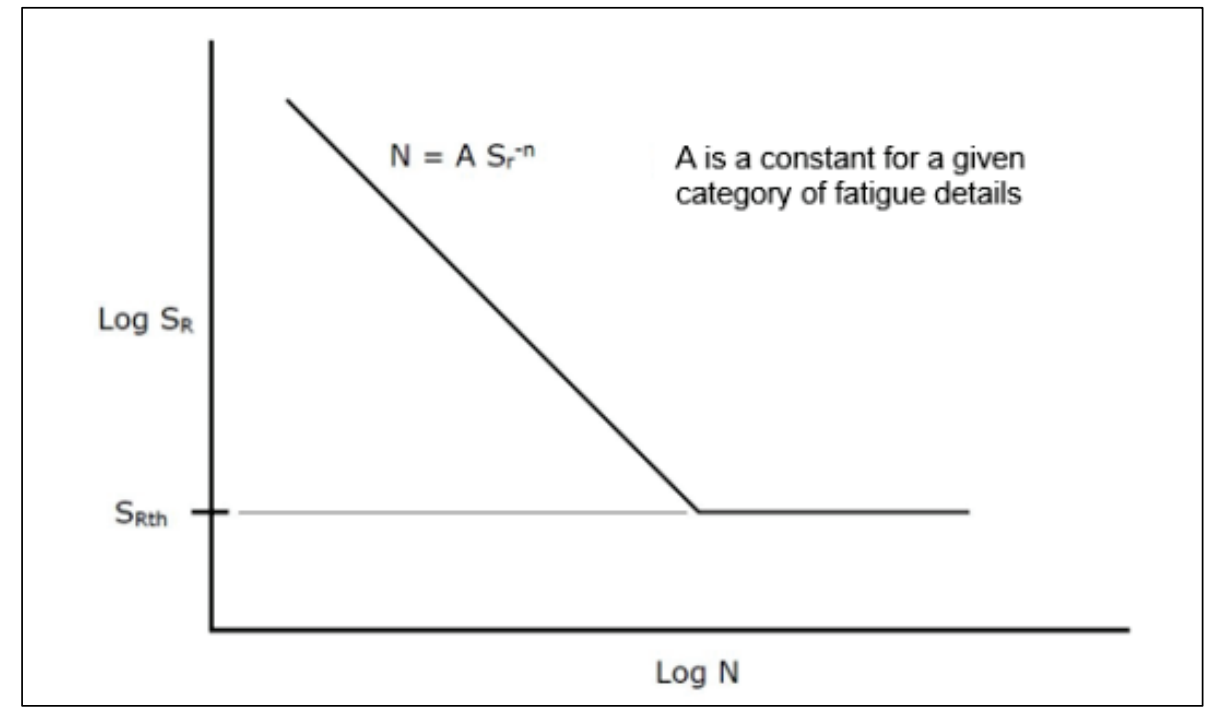


Figure 14. Example: S-N Curve (Thompson and Shephard).

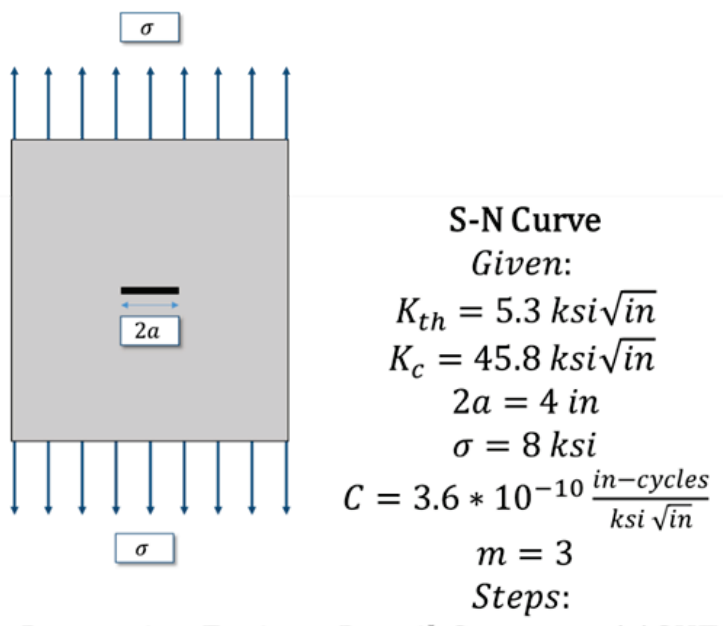

1. Determine Fatigue Detail Category AASHTO LRFD Table 6.6.1.2.3-1 Detail Category E' because there is already a crack

2. With the known stress range and known detail category calculate $N$ (Number of cycles)

$$
N=7.8 * 10^{5}
$$

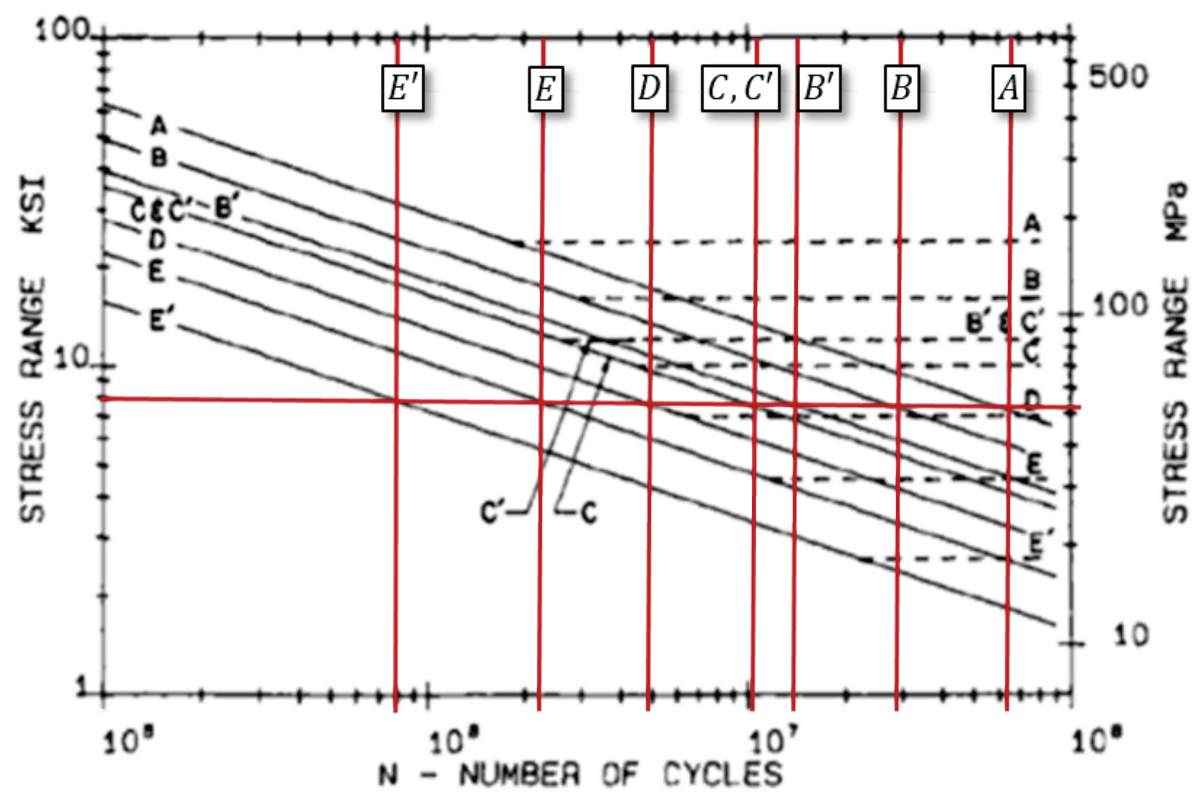

The stress intensity threshold, $K_{t h}$, can be related to the AASHTO fatigue detail categories through the threshold stress, $(\Delta F)_{t h}$, per the detail category or by deriving $K_{t h}$ from AASHTO cycle equation and Paris Law. To derive $K_{t h}$ set Equation 6, when $m=3$, equal to Equation 7 and solve for $K_{t h}$ as shown in Equations 9-11. Equation 13 demonstrates how using the AASHTO values for material constants $C$ and $m K_{t h}$ is determined from a known fatigue threshold stress $(\Delta F)_{t h}$ and fatigue detail category. It is important to note that $K_{i}$ is equal to zero because fatigue crack thresholds 
have to do with crack initiation and therefore, there are no cracks before the threshold is reached.

$$
\begin{gathered}
\int_{a_{f}}^{a_{i}} \frac{d a}{C K^{3}}=\frac{A}{\sigma^{3}} \\
\frac{1}{C}\left(K_{t h}^{-3}-K_{i}^{-3}\right)=\frac{A}{\sigma^{3}} \\
\text { when } K_{i}=0: K_{t h}^{-3}=\frac{A C}{\sigma^{3}} \\
K_{t h}==
\end{gathered}
$$

For both of the previously mentioned methods, the material constants $C$ and $m$ (when $C=3.6 \times$ and $m=3$ ), geometry, and the initial flaw size, $W$ and $Y$ are predetermined by AASHTO (based on experimental data) (Russo et al. 2016; AASHTO 2011). The values derived from the AASHTO code are within a 10-20\% range for reported literature values of $3.3-$ 5.5 ksi (Klingerman and Fisher 1973).

It is important to note that there is a lot of variability with $\mathrm{C}$ and $\mathrm{m}$ test data values due to the specimen's environment, stress concentration, material, and how the test is run. Any slight variations these values make a significant difference in the number of cycles. Table 1 shows different literature values for $\mathrm{C}$ and $\mathrm{m}$ in air and corrosive environment along with the number of cycles to reach critical failure at the given stress range.

Table 1. Different literature $C \& m$ values and cycles to critical crack failure.

\begin{tabular}{|c|c|c|c|c|}
\hline Environment & C & m & $\begin{array}{c}\text { Applied Stress } \\
(\mathbf{k s i})\end{array}$ & Cycles (N) \\
\hline Air $^{1}$ & $3.6 \mathrm{E}-10$ & 3 & 8 & 770000 \\
\hline Corrosive $^{2}$ & $3.6 \mathrm{E}-06$ & 3 & 8 & 77 \\
\hline
\end{tabular}

\subsection{Toughness}

Toughness is the ability for a material to absorb energy and plastically deform without fracturing. Tests, such as the Charpy and Izod notched impact strength tests, determine a material's toughness. Toughness is used to find the critical energy rate and critical strength intensity factor. The

1 (J. M. Barsom, 1987)

2 (Hunt, 2013) 
critical energy rate and strength intensity factor are material properties required to calculate fracture and fatigue. The tests apply the law of conservation of energy by calculating the amount of energy a material absorbs upon impact.

The Charpy V and Izod Notch Impact tests calculate the energy absorbed by a material right after impact. Both tests have a pendulum arm with a striker at the end. The specimen is placed at the lowest point of the pendulum swing with a scale measuring the end-of-swing position (Figure 15). The differences between the Charpy V-Notch and the Izod Notch are the specimen placement and the type of notch used in the specimen.

The potential energy, at the starting position and end position, is calculated. The amount of energy absorbed by the specimen is the difference in potential energy (Figure 15). The material's toughness is directly related to the energy absorbed (ASTM International 2018).

Figure 15. Impact Test; conservation of energy.

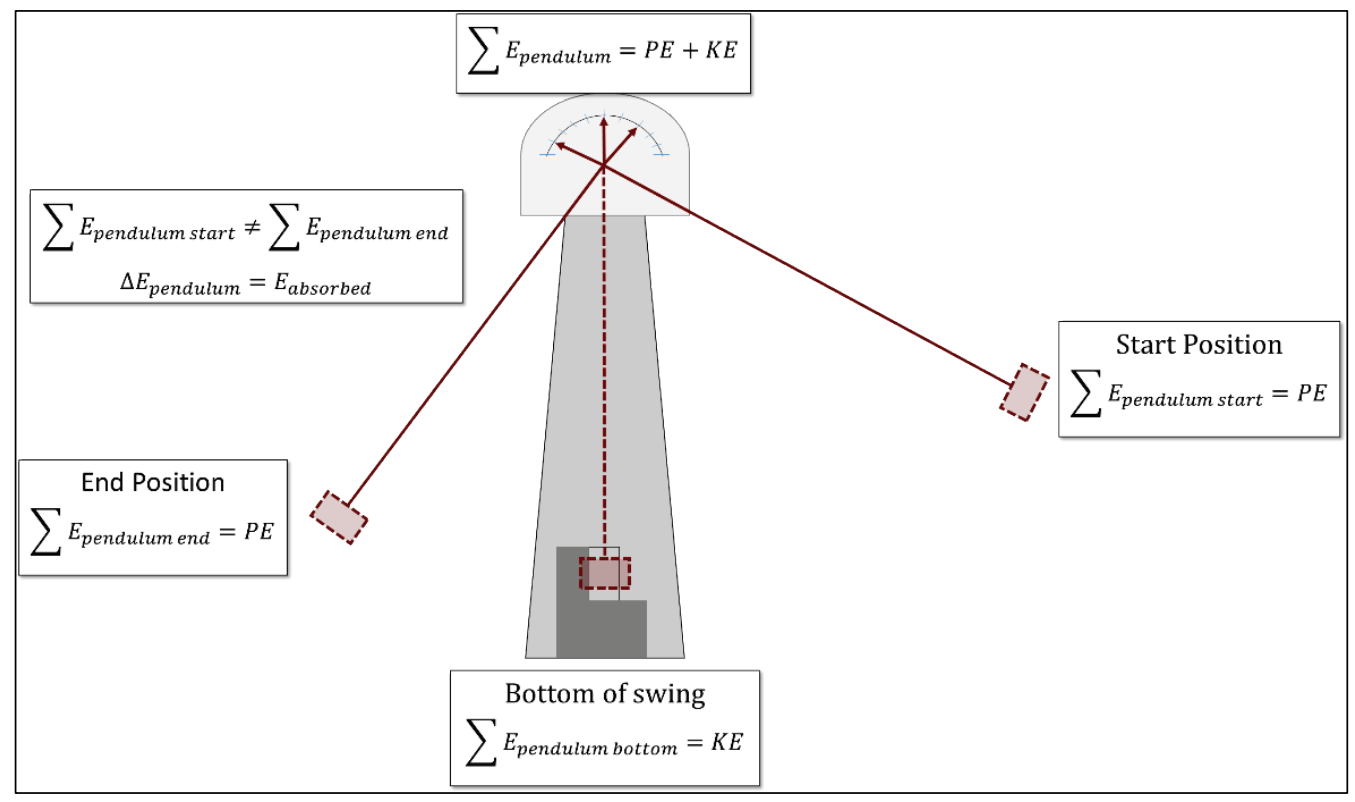

\subsection{Welds}

Welding is the process of joining to separate sections through heat. The welding torch heats the two separate materials, the heated materials mix together, and once fully cooled become one (ISO 2016). There are three main types of weld profiles currently in use; fillet weld, groove weld, and 
plug or slot weld (AISC 2017). Proper weld design and application is vital to the integrity of structures (Segui 2013) since it reduces post-weld residual stresses and the possibility of micro-cracks forming as the weld cools. Welded connections are the most common connection used in HSS (Segui 2013).

Welds are a weak point within a connection due to high-stress concentrations induced through the welding process. Due to research and guideline implementation within the past 50-60 years, weld quality has improved significantly, increasing the fatigue life of welded connections. To determine the fatigue life of welded connections, AASHTO has established guidelines based on different components that have created several weld categories. The different fatigue weld categories are given by AASTHO LRFD Table 6.61.2.3-1 (AASHTO 2012).

\subsubsection{Weld profiles}

Fillet welds join two sections by adding material to the outside of the two sections. The addition of the material forms a triangular cross-section (Figure 16). Groove welds cut into the base material to join the section. There are two types of groove welds full penetration and partial penetration (Figure 17). Plug and slot welds fill holes in the material (Figure 18) (AISC 2017).

Figure 16. Fillet weld profiles.

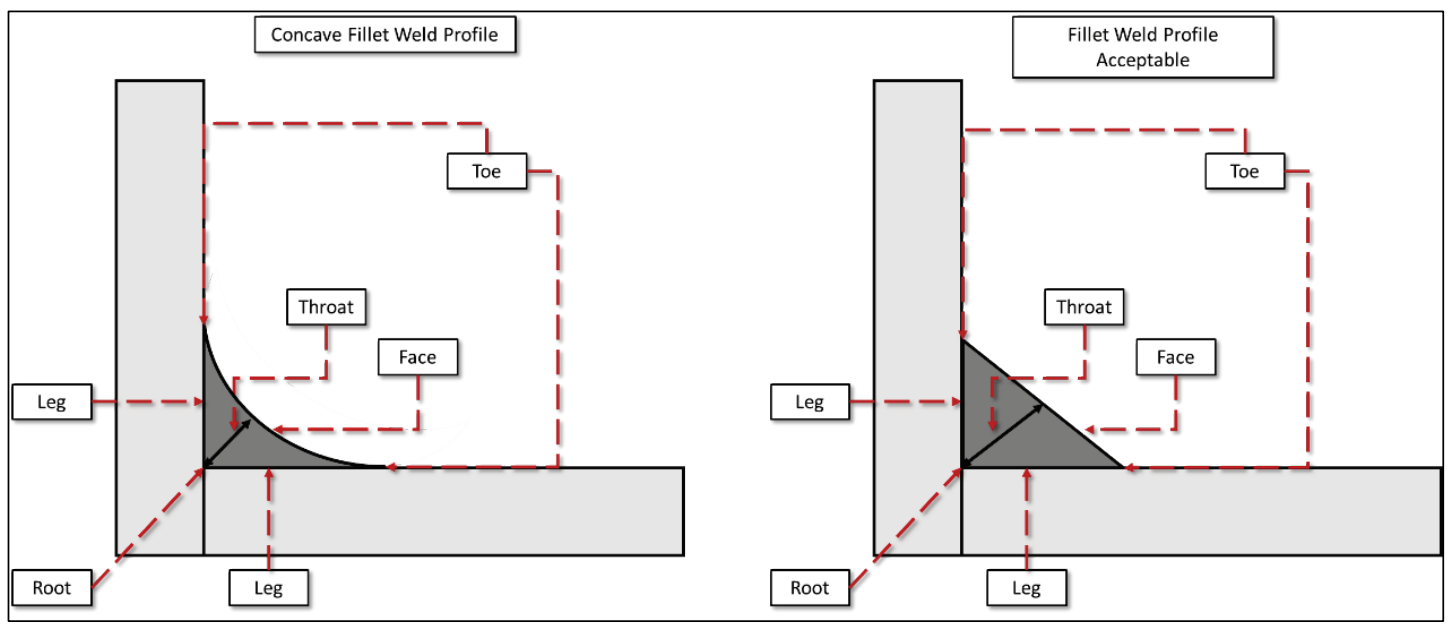


Figure 17. Groove weld profiles.

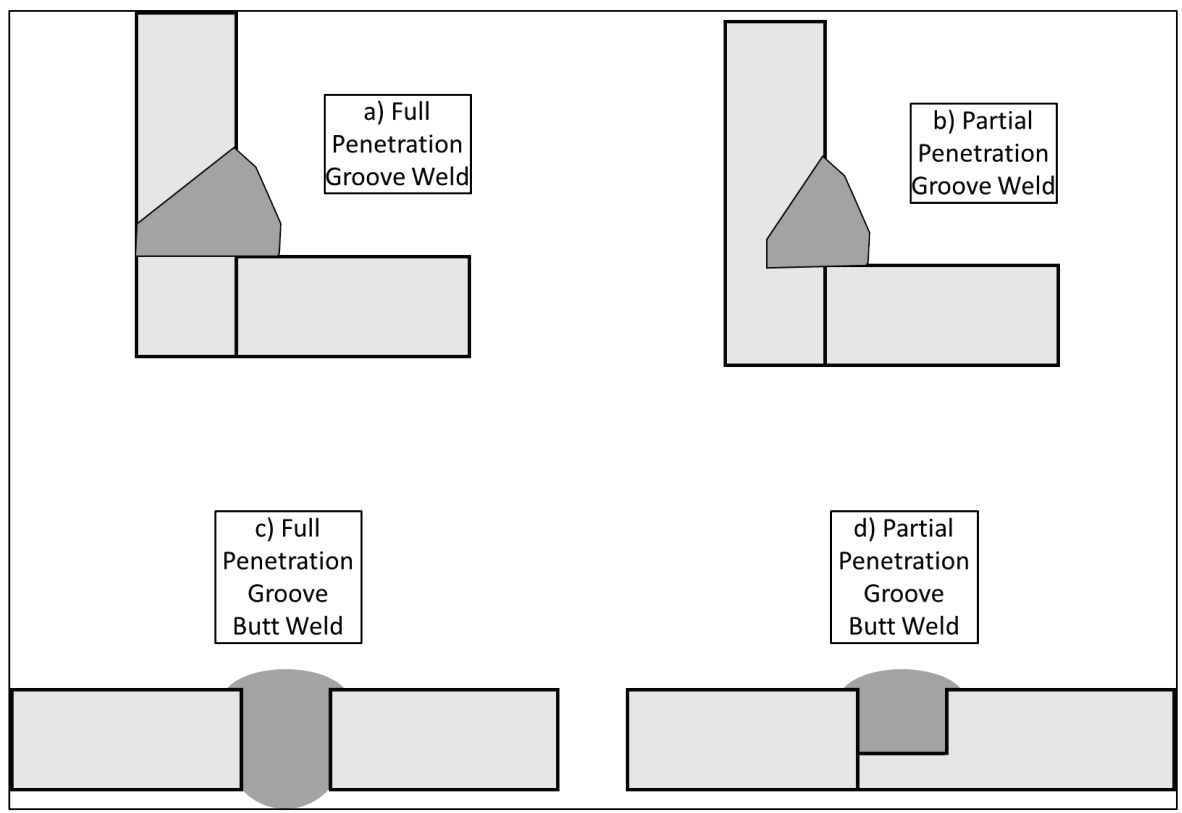

Figure 18. Plug and Slot weld profiles.

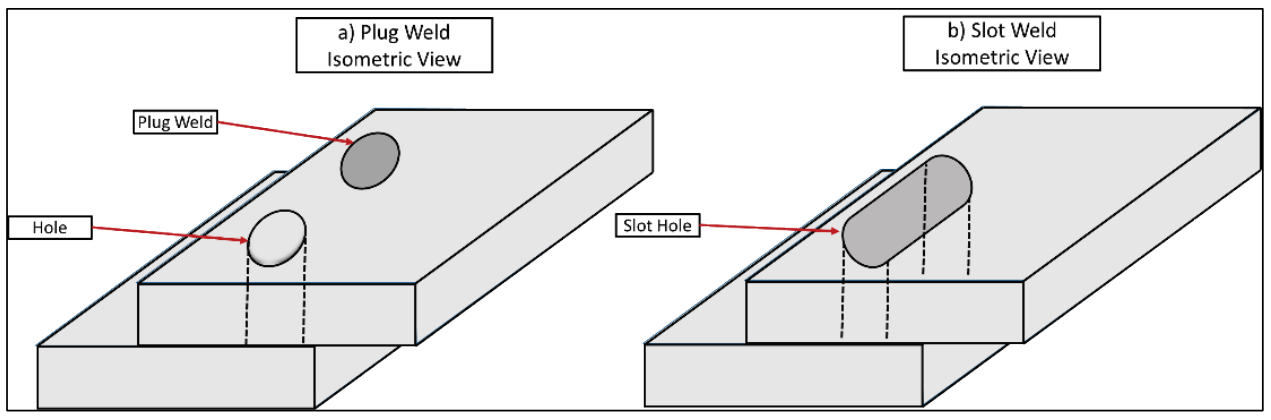

\subsubsection{Weld defects}

Small defects in welds can originate due to initial weld quality, high stresses and/ or cyclic stresses. Some of the initial weld defects, which can grow into larger cracks, are the following: micro or macro cracks, pores and shrinkage cavities, solid inclusions, lack of fusion, inadequate penetration, and small imperfections (habil 1990). Defects mainly originate from improper weld design, incorrect welding process, or incorrect choice of weld material (Yusof 2014). Welded connections are the weakest point in a section, so even if a weld is of the highest quality (no initial defects), it may still develop cracks due to high tensile stress or cyclic tensile stresses.

Cracks can begin to form as soon as the weld begins to cool. As the weld cools, it contracts and introduces residual stresses and small cracks 
(micro-cracks) (Figure 19). Under cyclic loading, the residual stresses lower the fatigue life by increasing the overall tensile stress at the connection. As the micro-cracks continue to propagate, under the increased tensile stresses, they become larger macro-cracks.

Figure 19. Tensile residual stresses as weld cools.

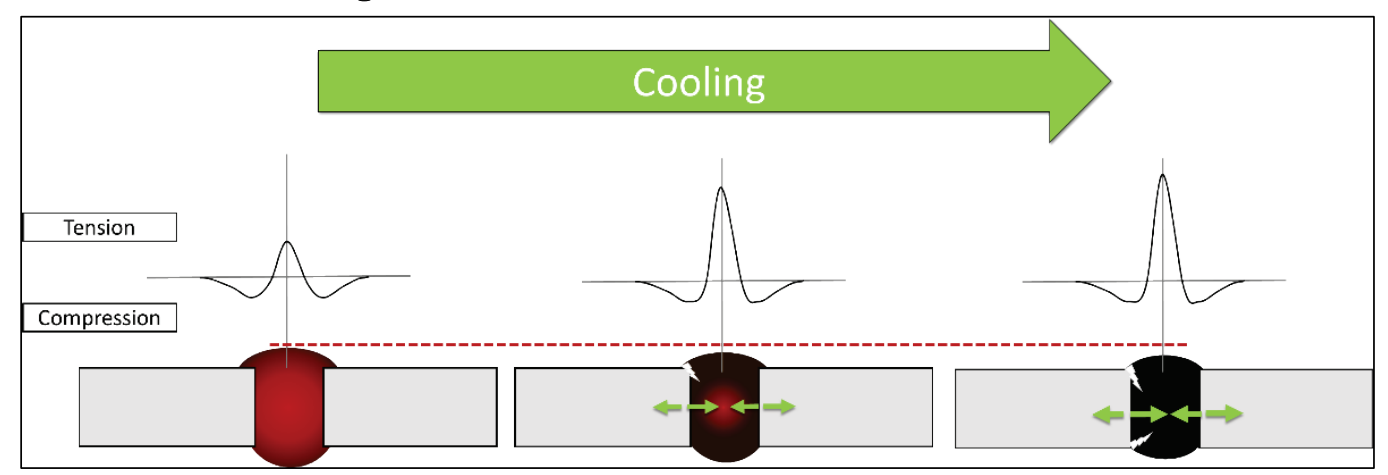

Weld quality is highly dependent on the environment during the welding processes workmanship. For example, a shop weld is made in an environment where the energy source, temperature, and humidity are highly controlled, and is therefore of better quality than a field weld that is out in the elements, has difficult positioning, and an unsteady power source. Welding quality is also highly dependent on the experience and training of the welding operator. A highly trained welder provides a higher quality weld because of their knowledge with the material and requirements for the specific weld (i.e. speed of the welding pass, thickness of the weld, number of passes, shape of the weld, etc.) (Yusof 2014). Proper weld quality, in accordance with specifications and standards such as the American Welding Society (AWS), is crucial in preventing the chances of initial micro-cracks and increasing the fatigue life of the weld. Note, that according to USACE EM 385-1-1 all structural welds on critical members is to be performed by and AWS certified welder and they are to be inspected by an AWS certified inspector (U.S. Army Corps of Engineers 2014).

\subsubsection{Weld acceptance criteria}

An integral part of the welding process is providing quality control of structural welds. The AWS provides an acceptability criterion (AWS D.1.1 Table 6.1) to help inspectors as they perform quality control inspections. According to AWS, a weld's acceptability can be determined by the following methods: visual inspection and non-destructive testing such as 
liquid penetrant, magnetic particle, and ultrasonic testing (AWS 2000). The most common method of field weld inspection is visual inspection that needs to be in accordance with AWS D.1.1 Table 6.1. Table 2 lists the eight criteria AWS uses to determine acceptability: Crack prohibition, Fusion of the weld, crater cross section, weld profiles, time of inspection, undersized welds, and porosity (AWS 2000). The following sections give a more in-depth explanation of each acceptance criteria. 
Table 2. AWS acceptability criteria.

\begin{tabular}{|l|l|l|l|}
\hline \multicolumn{1}{|c|}{ Inspection Criteria } & \multicolumn{2}{c|}{ Non-Tubular Connection } & \multicolumn{1}{c|}{ Tubular Connections } \\
\hline Crack Prohibition & $\mathrm{x}$ & $\mathrm{x}$ & \multicolumn{1}{c|}{ Cll Loads } \\
\hline Weld and Base Metal Fusion & $\mathrm{x}$ & $\mathrm{x}$ & $\mathrm{x}$ \\
\hline Crater Cross Section & $\mathrm{x}$ & $\mathrm{x}$ & $\mathrm{x}$ \\
\hline Weld Profiles & $\mathrm{x}$ & $\mathrm{x}$ & $\mathrm{x}$ \\
\hline Time of Inspection & $\mathrm{x}$ & $\mathrm{x}$ & $\mathrm{x}$ \\
\hline Undersized Welds & $\mathrm{x}$ & $\mathrm{x}$ & $\mathrm{x}$ \\
\hline Undercut (A) & $\mathrm{x}$ & & $\mathrm{x}$ \\
\hline Undercut (B) & & $\mathrm{x}$ & \\
\hline Porosity (A) & $\mathrm{x}$ & & $\mathrm{x}$ \\
\hline Porosity (B) & & $\mathrm{x}$ & \\
\hline Porosity (C) & & $\mathrm{x}$ & $\mathrm{x}$ \\
\hline
\end{tabular}

\subsubsection{Crack prohibition}

During the weld fabrication process, there are two main crack categories: hot and cold cracks. Hot cracks form while the weld material and base metal are still hot, and usually occurs due to the weld's solidification. Cold cracks form after the weld is cool and are largely due to excessive stresses at the weld area or hydrogen diffusion. These two crack categories form the following crack types: longitudinal, crater, and transverse. Longitudinal cracks in welds usually initiate at the weld's throat and extend along the length of the weld (Figure 20 a). Crater cracks are another type of hot crack. These cracks form at the weld line and radiate out in a star-shaped type patter (Figure $20 \mathrm{~b}$ ). Transverse cracks are cold cracks that typically form under high strain, initiating from the toe of the weld (Figure 21) (Kelkar 2008). According to AWS, there are to be no visible cracks in any recently laid weld. 
Figure 20. Hot cracks: a) Longitudinal crack; b) Crater crack.

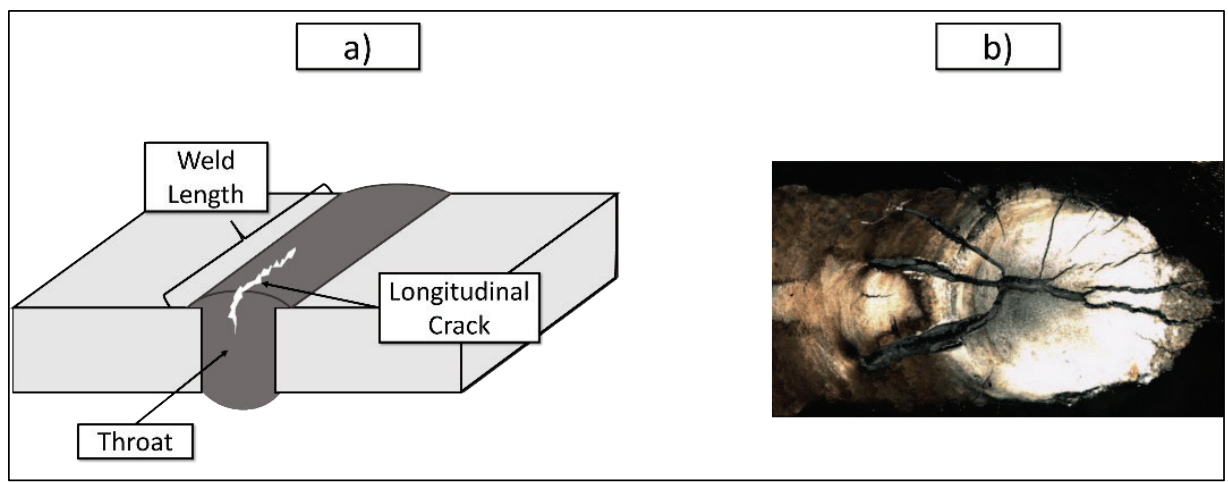

Figure 21. Transverse crack.

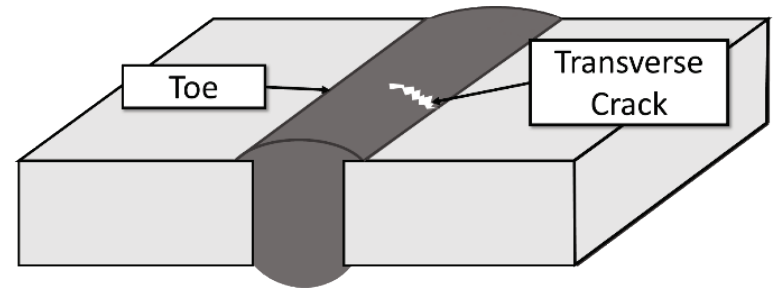

\subsubsection{Weld fusion}

Fusion is when the weld metal and the base metal, or base metal only, melt and fully join to create a whole, Figure 22 (AWS 2000). Incomplete fusion is visually determined by the weld's bead pattern. Figure 23 gives an example of a weld with incomplete fusion. The AWS acceptance criteria require fully fused welds.

Figure 22. Incomplete fusion.

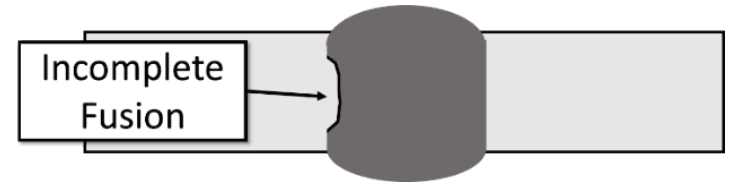

Figure 23. Example of weld bead with incomplete fusion (John 2014).

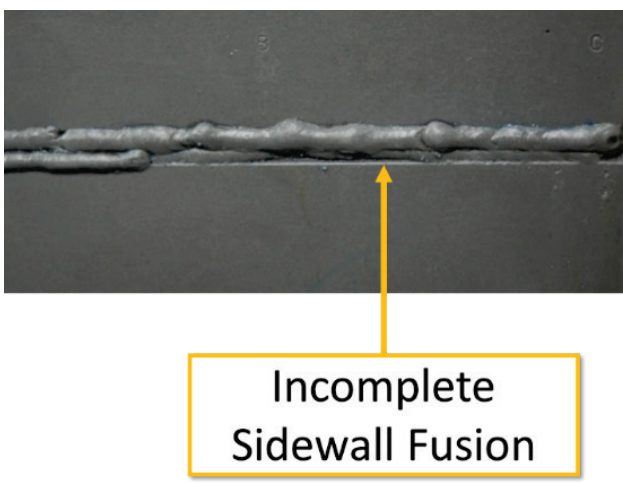




\subsubsection{Crater cross section}

Craters are the unfilled ends of a weld (Figure 24). If not properly filled in, craters can lead to radiating crater cracks due to low strength in the area (AXIS Inspection Group Ltd. 2015). AWS criteria states that no craters are allowed, and any craters are to be filled to meet the weld size (AWS 2000).

Figure 24. a) Cratering at the end of a weld b) Radial cracking within a crater.

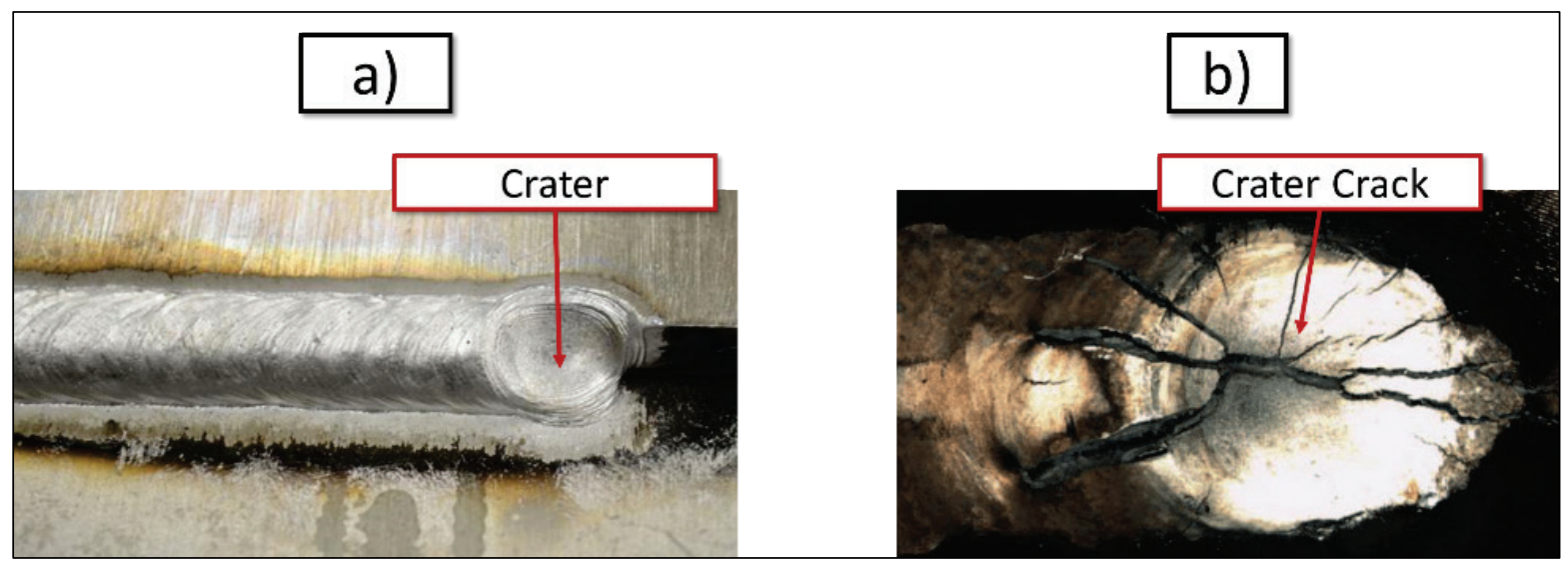

\subsubsection{Weld profiles}

Welds require a specific shape and size to reach their full-strength capacity. To pass inspection, welds must conform to the specifications given by AWS D1.1-5.24 and AWS D1.1-Table 6.1. Section 5.24 of the AWS specification gives further guidance for weld profiles and finishing methods (AWS 2000).

\subsubsection{Time of inspection}

Welds can be inspected right after they are completed. Based on the AWS and ASTM standards (ASTM A 514, A 517, and A 709), a weld must be visually inspected no less than $48 \mathrm{hr}$ after the weld was completed (AWS 2000).

\subsubsection{Undersized welds}

It is important to maintain the specified weld size in order to develop the full-strength capacity of the weld (AISC 2017). Table 3 gives the allowable undersize limits (U) for a fillet weld (L) as per AWS Table 6.1 (AWS 2000). In Table $3, \mathrm{~L}$ is the specified nominal weld size while $\mathrm{U}$ is the allowable undersize for L. It is important to note that the undersize cannot exceed $10 \%$ of the weld length. In addition, when there is a web to flange weld 
connection, there is to be no underrun at the ends for a length that is equal to twice the width of the flange (AWS 2000).

Table 3. Acceptable weld under sizing.

\begin{tabular}{|c|c|}
\hline $\mathrm{L}$ (in) & $\mathrm{U}$ (in) \\
\hline$\leq$ & $\leq$ \\
\hline & $\leq$ \\
\hline$\leq$ & $\leq$ \\
\hline
\end{tabular}

\subsubsection{Undercut}

Undercuts are a hole usually located at the toe of weld, Figure 25 and are considered a flaw in the weld, which weakens the weld. Therefore, undercuts need to be limited as much as possible. Table 4 gives the limitations for undercuts specified by AWS Table 6.1. In HSS, no undercuts should be allowed in order to maintain the full structural integrity of the weld under a highly corrosive environment.

Figure 25. Example of an undercut profile.

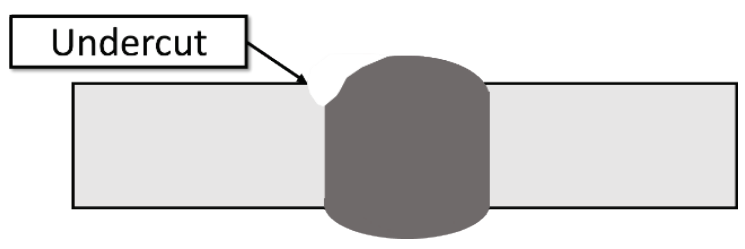

Table 4. Undercut acceptability criteria.

\begin{tabular}{|c|c|c|c|c|}
\hline & & \multicolumn{3}{|c|}{ Connection Type } \\
\hline \multicolumn{2}{|c|}{ Limits } & \multicolumn{2}{|c|}{ Non-Tubular Connection } & $\begin{array}{c}\text { Tubular } \\
\text { Connections }\end{array}$ \\
\hline Thickness (in.) & Undercut Criteria & Static Load & Cyclic Load & All Loads \\
\hline$<1$ & $<$ & $\mathrm{x}$ & & \\
\hline$<1$ & $\begin{array}{l}\text { If the undercut is } \\
\geq \text { but }<\text { an } \\
\text { accumulated length of } \\
2 \text { in. per foot of undercut } \\
\text { is acceptable }\end{array}$ & $\mathrm{x}$ & & \\
\hline$\geq 1$ & $<$ & $\mathrm{x}$ & & \\
\hline $\begin{array}{l}\text { All Primary Members: } \\
\text { Weld transverse to } \\
\text { tensile stress }\end{array}$ & $<0.01$ deep & & $x$ & $\mathrm{x}$ \\
\hline $\begin{array}{l}\text { All Primary Members: All } \\
\text { other loading directions }\end{array}$ & $<$ deep & & $x$ & $\mathrm{x}$ \\
\hline
\end{tabular}




\subsubsection{Porosity}

Porosity is a small hole within a weld that occurs as gas becomes trapped within a weld during the solidification. Figure 26 demonstrates the different types of pores: distributed, surface, and wormholes. Porosity prevention includes proper gas shielding, keeping electrodes and other welding equipment free of moisture, making sure there are no leaks, and keeping a steady gas flow and weld rate. Table 5 gives the allowable criteria for pores within a weld. Note that pores are defects and will eventually lead to fatigue cracking, therefore it is advised to eliminate/limit porosity as much as possible.

Figure 26. Examples of porosity: a) distributed porosity b) surface porosity c) wormholes.

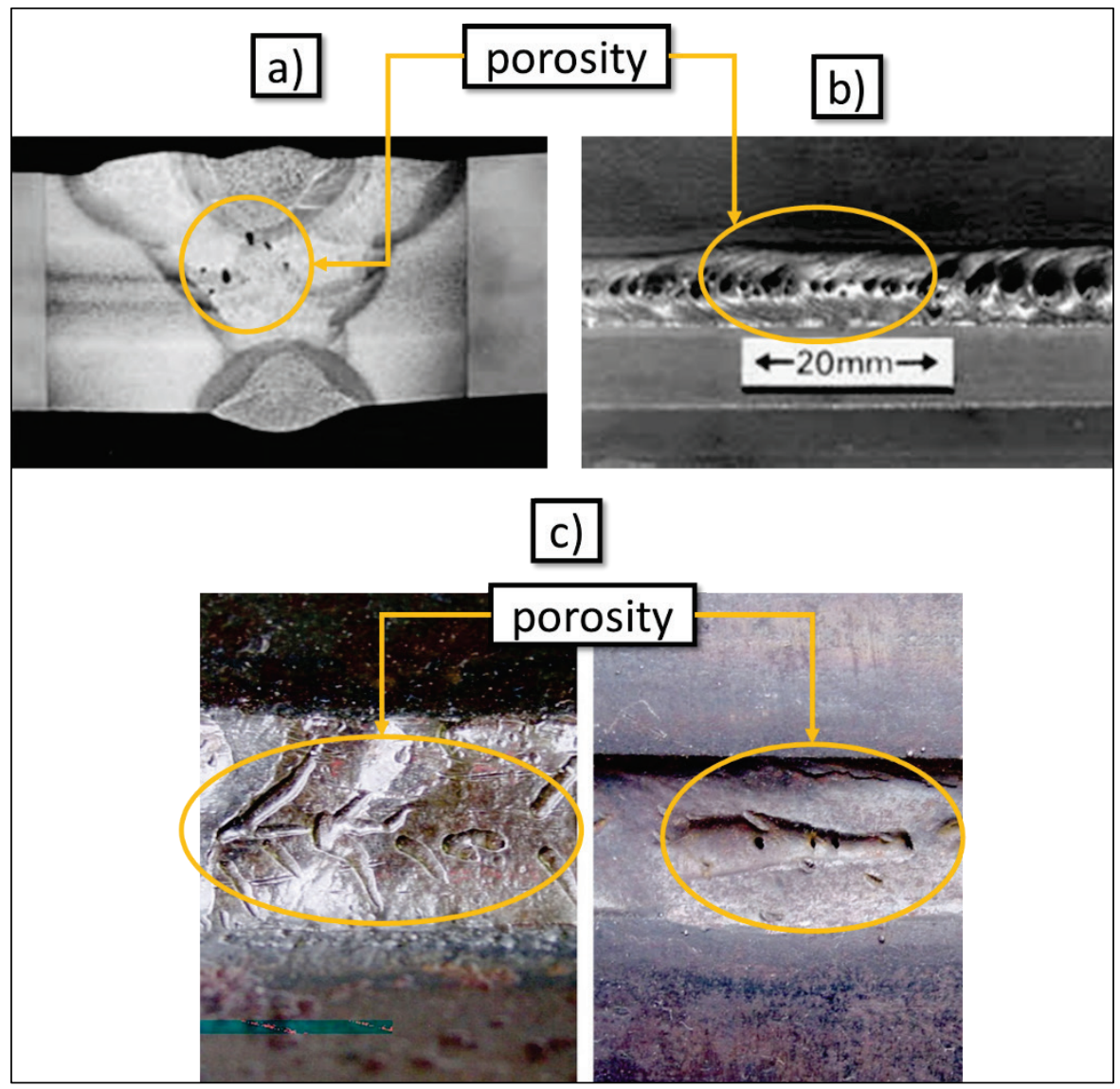


Table 5. Porosity acceptability limits.

\begin{tabular}{|c|c|c|c|c|}
\hline \multirow{2}{*}{\multicolumn{2}{|c|}{ Limits }} & \multicolumn{3}{|c|}{ Connection Type } \\
\hline & & \multicolumn{2}{|c|}{ Non-Tubular Connection } & $\begin{array}{l}\text { Tubular } \\
\text { Connections }\end{array}$ \\
\hline Weld Type & Porosity Criteria (in) & Static Load & Cyclic Load & All Loads \\
\hline $\begin{array}{l}\text { Complete joint } \\
\text { penetration groove weld } \\
\text { in butt joints transverse } \\
\text { to the direction of stress }\end{array}$ & No visible porosity & $\mathrm{x}$ & & \\
\hline $\begin{array}{l}\text { All other groove and fillet } \\
\text { welds }\end{array}$ & $\begin{array}{l}\text { The sum of the porosity } \\
\text { is } \leq \text { but no pore } \\
\text { diameter can be } \geq \text { in a } \\
\text { linear inch of weld and } \\
\text { no pore can have a } \\
\text { diameter } \geq \text { in a foot of } \\
\text { weld }\end{array}$ & $\mathrm{x}$ & & \\
\hline $\begin{array}{l}\text { Stiffener to web fillet } \\
\text { weld }\end{array}$ & $\begin{array}{l}\text { The sum of the } \\
\text { diameters }<\text { in a linear } \\
\text { inch of weld and no pore } \\
\text { can have a diameter } \geq \text { in } \\
\text { a foot of weld }\end{array}$ & & $\mathrm{x}$ & $\mathrm{x}$ \\
\hline All other fillet welds & $\begin{array}{l}\text { Cannot have more than } 1 \\
\text { pore for every } 4 \text { linear } \\
\text { inches } \\
\text { The pore diameter } \\
\text { cannot be } \geq\end{array}$ & & $\mathrm{x}$ & $\mathrm{x}$ \\
\hline $\begin{array}{l}\text { Complete joint } \\
\text { penetration groove weld } \\
\text { in butt joints transverse } \\
\text { to the direction of stress }\end{array}$ & No visible porosity & & $\mathrm{x}$ & $\mathrm{x}$ \\
\hline $\begin{array}{l}\text { All other groove and fillet } \\
\text { welds }\end{array}$ & $\begin{array}{l}\text { Cannot have more than } 1 \\
\text { pore for every } 4 \text { linear } \\
\text { inches } \\
\text { The pore diameter } \\
\text { cannot be } \geq\end{array}$ & & $\mathrm{x}$ & $\mathrm{x}$ \\
\hline
\end{tabular}

\subsubsection{Example of bad weld profiles}

Most of the welds referenced in this TR are field welds, which tend to be lower quality than shop welds. Shop welds have greater quality control because the welding process is more easily automated, leading to a better weld profile with lower residual stresses without micro-cracks. The environmental conditions and welding positions in a shop are controlled leading to higher quality welds. Figure 27 gives examples of good and bad weld profiles while Figure 28 shows a poor weld profile with a crack. 
Figure 27. Examples of a) satisfactory b) passable and c) unacceptable weld profiles.

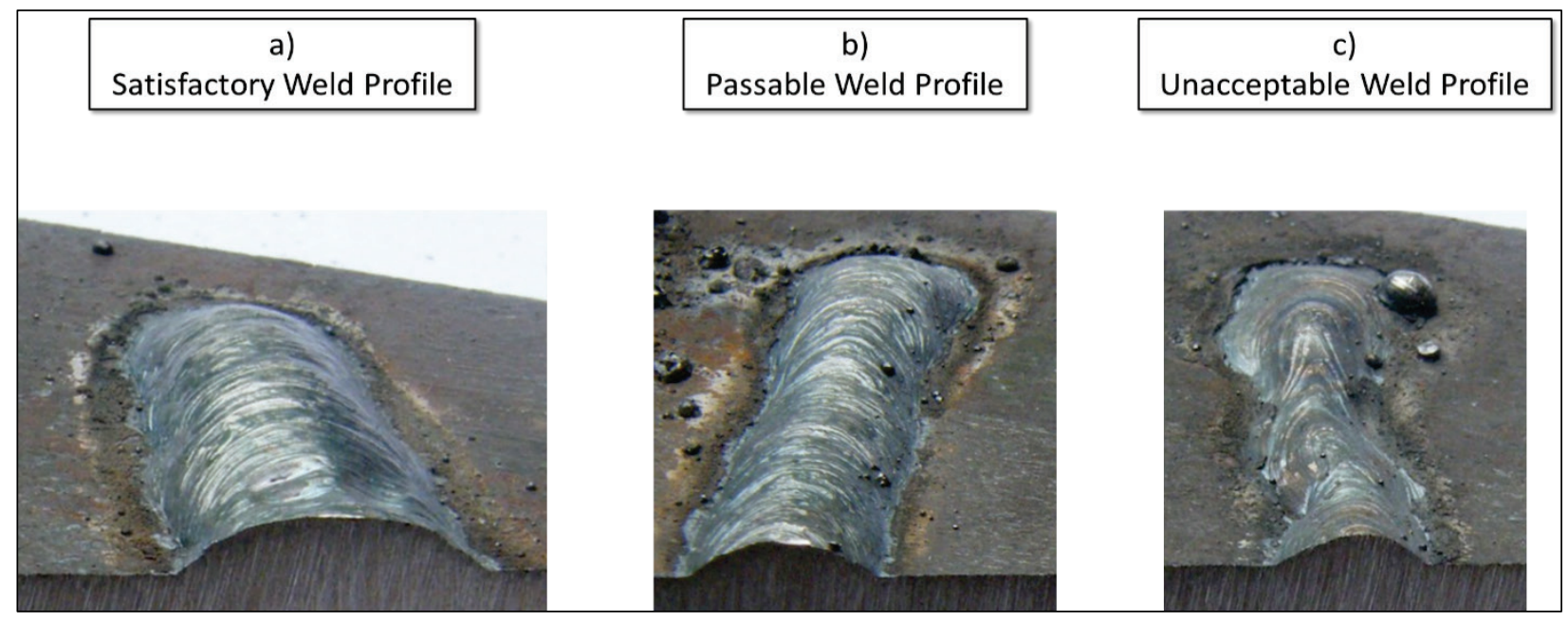

Figure 28. Poor lock and dam weld profile with crack (Old Hickory Lock and Dam).

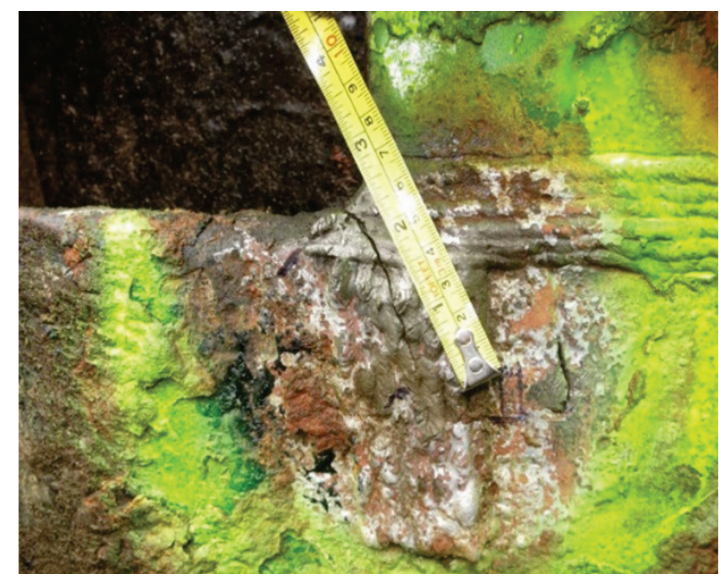

\subsection{Holes}

Holes are commonly used in HSS to connect members, allow access to an area, and as drainage holes. By their nature, holes can be considered as a flaw because of the removal of material. The fatigue and fracture capacity of a hole depends on the position and roughness of the hole's edge. As stress is redirected around a hole, it concentrates at the edges. The increased stress concentration at the hole's edge is at least 3 times the applied stress, possibly resulting in crack propagation (Figure 29 a). A smooth sided hole will have fewer stress concentrations than a rough-cut hole because sharper edges allow for a greater stress concentration (Figure $29 \mathrm{~b}$ ). Therefore, it is recommended that holes' circumference be ground smooth. Hole placement is of utmost importance as it can lead to the extension of cracks when the shear stresses are the controlling stresses. Figure 30 gives an infield example of cracking at holes. 
Figure 29. a) Stress flow and stress concentrations around a smooth hole. b) Stress flow and stress concentrations around a rough hole (small defects).

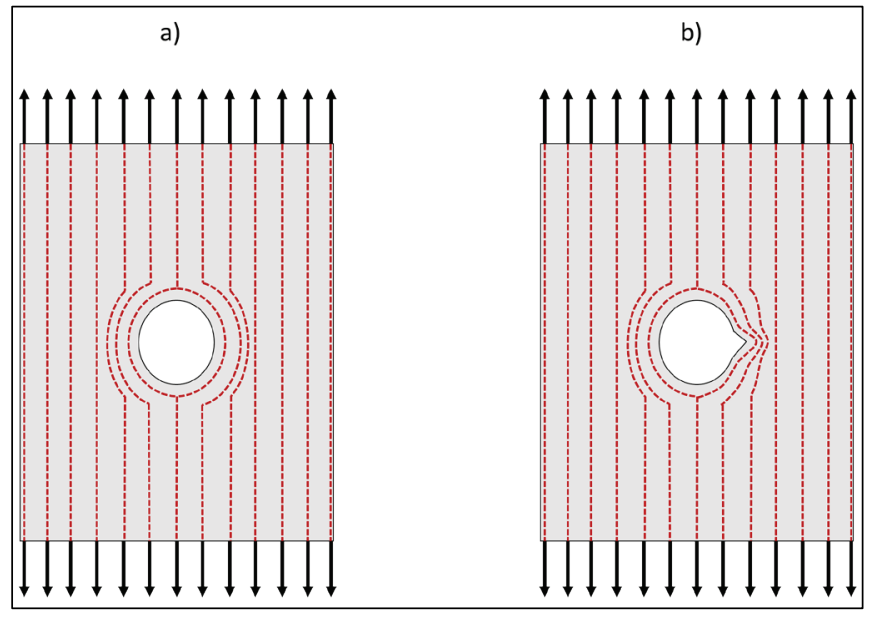

Figure 30. Crack at a riveted connection hole detail (USACE 2009).

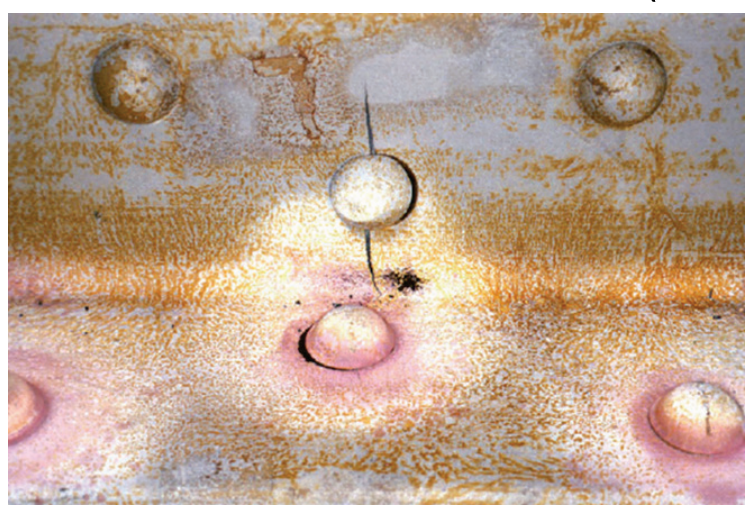




\section{A Guide to a Fitness-For-Purpose Report}

HSS, under the supervision of the USACE, are required to meet the AASHTO/AWS D1.5, Bridge Welding Code (USACE 2018). The AWS D1.5 is the code for high cycle fatigue. According to the code, all butt joints and secondary welds attached to fatigue-critical members, over 4.02 in., require ultrasonic testing. The code allows for exceptions; if an in-use structure, with known defects, has their capacity analyzed the structure can continue operating (AWS, AASHTO 2015).

The AWS provides guidance and procedure for welds in newly fabricated structures. Most of the United States' HSS are not new and do not comply with the AWS tolerances. Most of the HSS were built between 1930 and 1960 (Cook 2017), before any fatigue and fracture design specifications were developed (Russo et al. 2016). The study of fatigue and fracture first began in the 1940s (Barsom 1987). Fatigue and fracture specifications were not added to the AASHTO specifications until 1960 (Russo et al. 2016) and the first mention of fatigue and fracture in the AWS code was not until 1995 (Russo et al. 2016). A different method besides the AWS specifications to analyze HSS' welds, in critical fatigue and fracture sections, is required. The fitness-for-purpose analysis, dictated by the British Standard 7910 (BS7910 2015), provides a way to determine a structure's current state, the structure's factor of safety against fracture, and the risk of collapse (Dexter et al. 2007).

The fitness for service (FFS) provides a method of evaluating existing structures and creating an acceptance level for flaws (BS7910 2015). The procedure provides information for decision makers to decide whether to continue operation, repair, or replace, as well as finding the limiting state of the structure (Bezensek et al. 2011). There are two main codes used to conduct a FFS the British Standard (BS) 7910 and the American Society of Mechanical Engineers' (ASME) Boiler and Pressure Vessel code. The difference between these two standards is that the BS 7910 uses fatigue and fracture mechanics for the assessment while the ASME's code uses flaw acceptance tables, with non-mandatory further assessment in the appendices (Bezensek et al. 2011). The FFS assessment is not an alternative to quality control specifications, but instead a method of further evaluation of the current capacity of a structure based on the existing status and future use (BS7910 2015). 


\subsection{Fitness for purpose: BS7910}

The BS7910 provides three applicable options depending on the Nondestructive Testing (NDT) results:

1. No action is required if flaws do not exceed the levels provided by quality control specifications.

2. If there has been a previous FFS or analysis for the structure, the flaws need to be assessed based on the previous documentation.

3. When there is no previous FFS or flaw analysis, an FFS needs to be performed based on the guidelines provided by the BS7910.

The FFS requires accurate flaw information based on non-destructive testing of a structure. The information required to perform a proper FFS assessment depends on the amount of available data. The following information is the minimum information required for an FFS (Engineering Critical Assessment [ECA]):

1. Flaw size, position, and orientation

2. Applied stresses in the location of the flaw

3. Material toughness and strength capacity properties of the section containing the flaw

4. Geometry of the structure and welds

5. Fabrication procedure (if known)

6. Fatigue and corrosion data

a. $\mathrm{S} / \mathrm{N}$ data

b. Crack propagation data

7. Creep data

8. Bulk corrosion

The FFS provides a "safe" result, due to the included and optional factors of safety. As the level or option of FFS increases the accuracy level of the FFS increases as well. As part of a complete structural management plan, it is important to consider the following items along with the FFS assessment (BSI 7910:2013 +A1:2015 2015):

1. Flaw source as well as repair methods to prevent further growth or more flaws.

2. Failed detection of flaw along with the cause, such as detection technique or crack growth assumptions. 
3. Are the flaws' location, nature, and size consistent with its overall and operational history?

4. Does the inspection reveal crack growth and is the growth consistent with crack mechanics and loading of the structure?

5. Does any modification to the structure affect other structures?

6. Are there similar type flaws in other structures of similar size, age, and loading?

A complete structural management provides an analysis, with a factor of safety, of the structure in question as well as other items, listed above, to provide detailed information on the structure's current state to decision makers. A structural management plan will also consider fatigue effects and quantify the extent of the growth (BSI 7910:2013 +A1:2015 2015).

There are three different options of FFS; each option is based on the amount of available information (BSI 7910:2013 +A1:2015 2015) (Overview of BS7910:2013 2013) and how conservative/accurate of a result is desired.

1. Option 1: The most conservative option. This option does not require a stress/strain data.

2. Option 2: Requires the section's material stress-strain data.

3. Option 3: Most detailed option and it requires numerical analysis of the structure.

\subsection{Fitness for purpose: Failure assessment options}

Each option requires a failure assessment diagram (FAD), Figure 31. The FAD has its foundation on fracture mechanics principles. In Figure 31, the vertical axis is known as the fracture axis, the horizontal axis is the collapse axis, and the line formed based on the equations from the chosen FFS option, given in BS7910, forms the assessment line (Riveros 2018). The fracture ratio, the ratio of the applied stress intensity, $K$, to the critical stress intensity, is the basis for the fracture axis. The basis for the collapse axis is the collapse ratio. The collapse ratio is the ratio of applied stress to the collapse stress (average of the yield and tensile strength of the material) (BSI 7910:2013 + A1:2015 2015). The flaws acceptability is determined based on where the flaw's calculated position, calculated using one of the BS7910's three options (BSI 7910:2013 +A1:2015 2015) (Overview of BS7910:2013 2013). If the flaw is below and to the left of the assessment line, it is acceptable. 
Figure 31. Failure Assessment Diagram (FAD) Option 1, Continuous and Discontinuous Yielding.

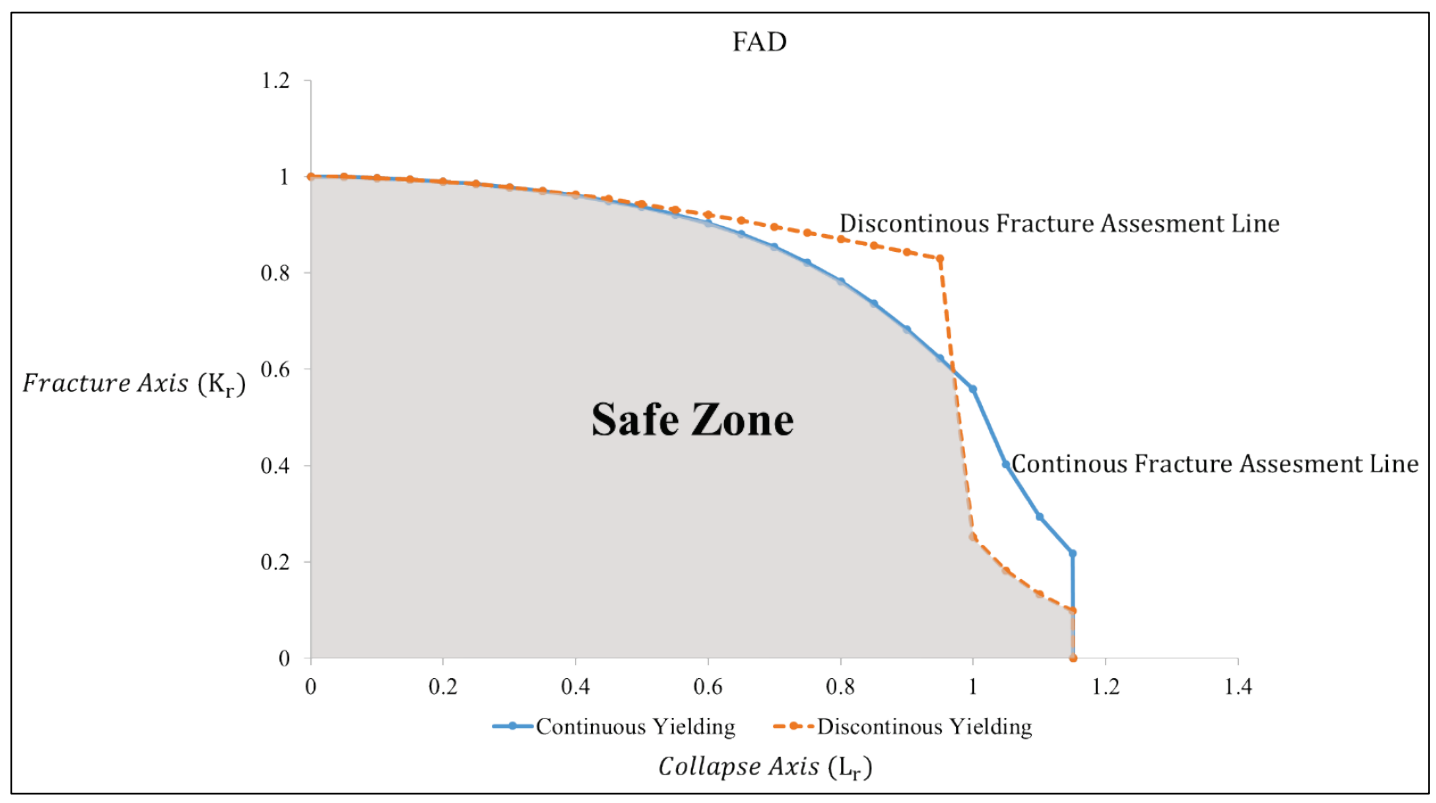

Different criteria must be considered in order to determine the appropriate FFS criteria. Figure 32 demonstrates a flow chart of the different criteria required to determine the appropriate FFS option. The first criteria is to ask if the flaw in question is within the quality control specifications. If the answer to the first criteria is yes, then no further action is required, but if the answer is negative then proceed to the next criteria. The second criteria is to ask if there are stress-strain data available for the material of the section in question. If there is no stressstrain data then proceed to Option 1, but if there is stress-strain data then the third criteria needs to be considered. Note, if the yielding behavior of the section/material is crucial to the FFS then the use of Option 2 based on tensile testing is suggested. The third criteria is to ask if there is a specific loading, material, or geometry that requires a finite element elastic-plastic analysis of the section. If an elastic-plastic analysis is required then proceed to Option 3, if not then proceed to Option 2 (BSI 7910:2013 +A1:2015 2015). 
Figure 32. Option selection flowchart.

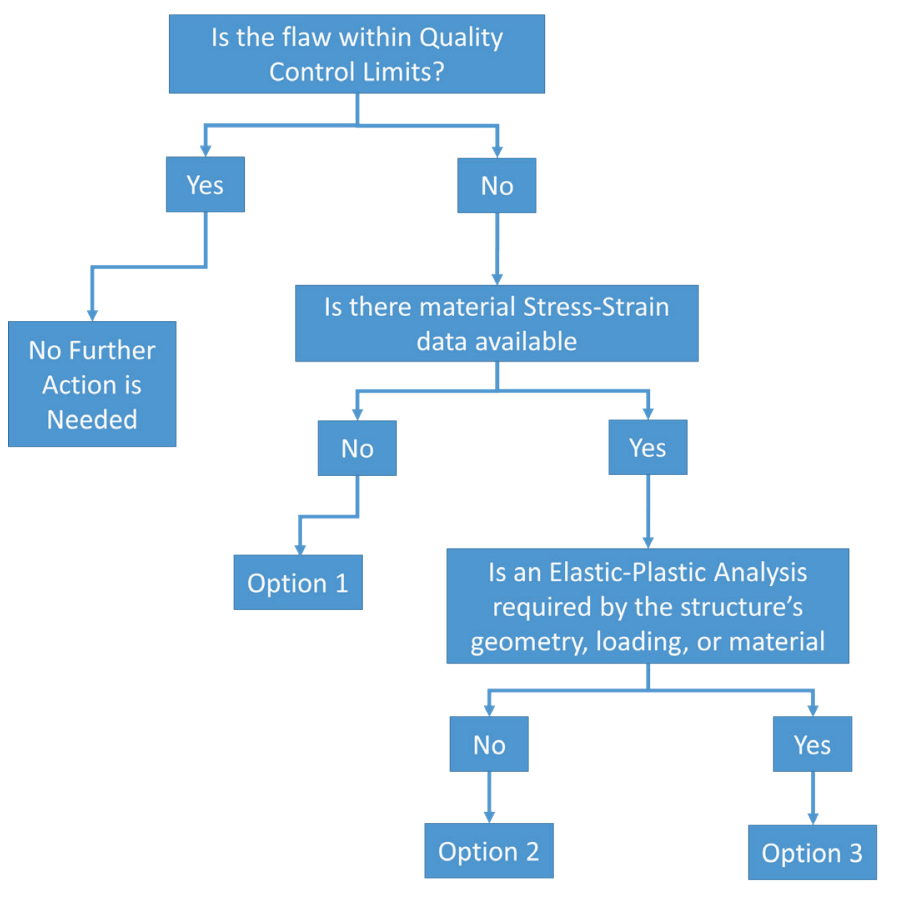

Option 1 of the FFS is the broadest and most conservative option. This option only requires tensile and ultimate strength properties of the material. Option 1 has two assessment line options; one that considers yield discontinuity and one that does not. Yield discontinuity is a phenomenon often seen in mild steel (low carbon) where there is a high and low stress range at yield (BSI 7910:2013 +A1:2015 2015; Rana 2014), Figure 33. Since yield discontinuity can also be influenced by temperature at the time of loading (Hassan 2017), both the discontinuous and continuous assessment line should be calculated, and the more conservative FAD selected.

Figure 33. Continuous and discontinuous yielding stress-strain.

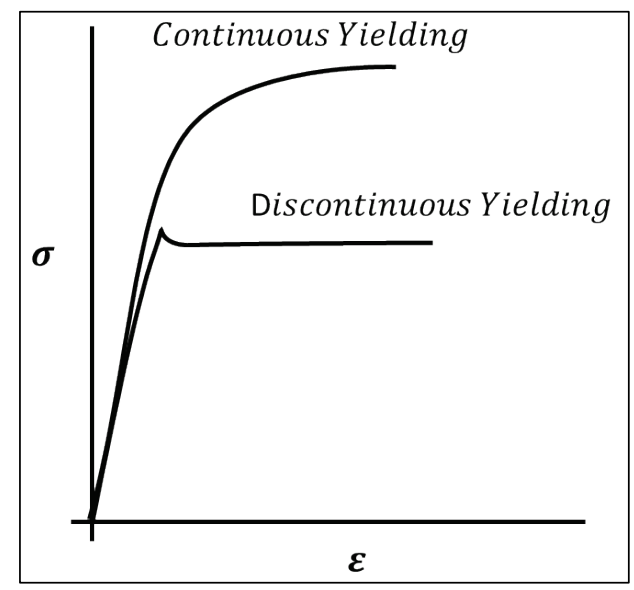


Option 2 requires stress-strain data of the material at the operating temperature, which can be utilized with all metals. Since this option utilizes stress-strain data, discontinuities will be represented by the assessment curve, typically at values below 1 . To calculate an accurate fracture assessment line, a total of at least 6 calculated values at the following are required: $0.7,0.9,0.98,1.0,1.02,1.1$. Then depending on the detail required more points may be added to define the rest of the curve. (BSI 7910:2013 +A1:2015 2015).

Option 3 requires a finite element analysis of the elastic and elastic-plastic behavior. This option is specific to the material, geometry, and loading configuration. The equations for Option 3 are dependent on the J-integral derived from the finite element analysis. Option 3 is to be used only as an alternative to Options 1 and 2 and is not suitable for all analyses (BSI 7910:2013 +A1:2015 2015; Overview of BS7910:2013 2013).

\subsection{Fitness for purpose: Variables}

The fracture ratio is the calculated stress intensity of the current crack over the fracture toughness of the section in question. When considering fracture, only the ratio takes into account primary and secondary stresses as well as plasticity interaction effects, but for fatigue (the primary cause of cracking in HSS) primary stresses are the only stresses taken into account (Per Annex M of BS7910). Primary stresses are stresses caused by primary loads (BS7910 2015) and cause fracture and plastic collapse failure, while secondary stresses only cause fracture (Mechanical Loading and Residual Stress / Fracture: Pt I., 2013). Secondary stresses are typically thermal and residual stresses; they can be relieved through local yielding or heat treatment of the area. Both primary and secondary stresses are divided into membrane (the mean stress through the thickness of the section) or bending (the stress that varies linearly through the thickness) stresses (BSI 7910:2013 +A1:2015 2015). If the section experiences a mixed mode loading, then an effective stress intensity is calculated. This considers both membrane and bending stresses. Equation 12 calculates the fatigue fracture ratio

$$
K_{r}=\frac{K_{e f f}}{K_{c}}
$$

Where $K_{r}$ is the fracture ratio, $K_{e f f}$ is the effective stress intensity based on the loading condition, and $K_{c}$ is the material's critical fracture toughness. 
For a conservative analysis the load ratio, $L_{r}$, is calculated using the reference stress, $\sigma_{r e f}$, over the yield stress, $\sigma_{y}$, Equation 13.

$$
\mathrm{L}_{\mathrm{r}}=\frac{\sigma_{\mathrm{ref}}}{\sigma_{\mathrm{y}}}
$$

The reference stress in HSS structures is the applied load. If the applied load is a mixed mode load then the Von Misses stress (Equation 14) is calculated and used as the reference stress (BSI 7910:2013 +A1:2015 2015).

$$
\sigma_{\text {vonmisses }}=\sqrt{\sigma_{y}^{2}-\sigma_{y} \sigma_{x}+\sigma_{x}^{2}}
$$

Where $\sigma_{\text {vonmisses }}$ is the Von Misses stress, $\sigma_{y}$ is the stress in the y direction, and $\sigma_{x}$ is the stress in the x-direction.

\subsection{FFS: Option 1}

Within the USACE's HSS, Option 1 is the most common type of FFS. This TR outlines the steps, provided by the BS7910, required to conduct the FFS' Option 1. The equations given by the BS7910 are in SI units, with $\frac{d a}{d N}=\frac{m m}{c y c l e}$ and $K=M p a \sqrt{m}$. A full Mode I (HSS: Tainter Valve) and Mixed Mode (HSS: Front Flange) example is provided in Appendix A.

The following are the steps used to execute Option 1.

1. Collect data of the section and flaw through visual inspection and use of NDT.

a. Section's geometric Properties
(1) Length
(2) Width
(3) Thickness

2. Flaw Properties
a. Length
b. Width
c. Direction with respect to the section's geometry and primary loading condition. The flaw's orientation will
(1) Is the flaw perpendicular or at an angle to the loading condition?
(2) Is the flaw in the center or at an edge? 
(3) Is the flaw at an angle within/edge of the section?

3. Collect and calculate material properties and load conditions

a. Material Properties

(1) Yield strength, $\sigma_{y}$, and ultimate stress, $\sigma_{u}$

(2) Yield strain, $\varepsilon_{y}$, and ultimate strain is $\varepsilon_{u}=5 \%$ if the ultimate strain is unknown per BS7910 section 7.1.3.5 (BSI 7910:2013 +A1:2015 2015)

(3) Young's Modulus, $E$

(4) Poisson's ratio, $\mu$

(5) Fracture toughness. Commonly used fracture toughness values for steel in air and marine environments are 100 $\mathrm{Mpa}$ (BSI 7910:2013 +A1:2015 2015) and 81.3 Mpa (Riveros 2018), respectively. To be conservative, it is recommended that the lower value is used for FFS calculations.

(6) Fatigue-Paris Law (BSI 7910:2013 +A1:2015 8.2.3.5)

4. Loading conditions/stresses

a. Loading type

(1) Tension, shear, bending, moment

b. Stress directions

(1) In-plane ( $\mathrm{x}$ and $\mathrm{y}$ directional components)

(2) Out-of-plane

c. Equation 15, R ratio of minimum stress, to maximum stress,

$$
R=\frac{\sigma_{\min }}{\sigma_{\max }}
$$

5. Calculate the FAD

a. Determine $L_{r \max }$, Equation 16

$$
L_{r \max }=\frac{\sigma_{y}+\sigma_{u}}{2 \sigma_{y}}
$$

Where $\sigma_{y}$ is the yield stress and $\sigma_{u}$ the ultimate stress.

1. Calculate the continuous yielding assessment line.

a. Several points need to be plotted to determine the path of the nondiscontinuous FAD line. The plots include $L_{r}$ when it is less than or 
equal to 1 (Equation 17), greater than 1(Equation 18), and less than $L_{\text {rmax }}$ (Equation 19), and when it is greater than or equal to $L_{r \max }$.

$$
\begin{gathered}
f\left(L_{r}\right)=\left(1+\frac{1}{2} L_{r}^{2}\right)^{-\frac{1}{2}}\left[0.3+0.7 \exp \left(-\mu L_{r}^{6}\right)\right] \text { for } L_{r} \leq 1 \\
f\left(L_{r}\right)=f(1) L_{r}^{\frac{N-1}{2 N}} \text { for } 1<L_{r}<L_{r m a x} \\
f\left(L_{r}\right)=0 \text { for } L_{r} \geq L_{r m a x} \\
\mu=\min \left(0.001 \frac{E}{\sigma_{y}}, 0.6\right) \\
N=0.3\left(1-\frac{\sigma_{y}}{\sigma_{u}}\right)
\end{gathered}
$$

Where $E$ is the Young's Modulus, $\sigma_{y}$ is the yield stress, and $\sigma_{u}$ the ultimate stress.

2. Calculate the discontinuous yielding assessment line (Equations 22-25).

$$
\begin{gathered}
f\left(L_{r}\right)=\left(1+\frac{1}{2} L_{r}^{2}\right)^{-\frac{1}{2}} \text { for } L_{r}<1 \\
f\left(L_{r}\right)=\left(\lambda+\frac{1}{2 \lambda}\right)^{-\frac{1}{2}} \text { for } L_{r}=1 \\
f\left(L_{r}\right)=f(1) L_{r}^{\frac{N-1}{2 N}} \text { for } 1<L_{r}<L_{r \max } \\
f\left(L_{r}\right)=0 \text { for } L_{r} \geq L_{r \max } \\
\lambda=1+\frac{E \Delta \varepsilon}{\sigma_{y}}
\end{gathered}
$$

Where $E$ is the Young's Modulus, $\sigma_{y}$ is the yield stress, and $\Delta \varepsilon$ the strain. For materials where $\sigma_{y}<946 \mathrm{Mpa}$ or 137,200 psi the strain, $\Delta \varepsilon$, is estimated by Equation 27:

$$
\Delta \varepsilon=0.0375\left(1-0.001 \sigma_{y}\right) \text { for } \sigma_{y} \leq 1000 \text { Mpa or } 145,000 \text { psi }
$$

When $L_{r}=1$ the FAD exhibits a discontinuity and a vertical line connects Equations 24 and 25. 
1. Calculate the load ratio factor, $L_{r}$, (Equation 28) at the point of inspection.

a. Determine the reference stress, $\sigma_{\text {ref }}$. If the crack demonstrates Mixed Mode behavior, the von mises stress is used as the reference stress, otherwise the applied stress is used.

$$
L_{r}=\frac{\sigma_{r e f}}{\sigma_{y}}
$$

2. Calculate the fatigue fracture ratio, $K_{r}$, (Equation 29) based on the stress intensity, $K_{I}$ or $K_{\text {eff }}$ (Equation 30).

$$
\begin{gathered}
K_{r}=\frac{K_{I}}{K_{c}} \text { for Mode I } \\
K_{r}=\frac{K_{\text {eff }}}{K_{c}} \text { for Mixed Mode }
\end{gathered}
$$

Where $K_{r}$ is the fatigue fracture ratio, $K_{\text {eff }}$ is the effective stress intensity, $K_{c}$ is the material's fracture toughness, and $\rho$ is the additive secondary stress factor. The effective stress intensity, $K_{e f f}$, is dependent on multiple loading factors based on the crack location, flaw type, and flaw geometry. Typically, the cracks in HSS are through and surface cracks, but since a through crack is the worst of the two types a through crack should be assumed.

1. Determine the crack type

a. Location factor, $f_{w}$ : edge, center, or not enough data on the crack

(1) Edge Crack (Figure 34) Annex M (M.7-M.8):

Figure 34. Edge crack geometric dimensions.

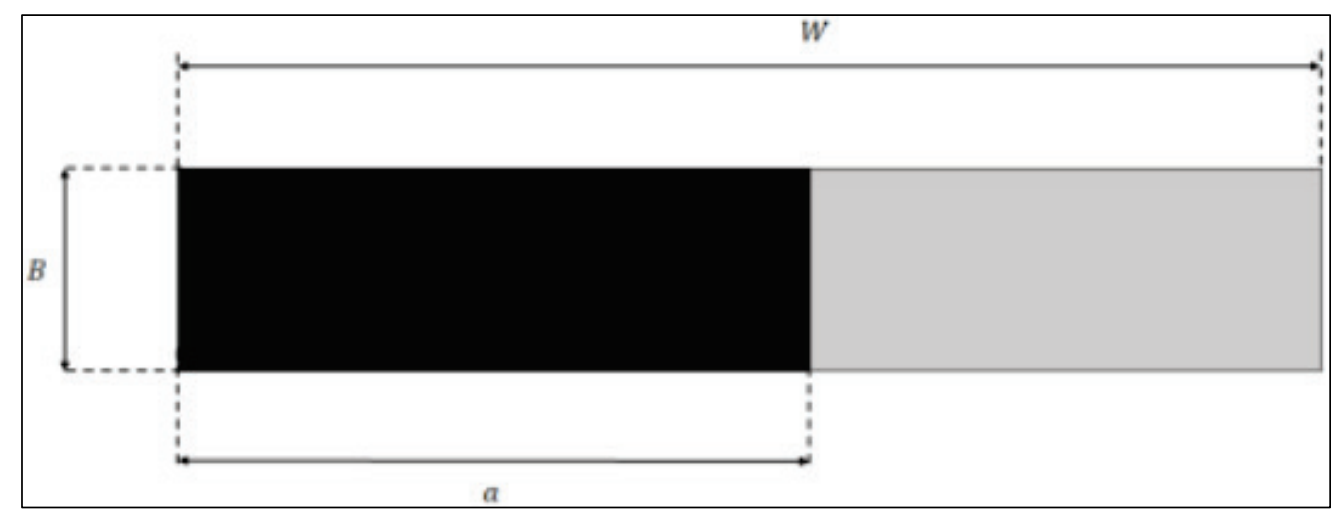

Flaw configuration factor: $M=1$ 


$$
\begin{gathered}
a=\text { Crack Length } \\
B=\text { Crack Thickness } \\
w=\text { Cross Section of piece where crack is }
\end{gathered}
$$

Geometry factor: $f_{w}=1$

Edge crack in tension flaw configuration factor:

$$
M_{m}=1.12-0.23 *\left(\frac{a}{w}\right)+10.6 *\left(\frac{a}{w}\right)^{2}-21.7 *\left(\frac{a}{w}\right)^{3}+30.4 *\left(\frac{a}{w}\right)^{4}
$$

Edge crack in bending flaw configuration factor:

$$
M_{b}=M_{m}
$$

2. Center Crack (Figure 35):

Figure 35. Center crack geometric dimensions.

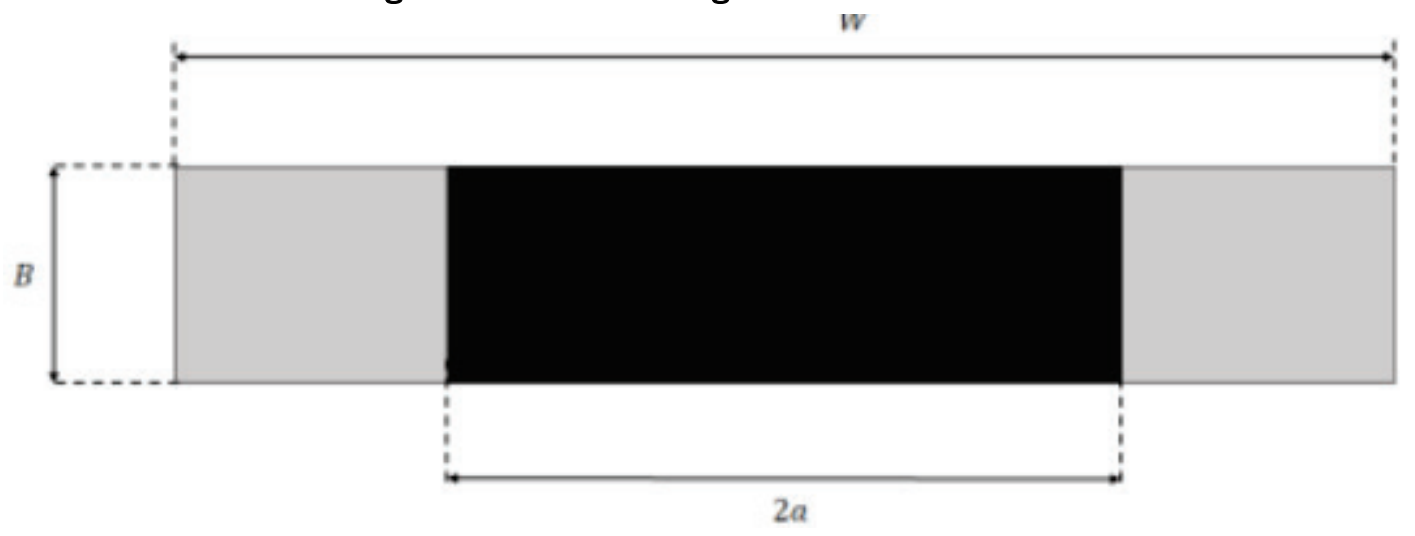

Flaw configuration factor:

$$
M=1
$$

Flaw configuration factor in tension and bending:

$$
M_{m}=M_{b}=M
$$

Geometric Factor: 


$$
\begin{gathered}
f_{w}=\left(\sec \left(\frac{\pi * A_{\text {through crack }}}{w}\right)\right)^{\frac{1}{2}} \\
a=\frac{\text { Crack Length }}{2} \\
w=\text { Cross Section of piece where crack is }
\end{gathered}
$$

Local Stress Concentration Factor: The local stress concentration factor is for areas of high concentrated stress such as toe welds. Figure 36 gives examples of welded connections with high concentrated stresses.

The stress concentration factor needs to be calculated for tension and bending as shown in Table 6. 
Figure 36. Welded joint geometries for local stress concentration factor (BSI 7910:2013 +A1:2015 2015).

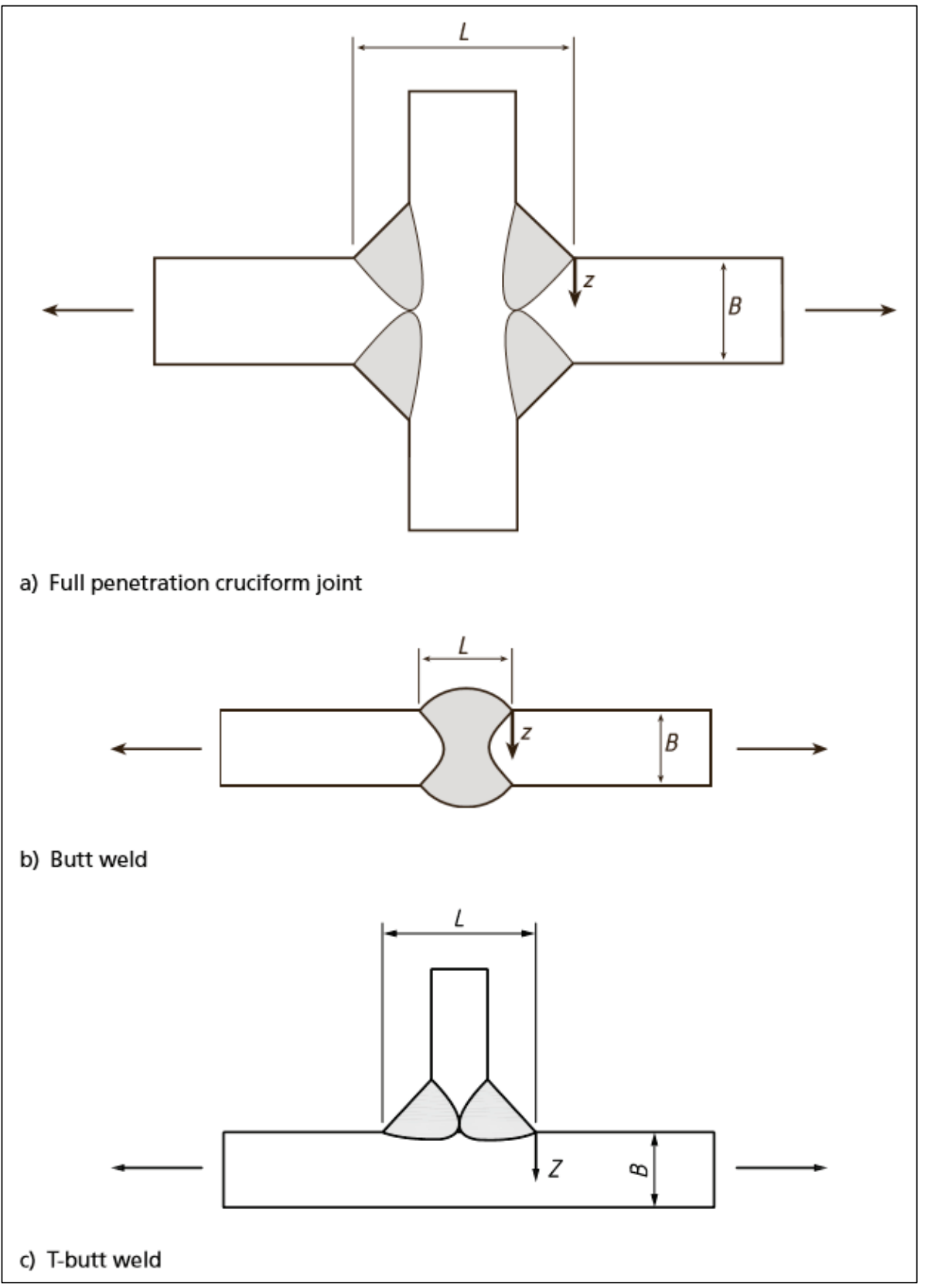


Table 6. Values for factors $v$ and $w$ used in calculating the stress concentration factor Mk (BSI 7910:2013 +A1:2015 2015).

\begin{tabular}{|c|c|c|c|c|}
\hline Loading Mode & L/B & $\mathrm{z} / \mathrm{B}$ & $\mathbf{v}$ & w \\
\hline \multirow{4}{*}{ Tension } & \multirow{2}{*}{$\leq 2$} & $\leq 0.05\left(\frac{L}{B}\right)^{0.55}$ & $0.51\left(\frac{L}{B}\right)^{0.27}$ & -0.31 \\
\hline & & $>0.05\left(\frac{L}{B}\right)^{0.55}$ & 0.83 & $-0.15\left(\frac{L}{B}\right)^{0.46}$ \\
\hline & \multirow{2}{*}{$>2$} & $\leq 0.073$ & 0.615 & -0.31 \\
\hline & & $>0.073$ & 0.83 & -0.20 \\
\hline \multirow{4}{*}{ Bending } & \multirow{2}{*}{$\leq 1$} & $\leq 0.03\left(\frac{L}{B}\right)^{0.55}$ & $0.45\left(\frac{L}{B}\right)^{0.21}$ & -0.31 \\
\hline & & $>0.03\left(\frac{L}{B}\right)^{0.55}$ & 0.68 & $-0.19\left(\frac{L}{B}\right)^{0.21}$ \\
\hline & \multirow{2}{*}{$>1$} & $\leq 0.03$ & 0.45 & -0.31 \\
\hline & & $>0.03$ & 0.68 & -0.19 \\
\hline
\end{tabular}

$$
M_{k}=v\left(\frac{Z}{B}\right)^{w}
$$

3. When there is not enough information:

$$
\begin{gathered}
\text { Geometry Factor: } \\
f_{w}=\left(\sec \left(\frac{\pi * A_{\text {through crack }}}{2 * A_{2}}\right)\right)^{\frac{1}{2}} \\
A_{\text {through crack }}=2 * a * B \\
A_{2}=B * w \\
a=\frac{\text { Crack Length }}{2} \\
B=\text { Crack Thickness } \\
w=\text { Cross Section of piece where crack is }
\end{gathered}
$$

4. Depth: Assume a through crack, due to the more critical nature of a through crack and the available visual and NDT inspection methods typically utilized in the USACE's HSS. 
5. Crack orientation (Tension, Shear, or Mixed Mode crack)

6. Calculate the effective Stress Intensity Equation (Equations 31-37). With the known factors the stress intensity factors can be calculated using the stress multiplied by the factors (Equation 31).

$$
\begin{gathered}
\gamma \Delta \sigma=M * f_{w} *\left(k_{t m} * M_{k m} * M_{m} * \Delta \sigma_{\text {tension }}+k_{t b} * M_{k b} * M_{b} *\right. \\
\left.\left(\Delta \sigma_{\text {bending }}+\left(k_{m}-1\right) * \Delta \sigma_{\text {tension }}\right)\right) \\
K_{I}=\gamma \Delta \sigma_{I} \sqrt{\pi a} \text { for Mode I } \\
K_{I I}=\gamma \Delta \tau \sqrt{\pi a} \text { for Mode II } \\
K_{I I I}=\gamma \Delta \sigma_{I I I} \sqrt{\pi a} \text { for Mode III } \\
K_{e f f}=\left(\frac{K_{I}^{2}+K_{I I}^{2}+K_{I I I}^{2} \alpha}{1-v}\right)^{\frac{1}{2}} \text { for } r \geq 6.3 \text { or } K_{I I}>K_{c} \\
K_{e f f}=\left(\frac{K_{12}^{2}+K_{I I}^{2} \alpha}{1-v}\right)^{\frac{1}{2}} \text { for any other Mixed Mode crack } \\
\left.K_{12}=\left(\frac{2 * K_{I}+6 \sqrt{K_{I}^{2}+8 * K_{I I}^{2}}}{8}\right)\left(\frac{K_{I}^{2}+12 * K_{I I}^{2}+K_{I} *}{2 * K_{I}^{2}+18 * K_{I I}^{2}}\right)^{\frac{3}{K_{I}^{2}+8 * K_{I I}^{2}}}\right)^{\frac{3}{2}} \text { for } \frac{K_{I}}{K_{I I}} \geq 0.466 \\
K_{12}=\frac{K_{I I}}{0.7} \text { for } \frac{K_{I}}{K_{I I}}<0.466
\end{gathered}
$$

7. Calculate the threshold and critical crack length to compare against the crack length noted during the inspection and determine the acceptability of the flaw size (Equations 39-40).

$$
\begin{gathered}
a_{t h}=\left(\frac{K_{t h}}{\gamma \Delta \sigma_{I}}\right)^{2}\left(\frac{1}{\pi}\right) \\
a_{c}=\left(\frac{K_{c}}{\gamma \Delta \sigma_{I}}\right)^{2}\left(\frac{1}{\pi}\right) \\
\text { if } a_{t h} \leq \text { crack length } * \text { S.F. } \leq a_{c} \text { then the crack size acceptable }
\end{gathered}
$$

Where $a_{t h}$ is the threshold crack length, S.F. is the safety factor (Table 7), and $a_{c}$ is the critical crack length. If the crack length is over the critical 
crack length, the section's failure is eminent. If the crack length is greater than the threshold crack length and less than the critical crack length, then number of cycles to the design life needs to be considered.

Table 7. Factor of Safety based on failure consequence and section redundancy (BSI 7910:2013 +A1:2015 2015).

\begin{tabular}{|l|l|l|l|l|l|}
\hline & \multicolumn{1}{|c|}{$\begin{array}{c}\text { Standard } \\
\text { Deviation }\end{array}$} & \multicolumn{1}{|c|}{ Moderate } & Severe & $\begin{array}{c}\text { Very } \\
\text { Severe }\end{array}$ & Extremely Severe \\
\hline \multirow{5}{*}{ Redundant Member } & 0.1 & 1 & 1.4 & 1.5 & 1.7 \\
\cline { 2 - 7 } & 0.2 & 1.05 & 1.45 & 1.55 & 1.8 \\
\cline { 2 - 7 } & 0.3 & 1.08 & 1.5 & 1.65 & 1.99 \\
\cline { 2 - 7 } & 0.5 & 1.15 & 1.7 & 1.85 & 2.1 \\
\hline \multirow{5}{*}{ Non-Redundant Member } & 0.1 & 1.4 & 1.5 & 1.7 & 2.1 \\
\cline { 2 - 7 } & 0.2 & 1.45 & 1.55 & 1.8 & 2.2 \\
\cline { 2 - 7 } & 0.3 & 1.5 & 1.65 & 1.99 & 2.3 \\
\cline { 2 - 6 } & 0.5 & 1.7 & 1.85 & 2.1 & 2.5 \\
\hline
\end{tabular}

8. Calculate the number of cycles at the given crack length and at the critical crack length then compare the values to the structure's design life. Table 8 gives a list of fatigue and fracture properties for steel in air and marine environments.

Table 8. Steel fracture toughness and Paris Law constants based on environment.

\begin{tabular}{|c|c|c|c|c|}
\hline & $\begin{array}{c}K_{t h} \\
M p a \sqrt{m}\end{array}$ & $\begin{array}{l}K_{c} \\
M p a \sqrt{m}\end{array}$ & $C^{1}$ & $\mathbf{M}^{1}$ \\
\hline Air & $2^{2}[1]$ & $100^{3}[9]$ & $5.21 \mathrm{E}-13[1]$ & 3 \\
\hline Marine & $2^{2}[1]$ & $81.3^{4}[5]$ & $2.3 \mathrm{E}-12[1]$ & 3 \\
\hline \multicolumn{5}{|c|}{$\begin{array}{l}\text { 1. When } \frac{d a}{d N} \text { is } \frac{m m}{c y c l e} \text { and } \Delta K \text { is } M p a \sqrt{m} \text { (BS7910 2015) } \\
\text { (Cui 2014) }\end{array}$} \\
\hline
\end{tabular}

9. Paris Law is only utilized within the limits of the threshold and critical crack growth.

$$
K_{t h} \leq K_{\text {eff }} \leq K_{c}
$$

10. Number of cycles at the NDT inspection's crack length

$$
N_{\text {cracklength }}=\frac{1}{C\left(\gamma \Delta \sigma_{p}\right)^{m} \pi^{\frac{m}{2}}} \int_{a_{t h}}^{\text {CrackLength }} \frac{1}{a^{\frac{m}{2}}} d a ; m \neq 2
$$


Where $d a$ is the change in crack length.

11. Number of cycles to critical crack length

$$
N_{\text {critical }}=\frac{1}{C\left(\gamma \Delta \sigma_{p}\right)^{m} \pi^{\frac{m}{2}}} \int_{a_{t h}}^{\text {CriticalCrackLength }} \frac{1}{a^{\frac{m}{2}}} d a ; m \neq 2
$$

12. Calculate the section's service life number of cycles based on the operational cyclical loads. For example, a flange section of a Miter gate will see 4 cycles per lockage. With lockage history an estimate of service life number of cycles can be calculated.

Compare the critical crack length number of cycles to the service life of the structure. If the critical crack length number of cycles is less than the service life, then compare the current crack length number of cycles to the critical crack length number of cycles. Otherwise, compare the current crack length number of cycles to the section's service life remaining number of cycles. A fatigue crack is acceptable if the current number of cycles has not exceeded either the service life or critical crack length number of cycles (whichever is the smaller value). 


\section{Application of Finite Elements}

Technology has improved, which allows for problems, such as fatigue and fracture, to be modeled using Finite Element Modeling (FEM). FEM allows a full HSS to be modeled and have its life cycle loads applied over time. FEM minimizes the time required to determine the stresses, behavior, and the effects of degradation of HSS. Fatigue behavior and cracking can take millions of load cycles to manifest. FEM condenses the load cycles into less time facilitating the study of fatigue behavior and its effects.

FEM is a computerized method that allows users to solve large or complicated problems more accurately and, in less time than it would take by hand. FEM takes a structure or system and divides it into elements (structural pieces) (Figure 37). The elements are connected to each other through nodes. The behavioral response to any applied force, stress, or energy on a system is calculated at the integration points and extrapolated to the individual nodes. In order to solve the overall global system, the nodes' extrapolated stresses are transferred to the global structure. Through the discretization method, FEM is able to effectively calculate the behavior of a large complex structure (McGuire 2000) (Koutromanos 2018).

Figure 37. Typical structural analysis a) 1D structural analysis b) 2D structural analysis c) 3D structural Analysis.

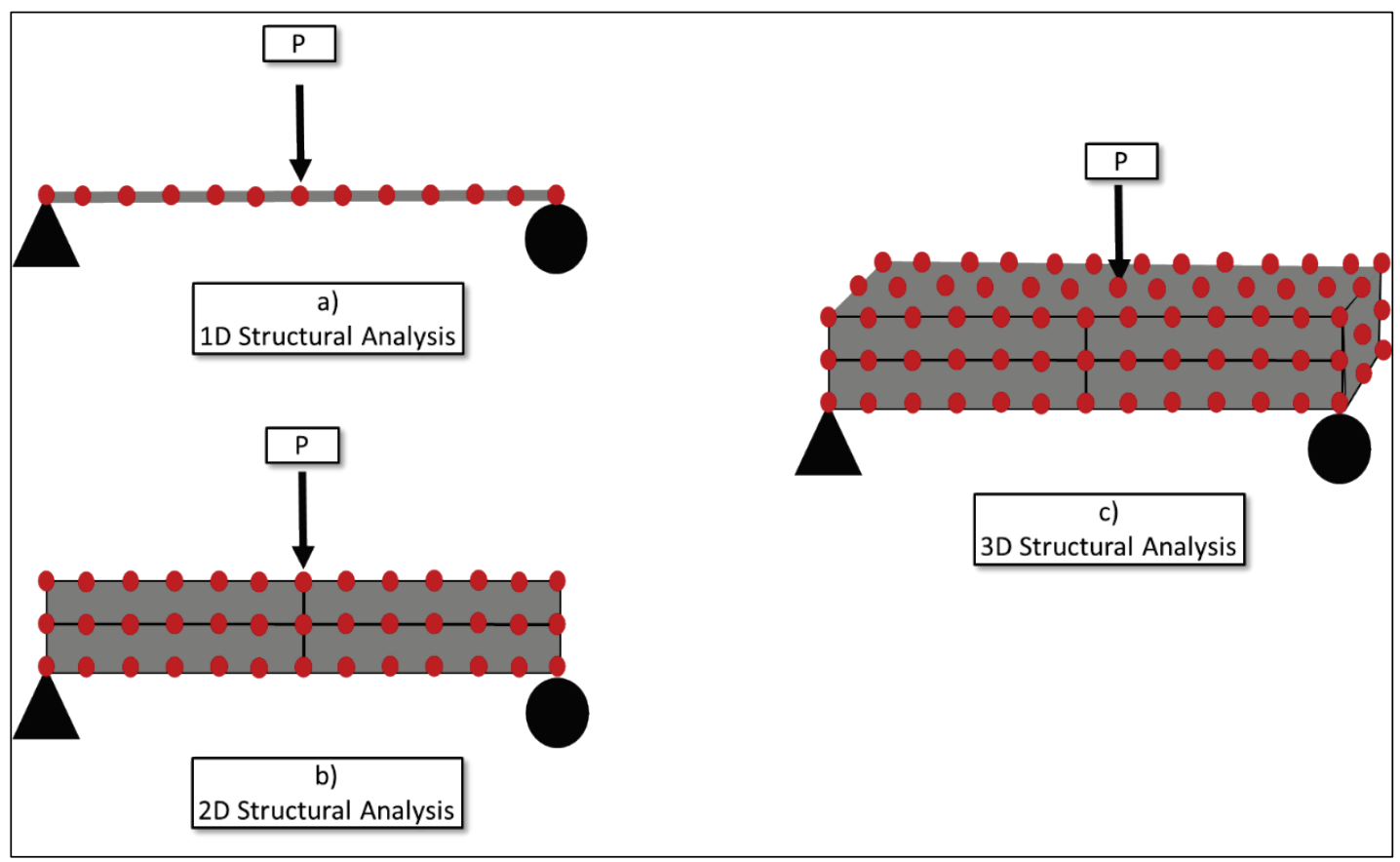


Within the USACE, FEM is used to model HSS and their state of stresses to study methods to improve and strengthen the current infrastructure. For example, FEM has been used to determine the critical fatigue and fracture areas of HSS, such as reverse tainter valves, Figure 38 . Figure 38 a) and b) shows how FEM identifies the areas of localized high stresses that can lead to fatigue and fracture, while Figure $38 \mathrm{c}$ ) demonstrates the field implementation of innovative repairs that were developed using the FEM results. FEM has given engineers and scientists within the USACE a better understanding of the state of stresses within HSS along with allowing scientists to discover, test, and determine the impact of new improvements before field implementation (Riveros 2018).

Figure 38. a) Global tainter valve model with location of high stress b) tainter valve high stress results c) CFRP repairs (Riveros 2018).

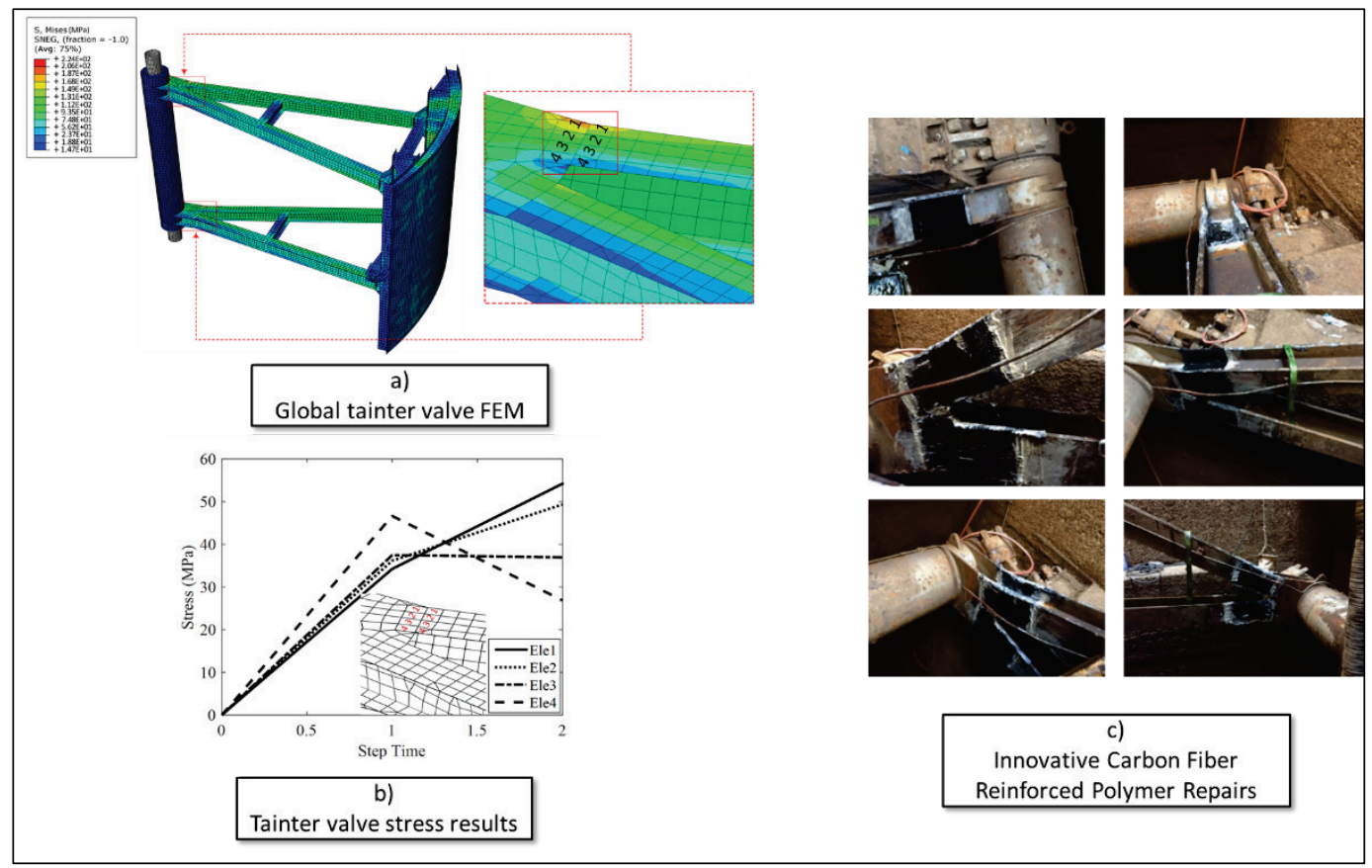




\section{Fatigue Repairs}

\subsection{Crack detection techniques}

Each method of crack detection relies on the disturbance that a crack creates in the material. The two most common non-destructive crack detection methods are dye-penetrant and magnetic particle inspection (MPI). Some other methods used during crack inspections are eddy current inspection, ultrasonic inspection, time-of-flight diffraction, and alternating current field measurement (ACFM). In the case of underwater crack detection, sonar cameras have proven to aid in visual crack detection. The best crack detection method depends on the structure, the availability of the full structure's connection points and critical sections, as well as the inspection budget. Dye-penetrant and MPI are the most economical of the detection methods, but they require a trained inspector in the field, dry conditions, and full visibility of the structure. The other detection methods (eddy current inspection, ultrasonic inspection, timeof-flight diffraction, and ACFM) can be used underwater, but are expensive and require computers, probes, recording equipment, magnetic current, electric current, or sound wave inducing equipment.

In dye-penetrant testing and MPI, a developing substance applied to the surface of a material isolates the cracks/flaws. Dye-penetrant testing and MPI require a clean surface before the developer is applied. During dyepenetrant testing, the crack's surface tension forces use capillary action to draw a liquid penetrant into the crack (Figure 39) (Iowa State University 2014). After the excess penetrant is wiped off the material's surface, a developing liquid is applied. The developer reacts with the penetrant, within the crack, revealing the crack to visual inspection (Iowa State University 2014) (Magnaflux 2017). Crack growth reverses the magnetic field lines of a material, and during MPI, magnetic field lines form when the material is magnetized. The reversed magnetic field lines will draw the ferrous developer into the crack making the crack visible (Figure 40) (Iowa State University 2014). 
Figure 39. Dye-penetrant inspection process.

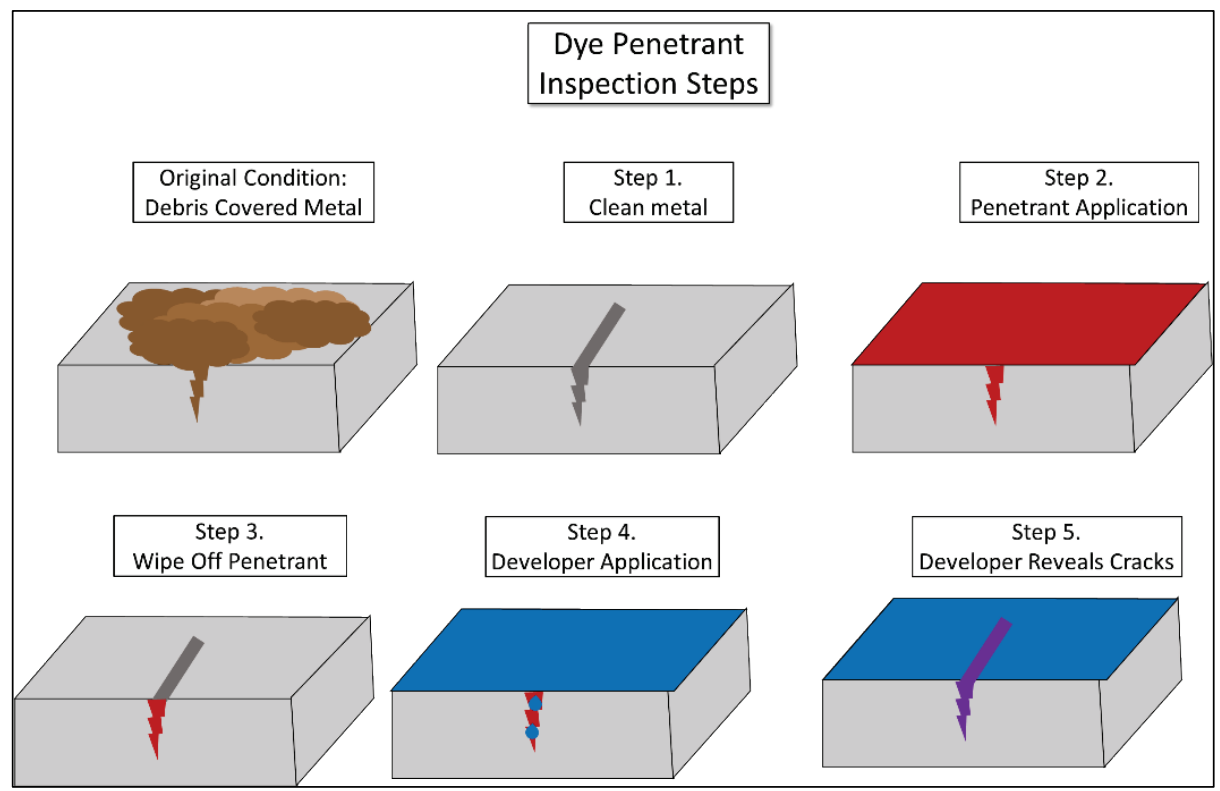

Figure 40. Magnetic particle inspection.

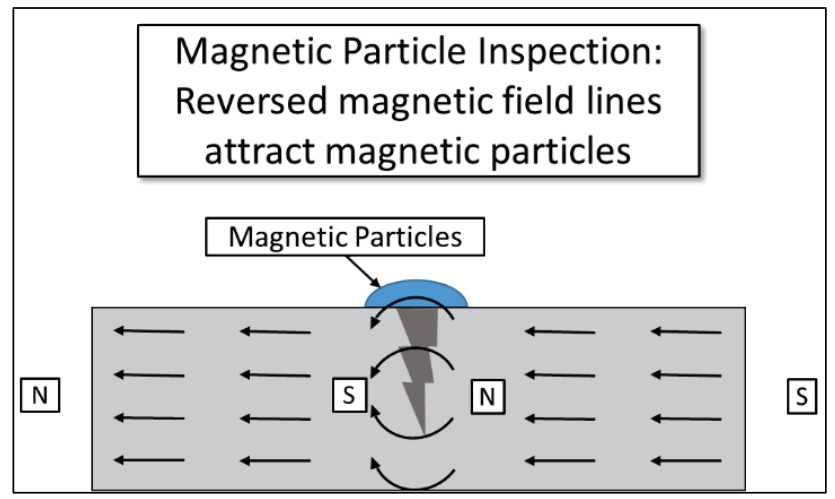

Crack detection methods, such as eddy current inspection, ultrasonic inspection, time-of-flight diffraction, and ACFM require the following: probes, receivers, or sensors; magnetic or electric field inducing systems; and a computing system to record, review and analyze the output data. Eddy current inspection works by inducing a magnetic current around a magnetic coil, which causes eddy currents to penetrate the steel section. Flaws or cracks cause a disturbance within the eddy current that causes a change in the phase and amplitude of the magnetic current (registered as a blip in a screen output), Figure 41 (Iowa State University 2014; Nelligan 2018; Hansen 2016). Ultrasonic and time-of-flight inspections utilize wave reflections and wave path changes to determine and record the location and size of the crack (Figure 42) (Iowa State University 2014). Ultrasonic waves are disrupted and reflected by any cracks or flaws. The time-of- 
flight inspection method, specifically, uses the elapsed time between the outputted signal and subsequent reflected response to detect cracks (Figure 43) (TWI 2018; Olympus 2018). ACFM uses alternating current (AC) to emit uniform and shallow electrical field waves. The ACFM sensors read current density changes along the crack length $(\mathrm{Bx})$ and the change in current rotation at the crack ends (Bz). When an electrical current is applied to the area, the $\mathrm{Bx}$ reading provides the crack depth while the $\mathrm{Bz}$ reading provides the crack length (Figure 44) (Dover 1991). The ACFM method does not require immediate contact of the magnetic surface and can therefore be used over coatings. (TWI 2018; Topp 2000; Laenen et al. 2007).

Figure 41. Eddy current inspection.

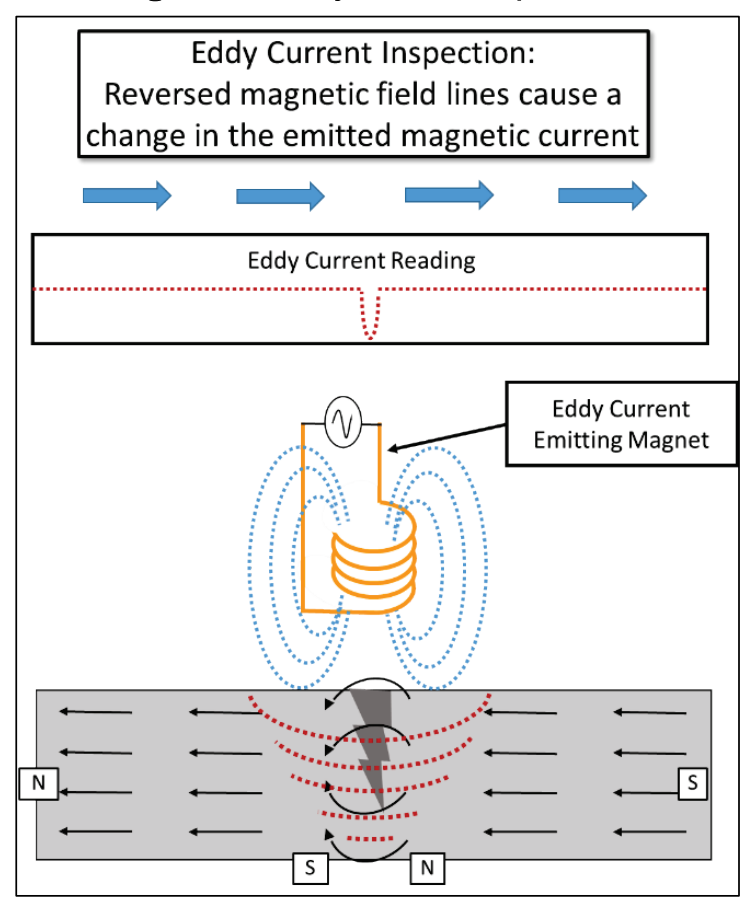


Figure 42. Ultrasonic inspection.

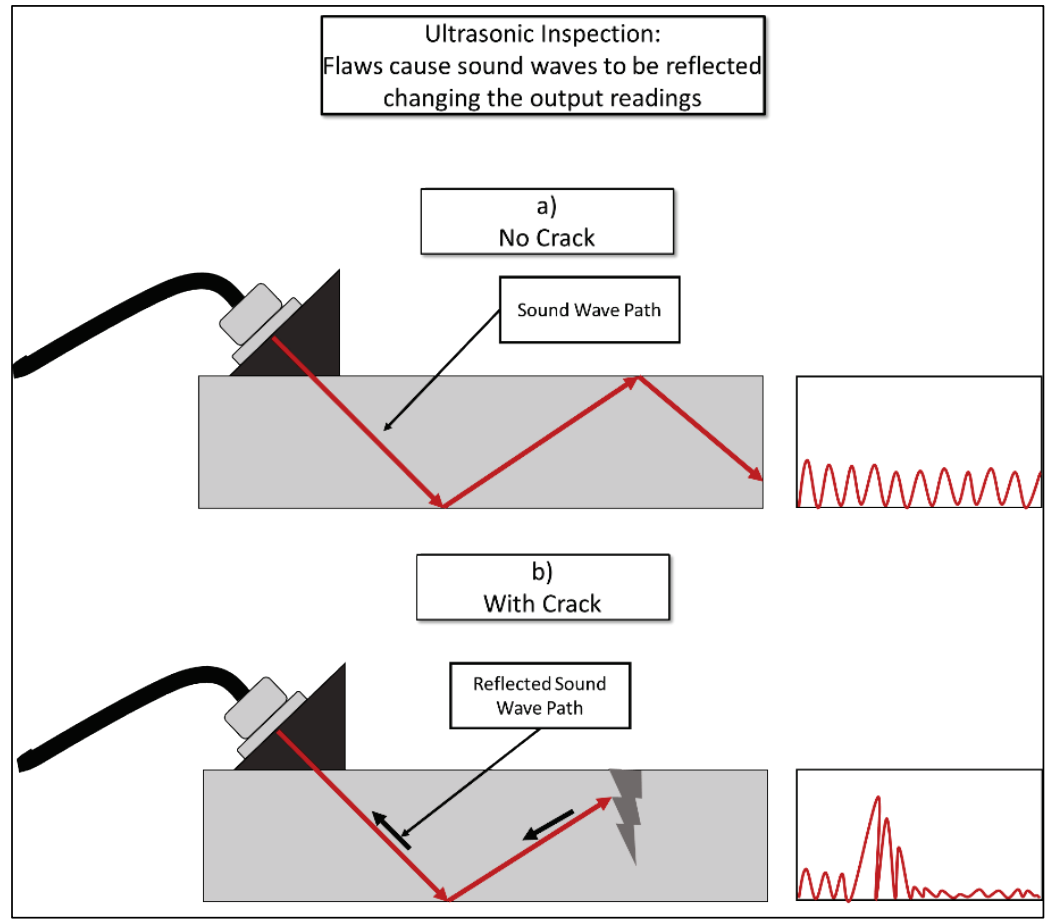

Figure 43. Time-of-flight diffraction inspection.

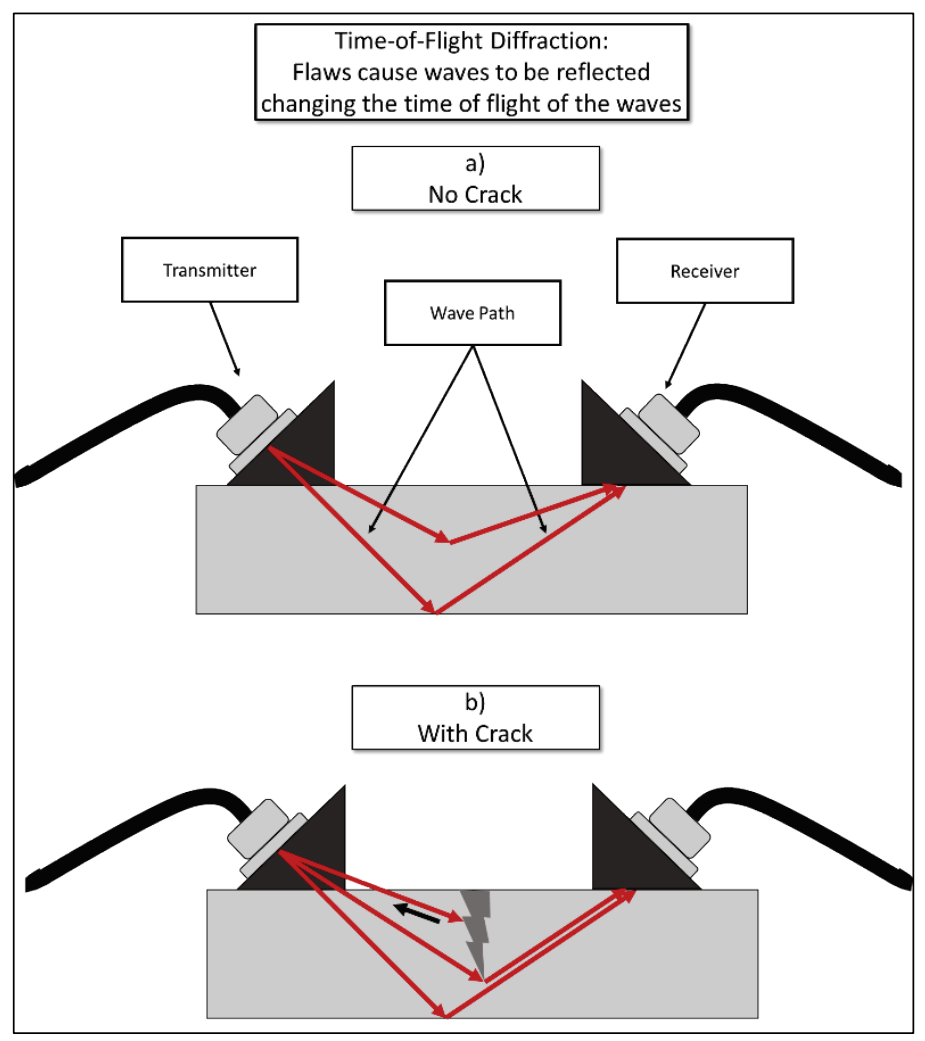


Figure 44. ACFM inspection.

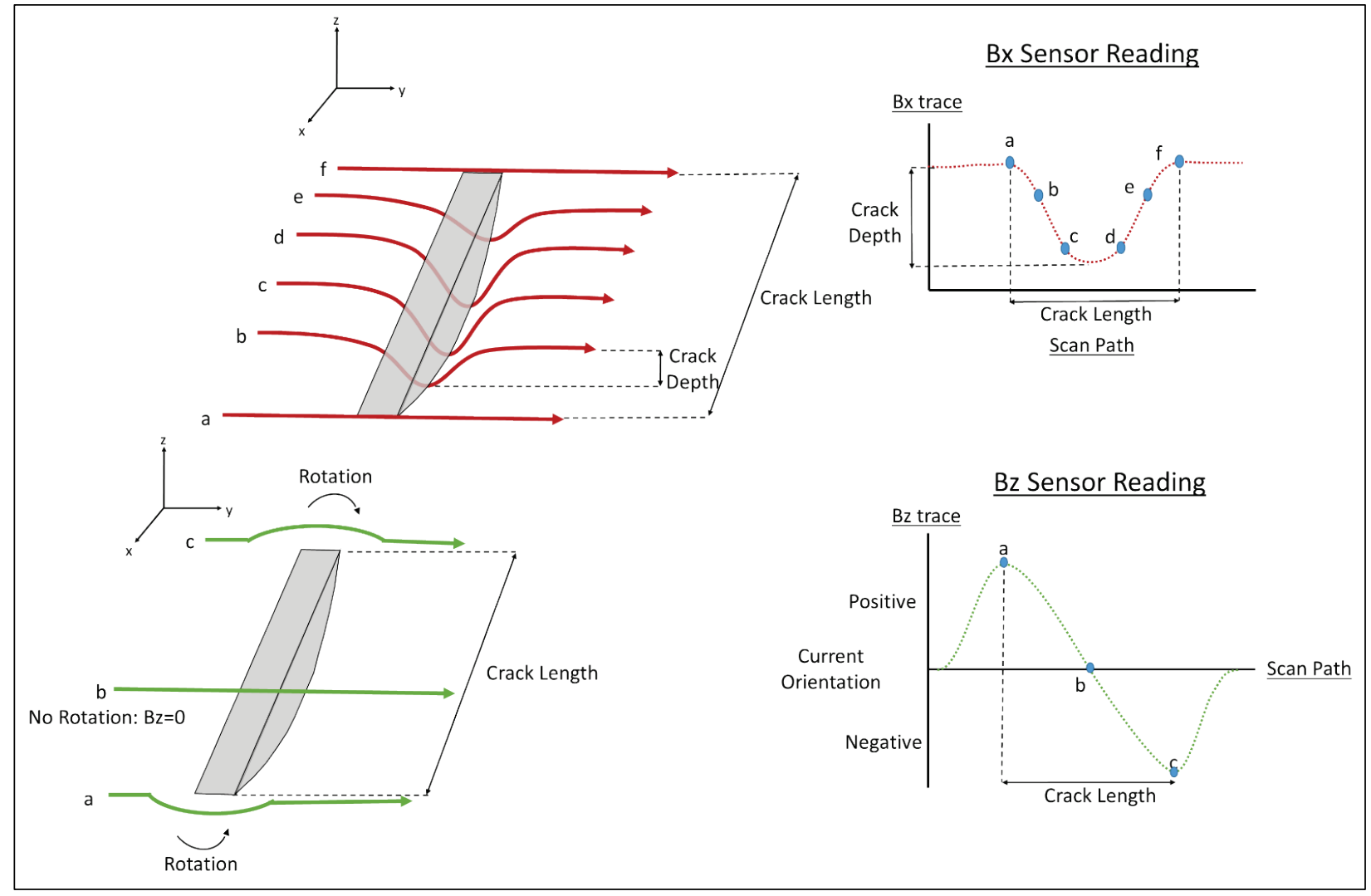

Each non-destructive crack detection test method has advantages and disadvantages, which can be seen in Table 8 . 
Table 9. Advantages and disadvantages of most common crack inspection methods.

\begin{tabular}{|c|c|c|}
\hline Inspection Type & Advantages & Disadvantages \\
\hline $\begin{array}{l}\text { Dye-Penetrant } \\
\text { Inspection }\end{array}$ & $\begin{array}{l}\text { Makes the surface crack } \\
\text { visible } \\
\text { Limited training required } \\
\text { Low-cost } \\
\text { Fast inspection time } \\
\text { Portable equipment } \\
\text { Little dependence on } \\
\text { material of section }\end{array}$ & $\begin{array}{l}\text { 1. Pre-cleaning required } \\
\text { 2. Post-cleaning required } \\
\text { 3. Limited to surface flaws } \\
\text { 4. Can be unreliable due to } \\
\text { surface condition } \\
\text { 5. Sensitivity based on inspector } \\
\text { 6. No depth measurement }\end{array}$ \\
\hline $\begin{array}{l}\text { Magnetic Particle } \\
\text { Inspection (MPI) }\end{array}$ & $\begin{array}{l}\text { Makes the surface crack } \\
\text { visible } \\
\text { Low to medium cost } \\
\text { Fast inspection time } \\
\text { Portable equipment }\end{array}$ & $\begin{array}{l}\text { 1. Pre-cleaning required } \\
\text { 2. Extensive experience and } \\
\text { training required } \\
\text { 3. Limited to surface flaws } \\
\text { 4. Demagnetization required } \\
\text { 5. Magnetic materials only } \\
\text { 6. Sensitivity based on inspector } \\
\text { and equipment } \\
\text { 7. No depth measurement }\end{array}$ \\
\hline $\begin{array}{l}\text { Eddy Current } \\
\text { Inspection }\end{array}$ & $\begin{array}{l}\text { External crack/flaw } \\
\text { Can be used underwater } \\
\text { Can be used over } \\
\text { coating/paint } \\
\text { Can measure the depth of } \\
\text { crack/flaw } \\
\text { Moderate to high } \\
\text { sensitivity (can detect } \\
\text { small flaws) }\end{array}$ & $\begin{array}{l}\text { 1. Slow } \\
\text { 2. Limited by the material } \\
\text { thickness } \\
\text { 3. Very sensitive to any material } \\
\text { changes } \\
\text { 4. Moderate experience and } \\
\text { training required } \\
\text { 5. Moderate to high cost } \\
\text { 6. Pre-cleaning required }\end{array}$ \\
\hline $\begin{array}{l}\text { Ultrasonic } \\
\text { Inspection }\end{array}$ & $\begin{array}{l}\text { Internal and surface flaws } \\
\text { Can measure the depth of } \\
\text { crack/flaw } \\
\text { Portable equipment } \\
\text { High sensitivity (can } \\
\text { detect small flaws) } \\
\text { High accuracy }\end{array}$ & $\begin{array}{l}\text { 1. High-cost } \\
\text { 2. Extensive experience and } \\
\text { training required } \\
\text { 3. Can be hard to inspect } \\
\text { sections with rough surfaces } \\
\text { 4. Pre-cleaning required } \\
\text { 5. Contact with the section is } \\
\text { required }\end{array}$ \\
\hline $\begin{array}{l}\text { Time-of-Flight } \\
\text { Diffraction }\end{array}$ & $\begin{array}{l}\text { Portable } \\
\text { High sensitivity (can } \\
\text { detect small flaws) } \\
\text { High accuracy } \\
\text { Internal and surface flaws }\end{array}$ & $\begin{array}{l}\text { 1. There is a "dead-zone" just } \\
\text { below the inspection surface } \\
\text { 2. Extensive experience and } \\
\text { training required } \\
\text { 3. Pre-cleaning required } \\
\text { 4. High Cost }\end{array}$ \\
\hline $\begin{array}{l}\text { Alternating Current } \\
\text { Field Measurement } \\
\text { (ACFM) }\end{array}$ & $\begin{array}{l}\text { No pre-cleaning } \\
\text { High Accuracy } \\
\text { Can be used underwater } \\
\text { Can be used over } \\
\text { coating/paint } \\
\text { Portable } \\
\text { Not as sensitive to } \\
\text { material changes } \\
\text { Internal and surface flaws }\end{array}$ & $\begin{array}{l}\text { 1. High Cost } \\
\text { 2. Extensive experience and } \\
\text { training required } \\
\text { 3. Depth limitation based on } \\
\text { equipment }\end{array}$ \\
\hline
\end{tabular}




\subsection{Current crack repair and retrofit methods}

\subsubsection{Surface treatments}

\subsubsection{Grinding}

Micro-cracks can form from the high stresses generated in welded sections with a poor weld toe to base metal transition or a sharp geometric transition. Surface grinding, Figure 45, of the area in question can help reduce the high stresses and improve the weld fatigue category (Dexter 2013). Most weld profiles in HSS are considered Category D, E, or E' due to poor weld quality. Surface grinding is used to remove small defects or micro-cracks.

Figure 45. Weld surface finish a) no finish b) ground finish.
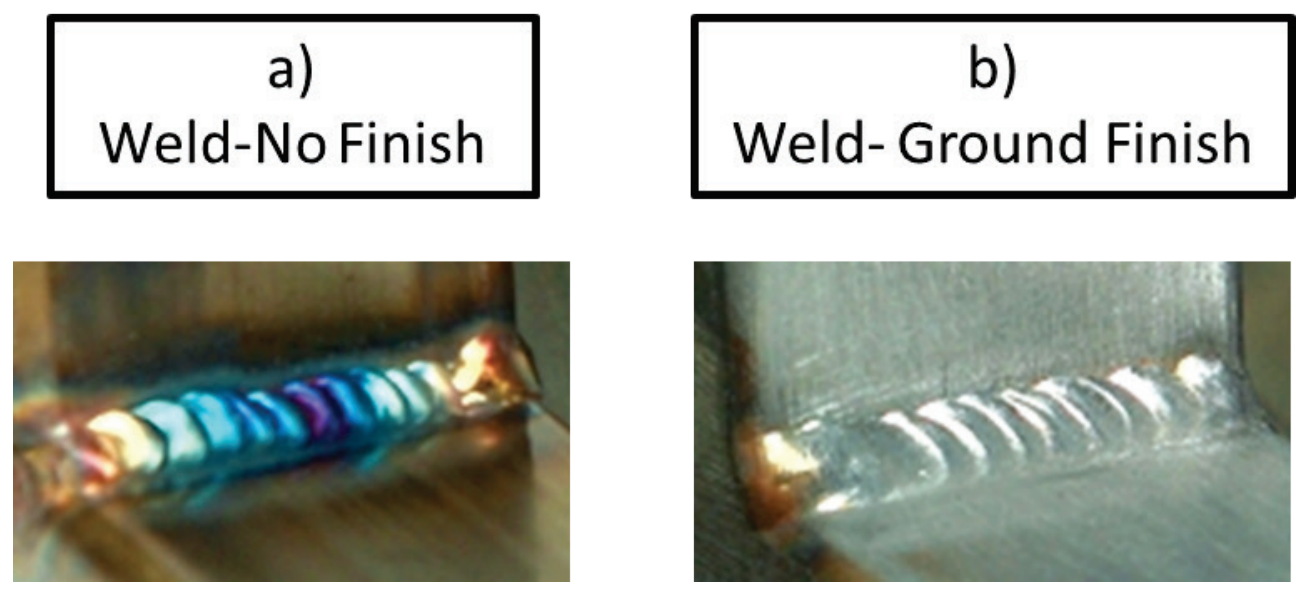

The two most common types of grinding are toe grinding and full-profile grinding. Toe grinding is applied when the transition from the weld to the base metal is too steep or sharp. Abrupt transitions, caused by sharp angles, create high-stress concentrations that lead to micro-cracks. Grinding the weld toe, between 0.02-0.08 in., creates a radiated fillet (Figure 46) smoothing the weld to base metal transition and reducing the stress concentrations at the toe weld. A weld's full profile is ground when the overall shape of the weld does not adhere to code and/or has developed micro-cracks or small defects. As seen in Figure 47, full-profile grinding reshapes the weld or takes off a portion of the weld that had formed micro-cracks (Dexter 2013; Johnson 2017) and can increase the fatigue life between 50 to 100\% (Haagensen 1993). 
Figure 46. Toe grinding.

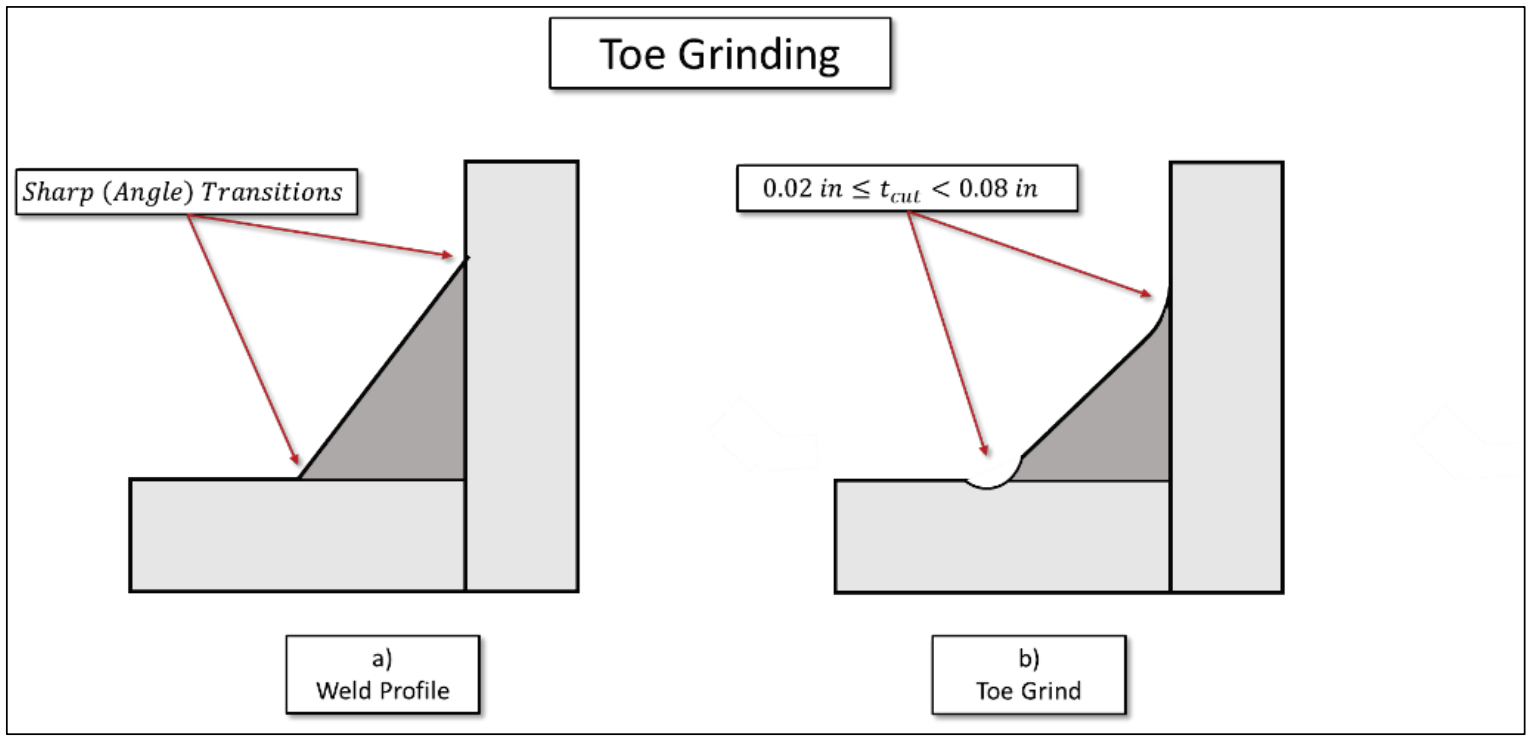

Figure 47. Full-profile grinding.

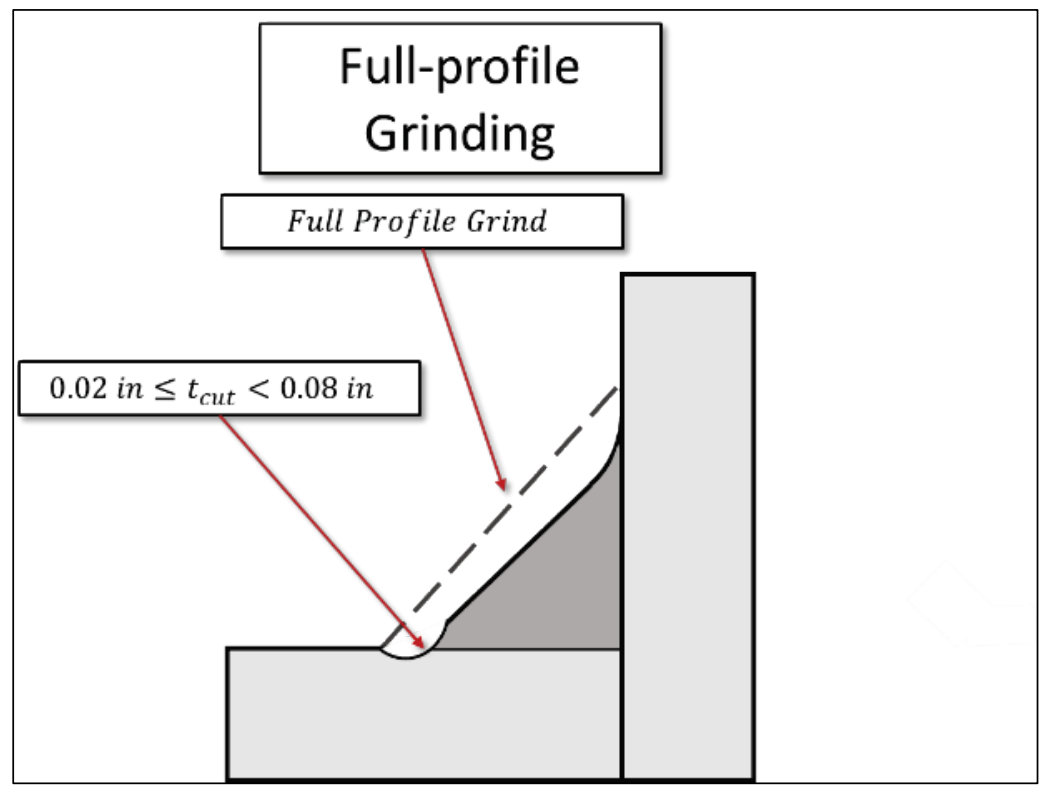

\subsubsection{Re-melting: Gas Tungsten Arc (GTA) and plasma}

Re-melting of a weld at the intersection between weld and base metal reduces the stress concentration at the weld toe (Dexter 2013). Weld remelting creates a smoother weld to base metal transition reducing the stress concentrations, removing any existing defects, and increasing the surface hardness of the re-melted zone (Haagensen 2011). For a re-melting repair, the operator's welding skills must be greater than or equal to an operator working in a fabrication shop. The limits for a re-melting repair 
are a maximum crack depth of $3 / 16$ in. The two most common methods of re-melting are Gas Tungsten Arc (GTA) and plasma dressing. The difference between GTA and plasma dressing is the heat level as plasma dressing runs at a higher heat, and the welding method, GTA uses a gas shield around the electrode (Figure 48) (Dexter 2013; Johnson, 2017).

Figure 48. GTA re-melting.

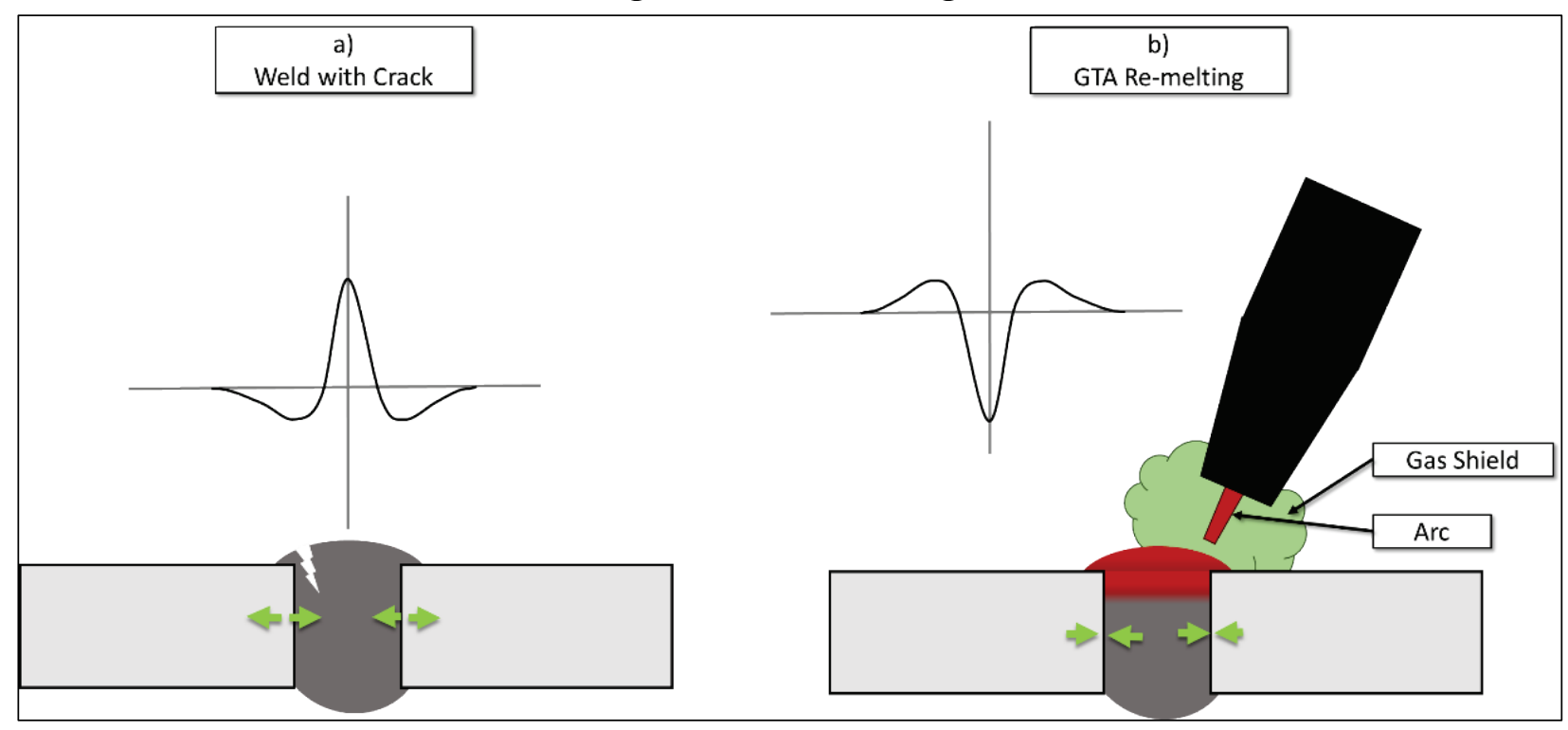

\subsubsection{Impact treatments}

Impact treatments, such as air-hammer peening and ultrasonic impact treatment, introduce compressive stresses to the weld toe area. The introduced compressive stresses reduce the local high-stress concentrations, which increase the fatigue life of the section (Figure 49). The impact treatments create a smoother, radial transition between the weld and the base metal further lowering the high-stress concentration (Figure 49) (Dexter 2013; Shimanuki 2015). Impact treatments can increase the fatigue life of a welded joint by up to 6 times (Zhao 2016). 
Figure 49. Impact treatment process.

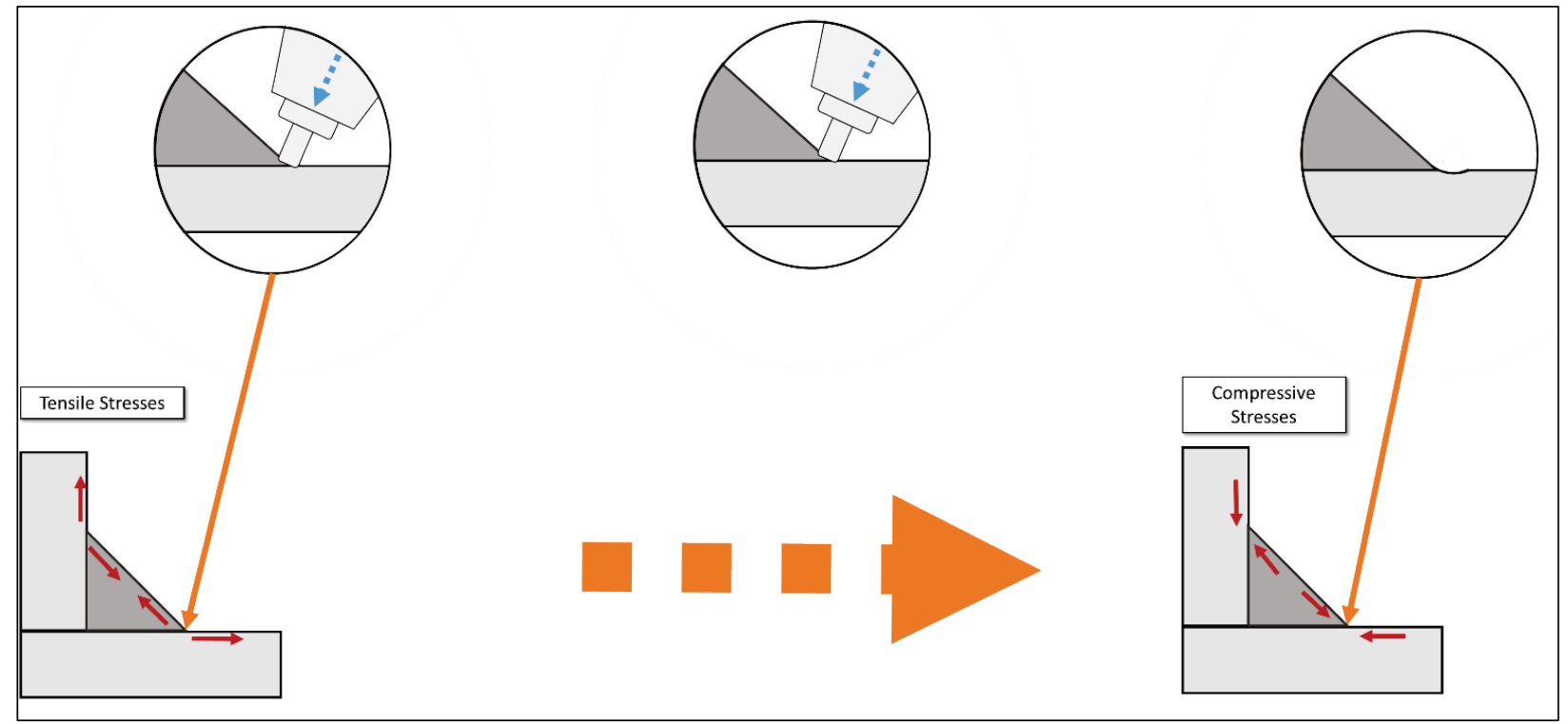

The two most common impact treatments in use are air hammer peening and ultrasonic impact treatment. Air hammer peening uses an air hammer, with a blunt tip and optimum air pressure of $40 \mathrm{psi}$, at an angle of $45^{\circ}$ from the base metal to repeatedly hammer the weld and introduce the compressive stresses. Depending on the section's thickness, the recommended depth of penetration for air hammer peening is 0.03-0.06 inches and is effective for cracks up 0.12 in. deep. Peening must be performed with care as it can introduce lap-type defects to the welded section. Grinding the surface of the weld section after peening helps to minimize the lap-type defects (Dexter 2013).

\subsubsection{Hole drilling}

The most common method of repairing fatigue cracks is hole drilling. This method is only effective for Mode I (pure tension) cracks (Figure 50) because a hole will only increase the crack size if the controlling load condition is a shear load (Mode II, III, or Mixed Mode). Cracks controlled by shear have a crack angle between 30 and 60 degrees (Figure 51). Note, due to boundary condition deterioration, corrosion, and overloads many HSS cracks are Mixed Mode. Therefore, to be conservative If the controlling load is Mode I a hole is placed at the crack tip to help redistribute the stress concentration (Section 2.6 Holes), Figure 50. Typically, holes are 2-4 in. in diameter. The proper hole size can be determined using Equation 43 


$$
D=\frac{s_{r} \pi a}{8 \sigma_{y}} \geq 1.0 \mathrm{in}
$$

In Equation 43, $D$ is the required hole diameter (in.), $S_{r}$ is the nominal stress (ksi), $a$ is the half-crack length (in.), and $\sigma_{y}$ is the yield stress (ksi.). Ideally, the hole should be placed right outside the crack tip or over the crack tip (Figure 52). If the hole is large enough, plugging the hole with a fully tensioned bolt with washers gives the added benefit of introducing compressive stresses to the area (Dexter 2013). 
Figure 50. Hole drilling stress distributions: 1) Mode I; 2) Mode II; 3) Mixed mode.

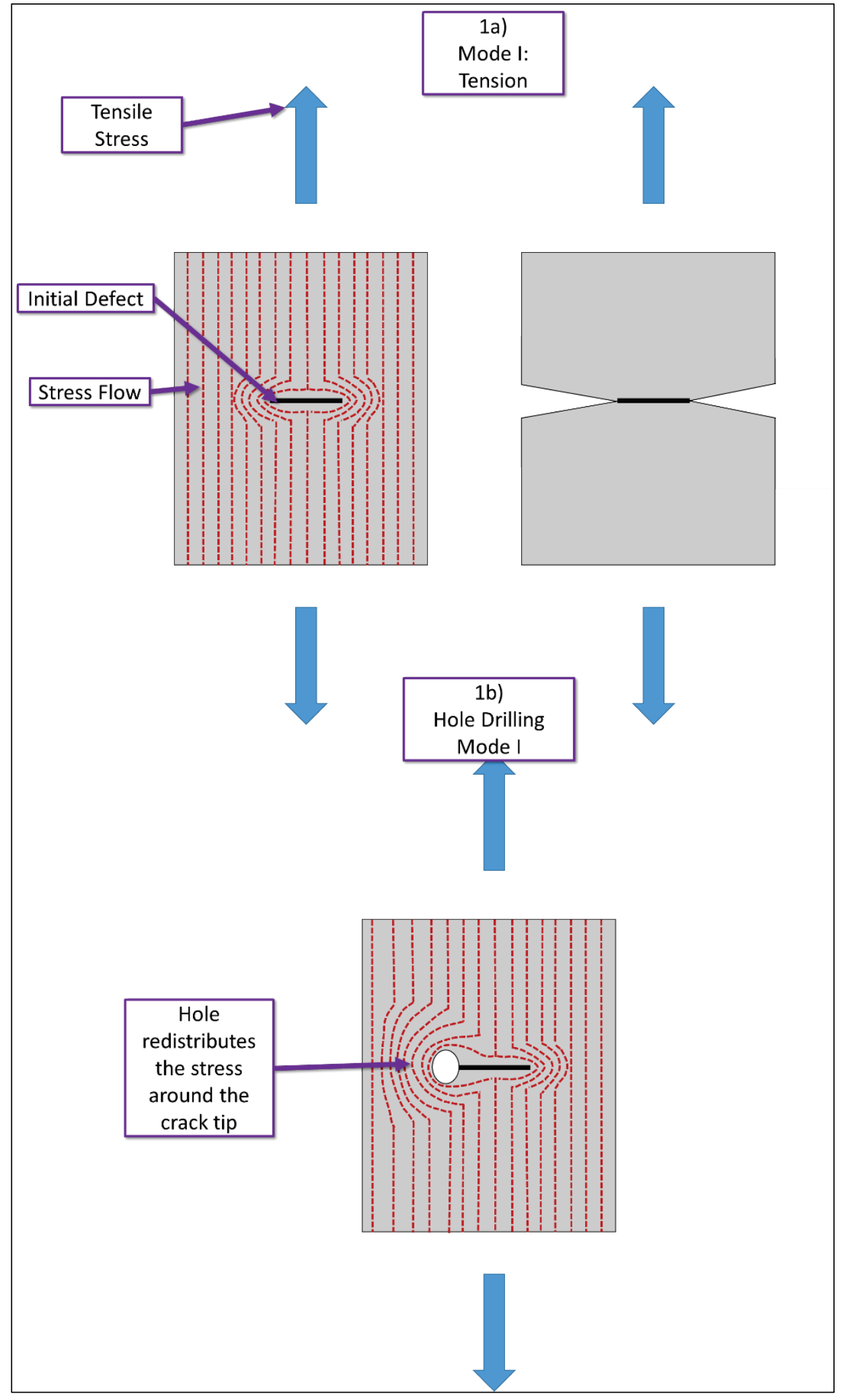


Figure 51. Mixed mode crack and angle.
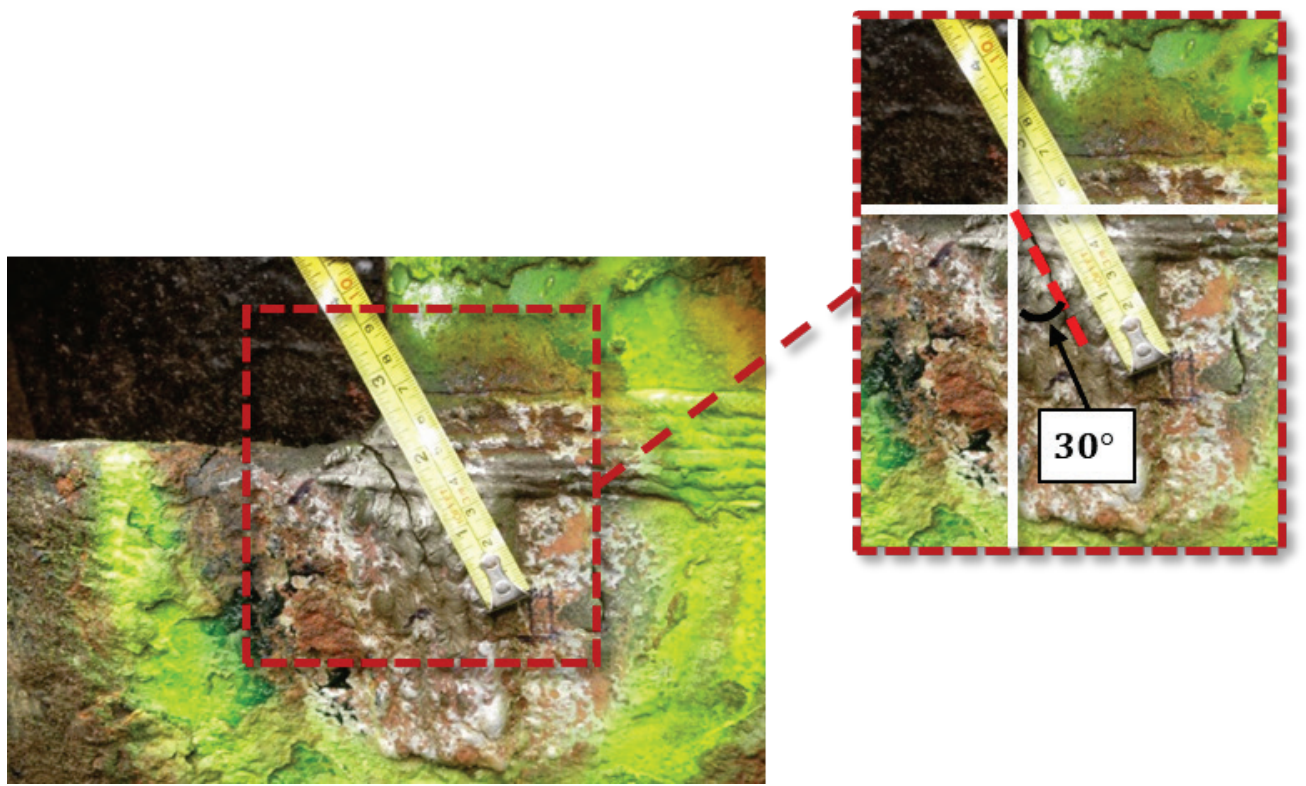

Figure 52. Hole placement: a) hole placement not acceptable; b) acceptable hole placement; c) ideal hole placement.

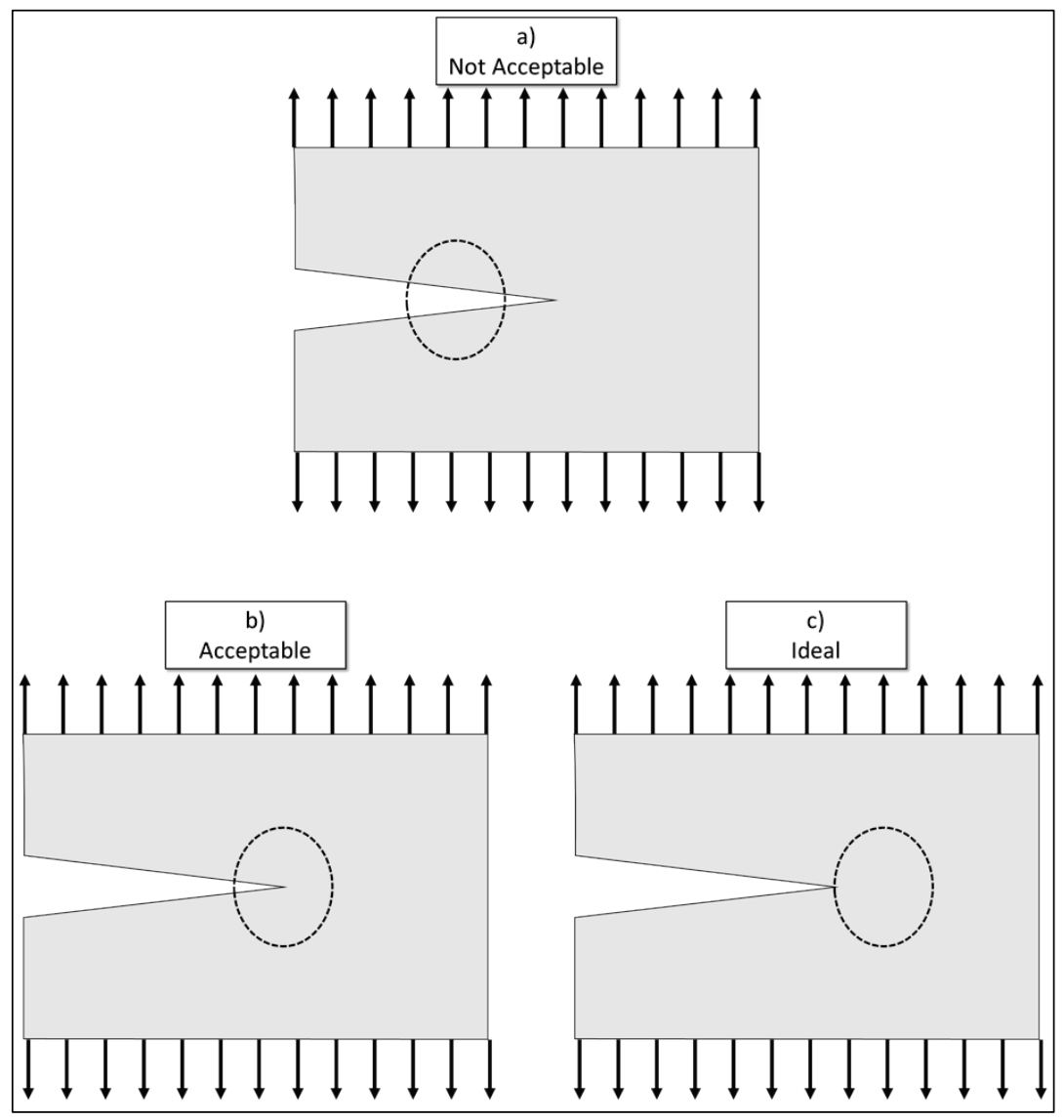




\subsubsection{Vee-and-weld}

The vee-and-weld method is the best method to repair long throughcracks. This method consists of gouging the crack on one side in a v-shape pattern up to $3 / 4$ of section's thickness and filling the gouge with weld metal, then the process repeats on the other side of the section (Figure 53). The crack is fully removed and replaced by gouging and refilling the crack from both sides. Air arc gouging is the preferred method of removal to avoid smearing or hiding defects. In order to ensure an improved weld detail, the welding operator should be certified and be able to weld better than or equal to a welder working in a fabrication shop. The vee-and-weld method is most effective repairing cracks in a weld detail not in base metal. A base metal repair would have a lower fatigue life than the original base metal since the fatigue life of base metal is greater than of a weld detail. To repair a base metal crack with a vee-and-weld, other fatigue repair methods are required (Dexter 2013).

Figure 53. Vee-and-weld method.

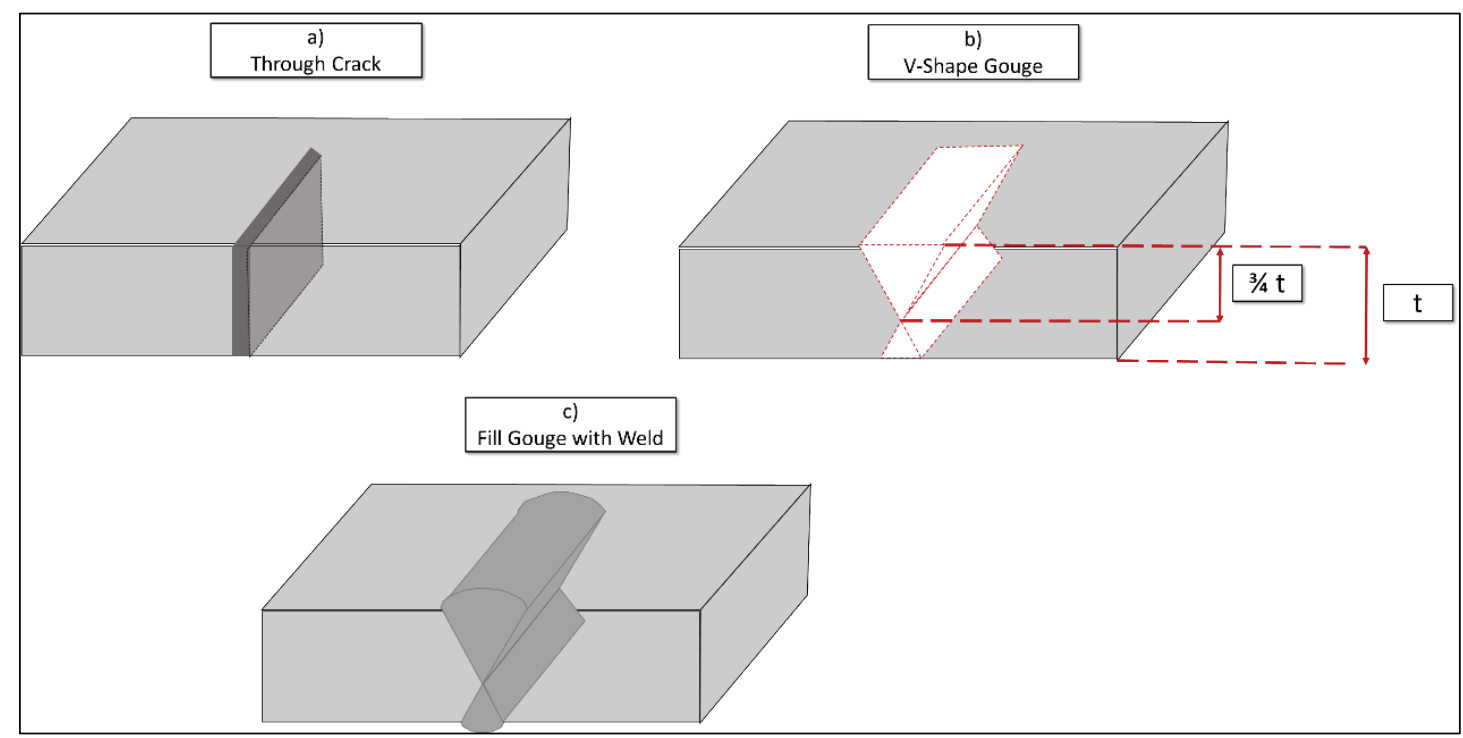

\subsubsection{Doubler/splice plates}

Stress is a force over an area, therefore applying a force over an increased area reduces the overall stress felt. Doubler/splice plates bolted over a crack create a greater cross-sectional area (Dexter 2013). The greater cross-sectional area reduces the overall stress range in the section (Figure 54). If the crack is a Mode I crack, then drilling a hole at the crack tip further reduces the stress concentration at the crack tip. 
Figure 54. Doubler/splice plate repair.

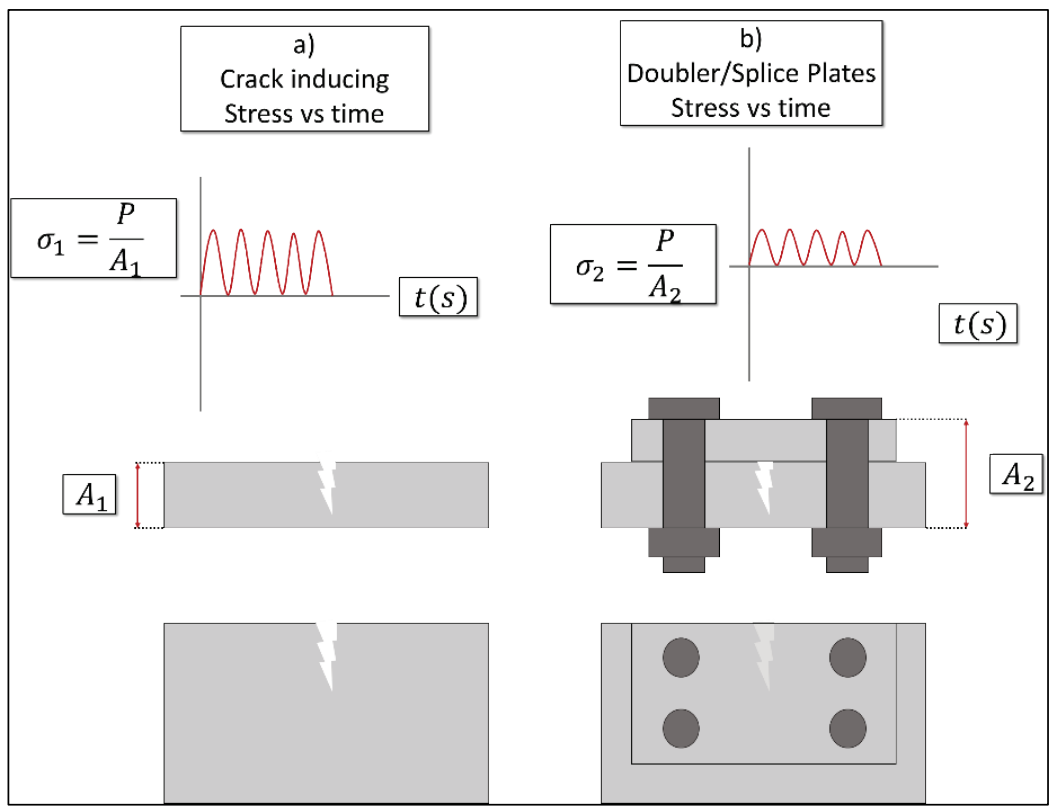

\subsubsection{Post-tensioning}

Post-tensioning works by putting the whole section in compression and not allowing the defect/micro-crack to open. Therefore, the crack does not propagate. As shown in Figure55a, when an operational load, P, is applied to a section it creates internal tensile forces. Applying post-tension places the section in compression as shown in Figure 55b. Depending on the applied post-tension the section can be placed in compression or have reduced internal tensile forces. In steel details, post-tension is most applied through pre-stressing strands, post-tensioning bars, or highly torqued nuts on threaded rods (Dexter 2013). 
Figure 55. a) Stresses under load; b) stresses with post-tension applied.

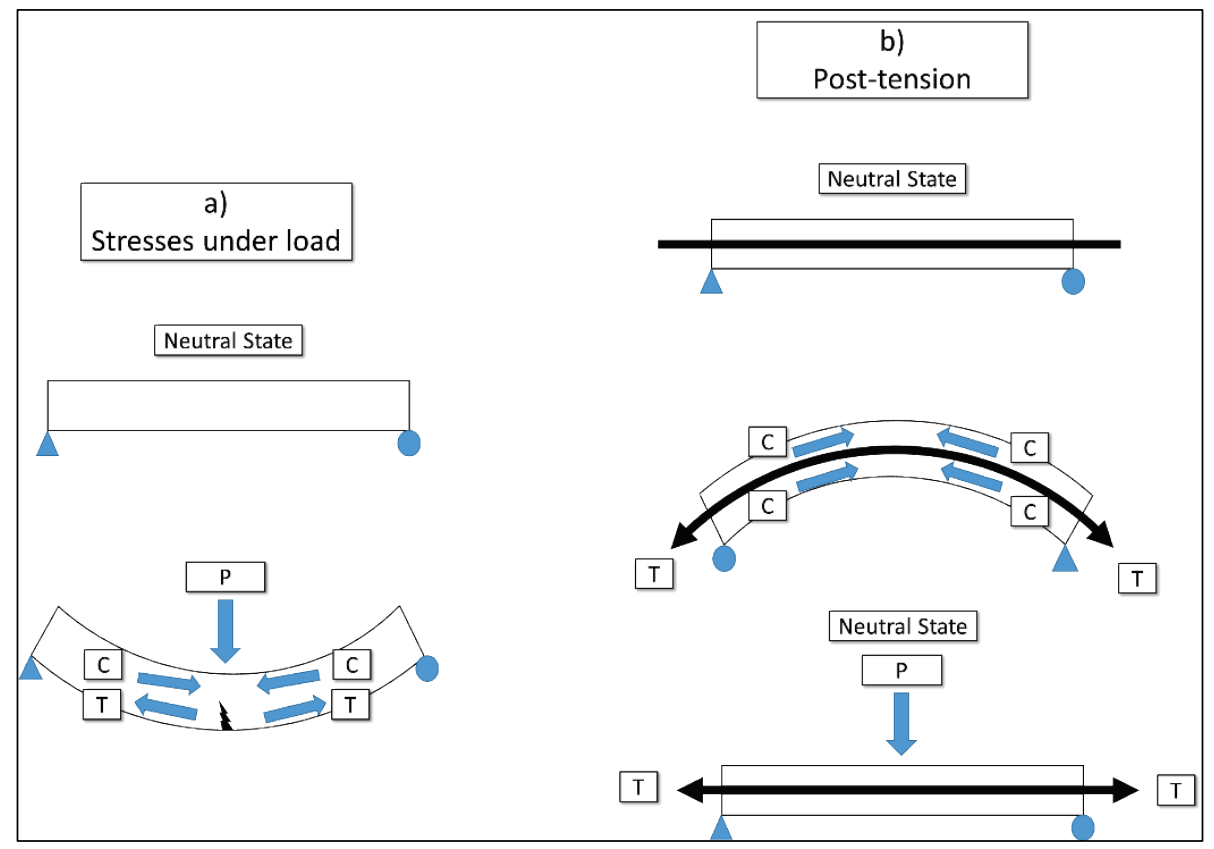

\subsubsection{Detail modification}

Another method of increasing fatigue life is by modifying the connection detail. According to the American Institute of Steel Construction (AISC) guidelines, an example of an improved detail modification is adding a cope to the detail, Figure 56 (AISC 2017). Detail modification requires careful design so as not to create a worse fatigue detail category connection (Figure 57). Figure 57 shows a category E' detail repair; the original detail was a category D (Riveros 2018). The repair detail in Figure 57 was tack welded to the cracked section. Tack welds are a weak weld corresponding to a fatigue detail category E' (AASHTO 2012). 
Figure 56. Detail modification: a) original detail; b) detail modification (lower stress concentration).

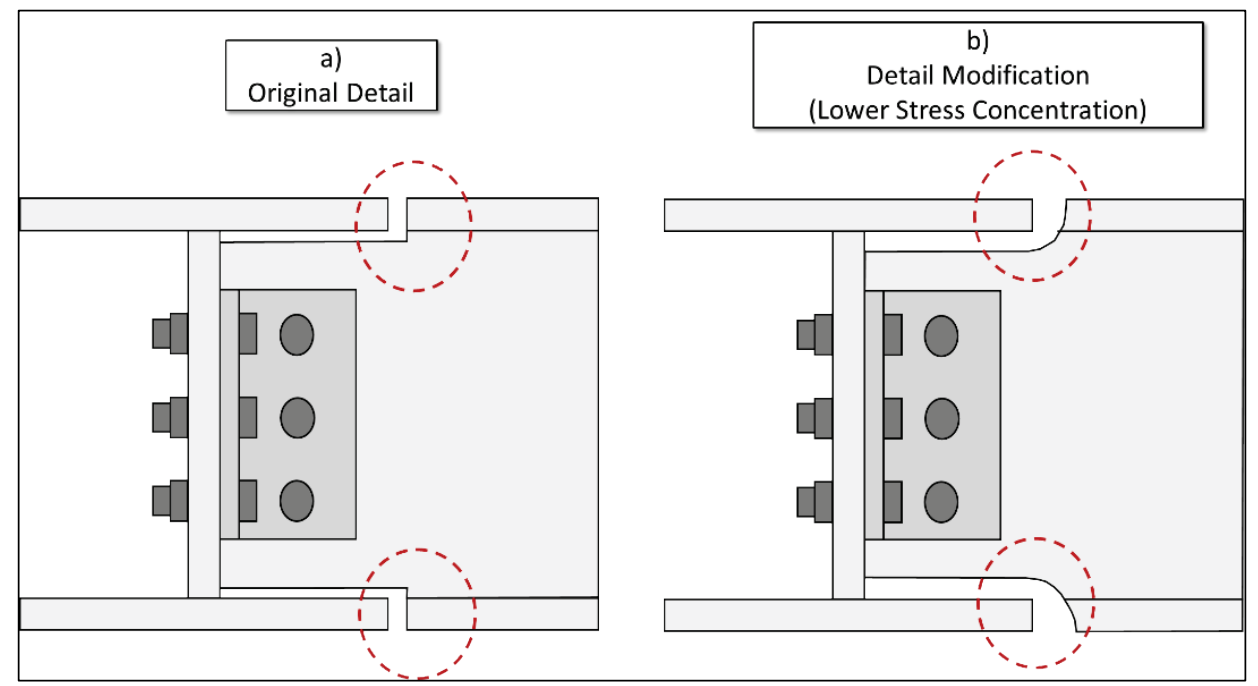

Figure 57. Detail modification repair: a) cracked section (detail category D); b) tack welded repaired section (detail category E').

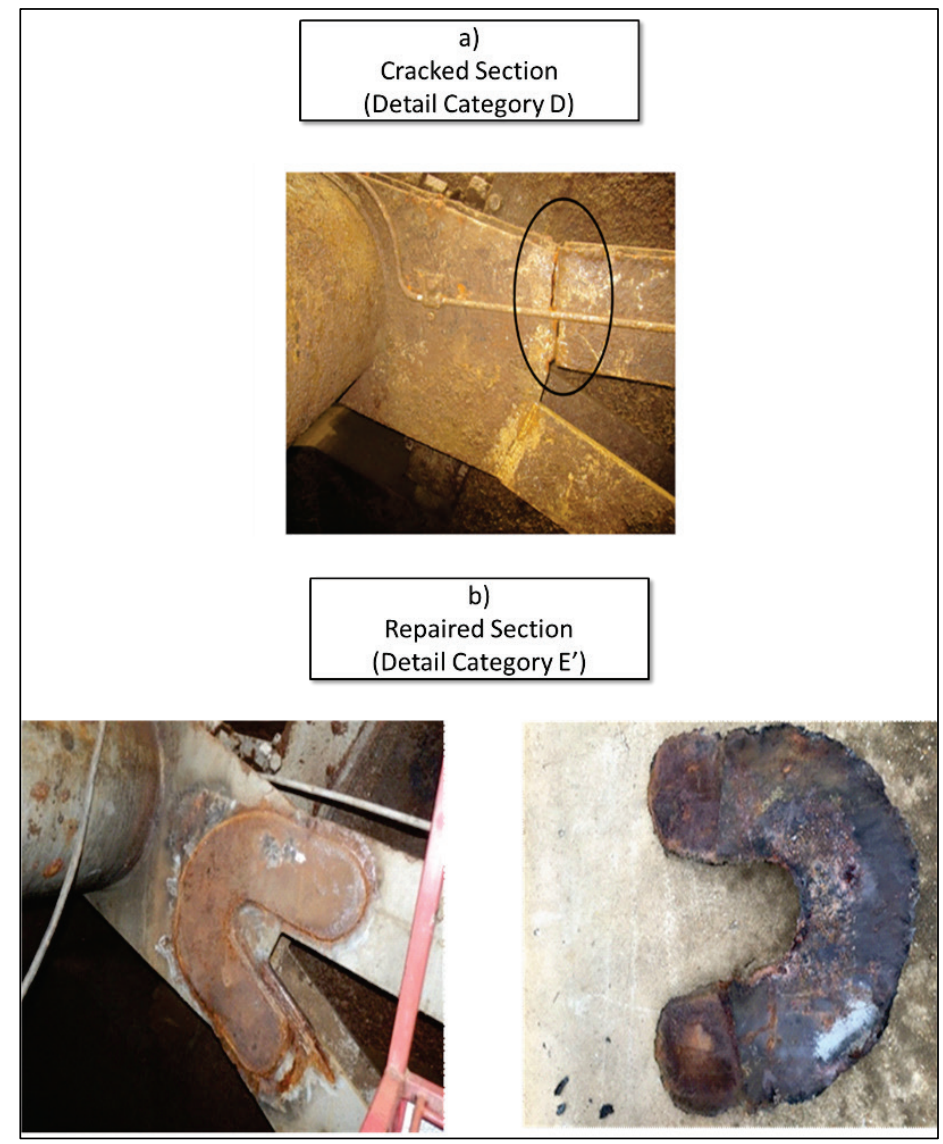




\subsection{Underwater crack repair and retrofit methods}

Wet welding and dry underwater welding are two methods of underwater welding commonly used on ships, in nuclear and hydroelectric power plants, and offshore oil and wind power rigs to repair cracks. During wetwelding, the operator is in the water, Figure 58a) (Grubbs 1993;

(Łabanowski 2008). In dry underwater welding, the welder is inside of a special pressurized chamber, Figure 58 b) (Łabanowski 2008). The primary weld method for a wet-weld is arc welding such as shielded metal arc welding (SMAW) or gas tungsten arc welding (GTA) (RodriguezSanchez 2014). Since dry underwater welding occurs in a pressurized chamber, any welding method is permissible. Both welding methods are dangerous since they require the operator to weld underwater. The two welding methods are also expensive because it requires experienced operators and surface assistance to operate current (wet welding) or air pumps (dry underwater welding) (Łabanowski 2008). Underwater dry welding is the preferred and safest option, but wet-welding is the least expensive, has a faster set-up, and has the most accessibility to the underwater sections (Łabanowski 2008).

Figure 58. Underwater welding: a) set weld; b) dry underwater welding/hyperbaric chamber welding.
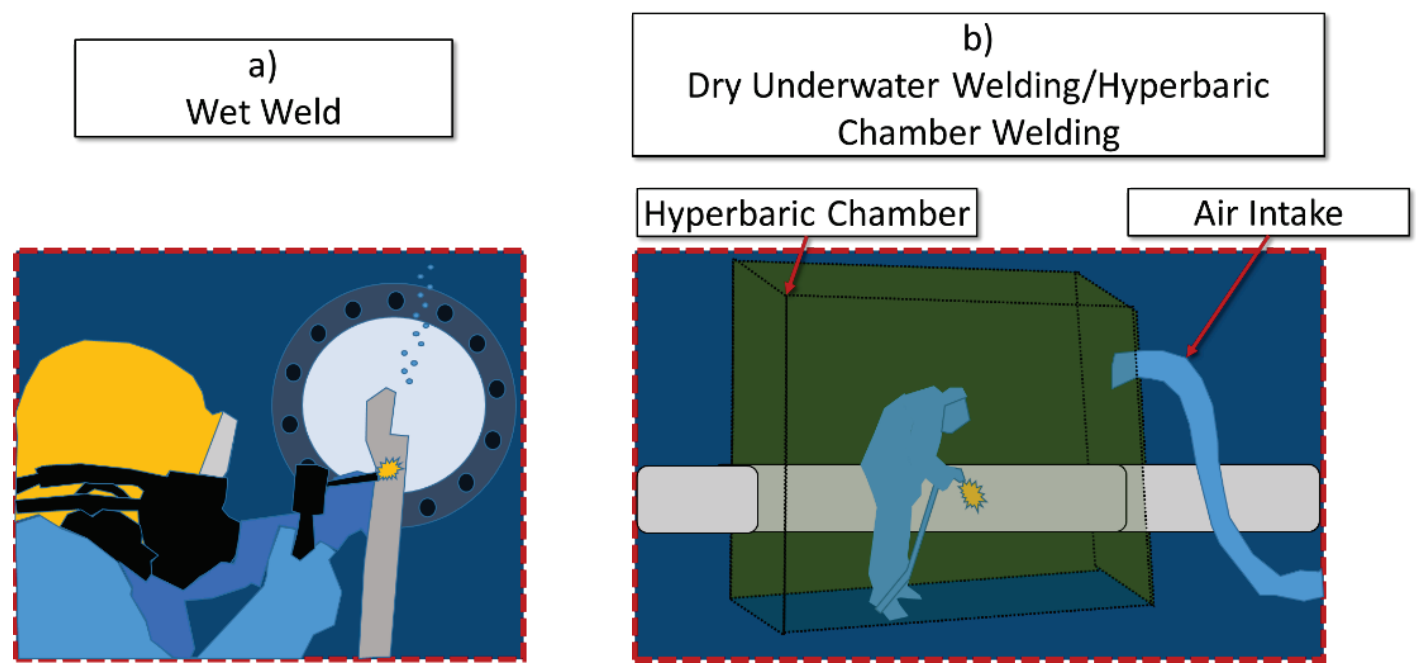

\subsection{Innovative crack repair and retrofit research and methodologies}

Due to the increase of fatigue in the current infrastructure system, new research has been conducted to investigate other methods of repairing fatigue cracks or retrofitting sections to increase fatigue life. Some of the new technology involves the addition of materials such as fiber reinforced 
polymers and shape memory alloys (SMA). The following section describes a few of the new fatigue and fracture repair methodologies available. Note, some of the new technologies have been implemented on current infrastructure.

\subsubsection{Fiber Reinforced Polymer (FRP)}

FRP is a composite material, which is made up of different parts or elements (Merriam Webster 2018). In the case of FRP, the fiber portion of the composite can be made of different types of materials such as carbon (CFRP), glass (GFRP), aramid (AFRP) (a synthetic material), and basalt (BFRP) (an igneous rock) (Sonnenscheina 2016). The polymer part of the composite forms the matrix of the composite that holds the fibers together in place (Figure 59). The different FRP composites have different material properties based on the type of fiber, fiber combination, fiber placement, and polymer type. Some common fiber placements are uni-directional, bidirectional, and quad-directional (Figure 60). Table 10 gives general material properties of the different fibers, and Table 11 gives some of the capabilities of the different composites.

Figure 59. FRP composite setup.

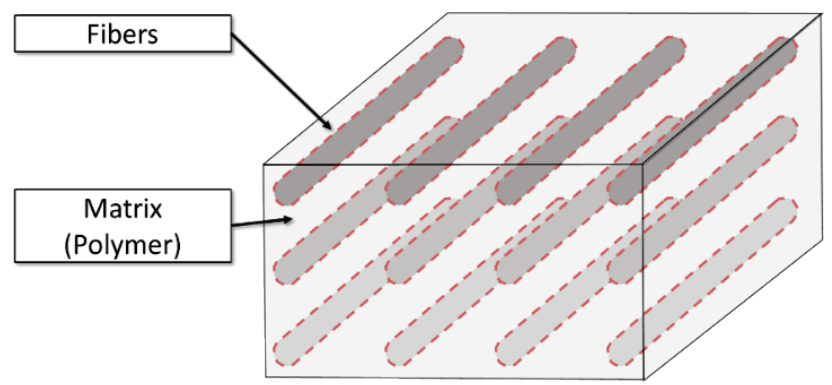

Figure 60. Composite layouts: a) uni-directional; b) bi-directional; c) quad-directional.
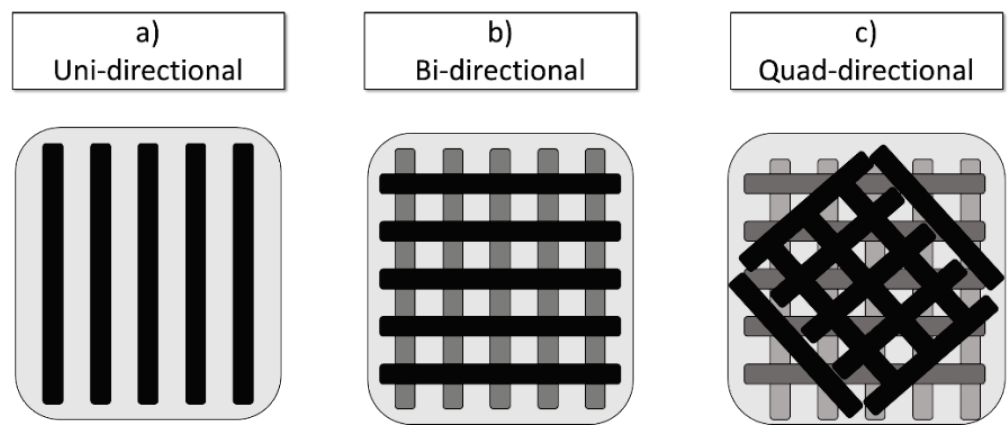
Table 10. Material properties of steel and common FRP (Sonnenscheina 2016).

\begin{tabular}{lllll}
\hline Material & $\begin{array}{l}\text { Density } \\
\rho(\text { pci) }\end{array}$ & $\begin{array}{l}\text { Modulus of Elasticity } \\
E(p s i)\end{array}$ & $\begin{array}{l}\text { Tensile Strength } \sigma_{y} \\
(p s i)\end{array}$ & $\begin{array}{l}\text { Strain } \\
\varepsilon(\%)\end{array}$ \\
\hline Steel & 0.284 & $2.9 \mathrm{E}+04$ & $7.25 \mathrm{E}+04$ & 2.5 \\
Carbon (High Strength) & 0.065 & $3 \cdot 34 \mathrm{E}+07$ & $3.6 \mathrm{OE}+05$ & 11 \\
Carbon (High Modulus) & 0.0686 & $5.37 \mathrm{E}+07$ & $2.60 \mathrm{E}+05$ & 0.5 \\
E-Glass & 0.0918 & $1.04 \mathrm{E}+07$ & $4.93 \mathrm{E}+05$ & 2.12 \\
S-Glass & 0.0914 & $1.29 \mathrm{E}+07$ & $6.67 \mathrm{E}+05$ & 1.93 \\
Aramid (Kevlar 29) & 0.052 & $1.20 \mathrm{E}+07$ & $4.24 \mathrm{E}+05$ & 3.5 \\
Aramid (Kevlar 49) & 0.052 & $1.80 \mathrm{E}+07$ & $5.22 \mathrm{E}+05$ & 2.9 \\
Basalt & 0.0975 & $1.31 \mathrm{E}+07$ & $5.80 \mathrm{O}+05$ & 2.25 \\
\hline
\end{tabular}

Table 11. Common advantages and disadvantages of different FRP (Sonnenscheina 2016).

\begin{tabular}{|c|c|c|}
\hline $\begin{array}{l}\text { Fiber } \\
\text { Type }\end{array}$ & Advantages & Disadvantages \\
\hline Carbon & $\begin{array}{l}\text { High Strength } \\
\text { High Modulus of Elasticity } \\
\text { Low density } \\
\text { High temperature resistivity } \\
\text { Non-corrosive } \\
\text { Versatile }\end{array}$ & $\begin{array}{l}\text { High on galvanic chart } \\
\text { Expensive compared to Glass and } \\
\text { Basalt }\end{array}$ \\
\hline Glass & $\begin{array}{l}\text { Inexpensive } \\
\text { High versatility } \\
\text { Low density } \\
\text { Resistant to electricity } \\
\text { Non-corrosive }\end{array}$ & $\begin{array}{l}\text { Low stiffness } \\
\text { Lower strength }\end{array}$ \\
\hline Aramid & $\begin{array}{l}\text { Synthetic Fiber } \\
\text { Best tensile strength to density ratio } \\
\text { Lowest density of all the fibers }\end{array}$ & $\begin{array}{l}\text { Quickly degraded by UV rays } \\
\text { Absorb moisture } \\
\text { Strength and stiffness decrease when } \\
\text { in contact with moisture }\end{array}$ \\
\hline Basalt & $\begin{array}{l}\text { Made from raw crushed basalt rock } \\
\left.\text { High heat resistivity (melting point } 1500^{\circ} \mathrm{C}\right) \\
\text { Wide application temperature range }\left(-269^{\circ} \mathrm{C} \text { to }\right. \\
\left.+650^{\circ} \mathrm{C}\right) \\
\text { Non-corrosive } \\
\text { Highly resistive to alkaline, acid, and salt } \\
\text { High compression strength } \\
\text { High shear strength } \\
\text { Low cost compared to Aramid and Carbon } \\
\text { Abrasion resistant }\end{array}$ & $\begin{array}{l}\text { Low Elastic Modulus of Elasticity } \\
\text { New fiber material }\end{array}$ \\
\hline
\end{tabular}

\subsubsection{FRP repairs}

There are currently two retrofit methods using FRP to repair fatigue cracks: 1) FRP patches (Figure 61) (Riveros 2018; Wang 2018; Karr 2015; Zarrinzadeh 2017) and 2) pre-stressed CFRP retrofits (Figure 62) (Ghafoori et al. 2018; Hosseini et al. 2018). The FRP patch method has been employed in different infrastructure applications to strengthen structures such as concrete beams and columns, steel beams and columns, and hydraulic steel structures (Riveros 2018), while the pre-stressed CFRP method has been tested and monitored on steel riveted steel bridges (Ghafoori et al. 2016). Due to HSS's aquatic environment and susceptibility to impact and turbulent forces, the CFRP patching repair 
method offers the best solution for fatigue and fracture repair of HSS. It is important to note that the application of the CFRP patches on miter gates and their respective parts is the only underwater application on steel.

Figure 61. a) Fatigue crack of tainter valve beam; b) CFRP patch repairs for fatigue crack in tainter valve steel beam (Riveros 2018).

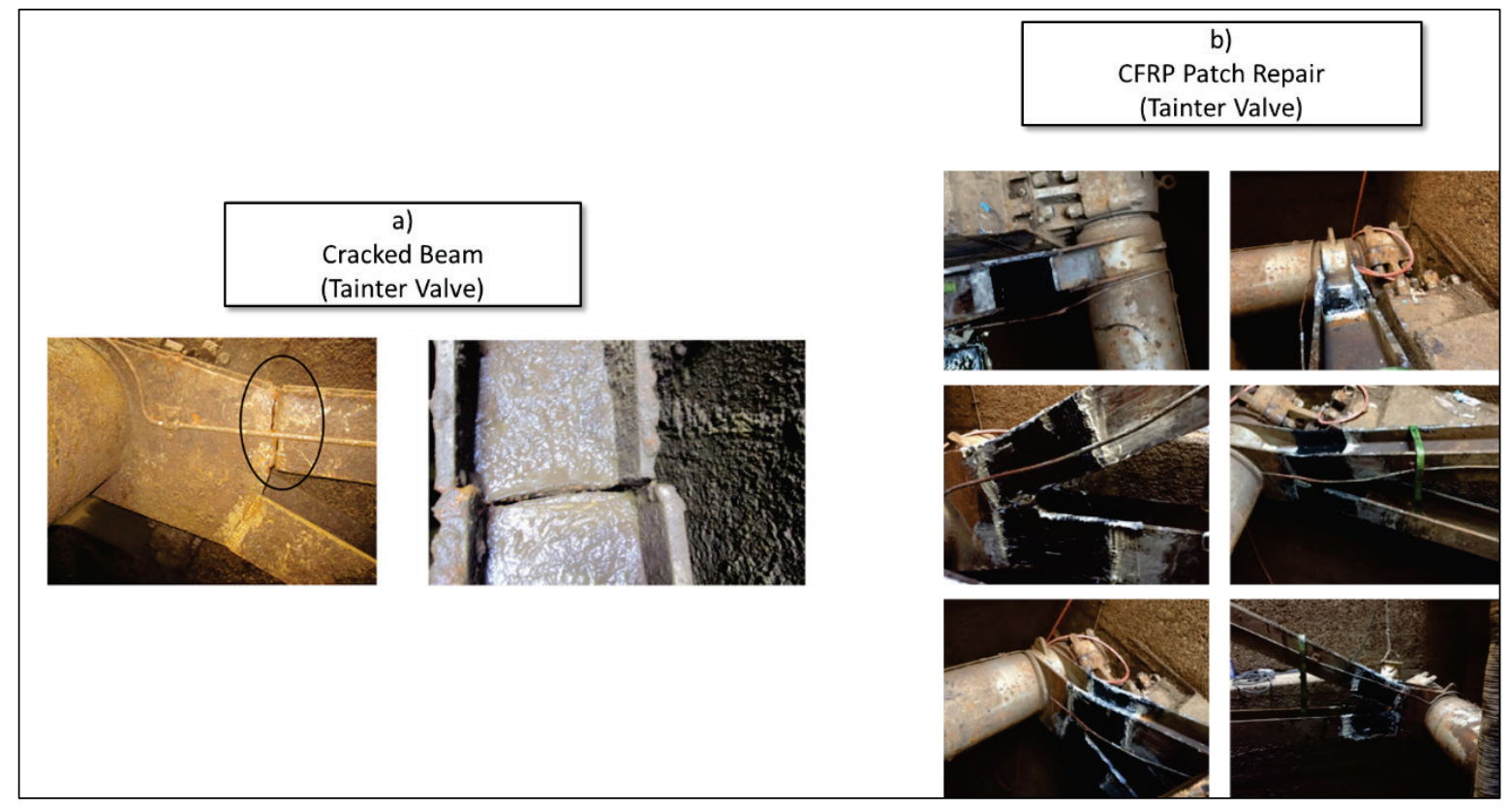

Figure 62. Pre-stressed CFRP retrofit a) Slack/unstressed CFRP; b) Pre-stressed CFRP (Ghafoori et al. 2016).

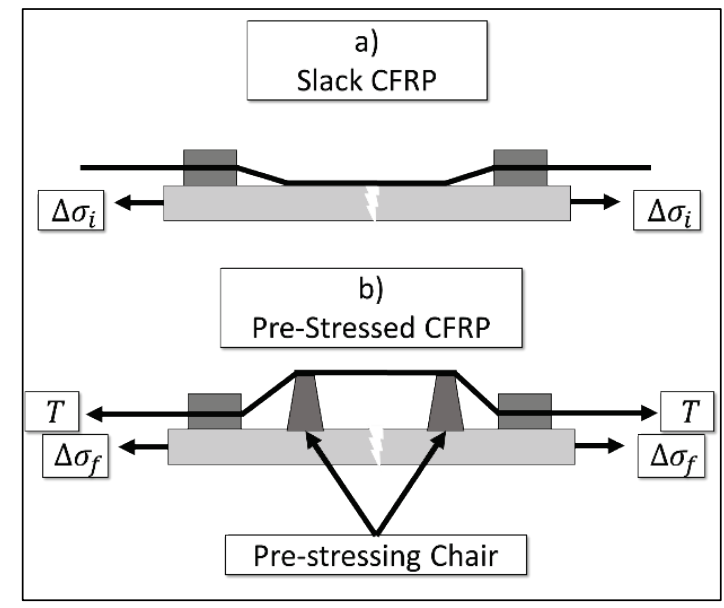

\subsubsection{CFRP patch repair}

Figure 58 demonstrates one of the many applications of CFRP patches on HSS applied by the USACE. The patch retrofits compromise of CFRP and GFRP layers bonded by high-strength adhesive to the steel. The GFRP layer is in-between the steel and CFRP to add an extra layer of strength 
and corrosion protection (Figure 63). CFRP patches provide extra strength and rigidity to the fatigued steel section (Riveros 2018).

Figure 63. CFRP patch layer configuration.

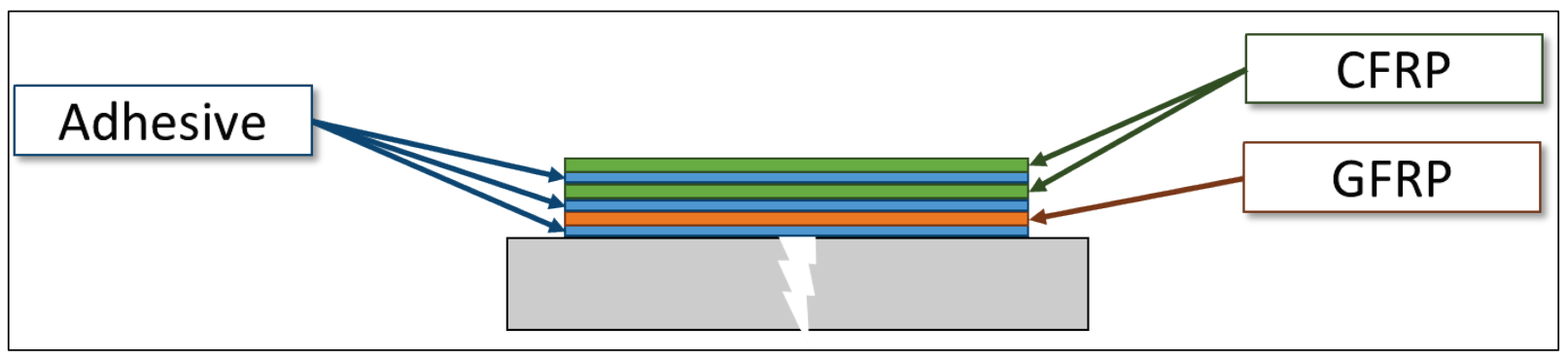

The U.S. Engineer Research and Development Center (ERDC) has conducted numerous experimental and numerical large-scale tests of the CFRP patches on steel plates (Figure 64). The CFRP patches were applied as strip retrofits beside the crack for better crack growth observation. The tests investigated the following types of environments (best to worst): dry, submerged, and submerged with turbulence. In the submerged worst environment, the CFRP patch strips offered an increase of 2 times the fatigue life (Riveros 2018; Mahmoud 2018). The experimental tests calibrated the numerical model's components and properties. A parametric analysis of a fully covered crack CFRP patch configuration (as applied in the field), using the calibrated model, shows at least a 4-7-time fatigue life increase. 
Figure 64. Large-scale experiment (Mahmoud 2018).

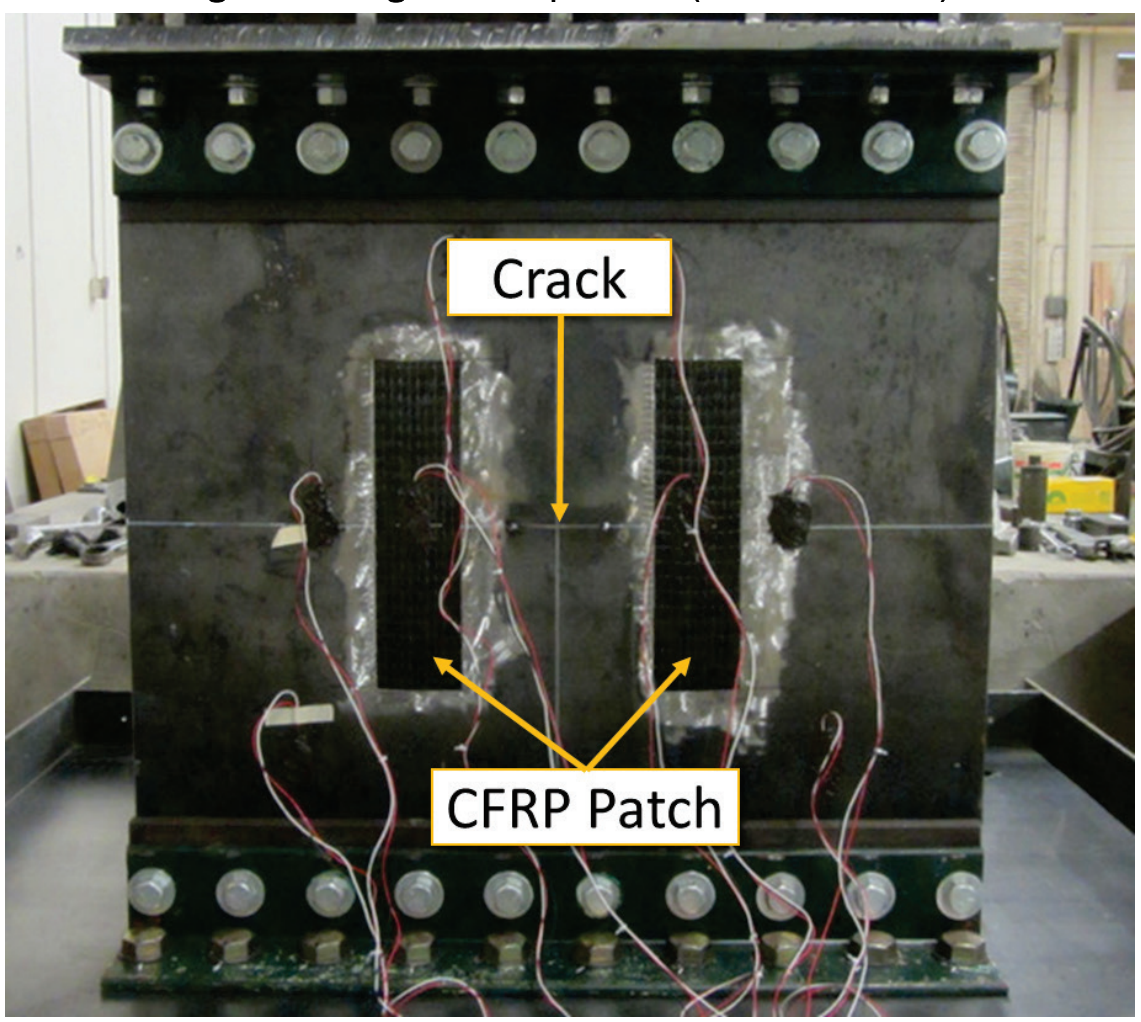

Due to the extreme corrosive environment, the adhesive's bond strength degrades over time and operation. The adhesive's degradation causes the CFRP patch to begin to debond at the edges. In the large-scale experiments, full debonding did not occur until the crack had propagated to the end of the patch (Mahmoud 2018). Experimental field applications of CFRP patches by the Corps, Figure 65 and Figure 66, have been in place for over five years without any signs of CFRP degradation or debonding; demonstrating the patches capability of withstanding submerged lock operation (Riveros 2018). Currently, the Corps is investigating stronger adhesives to increase the reliability, which in turn increases the fatigue life of the section. 
Figure 65. CFRP repairs on Pickwick Lock and Dam Tainter Valve.
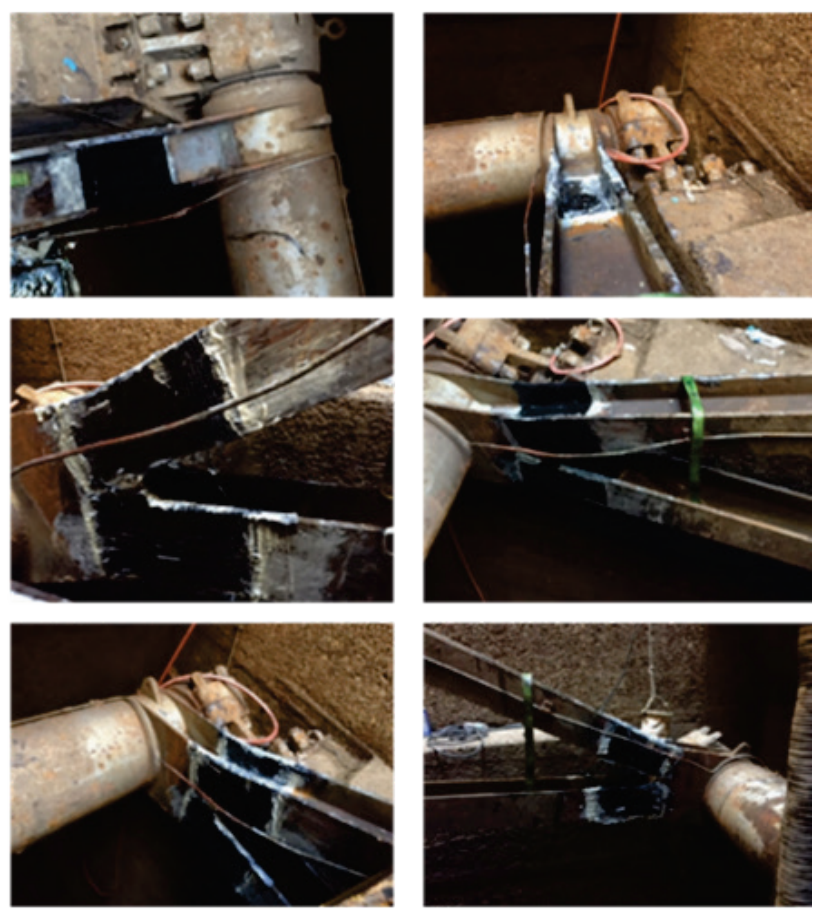

Figure 66. CFRP repair on Old Hickory Lock and Dam front flange.

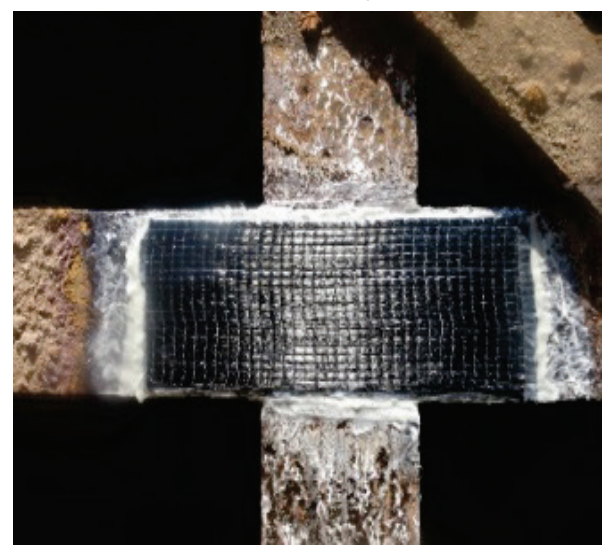

\subsubsection{Pre-stressed CFRP retrofit}

The pre-stressed CFRP retrofits (Figure 67) fasten the CFRP to the steel section while inducing a pre-stress. Pre-stressing shifts the mean stress in a section down (Figure 67), which increases the fatigue life of the section. The pre-stressed retrofit requires a mechanical connection with enough space for application and that is susceptible to slippage and impact forces (barges impacting the HSS). The pre-stressed retrofit is also susceptible to pre-stress losses over time requiring frequent monitoring of the retrofit. This method has been effectively used in bridges; however, due to impacts 
from objects such as barges, ice, and debris that can dislodge or break the retrofit.

Figure 67. Stress shift due to pre-stress retrofit (Ghafoori et al. 2018; Ghafoori 2016).

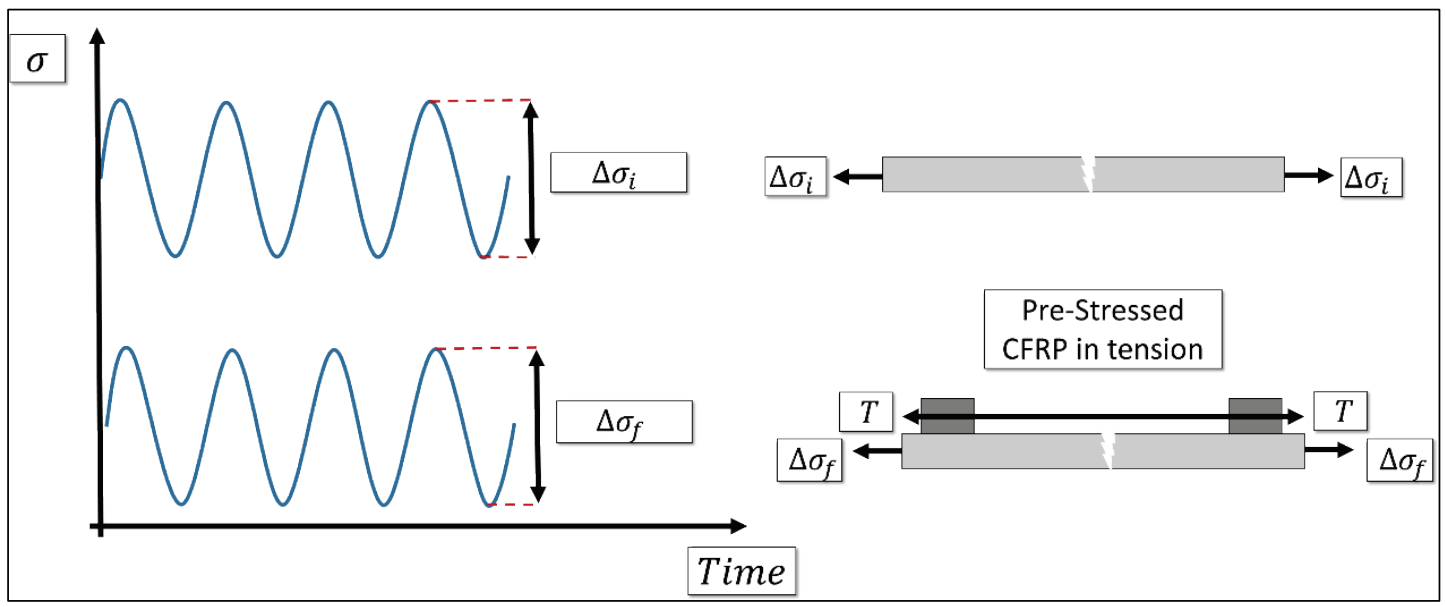

\subsubsection{Shape Memory Alloys (SMA)}

SMAs are a class of metal alloy that when heated can recover from permanent strain (Glenn Research Center 2018). There are two stable phases for SMAs; the martensite (low-temperature phase) and austenite (high-temperature phase). In the martensite phase, the SMA can be either twinned (first-order lattice state) or detwinned (deformed first-order lattice) based on the loading state, Figure 68 (Lagoudas 2008; Gong 2015). SMA's strain recovery ability occurs during the transition from the martensite phase to the austenite phase. While unloaded and cool, the SMA's microstructure is twinned martensitic, once the load is applied the micro-structure deforms and becomes detwinned. Heating the SMA returns it to its original (twinned state), and in the process removing any load induced deformation, Figure 68 (Lagoudas 2008; Gong 2015).

Research in SMA has developed several useful commercial and infrastructure applications (Song et al. 2006; Jani 2014; Johnson 2008; Paul 2013); one of them extending fatigue life. SMA's can increase fatigue life by introducing compressive stresses as they return to their undeformed phase (Hsu 2002). 
Figure 68. SMA microstructure and method of deformation recovery (Lagoudas 2008).

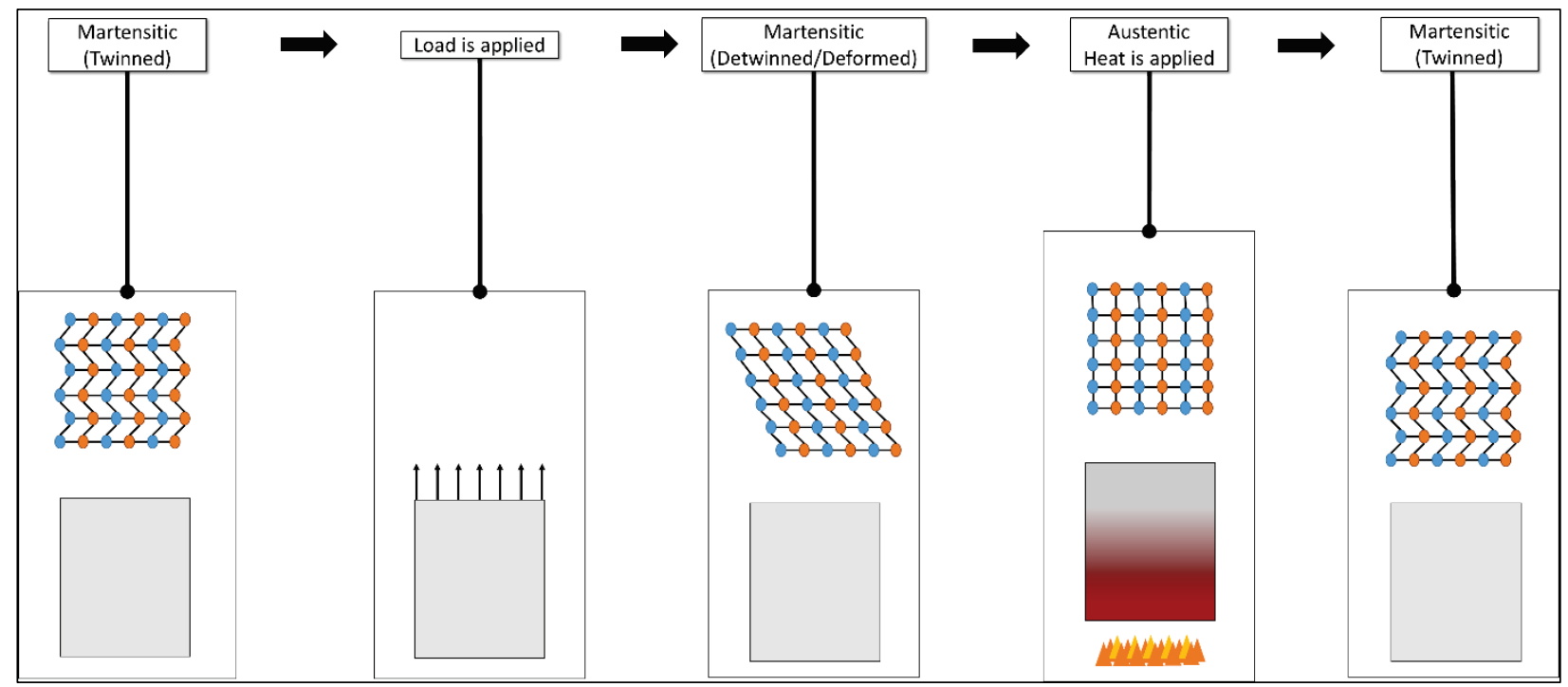

\subsection{Comparison of repair and retrofit methodologies}

When attempting to repair or retrofit fatigue cracks, care must be taken in choosing the best repair or retrofit method. This section assesses and compares the different available fatigue repair and retrofit methods. Table 12 gives a few of the disadvantages and advantages of the repair and retrofit methodologies presented in this report. For further information about the common repair or retrofit fatigue cracking methods, see the Manual for Repair and Retrofit of Fatigue Cracks in Steel Bridges published in 2013 by the U.S. Department of Transportation Federal Highway Administration (Dexter 2013). 
Table 12. Comparison of different repair and retrofit methodologies.

\begin{tabular}{|c|c|c|}
\hline Method & Advantages & Disadvantages \\
\hline Grinding & $\begin{array}{l}\text { Easy operation } \\
\text { Low Cost } \\
\text { Improves weld profile Removes high stress } \\
\text { concentrations } \\
\text { Fatigue life increase between } 50 \text { to } 100 \%\end{array}$ & Only removes small defects \\
\hline Re-melting & $\begin{array}{l}\text { Improves weld profile } \\
\text { Can be performed under water }\end{array}$ & Requires experienced operator \\
\hline Impact Treatments & $\begin{array}{l}\text { Reduces stresses } \\
\text { Easy operation } \\
\text { Improves weld toe to base metal transition } \\
\text { Fatigue life increase up to } 6 \text { times }\end{array}$ & $\begin{array}{l}\text { Need to be careful of } \\
\text { smearing and hiding a defect } \\
\text { Requires multiple pieces of } \\
\text { equipment }\end{array}$ \\
\hline Hole Drilling & $\begin{array}{l}\text { Easy operation } \\
\text { Reduces crack tip Stress concentration } \\
\text { Stops cracks }\end{array}$ & $\begin{array}{l}\text { Mode I only } \\
\text { Too big of a hole can appear } \\
\text { unsafe } \\
\text { If used for other Modes } \\
\text { increases the crack } \\
\text { propagation }\end{array}$ \\
\hline Vee-and-Weld & $\begin{array}{l}\text { Large cracks } \\
\text { Returns the detail to its original fatigue life }\end{array}$ & $\begin{array}{l}\text { Requires skilled weld operator } \\
\text { Need to be careful not to lose } \\
\text { the crack when gouging }\end{array}$ \\
\hline Doubler/Splice Plates & $\begin{array}{l}\text { Decreases the stress range } \\
\text { Simple installation }\end{array}$ & $\begin{array}{l}\text { Steel plates are heavy-can } \\
\text { make installation hard } \\
\text { Stress concentrations remain } \\
\text { Needs to be implemented with } \\
\text { another methodology to } \\
\text { remove crack/improve weld }\end{array}$ \\
\hline Post-Tensioning & $\begin{array}{l}\text { Places section in compression preventing } \\
\text { crack growth }\end{array}$ & $\begin{array}{l}\text { Need to be careful of wear } \\
\text { holes for retrofit are made } \\
\text { Stresses in the area need to be } \\
\text { analyzed to determine } \\
\text { appropriate post-tension } \\
\text { amount }\end{array}$ \\
\hline Detail Modification & Lowers stress & $\begin{array}{l}\text { Engineered design to avoid a } \\
\text { worse fatigue detail }\end{array}$ \\
\hline Fiber Reinforced Patches & $\begin{array}{l}\text { Strengthens the immediate area } \\
\text { Lowers the stress range in the section } \\
\text { Easy to implement } \\
\text { Light weight } \\
\text { Easily modified for different geometries }\end{array}$ & Requires layer of GFRP \\
\hline CFRP Pre-Stressed Retrofit & $\begin{array}{l}\text { Lowers mean stress } \\
\text { Easy to implement } \\
\text { Can implement over multiple fatigue and } \\
\text { fracture sections } \\
\text { Avoids corrosion of steel } \\
\text { Light weight }\end{array}$ & $\begin{array}{l}\text { Stresses in the area need to be } \\
\text { analyzed to determine } \\
\text { appropriate pre-stress } \\
\text { Pre-stress losses } \\
\text { Induces bending stress on the } \\
\text { other face of the section }\end{array}$ \\
\hline$S M A$ & Introduces local compressive forces & $\begin{array}{l}\text { Not as much information } \\
\text { Expensive }\end{array}$ \\
\hline
\end{tabular}




\section{Discussion and Conclusions}

This report provided a brief overview of fatigue and fracture, presented the fitness-for-purpose evaluation method, demonstrated the use of FEM to evaluate and predict fatigue and fracture cracks, presented and described common methods of repairing cracks, and finally, introduced new research on innovative fatigue and fracture repairs and retrofits. The brief overview of fatigue and fracture explained the fundamentals of fatigue and fracture, crack initiation and growth, and how high-stress concentrations cause fatigue and fracture. This report also described the different types of loading conditions, toughness' influence on fatigue and fracture and how to test for it, and the crack-inducing effect of connection elements such as welds and holes. The Corps has numerous HSS in service that have extensive cracking. A fitness-for-purpose evaluation provides a method to assess pre-existing structures' serviceability due to cracks in the structure. FEM to provide a more detailed structural analysis that helps determine the actual forces and state of stresses providing new insights into the HSS' behavior. Additionally, fitness-for-purpose evaluations utilize FEM to assess and analyze the HSS' current state and future behavior. As previously mentioned, the common methods of repairing fatigue and fracture were developed for the bridge industry and Mode I loading, and are therefore not as effective, due to the HSS' corrosive environment and mix mode loading, possibly causing further cracking. Therefore, the USACE is in the process of investigating, developing, and testing new methods of repairing fatigue and fracture cracks. Of the new repair methods, the CFRP patches provide the best combination of flexibility, cost-effectiveness, required strength, and fatigue life increase. 


\section{References}

AASHTO. 2011. Manual for bridge evaluation (MBE) (2 ed.). Washington, DC: American Association of State Highway and Transportation Officials.

AASHTO. 2012. AASHTO LRFD Bridge Design Specifications (6th ed.). Washington D.C.: AASHTO.

AISC. 2017. Steel Construction Manual (15th ed.). Chicago: American Institute of Steel Construction.

Anand, A., and A. Khajuria. 2013. Welding Processes in Marine Applications: A Review. International Journal of Mechanical Engineering and Robotics Research, 2(1): 215-225.

Anderson, T. L. 2005. Fracture Mechanics (3rd ed.). Boca Raton: Taylor \& Francis Group.

ASTM. 2018. ASTM E23-18 Standard Test Methods for Notched Bar Impact Testing of Metallic Materials. West Conshohocken: ASTM International.

ASTM International. 2018a. ASTM D256-1O Standard Test Methods for Determining the Izod Pendulum Impact Resistance of Plastics. West Conshhocken: ASTM International.

ASTM International. 2018b. ASTM E1820-18 Standard Test Method for Measurement of Fracture Toughness. West Conshohocken: ASTM International.

AWS, A. 2000. AWS D1.1: Structural Welding Code--Steel. Miami: American Welding Society.

AWS, AASHTO. 2015. AASHTO/AWS D1.5M/D1.5:2015-AMD1 BRIDGE WELDING CODE. Miami: AWS/ANSI.

AXIS Inspection Group Ltd. 2015. Weld Craters. Retrieved from axis inspection: https://www.axisinspection.com/weld-craters/

Bezensek, B., J. Sharples, I. Hadley, and H. Pisarski. 2011. "The History of BS 7910 Flaw Interaction Criteria." ASME 2011 Pressure Vessels and Piping Conference (pp. 837-843).

BSI. 2015. BSI 7910:2013 +A1:2015 Guide to methods for assessing the acceptability of flaws in metallic structures. British Standards Institution.

BSI. 2013. BSI 7910: Guide to methods for assessing the acceptability of flaws in metallic structures. British Standards Institution.

Cook, J. 2017. America's \$4tn infrastructure time bomb. Retrieved from BBC News: https://www.bbc.com/news/world-us-canada-39410561 
Dexter, R., H. N. Mahmoud, J. A. Padula, and G. Riveros. 2007. Fitness for purpose evaluation of hydraulic steel structures. ERDC TR-07-15. Vicksburg, MS: U.S. Army Corps of Engineers Research and Development Center. https://erdclibrary.erdc.dren.mil/jspui/handle/11681/8510.

Ghafoori, E., H. Ardalan, E. Pellissier, M. Hueppi, and M. Motavalli. 2018. "Application of Pre-Stressed Un-Bonded Cfrp for Strengthening of Metallic Structures.” In Proceedings 9th International Conference on Fibre-Reinforced Polymer (FRP) Composites in Civil Engineering.

Ghafoori, E., M. Motavalli, A. Herwig, A. Nussbaumer, G. Prinz, and M. Fontana. 2016. "Fatigue Strengthening of Riveted Girders in a Historic Railway Metallic Bridge in Switzerland Using Prestressed un-bonded CFRP Laminates." 8th International Conference on Bridge Maintenance, Safety, and Management. Foz do Iguacu.

Glenn Research Center. 2018. Shape Memory Alloys. Retrieved from NASA Technology Transfer Program: https://technology.nasa.gov/patent/LEW-TOPS-135

Haagensen, P. 1993. The Effect of Grinding and Peening on the Fatigue Strength of Welded T-Joints. Transactions on Engineering Sciences, 2.

Haagensen, P. 2011. "Fatigue Strength Improvement Methods." FRacture and Fatigue of Welded Joints and Structures, 297-329.

habil, D. R.-I. 1990. "Fatigue Strength for Infinite Life of Welded Joints in Structural Steel.” In D. R.-I. habil, Design and Analysis of Fatigue Resistant Welded Structures (pp. 35-65). Woodhead Publishing.

Hansen, J., K. GGardiner. 2016. What is Eddy Current Testing? Retrieved from Quality Magazine: https://www.qualitymag.com/articles/93652-what-is-eddy-current-testing

Hao Gong, K. G. 2015. "The Role of Twinned and Detwinned Structures on Memory Behavior of Shape Memory Alloys.” Advanced Materials Research, 78-82.

Hassan, S. Q., and T. Hassan. 2017. "Initial Residual Stresses in Hot-Rolled Wide-Flange Shapes: A Computational Technique and Influence on Structural Performances." J. Struct. Eng., 143(5). doi:10.1061/(ASCE)ST.1943-541X.0001739

Hiroshi Shimanuki, M. T. (2015). Application of UIT to Suppress Fatigue Cracks of Welded Structures. NIPPON STEEL \& SUMITOMO METAL. https://www.nipponsteel.com/en/tech/report/nssmc/pdf/110-16.pdf.

Hosseini, A., E. Ghafoori, M. Motavalli, A. Nussbaumer, X-L. Zhao, and R. Koller. 2018. "Prestressed Unbonded Reinforcement System with Multiple CFRP Plates for Fatigue STrengthening of Steel Members." Polymers, 10(3): 264.

Hunt, E. M. 2013. CRACK INITIATION AND GROWTH BEHAVIOR AT CORROSION PIT IN 7075-T6 HIGH STRENGTH ALUMINUM ALLOY. Air Force Institute of Technology . 
Iowa State University. 2014. Basic Principles of Eddy Current Inspection. Retrieved from NDT Resource Center: https://www.ndeed.org/EducationResources/CommunityCollege/EddyCurrents/Introduction/IntroductiontoET.ht $\underline{m}$

Iowa State University. 2014. Basic Principles of Ultrasonic Testing. Retrieved from NDT Resource Center: https://www.ndeed.org/EducationResources/CommunityCollege/Ultrasonics/Introduction/description.htm

Iowa State University. 2014. Basic Processing Steps of a Liquid Penetrant Inspection. Retrieved from NDT Resource Center: https://www.ndeed.org/EducationResources/CommunityCollege/PenetrantTest/Principles/liquidpi.htm

Iowa State University. 2014. MPI-Basic Principles. Retrieved from NDT Resource Center: https://www.ndeed.org/EducationResources/CommunityCollege/MagParticle/Introduction/basicprinciples.htm

ISO. 2016. ISO/TR 25901-1. Geneva: International Organiztaion for Strandardization. https://www.iso.org/standard/55758.html.

Klingerman, D. J., and J. Fisher. 1973. Threshold crack growth in A36 steel. Bethlehem: Lehigh University.

Laenen, A., G. Salazar, and D. Topp. 2007. "Application of the ACFM inspection method for the inspection of internal tank welds." In IV Conferencia Panamericana de END. Buenos Aires.

Łabanowski, Jerzy, Dariusz Fydrych, and Grzegorz Rogalski. 2008. Underwater WeldingA Review. Advances in Materials Science, 8(3): 11-22.

Li, Y., J. Shuai, and K. Xu. 2018. "Investigation on Size Tolerance of Pore Defect of Girth Weld Pipe.” Plos One, 13(1).

Patel, A. B., and R. K. Pandey. 1981. "Fatigue Crack Growth Under Mixed Mode Loading." Fatigue of Engineering Materials and Structures, 4(1): 65-77.

(n.d.). Engineering Critical Assessment (ECA). Cambridge: The Welding Institute. Retrieved from twi-global.com/technical-knowledge/faqs/faq-engineering-criticalassessment-eca.aspx

F. Yusof, M. J. (2014). Welding and Bonding Technologies. Comprehensive Materials Processing, 125-134. https://www.elsevier.com/books/comprehensive-materialsprocessing/hashmi/978-0-08-096532-1

Riveros, G. A., C. M. 2019. Blind prediction of FRP repairs for multiaxial fatigue cracks on Hydraulic Steel Structures. ICMFF 12. Bordeaux: ICMFF.

Riveros, G. A., H. M. 2018. "Fatigue repair of underwater navigation steel structures using Carbon Fiber Reinforced Polymer (CFRP).” Engineering Structures, 173, 718-728. 
Rodriguez-Sanchez, J. E., F. Perez-Guerrero, S. Liu, A. Rodriguez-Castellanos, and A. Albiter-Hernandez. 2014. "Underwater repair of fatigue cracks by gas tungsten arc welding process." Fatigue and Fracture of Engineering Materials and Structures, 37(6): 637-644.

Rolfe, Stanley Theodore, and John M. Barsom. 1987. Fracture and Fatigue Control in Structures: Applications of Fracture Mechanics. Englewood: Prentice-Hall Inc.

Russo, F. M., D. R. Mertz, K. H. Frank, and K. E. Wilson. 2016. Design and Evaluation of Steel Bridges for Fatigue and Fracture - Reference Manual. Arlington: Federal Highway Administration.

Song, G., N. Ma, and H-N. Li. 2006. "Applications of shape memory alloys in civil structures.” Engineering Structures, 28(9): 1266-1274.

Wang, Hai-Tao, Gang Wu, and Yu-Yang Pang. 2018. Theoretical and Numerical Study on Stress Intensity Factors for FRP-Strengthened Steel Plates with Double-Edged Cracks. Sensors, 18(7): 2356-2375.

Zarrinzadeh, H., M. Z. Kabir, and A. Deylami. 2017. "Experimental and numerical fatigue crack growth of an aluminium pipe repaired by composite patch." Engineering Structures, 133: 24-32.

J. Quian, and A. Fatemi. 1996. "Mixed Mode Fatigue Crack Growth: A Literature Survey." Engineering Fracture Mechanics, 55(6): 969-990.

Jani, Jaronie Mohd, Martin Leary, Aleksandar Subic, and Mark A. Gibson. 2014. “A review of shape memory alloy research, applications and opportunities." Materials and Design, 1980-2015.

Jer-Wen Hsu, P. S. (2002). Structural Repair and Retrofit Systems Based on ShapeMemory Alloys. U.S. Department of Energy. Lansing: Pacific Northwest Laboratory. https://p2infohouse.org/ref/23/22374.pdf

John, J. 2014. Welding Inspector Duties and Responsibilities. Retrieved from https://www.slideshare.net/JithuJohn2/61769477-weldinginspectioncswipgud

Johnson, M. (n.d.). Fatigue Improvement Techniques for Welds. Pelham : Process Barron. https://processbarron.com/fatigue-improvement-techniques-welds/.

Karr D.G., B. C. 2015. Strength and Fatigue Testing of Composite Patches for Ship Plating Fracture Repair. Washington D.C. : Ship Structure Committee. http://www.shipstructure.org/pdf/469.pdf.

Kelkar, G. P. 2008. Weld Cracks- An Engineer's Worst Nightmare. WJM Technologies. Retrieved from http://www.welding-consultant.com/WeldCracks.pdf

Kim Grubbs, C. Z. 1993. Underwater Repair Procedures for Ship Hulls (Fatigue and Ductility of Underwater Welds). Washington, D.C.: Ship Structure Committee.

Koutromanos, I. 2018. Fundamentals of Finite Element Analysis. Hoboken: John Wiley \& Sons. 
Lagoudas, D. C. 2008. Shape Memory Alloys: Modeling and Engineering Applications. College Station: Springer. Retrieved from Smart Lab.

Magnaflux. 2017. The Ultimate Guide to Visible Dye Penetrant Testing [Infographic]. Retrieved from Magnaflux: https://www.magnaflux.com/Magnaflux/Blog/Dye-PenetrantInfographic

Mahmoud, H. N., G. A. Riveros, M. Memari, A. Valsangkar, and B. Ahmadi. 2018. "Underwater Large-Scale Experimental Fatigue Assessment of CFRP-Retrofitted Steel Panels." ASCE Journal of Structural Engineering, 144(10).

(2013). Mechanical Loading and Residual Stress / Fracture: Pt I. Cambridge: The Welding Institute. Retrieved from twi-global.com/technicalknowledge/published-papers/effects-of-mechanical-loading-on-residual-stressand-fracture-part-i-background-to-the-bs-79102013-rules.aspx

Merriam Webster. (2018). Composite. Retrieved from Merriam Webster: https://www.merriam-webster.com/dictionary/composite

Grubb, M. A., K. E. Wilson, C. D. White, and W. N. Nickas. 2015. Load and Resistance Factor Design (LRFD) For Highway Bridge Superstructures - Reference Manual. Arlington: Federal Highway Administration.

Paul, N., and R. Nanda. 2013. "Shape Memory Alloy As Retrofitting Application in Historical Building and Monuments- A Review in Indian Perspective." International Journal of Civil Engineering and Technology, 4(1): 117-125.

Olympus. 2018. Introduction to Time of Flight Diffraction (TOFD) for Weld Inspection. Retrieved from Olympus: https://www.olympus-ims.com/en/applications/introduction-totime-of-flight-diffraction-for-weld-inspection/

(2013). Overview of BS7910:2013. Cambridge: The Welding Institute. https://www.twiglobal.com/technical-knowledge/published-papers/overview-of-bs79102013.

Paris, P. C. 1961. "A Rational Analytic Theory of Fatigue.” Trends Eng., 13, 9-14.

Rana, R., C. Lahaye, and R. K. Ray. 2014. "Overview of Lightweight Ferrous Materials: Strategies and Promises.” JOM, 66(9), 1734-1746. doi:10.1007/s11837-014-11265

Dexter, R. J., W. J. Wright, and J. W. Fisher. 2004. "Fatigue and Fracture of Steel Girders.” Journal of Bridge Engineering, 9(3): 278-286.

Johnson, R., J. E. Padgett, M. E. Maragakis, R. DesRoches, and M. S. Saiidi. 2008. "Large scale testing of nitinol shape memory alloy devices for retrofitting of bridges." Smart Materials and Structures, 17(3).

Riveros, G. A., J. L. Ayala Burgos, and J. Perez. 2009. Numerical investigation of miter gates. Vicksburg, MS: U.S. Army Engineer Research and Development Center.

Dexter, R. J., and J. M. Ocel. 2013. Manual for Repair and Retrofit of Fatigue Cracks in Steel Bridges. McLean: Federal Highway Administration. 
Sonnenschein, R., K. Gajdosova, and I. Holly. 2016. "FRP Composites and Their Using in the Construction of Bridges." Procedia Engineering, 477-482.

Segui, W. T. 2013. Steel Design. Stamford: Cengage Learning.

Nelligan, T., and C. Calderwood. 2018. Introduction to Eddy Current Testing. Retrieved from Olympus: https://www.olympus-ims.com/en/eddycurrenttesting/

Topp, D. A. 2000. Quantitative In-Service Inspection using the Alternating Current Field Measurement (ACFM) Method. Nondestructive Testing and Ultrasonics, 5(3).

Retrieved from NDT.net: https://www.ndt.net/article/v05n03/topp/topp.htm

TWI. 2018. Alternating Current Field Measurement-ACFM-Electromagnetic NDT. Retrieved from TWI-Global: https://www.twi-global.com/what-we-do/services-andsupport/asset-management/non-destructive-testing/ndt-techniques/alternating-current-fieldmeasurement

TWI. 2018. Time of Flight Diffraction-TOFD-NDT for Weld Inspection. Retrieved from TWI-Global: https://www.twi-global.com/what-we-do/services-and-support/assetmanagement/non-destructive-testing/ndt-techniques/time-of-flight-diffraction

U.S. Army Corps of Engineers. 2014. Safety and Health Requirements Manual. Washington D.C.: Department of the Army U.S. Army Corps of Engineers. https://www.publications.usace.army.mil/Portals/76/Publications/EngineerManuals/EM_3851-1.pdf.

USACE. 2001. EM 1110-2-6054: Inspection, Evaluation, and Repair of Hydraulic Steel Structures. Washington D.C.: United States Army Corps of Engineers. https://www.publications.usace.army.mil/Portals/76/Publications/EngineerManuals/EM_1110 -2-6054.pdf.

USACE. 2009. Engineering and Design: Responsibility for Hydraulic Steel Structures. Washington, DC: Department of the Army: U.S. Army Corps of Engineers. Retrieved from https://planning.erdc.dren.mil/toolbox/library/ERs/ER1110-28157_15Jun2009.pdf

USACE. 2014. Design of Hydraulic Steel Structures. Washington D.C.: U.S. Army Corps of Engineers.

https://www.publications.usace.army.mil/portals/76/publications/engineertechnicalletters/etl 1110-2-584.pdf.

USACE. 2018. Unified Facilities Guide Specifications: Fabrication of Hydraulic Steel Structures (UFGS-O5 59 20). Department of Defence.

Cui, W., X. Huang, and F. Wang. 2014. Towards a Unified Fatigue Life Prediction Method for Marine Structures. Springer.

Dover, W. D., S. Dharmavasan, D. A. Topp, and M. C. Lugg. 1991. 'Fitness for purpose' using ACFM for crack detection and sizing FACTS/FADS for analysis. Marine Structural Inspection, Maintenance, and Monitoring Symposium. Jersey City: The Society of Naval Architects and Marine Engineers. 
Zhang, W., X. Liu, H. Wang, W. Dai, and G. Fu. 2017. "Quantitative Analysis of Weld Pore Size and Depth and Effect on Fatigue Life of Ti-6Al-2Zr-1Mo-1V Alloy Weldments." Metals, 7(10): 417.

Walsh, W. J., BN LEIS, and J. Y. Yung. 1990. Influence of Weld Porosity on the Integrity of Marine Structure. Columbus: Ship Structure Committee.

McGuire, W., R. H. Gallagher, and R. D. Ziemian. 2000. Matrix Structural Analysis. New York: John Wiley \& Sons.

Zhao, X., M. Wang, Z. Zhang, and Y. Liu. 2016. The Effect of Ultrasonic Peening Treatment on Fatigue Performance of Welded Joints. Materials, 9(6): 471. 


\section{Appendix A}




\section{Appendix A:Fitness for Service Example 1}

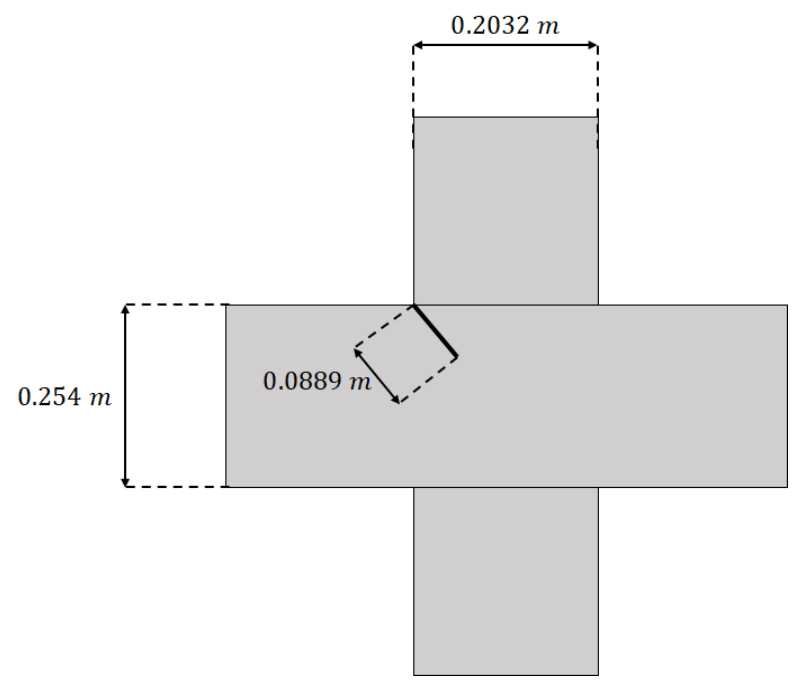

Note be careful of units.

The BS 7910 is in metric units

Make sure that when making calculations

the units are approriately used.

Front flange of Miter Gate

-corrosive environment

-experiencing freeze and thaw

assume temperatures as low as $-50 \mathrm{C}$

to be conservative

-Welded Joint in a Marine Environment

-Mixed Mode loading and crack

Material Properties:

A572 Steel

$\sigma_{y}:=345 \mathrm{MPa}$

$\sigma_{u}:=448 \mathrm{MPa}$

$\mathrm{E}:=207 \mathrm{GPa}$

$\varepsilon_{y}:=\frac{\sigma}{E}$

$\varepsilon_{u}:=\frac{5}{100} \quad \varepsilon_{u}=0.05$

$v:=0.3$

$\mathrm{L}_{\text {throat }}:=19.05 \mathrm{~mm}$
Yield strength of steel

Ultimate strength of steel

Young's modulus of steel

Yield strain.

Ultimate strain. Per BS7910

Poisson's ratio

Weld throat

Fatigue Values: BS 8.2.3.5 when da/dN is in mm/cycle and $\Delta \mathrm{K}$ is in $\mathrm{Mpa}^{\star} \mathrm{m}^{\wedge} 1 / 2$ Fatigue Threshold in corrosive environment per BS 8.2.3.6

$\mathrm{n}:=3$

$\mathrm{A}:=2 \cdot 3 \cdot 10^{-12} \cdot \frac{\mathrm{mm}}{(\mathrm{MPa} \cdot \sqrt{\mathrm{m}})^{\mathrm{n}}}$

$\Delta \mathrm{K}_{\mathrm{th}}:=2 \mathrm{MPa} \cdot \sqrt{m}$

\section{Section Geometry:}

Material coefficient: Paris Law exponent

Material coefficient: Paris Law constant

Threshold stress intensity

$$
\begin{aligned}
& \text { Flange }_{h}:=0.254 \mathrm{~m} \\
& \text { Flange }_{\mathrm{v}}:=0.2032 \mathrm{~m} \\
& \text { Flange }_{t}:=0.019 \mathrm{~m}
\end{aligned}
$$

Width of the horizontal flange

Width of the vertical flange

Flange thickness 


\section{Crack Geometry and Detail:}

Edge; Through Crack; 45 degree angle (Mixed Mode)

Note that mixed mode and shear controlled cracks have angles between 30 and 60 degrees.

$$
\begin{array}{ll}
\text { Crack }_{\text {length }}:=0.0889 \mathrm{~m} & \text { Length of the crack } \\
\text { Crack } & \\
\text { angle }:=45 \mathrm{deg} & \text { Angle of the crack, }
\end{array}
$$

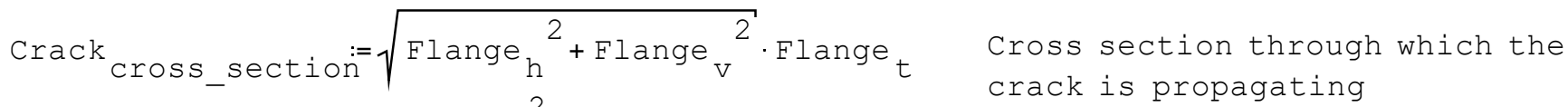$$
\text { Crack cross_section }=0.0062 \mathrm{~m}^{2}
$$

$$
\begin{aligned}
& \text { Crack }_{\text {cross_length }}: \sqrt{\text { Flange }_{\mathrm{h}}^{2}+\text { Flange }_{\mathrm{V}}^{2}} \quad \text { Length of the crack } \\
& \text { Crack }_{\text {cross_length }}=0.3253 \mathrm{~m}
\end{aligned}
$$

\section{Section Loading:}

$$
\begin{aligned}
& \sigma_{\text {xdirection }}:=82 \mathrm{MPa} \\
& \sigma_{\text {xmin }}:=0 \mathrm{MPa} \\
& \sigma_{y d i r e c t i o n}=34 \mathrm{MPa} \\
& \sigma_{\mathrm{ymin}}:=0 \mathrm{MPa} \\
& \mathrm{R}_{\mathrm{x}}:=\frac{\sigma \mathrm{xmin}}{\sigma \mathrm{xdirection}} \\
& \mathrm{R}_{\mathrm{x}}=0 \\
& \mathrm{R}_{\mathrm{y}}:=\frac{0}{\sigma \text { ydirection }} \\
& \sigma \text { ymin }
\end{aligned}
$$

Horizontal maximum applied stress

Horizontal minimum applied stress

Vertical maximum applied stress

Vertical minimum applied stress

Ratio of minimum horizontal stress to the maximum horizontal stress

Ratio of minimum vertical stress to the maximum vertical stress 


\section{Material Critical Stress Intensity Factor:}

Based on CVN estimated data reported in Fatigue repair of underwater navigation steel structures using Carbon Fiber Reinforced Polymer (CFRP) by Riveros et.al in 2018. Based on a conservative CVN value

$\mathrm{CVN}:=50 \mathrm{~J}$

$\mathrm{K}_{\text {material }}:=81 \cdot 3 \mathrm{MPa} \cdot \sqrt{\mathrm{m}}$

Critical stress intensity of steel

Based on CVN conservative data

\section{Step 1: Create the Failure Assessment Diagram (FAD)}

1a) Determine Lrmax

$L_{\text {rmax }}:=\frac{\sigma_{y}+\sigma_{u}}{2 \cdot \sigma_{y}}$

$L_{\text {rmax }}=1.1493$
BS $79107.3 .2(25)$

Max load ratio Eq 16

1b) Determine Non Discontinuity Line (Continuous)

Plot several points to create the line

$\mathrm{L}_{\mathrm{rC1} 1}:=1$

$\mu:=\min \left(\begin{array}{c}0.001 \cdot \frac{E}{\sigma_{y}} \\ 0.6^{y}\end{array}\right) \quad \mu=0.6$

$\mathrm{N}:=0.3 \cdot\left(1-\frac{\sigma_{\mathrm{y}}}{\sigma_{\mathrm{u}}}\right) \quad \mathrm{N}=0.069$

When $\operatorname{Lr}=1$ :

BS $79107.3 .3(26)$

$\mathrm{L}_{\mathrm{rCl} 1}:=1$

$f_{r C 1}:=\left(1+\frac{1}{2} \cdot L_{r C 1}\right)^{-\frac{1}{2}} \cdot\left(0 \cdot 3+0 \cdot 7 \cdot \exp \left(-\mu \cdot L_{r C 1}{ }^{6}\right)\right.$

$f_{r C 1}=0.5586$
Load ratio variable used to determine the non-discontinuousline, as the variable changes the line is plotted Non-discontinuous line constant (Eq. 20) Non-discontinuous line constant (Eq. 21) vertical component of the non-discontinuousline if Lr is Equal to 1 (Eq. 17) 
When $\operatorname{Lr} \leq 1$ :

BS 79107.3 .3 (26)

$\mathrm{L}_{\text {rC } 2}:=0.5$

$\mathrm{f}_{\mathrm{rC} 2}:=\left(1+\frac{1}{2} \cdot \mathrm{L}_{\mathrm{rc} 2}\right)^{-\frac{1}{2}} \cdot\left(0.3+0.7 \cdot \exp \left(-\mu \cdot \mathrm{L}_{\mathrm{rc} 2}\right)^{6}\right)$

$\mathrm{f}_{\mathrm{rC} 2}=0.9367$

vertical component of the non-discontinuousline if Lr is Less than or equal to 1 (Eq. 17)

When $1<\operatorname{Lr}<$ Irmax:

BS 79107.3 .3 (27)

$\mathrm{L}_{\text {rC } 3}:=1 \cdot 1$

$\mathrm{f}_{\mathrm{rC} 3}:=\mathrm{f}_{\mathrm{rC} 1} \cdot \mathrm{L}_{\mathrm{rC} 3} \frac{\mathrm{N}-1}{2 \cdot \mu}$

$\mathrm{f}_{\mathrm{rc} 3}=0.5188$

When Ir $\geq$ Lrmax:

BS 79107.3 .3 (28)

$\mathrm{L}_{\text {rC } 4}:=1.16$

$\mathrm{f}_{\text {rC } 4}:=0$

FAD

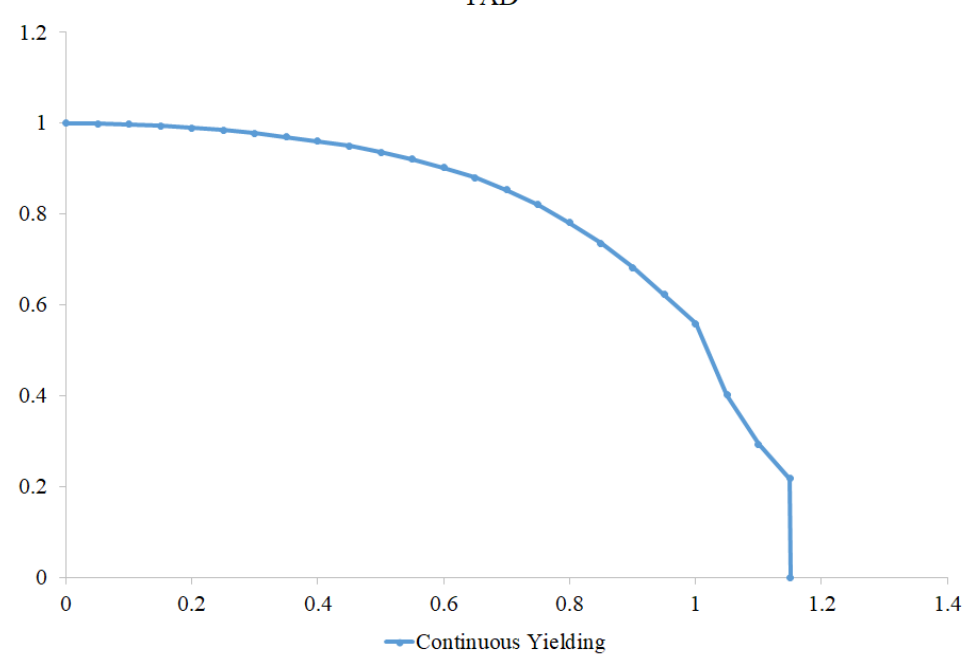

$4 / 19$
Load ratio variable used to determine the non-discontinuousline, as the variable changes the line is plotted

vertical component of the non-discontinuousline if Lr is greater than 1 and less than Lrmax (Eq. 18)
Load ratio variable used to determine the non-discontinuousline, as the variable changes the line is plotted

vertical component of the non-discontinuous line if $\mathrm{Lr}$ is greater than Lrmax (Eq. 19) 
1c) Determine Discontinuous Line

BS 79107.3 .3 (33)

Plot several points to create the line

$$
\begin{aligned}
& \Delta \varepsilon:=0.0375 \cdot\left(1-0.001 \cdot \sigma_{\mathrm{y}} \cdot \frac{1}{M P a}\right) \quad \Delta \varepsilon=0.0246 \quad \text { Strain estimation BS } 7910 \\
& \text { (Eq. 27) } \\
& \lambda:=1+\frac{E \cdot \Delta \varepsilon}{\sigma_{y}}
\end{aligned}
$$

When Ir < 1 :

BS 79107.3 .3 (29)

$\mathrm{L}_{\mathrm{rd} 1}:=0.5$

Discontinuous load ratio less

$$
f_{r d 1}:=\left(1+\frac{1}{2} \cdot L_{r d 1}^{2}\right)^{-\frac{1}{2}}
$$

\section{than 1}

vertical component of the discontinuous line if $\mathrm{Lr}$ is less than 1 (Eq. 22)

When $\operatorname{Lr}=1$ :

BS 79107.3 .3 (30)

$$
\begin{aligned}
& \mathrm{L}_{\operatorname{rd} 2}:=1 \\
& \mathrm{f}_{\operatorname{rd} 2}:=\left(\lambda+\frac{1}{2 \cdot \lambda}\right)^{-\frac{1}{2}} \\
& \mathrm{f}_{\operatorname{rd} 2}=0.2518
\end{aligned}
$$

Discontinuous load ratio equals 1

vertical component of the discontinuous line if Lr is equal to 1 (Eq. 23)

When $1<$ Lr < Lrmax:

BS 79107.3 .3 (31)

$$
\begin{aligned}
& \mathrm{L}_{\text {rd3 }}:=1.05 \\
& \mathrm{f}_{\text {rd3 }}:=\mathrm{f}_{\mathrm{rd} 2} \cdot \mathrm{L}_{\mathrm{rd} 3} \frac{\mathrm{N}-1}{2 \cdot \mathrm{N}} \\
& \mathrm{f}_{\mathrm{rd3}}=0.1812
\end{aligned}
$$

Discontinuous load ratio greater than 1 and less than Lrmax

vertical component of the discontinuous line if Lr is greater than 1 and less than Lrmax (Eq. 24) 
When Ir $\geq$ Lrmax:

BS $79107.3 .3(32)$

$\mathrm{L}_{\text {rd } 4}:=1.16$

$\mathrm{f}_{\mathrm{rd} 4}:=0$
Discontinuous load ratio

greater than Lrmax

vertical component of the discontinuous line if Lr is greater than Lrmax (Eq. 25)

FAD

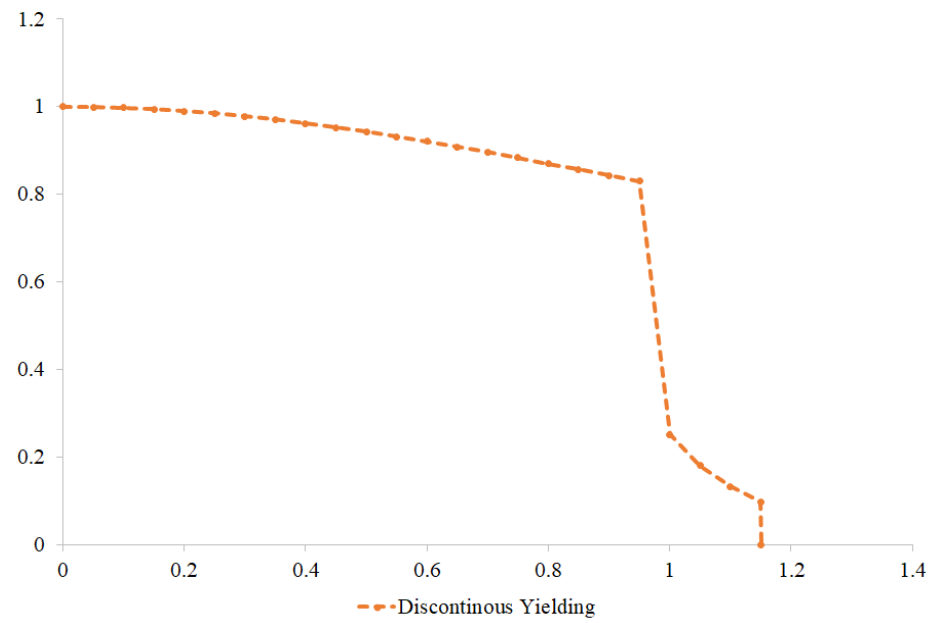

Both the continous and discontinuous lines charted together

FAD

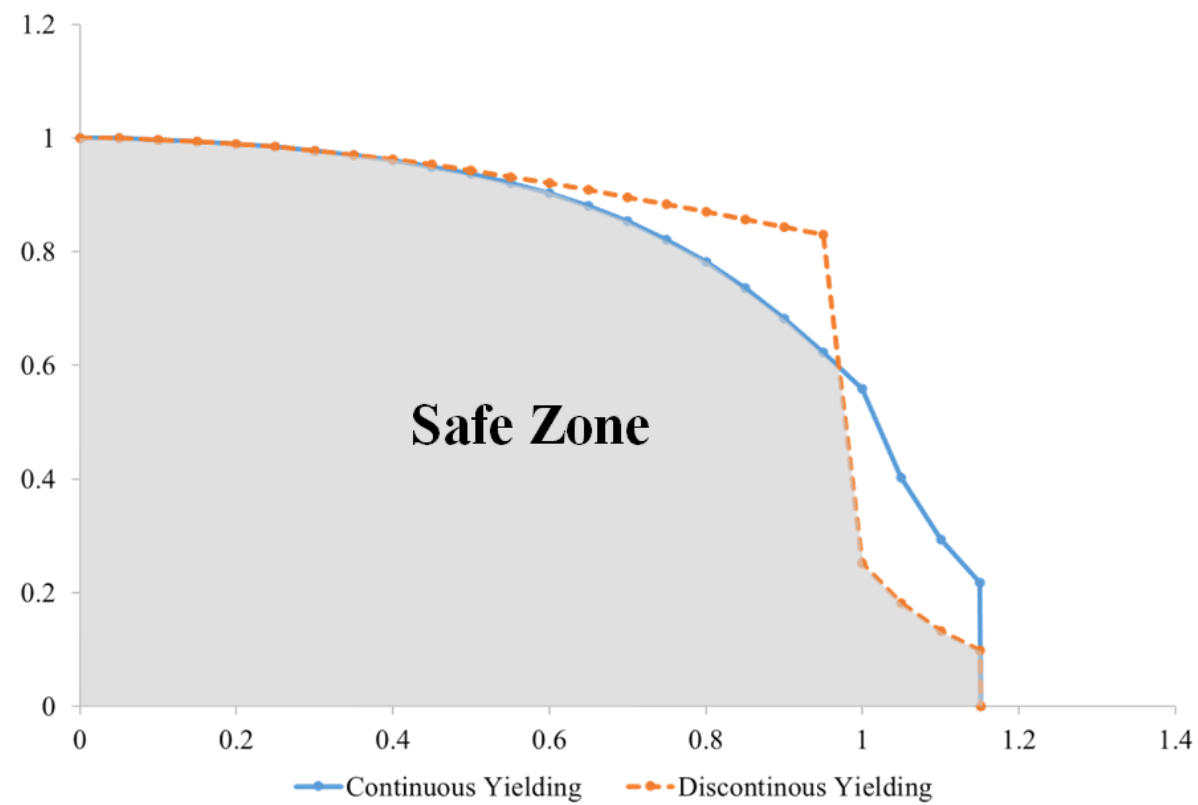




\section{Step 2: Calculate the load ratio factor(Lr)}

When there is a mixed mode load, determined by the angle of the crack growth, calculate the load ratio using the von Mises stresses

Note: When the crack angle is between 30-60 degrees the crack is experiencing mixed mode loads.

Due to only having stresses in the $x$ and $y$ directions (2 and 1 directions respectively) the principle plane stress von miss equation is utilized in this example.
$\sigma_{1}:=\sigma$ ydirection
Applied stress in the 1 direction
$\sigma_{2}:=\sigma_{\text {xdirection }}$
Applied stress in the 2 direction

$\sigma_{V}:=\sqrt{\sigma_{1}^{2}-\sigma_{1} \cdot \sigma_{2}+\sigma_{2}^{2}} \quad$ Von Misses Stress

$\sigma_{\text {ref }}:=\sigma_{V}$

Reference Stress

$\sigma_{\text {ref }}=71.3583 \mathrm{MPa}$

$\mathrm{L}_{\mathrm{r}}:=\frac{\sigma_{\mathrm{ref}}}{\sigma_{\mathrm{y}}}$

Load ratio factor (Eq. 28)

$\mathrm{L}_{r}=0.2068$

\section{Step 3: Calculate the fracture ratio (Kr)}

3a) Calculate the effective stress intensity, Keff, due to the loading and flaw type and geometry.

Crack type:

Edge; Through Crack; 45 degree angle (Mixed Mode)

Note that mixed mode and shear controlled cracks have angles between 30 and 60 degrees.

Since the crack is mixed mode a K effective will need to be calculated

According to Annex M Equation M. 6 there are only principal stresses

$Y \Delta \sigma_{\mathrm{p}}:=\mathrm{Mf}_{\mathrm{W}}\left(\mathrm{k}_{\mathrm{tm}} \cdot \mathrm{M}_{\mathrm{km}} \cdot \mathrm{M}_{\mathrm{m}} \cdot \Delta \sigma_{\mathrm{m}}+\mathrm{k}_{\mathrm{tb}} \cdot \mathrm{M}_{\mathrm{kb}} \cdot \mathrm{M}_{\mathrm{b}}\left(\Delta \sigma_{\mathrm{b}}+\left(\mathrm{k}_{\mathrm{m}}-1\right) \cdot \Delta \sigma_{\mathrm{m}}\right)\right) \quad$ BS 7910 Annex M (M. 6)

Typically in Hydraulic Steel structures (HSS) are through cracks and surface cracks. Through cracks are more critical and more extensive inspection equipment is required to determine the surface crack geometry. Therefore all HSS cracks are to be assumed as through cracks. 
When no formula is specified in the BS 7910 or there is not enough data.

$\mathrm{a}:=\frac{\text { Crack }_{\text {length }}}{2}$

$B:=$ Flange $_{t}$

$\mathrm{w}:=$ Crack ${ }_{\text {Cross_length }}$

$\mathrm{A}_{1 \text { surface }}:=2 \cdot \mathrm{a} \cdot \mathrm{c}$

$\mathrm{A}_{1 \text { embedded }}=4 \cdot \mathrm{a} \cdot \mathrm{c}$

$\mathrm{A}_{1 \text { through }}:=2 \cdot \mathrm{a} \cdot \mathrm{B}$

$\mathrm{A}_{2}:=\mathrm{B} \cdot \mathrm{W}$

BS 7910 Annex M (M. 7)

$\mathrm{f}_{\mathrm{w} 1}:=\left(\sec \left(\frac{\pi \cdot \mathrm{A}_{1 \text { through }}}{2 \cdot \mathrm{A}_{2}}\right)\right)^{\frac{1}{2}}$

$\mathrm{f}_{\mathrm{w} 1}=1.0487$
Crack geometry: Crack length

Crack geometry: Crack depth

Crack geometry: crack cross length

Geometric factor: flaw type constant

Geometric factor: flaw type constant

Geometric factor: flaw type constant

Geometric factor: flaw type constant

\section{Edge Crack}

Geometry Factor

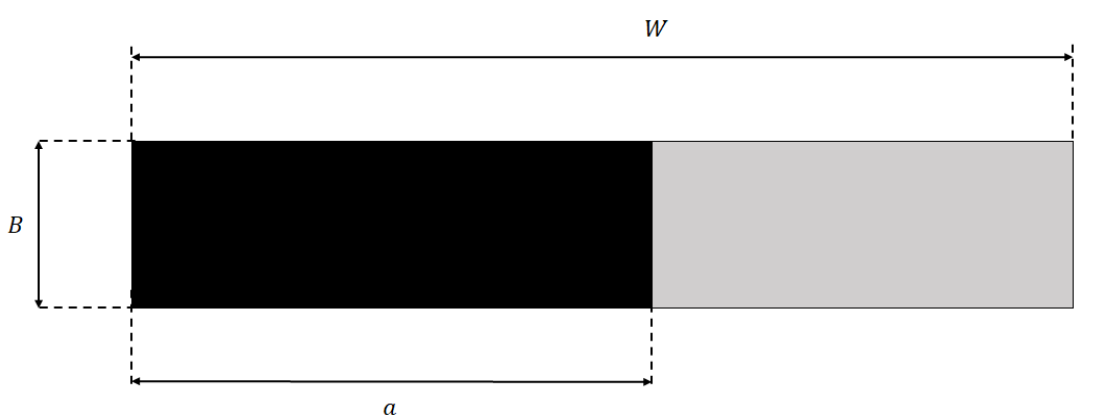

$$
\begin{aligned}
& M_{\text {edge }}:=1 \\
& \mathrm{a}:=\text { Crack } \text { length } \\
& \mathrm{B}:=\text { Flange } \\
& t \\
& \mathrm{~W}:=\text { Crack } \\
& \mathrm{f}_{\text {wedge }}:=1
\end{aligned}
$$

Flaw confiuration factor

Crack geometry: Crack length

Crack geometry: Crack depth

Crack geometry: crack cross length

Geometry Factor: Edge crack 
BS 7910 Annex M (M. 8)

$\begin{array}{ll}M_{\text {medge }}:=1.12-0.23 \cdot\left(\frac{a}{W}\right)+10 \cdot 6 \cdot\left(\frac{a}{W}\right)^{2}-21 \cdot 7 \cdot\left(\frac{a}{W}\right)^{3}+30.4 \cdot\left(\frac{a}{W}\right)^{4} & \begin{array}{l}\text { Flaw confiuration factor } \\ \text { Edge crack in tension }\end{array} \\ M_{\text {bedge }}:=M_{\text {medge }} & \text { Flaw confiuration factor } \\ M_{\text {bedge }}=1.5755 & \text { Edge crack in bending }\end{array}$

\section{Through Crack in plate}

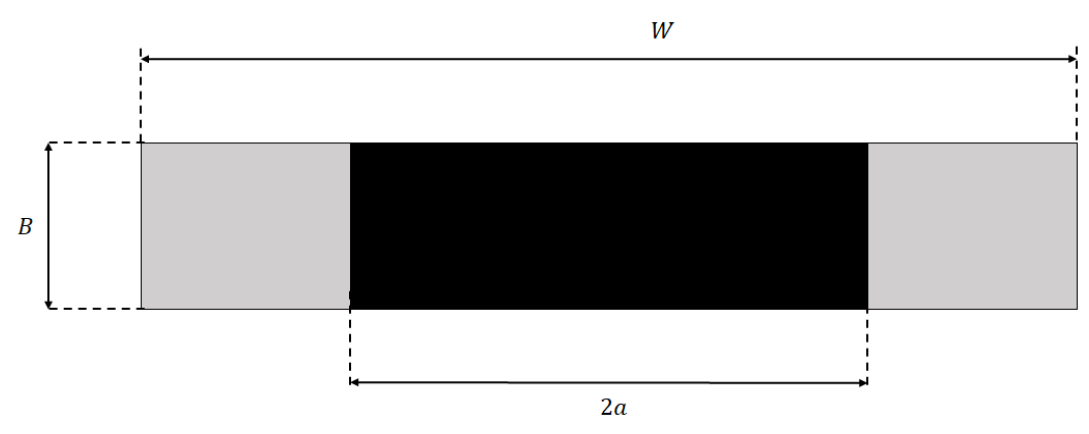

$\mathrm{M}_{\text {through }}:=1$

$\mathrm{M}_{\text {mthrough }}: \mathrm{M}_{\text {th }}$

$\mathrm{M}_{\text {bthrough }}{ }^{\mathrm{M}}$ thr

$a_{\text {through }}:=\frac{\text { Crack }_{\text {length }}}{2}$

$f_{\text {wthrough }}:=\left(\sec \left(\frac{\pi \cdot a_{\text {through }}}{w}\right)\right)^{\frac{1}{2}}$

$\mathrm{f}_{\text {wthrough }}=1.0487$

$k t, k t m, k t b$, and km factors
Flaw confiuration factor Through crack in tension

Elaw confiuration factor Through crack in bending

Crack geometry: Crack length Geometry Factor: Through crack

Stresses at structural discontinuities or due to mixed mode stresses

\section{State of cracked section:}

-There are no misalignments, deviationfrom the intended shape, or structural discontinuities at the cracked section.

Therefore the factors are equal to 1

$$
\mathrm{k}_{t}:=1 \quad \mathrm{k}_{\mathrm{tm}}:=1 \quad \mathrm{k}_{\mathrm{tb}}:=1 \quad \mathrm{k}_{\mathrm{m}}:=1
$$




\section{Mkm and $M k b$ factors}

Factors for flaws that are in regions of local stress concentration The areas are given in M11 of the BS7910. Areas of local stress concentrationsinclude the toe of a weld. Due to the Complete joint penetration of the butt weld in the section, seen in the figure below, the crack formed in the area of a welded joint (a local stress concentration area).

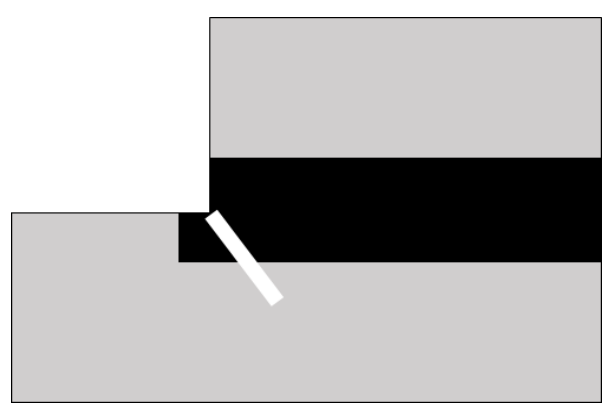

$\mathrm{B}=0.019 \mathrm{~m}$

$\mathrm{L}_{\text {throat }}=0.019 \mathrm{~m}$

$\mathrm{z}:=0.019 \mathrm{~m}$

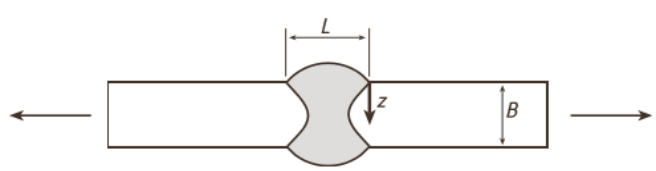

Plate Thickness

Full width of the welded connection from end to end

Depth penetration of weld

Values $\mathrm{v}$ and $\mathrm{w}$ are factors used in calculating the stress concentration factor Mk. These factors must be calculated for axial tension and bending.

$$
\begin{aligned}
& \mathrm{v}_{\text {axial }}:=\text { if } \frac{\mathrm{L}_{\text {throat }}}{\mathrm{B}} \leq 2 \\
& \text { if } \frac{Z}{B} \leq 0.05 \cdot\left(\frac{L_{\text {throat }}}{B}\right)^{0.55} \\
& 0.51 \cdot\left(\frac{L_{\text {throat }}}{B}\right)^{0.27} \\
& \text { else } \\
& 0.83 \\
& \text { else } \\
& \text { if } \frac{z}{B} \leq 0.073 \\
& 0.615 \\
& \text { else } \\
& 0.83
\end{aligned}
$$$$
\mathrm{w}_{\text {axial }}:=\text { if } \frac{\mathrm{L}_{\text {throat }}}{\mathrm{B}} \leq 2
$$$$
\text { if } \frac{Z}{B} \leq 0.05 \cdot\left(\frac{L_{\text {throat }}}{B}\right)^{0.55}
$$$$
-0.31
$$$$
\text { else }
$$$$
-0.15 \cdot\left(\frac{\mathrm{L} \text { throat }}{\mathrm{B}}\right)^{0.46}
$$$$
\text { else }
$$$$
\text { if } \frac{z}{B} \leq 0.073
$$$$
-0.31
$$$$
\text { else }
$$$$
-0.20
$$ 


$$
\begin{aligned}
& \mathrm{V}_{\text {bending }}:=\text { if } \frac{\mathrm{L}_{\text {throat }}}{\mathrm{B}} \leq 1 \\
& \text { if } \frac{z}{B} \leq 0.03 \cdot\left(\frac{L_{\text {throat }}}{B}\right)^{0.55} \\
& 0.45 \cdot\left(\frac{\mathrm{L} \text { throat }}{B}\right)^{0.21} \\
& \text { else } \\
& 0.68 \\
& \text { else } \\
& \text { if } \frac{z}{B} \leq 0.03 \\
& 0.45 \\
& \text { else } \\
& 0.68
\end{aligned}
$$

${ }^{\mathrm{w}}$ bending $:=$ if $\frac{\mathrm{L} \text { throat }}{\mathrm{B}} \leq 1$

if $\frac{z}{B} \leq 0.03 \cdot\left(\frac{L \text { throat }}{B}\right)^{0.55}$

else

$$
\begin{aligned}
& \quad-0.19 \cdot\left(\frac{L_{\text {throat }}}{B}\right)^{0.21} \\
& \text { else } \\
& \text { if } \frac{z}{B} \leq 0.03 \\
& \quad-0.31 \\
& \text { else } \\
& \quad-0.19
\end{aligned}
$$

values used to calculate the local stress concetration factor Mk in axial tension and bending
$\mathrm{v}_{\text {axial }}=0.83$
$\mathrm{w}_{\text {axial }}=-0.1502$
$\mathrm{V}_{\text {bending }}=0.68$
${ }^{\mathrm{W}}$ bending $=-0.19$

Local stress concentration factors for axial and bending
$\mathrm{M}_{\mathrm{km}}:=\mathrm{V}_{\text {axial }} \cdot\left(\frac{\mathrm{z}}{\mathrm{B}}\right)^{\mathrm{W}}$ axial
$\mathrm{M}_{\mathrm{kb}}:=\mathrm{V}_{\text {bending }}\left(\frac{\mathrm{z}}{\mathrm{B}}\right)^{\mathrm{W}}$ bending
$\mathrm{M}_{\mathrm{km}}=0.83$
$\mathrm{M}_{\mathrm{kb}}=0.68$ 


\section{3b) Calculate $\mathrm{K}$ factors for Mode I and Mode II}

The crack angle of the section is between 30-60 degrees and is therefore experiencing mixed mode crack growth. Due to the mixed mode the stress concentrations need to be modified to include an effective stress concetration

\section{Mode I:}

Mode I is axial

$$
\begin{aligned}
& \Delta \sigma_{\text {my }}:=\sigma_{\text {ydirection }} \quad \text { Axial tension stress } \\
& \Delta \sigma_{\mathrm{by}}:=0 \mathrm{MPa} \quad \text { Bending stress } \\
& M:=M_{\text {edge }} \quad f_{W}:=f_{\text {wedge }} \quad \text { Crack type and location factors } \\
& \mathrm{M}_{\mathrm{m}}:=\mathrm{M}_{\text {medge }} \quad \mathrm{M}_{\mathrm{b}}:=\mathrm{M}_{\text {bedge }} \quad \mathrm{f}_{\mathrm{w}}=1 \quad \text { Local stress concentration } \\
& \text { factors } \\
& r \Delta \sigma_{\mathrm{p}}:=\mathrm{M} \cdot \mathrm{f}_{\mathrm{w}} \cdot\left(\mathrm{k}_{\mathrm{tm}} \cdot \mathrm{M}_{\mathrm{km}} \cdot \mathrm{M}_{\mathrm{m}} \cdot \Delta \sigma_{\mathrm{my}}+\mathrm{k}_{\mathrm{tb}} \cdot \mathrm{M}_{\mathrm{kb}} \cdot \mathrm{M}_{\mathrm{b}} \cdot\left(\Delta \sigma_{\mathrm{by}}+\left(\mathrm{k}_{\mathrm{m}}-1\right) \cdot \Delta \sigma_{\mathrm{my}}\right)\right) \begin{array}{l}
\text { stress with } \\
\text { factors included }
\end{array} \\
& \gamma \Delta \sigma_{\mathrm{p}}=44.4614 \mathrm{MPa} \\
& K_{I}:=\gamma \Delta \sigma_{p} \cdot \sqrt{\pi \cdot a} \quad \text { stress intensity factor Mode I } \\
& \mathrm{K}_{\mathrm{I}}=23.4968 \mathrm{MPa} \cdot \sqrt{\mathrm{m}}
\end{aligned}
$$

\section{Mode II is shear loading}

$$
\begin{aligned}
& \Delta \tau_{m}:=\sigma_{x d i r e c t i o n} \quad \text { Shear stress } \\
& \Delta \tau_{\mathrm{b}}:=0 \mathrm{MPa} \quad \text { Bending shear stress-None } \\
& M:=M_{\text {edge }} \quad \mathrm{f}_{\mathrm{W}}:=\mathrm{f}_{\text {wedge }} \quad \text { Crack type and location factors } \\
& M_{m}:=M_{\text {medge }} \quad M_{b}:=M_{\text {bedge }} \quad f_{W}=1 \quad \text { Local stress concentration } \\
& \text { factors } \\
& V \Delta \tau_{\mathrm{p}}:=\mathrm{M} \cdot \mathrm{f}_{\mathrm{w}} \cdot\left(\mathrm{k}_{\mathrm{tm}} \cdot \mathrm{M}_{\mathrm{km}} \cdot \mathrm{M}_{\mathrm{m}} \cdot \Delta \tau_{\mathrm{m}}+\mathrm{k}_{\mathrm{tb}} \cdot \mathrm{M}_{\mathrm{kb}} \cdot \mathrm{M}_{\mathrm{b}} \cdot\left(\Delta \tau_{\mathrm{b}}+\left(\mathrm{k}_{\mathrm{m}}-1\right) \cdot \Delta \tau_{\mathrm{m}}\right)\right) \quad \begin{array}{l}
\text { stress with } \\
\text { factors included }
\end{array} \\
& \gamma \Delta \tau_{p}=107.2303 \mathrm{MPa} \\
& K_{I I}:=\gamma \Delta \tau_{p} \cdot \sqrt{\pi \cdot a} \quad \text { stress intensity factor Mode II } \\
& K_{I I}=56.6687 \mathrm{MPa} \cdot \sqrt{m} \\
& \mathrm{~K}_{\text {material }}=81.3 \mathrm{MPa} \cdot \sqrt{\mathrm{m}}
\end{aligned}
$$


3c) Calculate the mixed mode effective stress intensity factor

$$
\begin{aligned}
& \mathrm{K}_{\text {II I }}:=0 \\
& \alpha:=1 \\
& r:=\frac{\mathrm{K}_{\text {material }}}{\sigma_{\mathrm{y}}} \\
& r=7.452 \mathrm{~mm}^{\frac{1}{2}} \\
& K_{12}:=\text { if } \frac{K_{I}}{K_{I I}} \geq 0.466 \\
& \frac{\left(2 \cdot K_{I}+6 \cdot \sqrt{K_{I}^{2}+8 \cdot K_{I I}^{2}}\right)}{8} \cdot\left(\frac{K_{I}^{2}+12 \cdot K_{I I}{ }^{2}+K_{I} \cdot \sqrt{K_{I}^{2}+8 \cdot K_{I I}^{2}}}{2 \cdot K_{I}{ }^{2}+18 \cdot K_{I I}^{2}}\right)^{\frac{3}{2}} \\
& \text { else } \\
& \frac{K_{I I}}{0.7} \\
& \mathrm{~K}_{12}=80.9553 \mathrm{MPa} \cdot \sqrt{\mathrm{m}} \\
& K_{\text {eff }}:=\text { if } r \geq 6.3 \mathrm{~mm}^{\frac{1}{2}}
\end{aligned}
$$

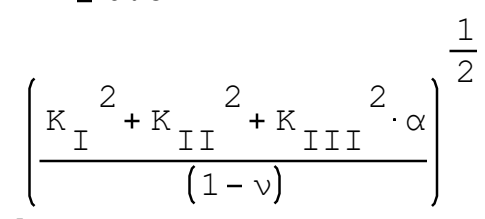

$$
\begin{aligned}
& \text { else } \\
& \text { if } \mathrm{K}_{\text {II }}>\mathrm{K}_{\text {material }}
\end{aligned}
$$

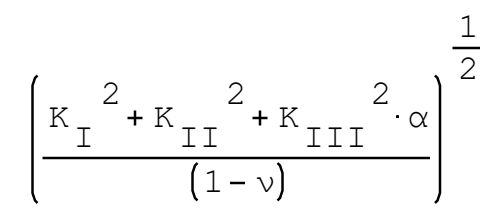

$$
\begin{aligned}
& \text { else } \\
& \left(\frac{K_{12^{2}}{ }^{2} K_{I I I}{ }^{2} \cdot \alpha}{(1-\nu)}\right)^{\frac{1}{2}} \\
& \mathrm{~K}_{\text {eff }}=73.3236 \mathrm{MPa} \cdot \sqrt{\mathrm{m}}
\end{aligned}
$$


3d) Calculate $\mathrm{Kr}$

$$
\begin{aligned}
& \mathrm{K}_{r}:=\frac{\mathrm{K}_{\text {eff }}}{\mathrm{K}_{\text {material }}} \\
& \mathrm{K}_{r}:=\frac{\mathrm{K}_{\text {eff }}}{\mathrm{K}_{\text {material }}} \\
& \mathrm{K}_{r}=0.9019
\end{aligned}
$$

According to Annex M. 6 there are no secondary stresses when evaluating for fatigue

Fracture assessment $K$ value used in FAD

\section{4) Crack Assesment}

$$
\mathrm{L}_{r}=0.2068 \quad \mathrm{~K}_{\mathrm{r}}=0.9019
$$

The crack assessment is within the safe zone of the FAD. Therefore the crack does not require immediate attention. A fatigue crack life assessment using is required to determine the life expectancy of the crack.

FAD

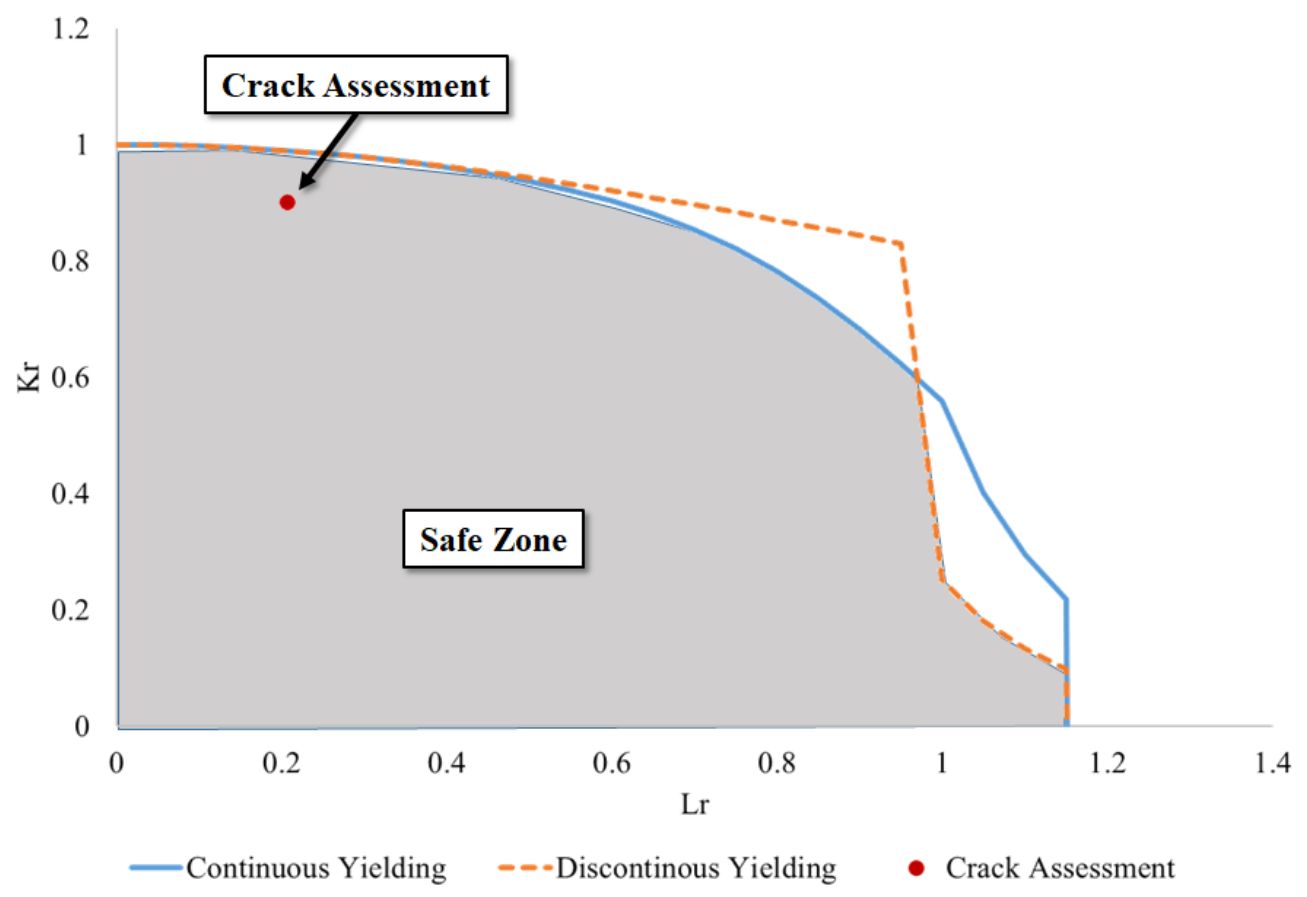


4a) Determine the flaw size acceptability and flaw size with Safety Factor

$a_{t h}:=\frac{\left(\frac{\Delta \mathrm{K}_{\mathrm{th}}}{\gamma \Delta \sigma_{\mathrm{p}}}\right)^{2}}{\Pi}$

$a_{t h}=0.0006 m$
Initial threshold flaw size

$a_{\text {material }}:=\frac{\left(\frac{K_{\text {material }}}{V \Delta \sigma_{p}}\right)^{2}}{\Pi} \quad$ Critical flaw size

$a_{\text {material }}=1.0643 \mathrm{~m}$

Table 1 Factor of Safety based on failure consequence and section redundancy[1]

\begin{tabular}{cccccc}
\hline & $\begin{array}{c}\text { Standard } \\
\text { Deviation }\end{array}$ & Moderate & Severe & $\begin{array}{c}\text { Very } \\
\text { Severe }\end{array}$ & $\begin{array}{c}\text { Extremely } \\
\text { Severe }\end{array}$ \\
\hline \multirow{2}{*}{ Redundant Member } & 0.1 & 1 & 1.4 & 1.5 & 1.7 \\
& 0.2 & 1.05 & 1.45 & 1.55 & 1.8 \\
Non-Redundant & 0.3 & 1.08 & 1.5 & 1.65 & 1.99 \\
Member & 0.5 & 1.15 & 1.7 & 1.85 & 2.1 \\
& 0.1 & 1.4 & 1.5 & 1.7 & 2.1 \\
& 0.2 & 1.45 & 1.55 & 1.8 & 2.2 \\
\end{tabular}

\footnotetext{
$\mathrm{SF}:=1.4$

Safety Factor determined from table

Check to see if crack length is acceptable

CrackLengthCheck= if $\mathrm{Crack}_{\text {length }} \mathrm{SF} \geq \mathrm{a}_{\text {material }}$

"Not Acceptable"

else

"Acceptable"

CrackLengthCheck= "Acceptable"

Crack length multiplied by the safety factor

Crack $_{\text {lengthS }}:=\mathrm{Crack}_{\text {length }}$ SF

Crack $_{\text {length } S F}=0.1245 \mathrm{~m}$
} 
4b) Determine if it is acceptable to use Paris Law

Paris Law is utilized only within the limits of the threshold and critical crack growth.
$\Delta \mathrm{K}_{\mathrm{th}}=2 \mathrm{MPa} \cdot \sqrt{m}$
Threshold stress intensity factor
$\mathrm{K}_{\text {material }}=81 \cdot 3 \mathrm{MPa} \cdot \sqrt{\mathrm{m}}$
Critical stress intensity factor
$\mathrm{K}_{\text {eff }}=73.3236 \mathrm{MPa} \cdot \sqrt{\mathrm{m}}$
Effective stress intensity factor

Check to see if use of the Paris Law is acceptable

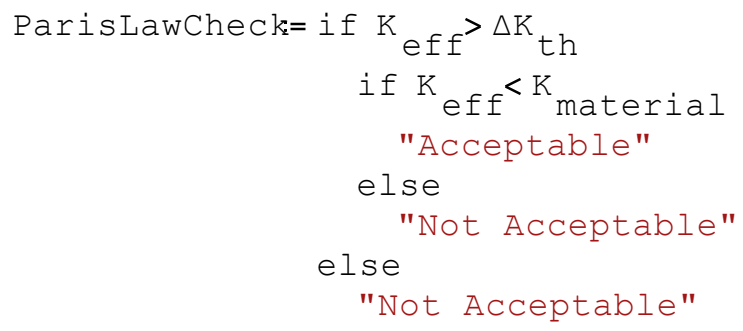

ParisLawCheck= "Acceptable"

4c) Determine the number of cycles at the crack length, critical crack length, and the number of service life cycles.

where $\mathrm{x}$ is the crack length and $\mathrm{dx}$ is the change in crack length

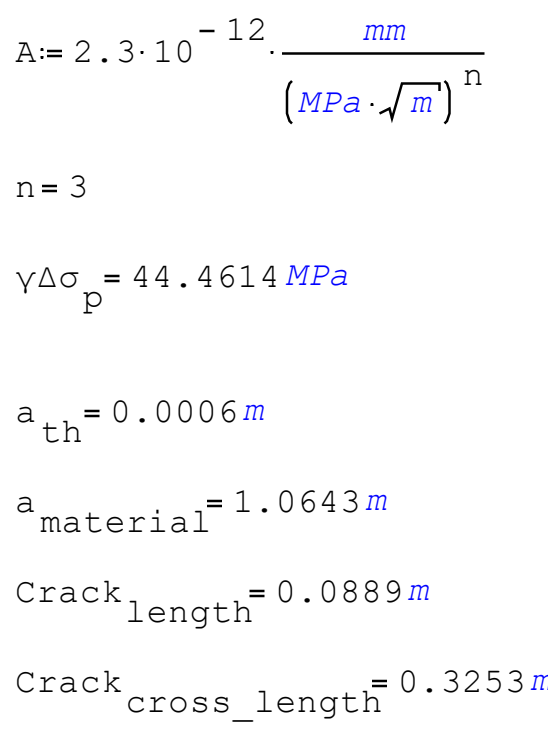

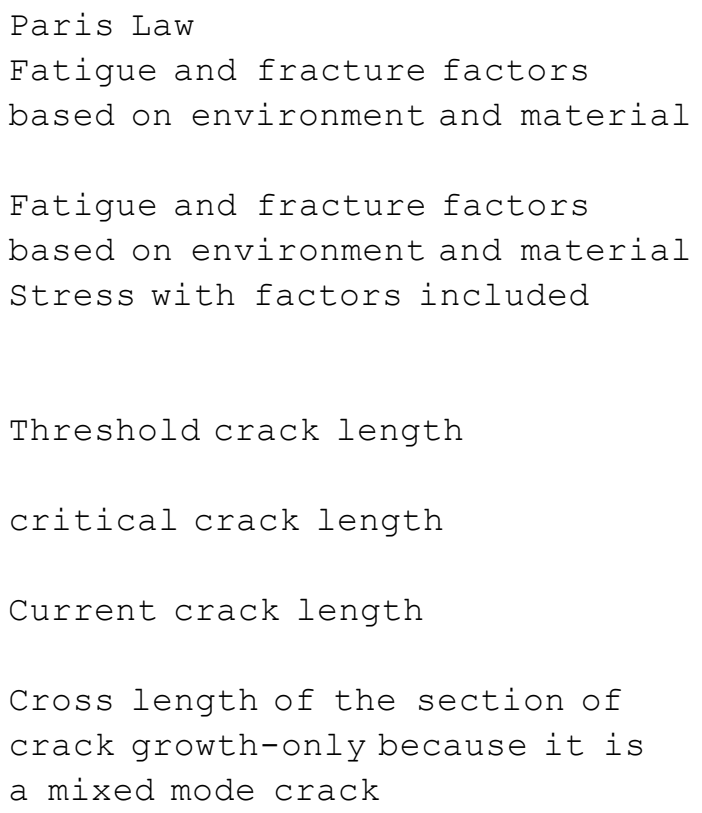


$\mathrm{N}_{\text {maxlength }}:=\int_{a_{\text {th }}}^{\text {MaxLength }} \frac{1}{\left(\gamma \Delta \sigma_{p} \cdot \sqrt{\Pi \cdot x}\right)^{n}} d x \quad \begin{aligned} & \text { Number of cycles to reach } \\ & \text { maximum crack length }\end{aligned}$

\begin{tabular}{|c|c|c|c|}
\hline & 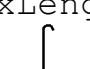 & $\begin{array}{r}1 \\
\end{array}$ & due to the units used \\
\hline maxlengthnounits & $\begin{array}{c}\mathrm{J} \\
a_{\text {th }}\end{array}$ & $2 \cdot 3 \cdot 10^{-12} \cdot(44 \cdot 4 \cdot \sqrt{\pi \cdot x})^{n}$ & $\begin{array}{l}\text { the correct answer is } \\
\text { given when multiplied } \\
\text { by no units as there } \\
\text { is no cycle unit in this } \\
\text { program }\end{array}$ \\
\hline
\end{tabular}

Number of cycles to reach the max crack length of $0.3253 \mathrm{~m}$

$\mathrm{N}_{\text {maxlengthnounits }}=6.7435 .10^{7} \quad$ Number of cycles to reach maximum crack length

Service Life Number of Cycles Estimation

Assuming that a Miter gate sees 4 cycles per lockage (2 cycles for water elevation change and 2 cycles for opening and closing the miter gate)

The gate in question sees 2000 lockages a year. The gate has been in operation

Lockage: $=2000$

Number of lockages per year

Lockage cycles $:=4$

Number of cycles per lockage

Servicecycles year ${ }_{\text {Lockage Lockage }}$ cycles Number of cycles per year

Servicecycles year $=8000$

Service yearstodate $=30 \quad$ Lock's time in service in

Service yearsdesign $:=50 \quad$ Lock's design life in years

$$
\begin{aligned}
& \begin{array}{r}
\text { Service yearsremaining : Service yearsdesign }{ }^{-S e r v i c e} \text { yearstodate Lock's remaining } \\
\text { time in service, in }
\end{array} \\
& \begin{array}{ll}
\text { Service } & \text { yearsremaining } \\
=20 & \text { years }
\end{array} \\
& \text { Servicecycles yearstodate: Service yearstodate Servicecycles year }{ }^{\text {Number of cycles to }} \\
& \text { Servicecycles yearstodate } 2 \cdot 4 \cdot 10^{5}
\end{aligned}
$$




$$
\begin{aligned}
& \begin{array}{r}
\text { Servicecycles remaining : Service yearsremaining Servicecycles year Number of cycles } \\
\text { remaining in the }
\end{array}
\end{aligned}
$$

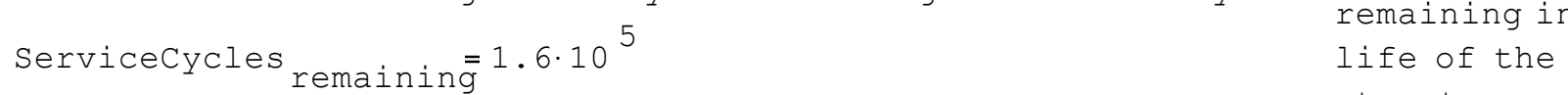

$$
\begin{aligned}
& \text { Servicecycles Design : Service yearsdesign Servicecycles year Number of cycles } \\
& \text { ServiceCycles } \operatorname{Design}=4 \cdot 10^{5} \\
& \text { in the design } \\
& \text { life of the } \\
& \text { structure }
\end{aligned}
$$

$\mathrm{N}_{\text {cracklengthnounits }}=6.4594 \cdot 10^{7}$

Number of cycles to reach the
current crack length

$\mathrm{N}_{\text {maxlengthnounits }}=6.7435 .10^{7}$

Number of cycles to reach the maximum crack length

$\mathrm{N}_{\text {remainingtomax }} \mathrm{N}_{\text {maxlengthnounits }}{ }^{\mathrm{N}}$ cracklengthnounits

Number of cycles left to reach the maximum

$\mathrm{N}_{\text {remainingtomax }}=2.8406 \cdot 10^{6}$ crack length

Servicecycles yearstodate $=2 \cdot 4 \cdot 10^{5} \quad$ Number of cycles to date

Servicecycles $\operatorname{Design}=4 \cdot 10^{5}$

Number of cycles in the design

ServiceCycles ${ }_{\text {remaining }}=1.6 \cdot 10^{5}$ life of the structure

Number of cycles remaining in the life of the structure

The Cycles at the crack length is greater than the service life remaining number of cycles. But the number of cycles remaining to reach the max cross length of half of the section's diagonal length is less than the remaining cycles to the end of the service life. But the fact that environmental factors such as corrosion can propagate the crack faster should be taken into consideration when making a decision of when to repair or not repair a flaw.

A good rule of thumb if the crack length, and stress intensity, and FAD are all acceptable is if the crack is less than $3 / 8$ the cross section length then it is safe. If the crack is more than $3 / 8$ of the cross section length then it is best to repair.

State:= if $\frac{\text { Crack }}{\text { Crack }{ }_{\text {length }}}<\frac{3}{8}$
"Safe"
else
"Repair"

State="Safe"

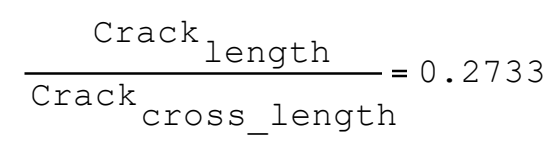




\section{Appendix B}




\section{Appendix B:Fitness for Service Example 2}

Fitness for Service: Example 1
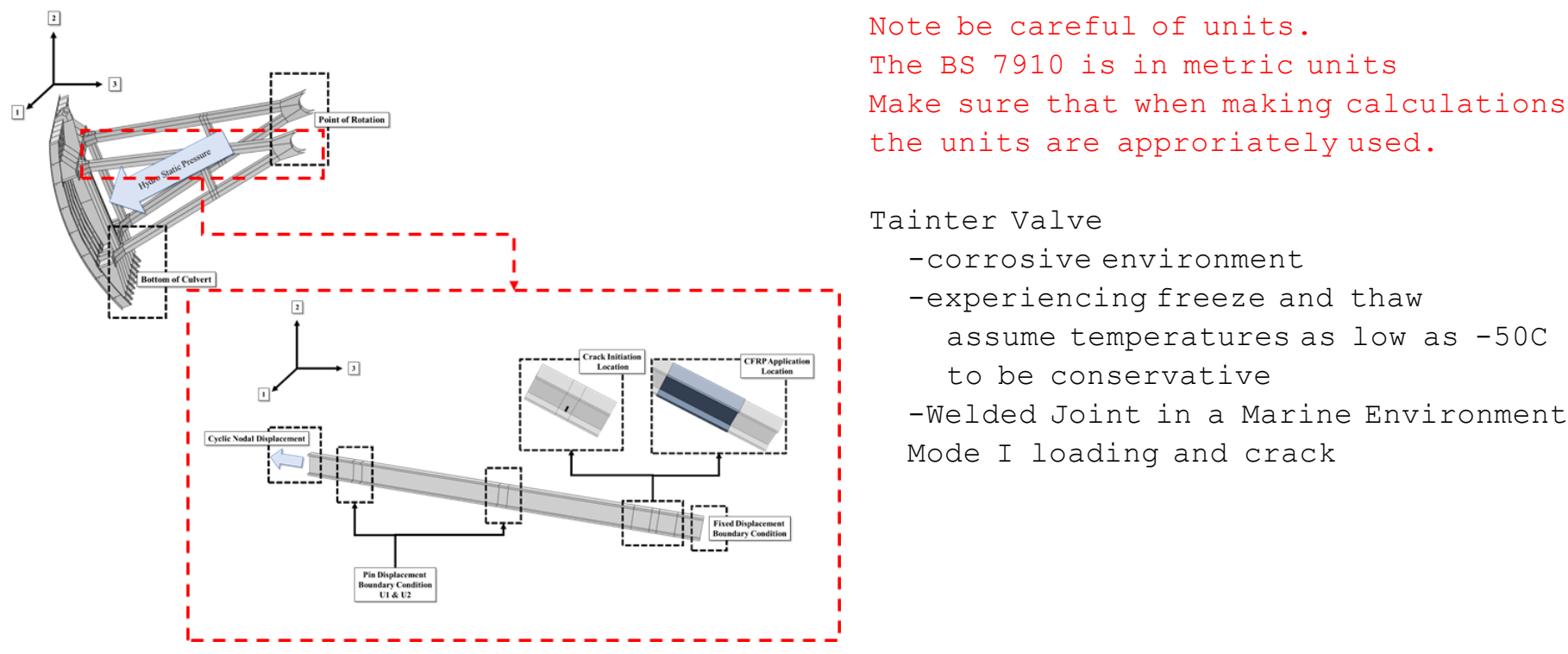

\section{Material Properties:}

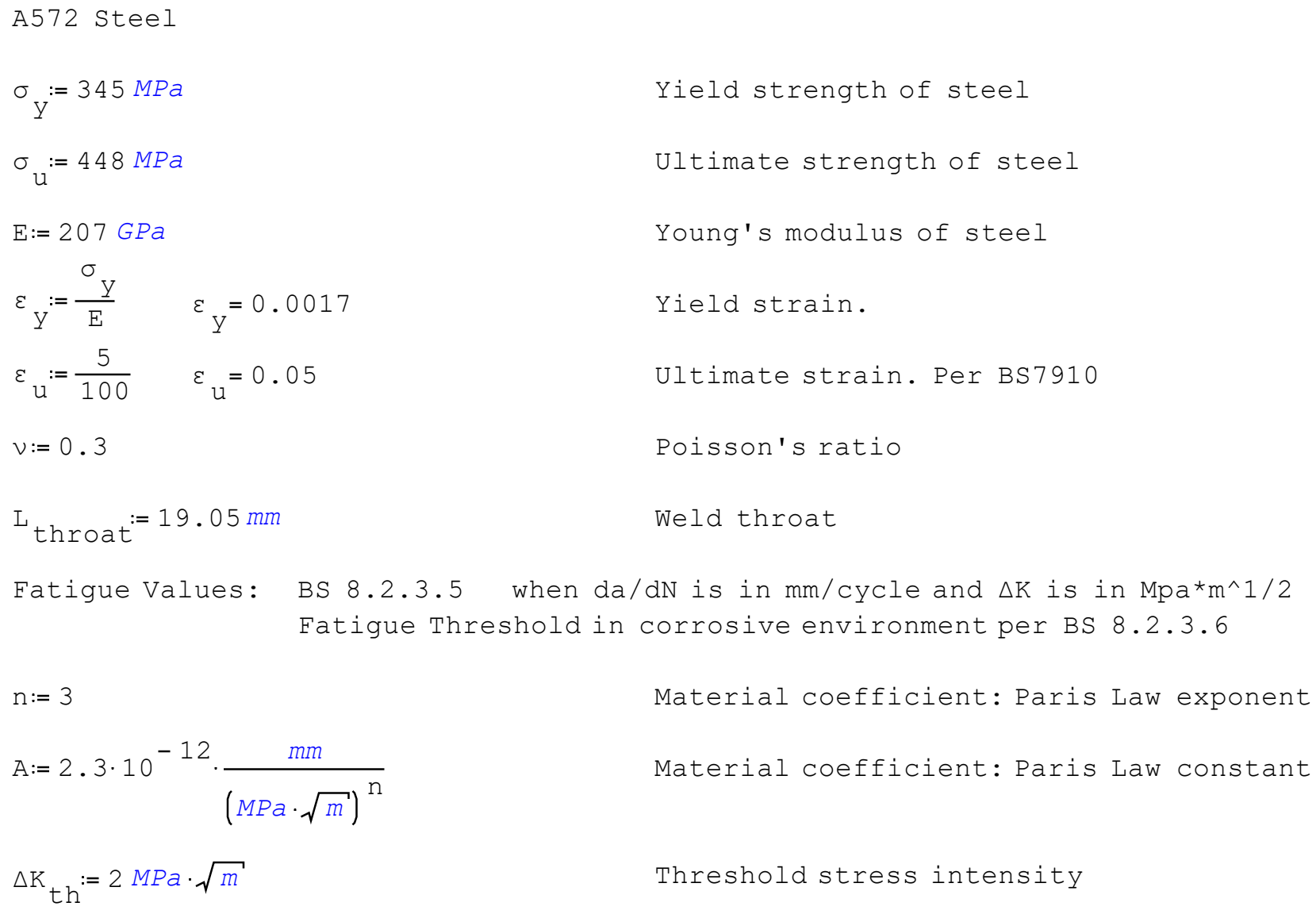

$n:=3$

$A:=2 \cdot 3 \cdot 10^{-12} \cdot \frac{\mathrm{mm}}{(\mathrm{MPa} \cdot \sqrt{\mathrm{m}})^{\mathrm{n}}}$

$\Delta \mathrm{K}_{\mathrm{th}}:=2 M P a \cdot \sqrt{m}$

Material coefficient: Paris Law exponent Material coefficient: Paris Law constant Threshold stress intensity 


\section{Section Geometry:}
Flange $_{h}:=0.254 \mathrm{~m}$
Width of the horizontal flange
Flange $_{\mathrm{V}}=0.2032 \mathrm{~m}$
Width of the vertical flange
Flange $_{t}:=0.019 \mathrm{~m}$
Flange thickness

\section{Crack Geometry and Detail:}
Edge; Through Crack; Mode I
Crack length: $0.0889 \mathrm{~m} \quad$ Length of the crack
Crack angle:=0 deg Angle of the crack,
from the horizontal edge
Crack $_{\text {Cross section }}=$ Flange $_{\mathrm{v}}$ Flange $_{t}$ Cross section through which the
crack is propagating
Crack ${ }_{\text {cross_section }}=0.0039 \mathrm{~m}^{2}$
Crack $_{\text {Cross_length }}:=$ Flange $_{\mathrm{V}}$
Length of the crack
Crack cross_length $=0.2032 \mathrm{~m}$

\section{Section Loading:}

$$
\begin{aligned}
& \sigma_{\text {ydirection }}:=34 \mathrm{MPa} \\
& \sigma_{\text {ymin }}:=0 \mathrm{MPa} \\
& \mathrm{R}_{\mathrm{y}}:=\frac{\sigma_{\text {ymin }}}{\sigma_{\text {ydirection }}} \\
& \mathrm{R}_{\mathrm{y}}=0
\end{aligned}
$$

Vertical maximum applied stress

Vertical minimum applied stress

Ratio of minimum horizontal stress

to the maximum horizontal stress 


\section{Material Critical Stress Intensity Factor:}

Based on CVN estimated data reported in Fatigue repair of underwater navigation steel structures using Carbon Fiber Reinforced Polymer (CFRP) by Riveros et.al in 2018. Based on a conservative CVN value

$C V N:=50 \mathrm{~J}$

$\mathrm{K}_{\text {material }}=81.3 \mathrm{MPa} \cdot \sqrt{\mathrm{m}} \quad$ Critical stress intensity of steel

Based on CVN conservative data

Step 1: Create the Failure Assessment Diagram (FAD)

1a) Determine Lrmax

BS $79107.3 .2(25)$

$L_{\text {rmax }}:=\frac{\sigma_{\mathrm{y}}+\sigma_{\mathrm{u}}}{2 \cdot \sigma_{\mathrm{y}}}$

Max load ratio Eq 16

$\mathrm{L}_{\text {max }}=1.1493$

1b) Determine Non Discontinuity Line

Plot several points to create the line

$$
\begin{aligned}
& \mathrm{L}_{\mathrm{rcl}}:=1 \quad \text { Load ratio variable used to determine } \\
& \text { the non-discontinuousline, as the } \\
& \mu=\min \left(\begin{array}{c}
0.001 \cdot \frac{\mathrm{E}}{\sigma_{\mathrm{y}}} \\
0.6^{\mathrm{y}}
\end{array}\right) \quad \begin{array}{l}
\text { variable changes the line is plotted } \\
\text { Non-discontinuousline constant (Eq. 20) }
\end{array} \\
& \mu=0.6 \\
& \mathrm{~N}:=0.3 \cdot\left(1-\frac{\sigma_{\mathrm{y}}}{\sigma_{\mathrm{u}}}\right) \quad \text { Non-discontinuous line constant (Eq. 21) } \\
& N=0.069
\end{aligned}
$$

When $\operatorname{Lr}=1$ :

BS 79107.3 .3 (26)

$$
\begin{aligned}
& \mathrm{L}_{\mathrm{rC1}}:=1 \\
& \mathrm{f}_{\mathrm{rC1} 1}:=0.5586
\end{aligned}
$$


When $\operatorname{Lr} \leq 1$ :

BS $79107.3 .3(26)$

$$
\begin{aligned}
& \mathrm{L}_{\text {rC } 2}:=0.5 \\
& \mathrm{f}_{\mathrm{rC} 2}:=\left(1+\frac{1}{2} \cdot \mathrm{L}_{\mathrm{rCl}}\right)^{-\frac{1}{2}} \cdot\left(0.3+0.7 \cdot \exp \left(-\mu \cdot \mathrm{L}_{\mathrm{rcl}}\right)^{6}\right) \quad \begin{array}{l}
\text { vertical component of the } \\
\text { non-discontinuous ine if }
\end{array} \\
& f_{\text {rc } 2}=0.5586 \\
& \text { Less than or equal to } 1 \text { (Eq. 17) }
\end{aligned}
$$

When $1<\operatorname{Lr}<$ Lrmax:

BS $79107.3 .3(27)$

$\mathrm{L}_{\text {rC } 3}:=1 \cdot 1$

$\mathrm{f}_{\mathrm{rC} 3}:=\mathrm{f}_{\mathrm{rCl} \cdot \mathrm{L}} \frac{\mathrm{N}-1}{2 \cdot \mu}$

$\mathrm{f}_{\mathrm{rc} 3}=0.5188$

When Ir $\geq$ Irmax:

$\mathrm{L}_{\text {rC } 4}:=1 \cdot 16$

$\mathrm{f}_{\text {rC } 4}:=0$

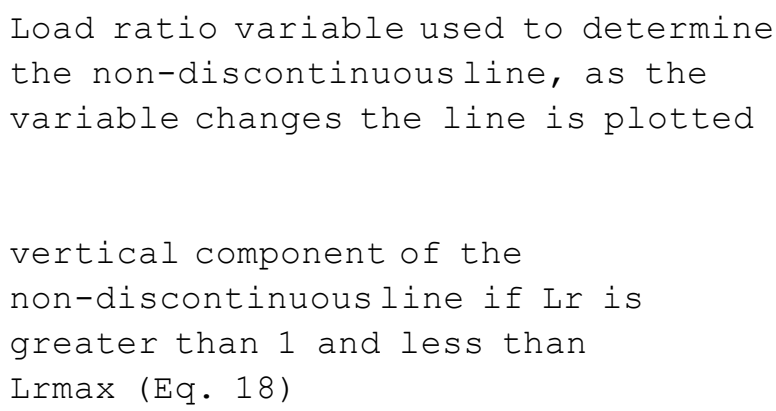

BS $79107.3 .3(28)$

Load ratio variable used to determine the non-discontinuousline, as the variable changes the line is plotted

vertical component of the non-discontinuousline if Lr is greater than Lrmax (Eq. 19)

FAD

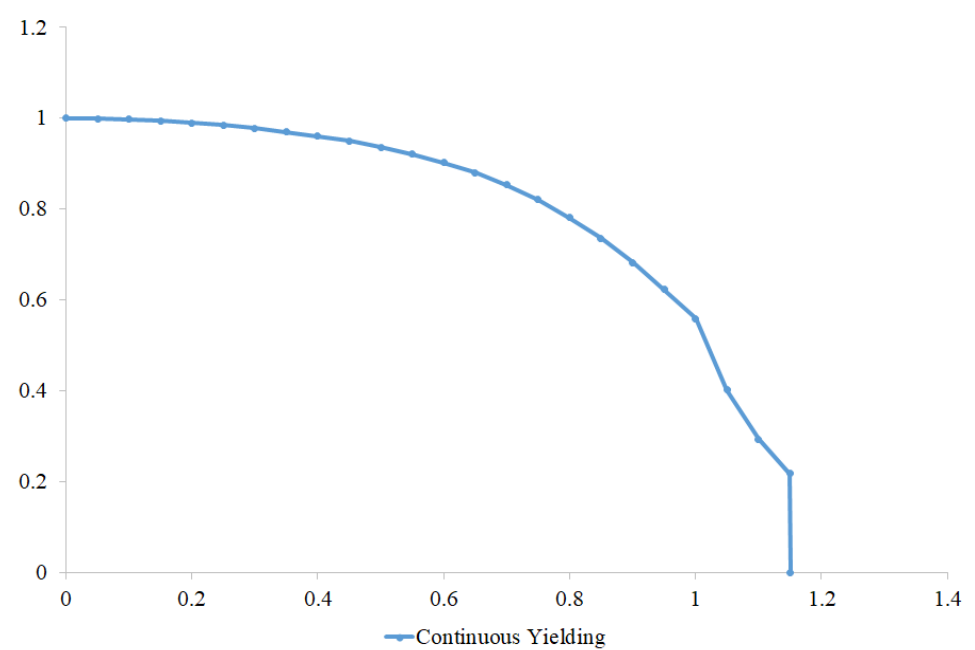


1c) Determine Discontinuous Line

BS 79107.3 .3 (33)

Plot several points to create the line

$$
\begin{array}{ll}
\Delta \varepsilon:=0.0375 \cdot\left(1-0.001 \cdot \sigma_{Y} \cdot \frac{1}{M P a}\right) & \begin{array}{l}
\text { Strain estimation BS } 7910 \\
(E q \cdot 27)
\end{array} \\
\Delta \varepsilon=0.0246 & \\
\lambda:=1+\frac{E \cdot \Delta \varepsilon}{\sigma_{Y}} & \begin{array}{l}
\text { Discontinuous yielding factor } \\
\text { used when Lr equals } 1 \text { (Eq. 26) }
\end{array}
\end{array}
$$

When $\operatorname{Lr}<1$ :

BS 79107.3 .3 (29)

$\mathrm{L}_{\mathrm{rd} 1}:=0.5$

$\mathrm{f}_{\mathrm{rdl}}:=\left(1+\frac{1}{2} \cdot \mathrm{L}_{\mathrm{rd} 1}\right)^{-\frac{1}{2}}$

$\mathrm{f}_{\mathrm{rd1}}=0.9428$
Discontinuous load ratio less than 1

vertical component of the discontinuous line if $\mathrm{Lr}$ is less than 1 (Eq. 22)

When $\operatorname{Lr}=1$ :

BS 79107.3 .3 (30)

$\mathrm{L}_{\operatorname{rd} 2}:=1$

$\mathrm{f}_{\mathrm{rd} 2}:=\left(\lambda+\frac{1}{2 \cdot \lambda}\right)^{-\frac{1}{2}}$

$\mathrm{f}_{\mathrm{rd} 2}=0.2518$
Discontinuous load ratio equals 1

vertical component of the discontinuous line if $\operatorname{Lr}$ is equal to 1 (Eq. 23)

When $1<\operatorname{Lr}<$ Lrmax:

BS 79107.3 .3 (31)

$\mathrm{L}_{\text {rd3 }}:=1.05$

Discontinuous load ratio greater than 1 and less than

$\mathrm{f}_{\mathrm{rd} 3}:=\mathrm{f}_{\mathrm{rd} 2} \cdot \mathrm{L}_{\mathrm{rd} 3} \frac{\mathrm{N}-1}{2 \cdot \mathrm{N}}$ Lrmax

vertical component of the discontinuous line if $\mathrm{Lr}$ is $\mathrm{f}_{\mathrm{rd} 3}=0.1812$ greater than 1 and less than Lrmax (Eq. 24) 
When Ir $\geq$ Lrmax:

BS 79107.3 .3 (32)

$$
\begin{aligned}
& \mathrm{L}_{\operatorname{rd} 4}:=1.16 \\
& \mathrm{f}_{\operatorname{rd} 4}:=0
\end{aligned}
$$

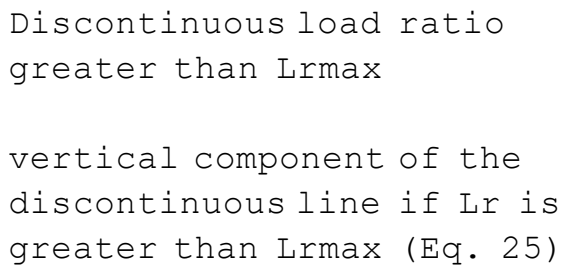

FAD

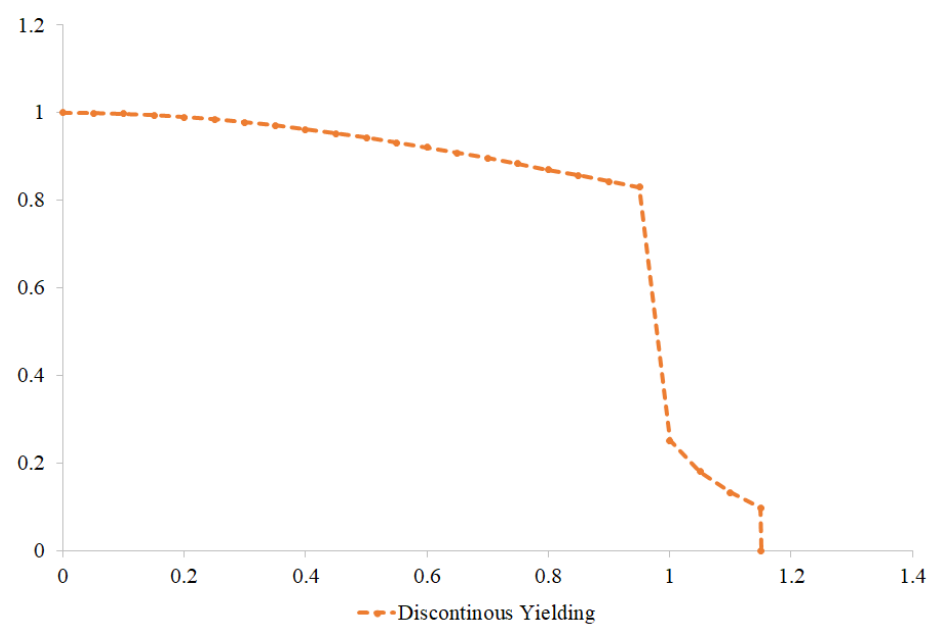

Both the continous and discontinuous lines charted together

FAD

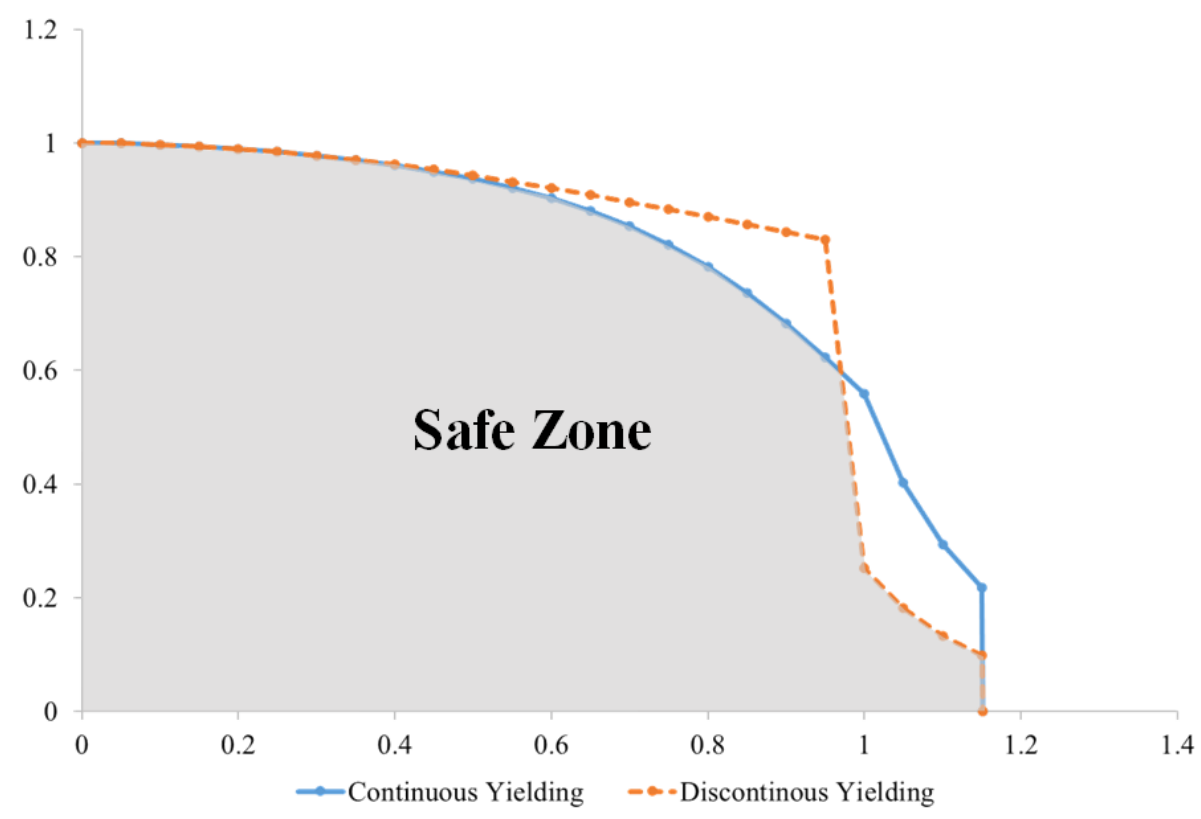




\section{Step 2: Calculate the load ratio factor(Lr)}

When there is a mixed mode load, determined by the angle of the crack growth, calculate the load ratio using the von Mises stresses

Note: When the crack angle is between 30-60 degrees the crack is experiencing mixed mode loads.

Due to only having stresses in the $x$ and $y$ directions (2 and 1 directions respectively) the principle plane stress von miss equation is utilized in this example.

$\sigma_{1}:=\sigma_{\text {ydirection }} \quad$ Applied stress in the 1 direction

$\sigma_{\text {ref }}:=\sigma_{1} \quad$ Reference Stress

$\sigma_{\text {ref }}=34 \mathrm{MPa}$

$L_{r}:=\frac{\sigma_{\text {ref }}}{\sigma_{y}} \quad$ Load ratio factor $(\mathrm{Eq} \cdot 28)$

$\mathrm{L}_{r}=0.0986$

\section{Step 3: Calculate the fracture ratio ( $\mathrm{Kr}$ )}

3a) Calculate the effective stress intensity, Keff, due to the loading and flaw type and geometry.

Crack type:

Edge; Through Crack; 0 degree angle (Mode I)

According to Annex M Equation M. 6 there are only principal stresses

$\gamma \Delta \sigma_{\mathrm{p}}:=\mathrm{Mf}_{\mathrm{W}}\left(\mathrm{k}_{\mathrm{tm}} \cdot \mathrm{M}_{\mathrm{km}} \cdot \mathrm{M}_{\mathrm{m}} \cdot \Delta \sigma_{\mathrm{m}}+\mathrm{k}_{\mathrm{tb}} \cdot \mathrm{M}_{\mathrm{kb}} \cdot \mathrm{M}_{\mathrm{b}}\left(\Delta \sigma_{\mathrm{b}}+\left(\mathrm{k}_{\mathrm{m}}-1\right) \cdot \Delta \sigma_{\mathrm{m}}\right)\right) \quad$ BS 7910 Annex M (M. 6)

Typically in Hydraulic Steel Structures (HSS) are through cracks and surface cracks. Through cracks are more critical and more extensive inspection equipment is required to determine the surface crack geometry. Therefore all HSS cracks are to be assumed as through cracks. 


\section{Step 3: Calculate the fracture ratio ( $\mathrm{Kr}$ )}

3a) Calculate the effective stress intensity, Keff, due to the loading and flaw type and geometry.

Crack type:

Edge; Through Crack; 45 degree angle (Mixed Mode)

Note that mixed mode and shear controlled cracks have angles between 30 and 60 degrees.

Since the crack is mixed mode a K effective will need to be calculated

According to Annex M Equation M. 6 there are only principal stresses

$\gamma \Delta \sigma_{\mathrm{p}}:=\mathrm{Mf}_{\mathrm{W}}\left(\mathrm{k}_{\mathrm{tm}} \cdot \mathrm{M}_{\mathrm{km}} \cdot \mathrm{M}_{\mathrm{m}} \cdot \Delta \sigma_{\mathrm{m}}+\mathrm{k}_{\mathrm{tb}} \cdot \mathrm{M}_{\mathrm{kb}} \cdot \mathrm{M}_{\mathrm{b}}\left(\Delta \sigma_{\mathrm{b}}+\left(\mathrm{k}_{\mathrm{m}}-1\right) \cdot \Delta \sigma_{\mathrm{m}}\right)\right) \quad$ BS 7910 Annex M (M. 6)

Typically in Hydraulic steel structures (HSS) are through cracks and surface cracks. Through cracks are more critical and more extensive inspection equipment is required to determine the surface crack geometry. Therefore all HSS cracks are to be assumed as through cracks.

When no formula is specified in the BS 7910 or there is not enough data.

$\mathrm{a}:=\frac{\text { Crack }_{\text {length }}}{2}$

$B:=$ Flange $_{t}$

$\mathrm{w}:=$ Crack Cross_length

A 1 surface $:=2 \cdot a \cdot c$

$\mathrm{A}_{1 \text { embedded }}: 4 \cdot \mathrm{a} \cdot \mathrm{c}$

$A_{1 \text { through }}:=2 \cdot a \cdot B$

$A_{2}:=B \cdot w$

BS 7910 Annex M (M. 7)

$$
\mathrm{f}_{\mathrm{w} 1}:=\left(\sec \left(\frac{\pi \cdot \mathrm{A}_{1 \text { through }}}{2 \cdot \mathrm{A}_{2}}\right)\right)^{\frac{1}{2}}
$$

\section{Edge Crack}

Crack geometry: Crack length

Crack geometry: Crack depth

Crack geometry: crack cross length

Geometric factor: flaw type constant

Geometric factor: flaw type constant

Geometric factor: flaw type constant

Geometric factor: flaw type constant

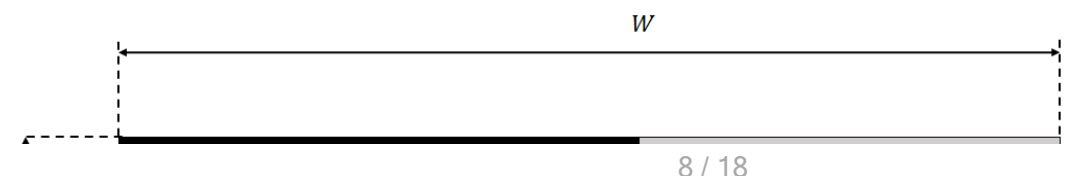



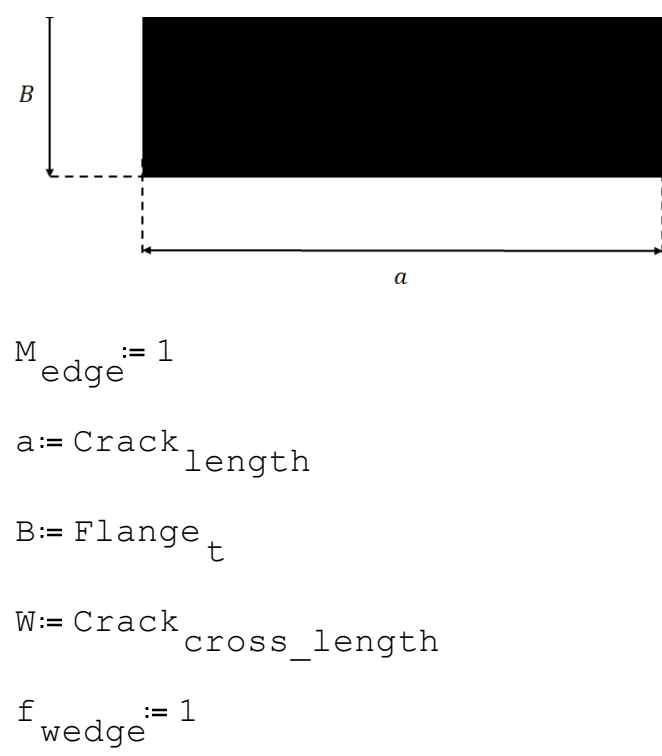

\section{BS 7910 Annex M (M.8)}

$$
\begin{array}{ll}
M_{\text {medge }}:=1.12-0.23 \cdot\left(\frac{a}{W}\right)+10 \cdot 6 \cdot\left(\frac{a}{W}\right)^{2}-21.7 \cdot\left(\frac{a}{W}\right)^{3}+30.4 \cdot\left(\frac{a}{W}\right)^{4} & \begin{array}{l}
\text { Flaw confiuration factor } \\
\text { Edge crack in tension }
\end{array} \\
M_{\text {bedge }}:=M_{\text {medge }} & \text { Flaw confiuration factor } \\
M_{\text {bedge }}=2.3449 & \text { Edge crack in bending }
\end{array}
$$

\section{Through Crack in plate}

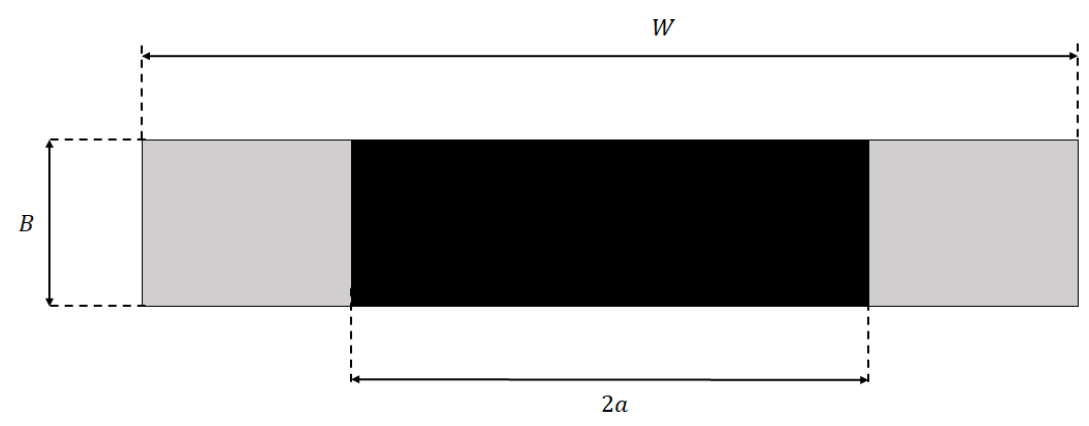

$\mathrm{M}_{\text {through }}:=1$

$\mathrm{M}_{\text {mthrough }} \mathrm{M}_{\text {th }}$

$M_{1 \_\ldots \ldots \ldots \ldots 1}:=M_{\perp \ldots \ldots}$
Flaw confiuration factor Through crack in tension

Flaw confiuration factor 
$a_{\text {through }}:=\frac{\text { Crack }_{\text {length }}}{2}$

Crack geometry: Crack length

$f_{\text {wthrough }}:=\left(\sec \left(\frac{\pi \cdot a_{\text {through }}}{w}\right)\right)^{\frac{1}{2}}$

Geometry Factor: Through crack

$\mathrm{f}_{\text {wthrough }}=1.1374$

$k t, k t m, k t b$, and $k m$ factors

Stresses at structural discontinuities or due to mixed mode stresses

\section{State of cracked section:}

-There are no misalignments, deviationfrom the intended shape, or structural discontinuities at the cracked section.

Therefore the factors are equal to 1

$\mathrm{k}_{t}:=1 \quad \mathrm{k}_{\mathrm{tm}}:=1 \quad \mathrm{k}_{\mathrm{tb}}:=1 \quad \mathrm{k}_{\mathrm{m}}:=1$

Factor for discontinuities or mixed mode 


\section{Mkm and Mkb factors}

Factors for flaws that are in regions of local stress concentration The areas are given in M11 of the BS7910. Areas of local stress concentrationsinclude the toe of a weld. Due to the complete joint penetration of the butt weld in the section, seen in the figure below, the crack formed in the area of a welded joint (a local stress concentration area).
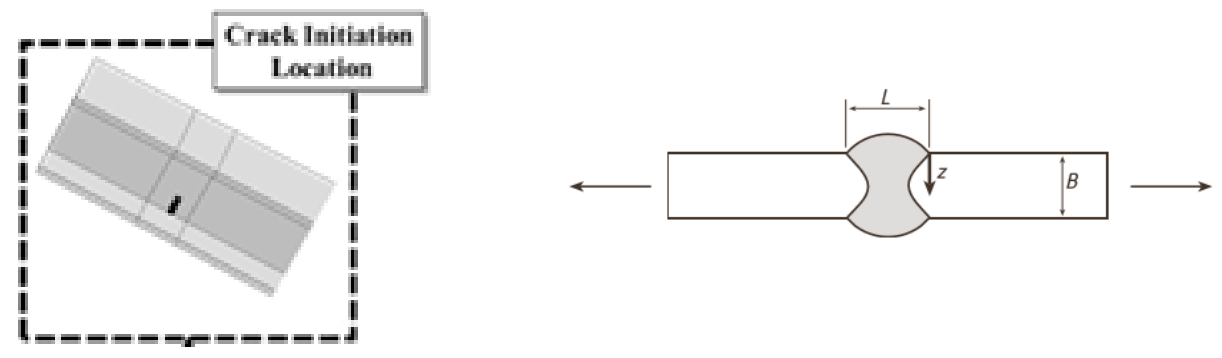

$$
\begin{aligned}
& B=0.019 \mathrm{~m} \\
& L_{\text {throat }}=0.019 \mathrm{~m} \\
& z:=0.019 \mathrm{~m}
\end{aligned}
$$

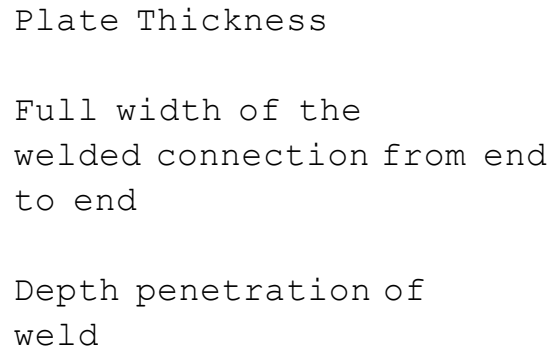

Values $\mathrm{V}$ and $\mathrm{w}$ are factors used in calculating the stress concentration factor Mk. These factors must be calculated for axial tension and bending.

$$
\begin{aligned}
& \mathrm{V}_{\text {axial }}:=\text { if } \frac{\mathrm{L}_{\text {throat }}}{\mathrm{B}} \leq 2 \\
& \text { if } \frac{z}{B} \leq 0.05 \cdot\left(\frac{L_{\text {throat }}}{B}\right)^{0.55} \\
& 0.51 \cdot\left(\frac{\mathrm{L} \text { throat }}{\mathrm{B}}\right)^{0.27} \\
& \text { else } \\
& 0.83 \\
& \text { else } \\
& \text { if } \frac{z}{B} \leq 0.073 \\
& 0.615 \\
& \text { else } \\
& 0.83
\end{aligned}
$$

$$
\begin{aligned}
& \text { waxial }_{\text {af }} \frac{\mathrm{L}_{\text {throat }}}{\mathrm{B}} \leq 2 \\
& \qquad \begin{aligned}
\mathrm{if} & \frac{\mathrm{z}}{\mathrm{B}} \leq 0.05 \cdot\left(\frac{\mathrm{L} \text { throat }}{\mathrm{B}}\right)^{0.55} \\
& -0.31
\end{aligned}
\end{aligned}
$$$$
\text { else }
$$$$
\text { else }
$$$$
-0.15 \cdot\left(\frac{L_{\text {throat }}}{B}\right)^{0.46}
$$$$
\text { if } \frac{z}{B} \leq 0.073
$$$$
-0.31
$$$$
\text { else }
$$

$$
-0.20
$$




$$
\begin{aligned}
& \mathrm{V}_{\text {bending }}:=\operatorname{if} \frac{\mathrm{L} \text { throat }}{\mathrm{B}} \leq 1 \\
& \text { if } \frac{z}{B} \leq 0.03 \cdot\left(\frac{L_{\text {throat }}}{B}\right)^{0.55} \\
& 0.45 \cdot\left(\frac{\mathrm{L} \text { throat }}{B}\right)^{0.21} \\
& \text { else } \\
& 0.68 \\
& \text { else } \\
& \text { if } \frac{z}{B} \leq 0.03 \\
& 0.45 \\
& \text { else } \\
& 0.68
\end{aligned}
$$

${ }^{\mathrm{w}}$ bending $:=$ if $\frac{\mathrm{L}_{\text {throat }}}{\mathrm{B}} \leq 1$

$$
\begin{aligned}
& \text { if } \frac{z}{B} \leq 0.03 \cdot\left(\frac{L \text { throat }}{B}\right)^{0.55} \\
& \quad-0.31 \\
& \text { else } \\
& \quad-0.19 \cdot\left(\frac{L \text { throat }}{B}\right)^{0.21} \\
& \text { else } \\
& \quad \text { if } \frac{z}{B} \leq 0.03 \\
& \quad-0.31 \\
& \text { else } \\
& \quad-0.19
\end{aligned}
$$

values used to calculate the local stress concetration factor Mk in axial tension and bending

$$
\begin{array}{ll}
\mathrm{v}_{\text {axial }}=0.83 & \mathrm{w}_{\text {axial }}=-0.1502 \\
\mathrm{~V}_{\text {bending }}=0.68 & \mathrm{w}_{\text {bending }}=-0.19
\end{array}
$$

Local stress concentration factors for axial and bending

$$
\begin{array}{ll}
\mathrm{M}_{\mathrm{km}}:=\mathrm{v}_{\text {axial }} \cdot\left(\frac{\mathrm{z}}{\mathrm{B}}\right)^{\mathrm{W}}{ }^{\text {axial }} & \mathrm{M}_{\mathrm{kb}}:=\mathrm{v}_{\text {bending }}\left(\frac{\mathrm{z}}{\mathrm{B}}\right)^{\mathrm{W}} \text { bending } \\
\mathrm{M}_{\mathrm{km}}=0.83 & \mathrm{M}_{\mathrm{kb}}=0.68
\end{array}
$$




\section{3b) Calculate $K$ factors for Mode I}

\section{Mode I:}

Mode I is axial

$$
\begin{aligned}
& \Delta \sigma_{\text {my }}:=\sigma_{\text {ydirection }} \quad \text { Axial tension stress } \\
& \Delta \sigma_{\mathrm{by}}:=0 \mathrm{MPa} \quad \text { Bending stress } \\
& \mathrm{M}:=\mathrm{M}_{\text {edge }} \mathrm{f}_{\mathrm{W}}:=\mathrm{f}_{\text {wedge }} \quad \text { Crack type and location factors } \\
& \mathrm{M}_{\mathrm{m}}:=\mathrm{M}_{\text {medge }} \mathrm{M}_{\mathrm{b}}:=\mathrm{M}_{\text {bedge }} \mathrm{f}_{\mathrm{W}}=1 \quad \text { Local stress concentration } \\
& \text { factors } \\
& \mathrm{V} \Delta \sigma_{\mathrm{p}}:=\mathrm{M} \cdot \mathrm{f}_{\mathrm{W}} \cdot\left(\mathrm{k}_{\mathrm{tm}} \cdot \mathrm{M}_{\mathrm{km}} \cdot \mathrm{M}_{\mathrm{m}} \cdot \Delta \sigma_{\mathrm{my}}+\mathrm{k}_{\mathrm{tb}} \cdot \mathrm{M}_{\mathrm{kb}} \cdot \mathrm{M}_{\mathrm{b}} \cdot\left(\Delta \sigma_{\mathrm{by}}+\left(\mathrm{k}_{\mathrm{m}}-1\right) \cdot \Delta \sigma_{\mathrm{my}}\right)\right) \\
& \gamma \Delta \sigma_{\mathrm{p}}=66.172 \mathrm{MPa} \\
& K_{I}:=\gamma \Delta \sigma_{p} \cdot \sqrt{\Pi \cdot a} \quad \text { stress intensity factor Mode I } \\
& \mathrm{K}_{\mathrm{I}}=34.9704 \mathrm{MPa} \cdot \sqrt{\mathrm{m}} \\
& K_{\text {eff }}:=K_{I} \\
& \text { Mode I effective stress intensity }
\end{aligned}
$$

\section{3d) Calculate $\mathrm{Kr}$}

$$
\mathrm{K}_{r}:=\frac{\mathrm{K}_{\mathrm{I}}}{\mathrm{K}_{\text {material }}}
$$$$
\mathrm{K}_{r}:=\frac{\mathrm{K}_{\mathrm{I}}}{\mathrm{K}_{\text {material }}}
$$

$K_{r}=0.4301$
According to Annex M.6 there are no secondary

stresses when evaluating for fatigue

Fracture assessment $K$ value used in FAD 


\section{4) Crack Assesment}

$$
L_{r}=0.0986 \quad K_{r}=0.4301
$$

The crack assessment is within the safe zone of the FAD. Therefore the crack does not require immediate attention. A fatigue crack life assessment using is required to determine the life expectancy of the crack.

FAD

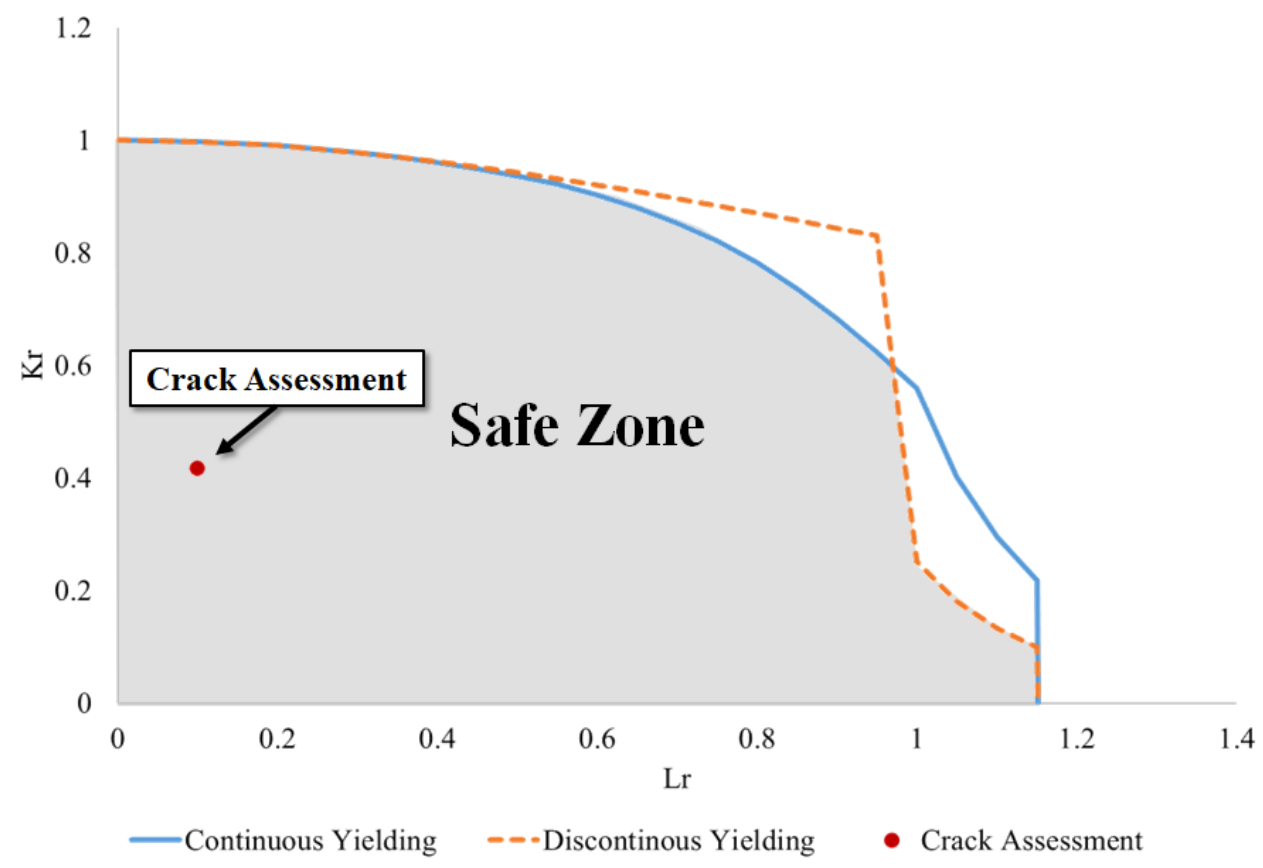

4a) Determine the flaw size acceptability and flaw size with Safety Factor

$a_{t h}:=\frac{\left(\frac{\Delta \mathrm{K}_{\mathrm{th}}}{\gamma \Delta \sigma_{\mathrm{p}}}\right)^{2}}{\Pi}$

$a_{t h}=0.0003 m$
Initial threshold flaw size

$$
\begin{aligned}
& a_{\text {material }}:=\frac{\left(\frac{K_{\text {material }}}{\gamma \Delta \sigma}\right)^{2}}{\Pi} \\
& a_{\text {material }}=0.4805 \mathrm{~m}
\end{aligned}
$$


Table 1 Factor of Safety based on failure consequence and section redundancy[1]

\begin{tabular}{cccccc}
\hline & $\begin{array}{c}\text { Standard } \\
\text { Deviation }\end{array}$ & Moderate & Severe & $\begin{array}{c}\text { Very } \\
\text { Severe }\end{array}$ & $\begin{array}{c}\text { Extremely } \\
\text { Severe }\end{array}$ \\
\hline \multirow{2}{*}{ Redundant Member } & 0.1 & 1 & 1.4 & 1.5 & 1.7 \\
& 0.2 & 1.05 & 1.45 & 1.55 & 1.8 \\
Non-Redundant & 0.3 & 1.08 & 1.5 & 1.65 & 1.99 \\
Member & 0.5 & 1.15 & 1.7 & 1.85 & 2.1 \\
& 0.1 & 1.4 & 1.5 & 1.7 & 2.1 \\
& 0.2 & 1.45 & 1.55 & 1.8 & 2.2 \\
& 0.3 & 1.5 & 1.65 & 1.99 & 2.3 \\
\hline
\end{tabular}

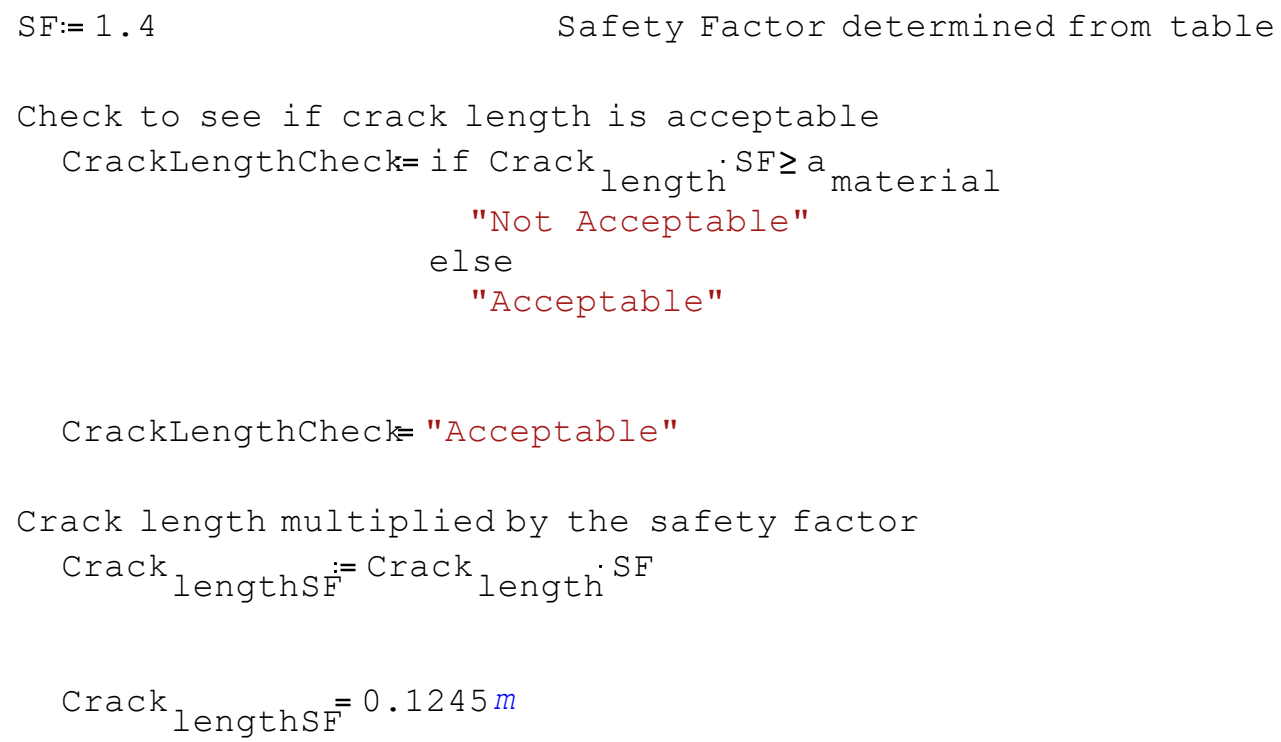

\section{4b) Determine if it is acceptable to use Paris Law}

Paris Law is utilized only within the limits of the threshold and critical crack growth.

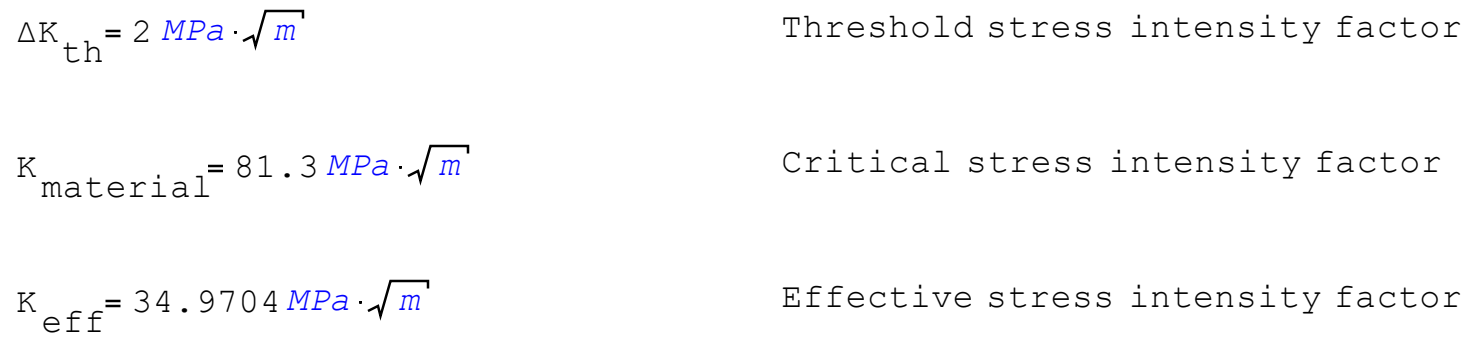

Check to see if use of the Paris Law is acceptable

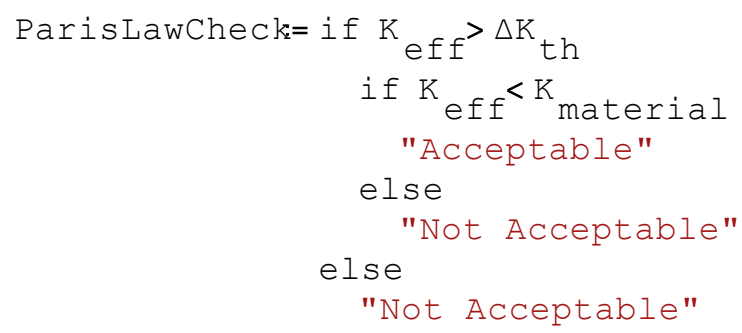


4c) Determine the number of cycles at the crack length, critical crack length, and the number of service life cycles.

where $\mathrm{x}$ is the crack length and $\mathrm{dx}$ is the change in crack length

$$
\begin{aligned}
& \mathrm{A}:=2.3 \cdot 10^{-12} \cdot \frac{\mathrm{mm}}{(\mathrm{MPa} \cdot \sqrt{\mathrm{m}})^{\mathrm{n}}} \\
& \mathrm{n}=3 \\
& \mathrm{\Delta} \sigma_{\mathrm{p}}=66.172 \mathrm{MPa} \\
& \mathrm{a}_{\text {th }}=0.0003 \mathrm{~m} \\
& \mathrm{a}_{\text {material }}=0.4805 \mathrm{~m} \\
& \text { Crack }_{\text {length }}=0.0889 \mathrm{~m} \\
& \text { Crack }_{\text {Cross_length }}=0.2032 \mathrm{~m}
\end{aligned}
$$

Paris Law

Fatigue and fracture factors based on environment and material

Fatigue and fracture factors based on environment and material Stress with factors included

Threshold crack length

critical crack length

Current crack length

Cross length of the section of crack growth-only because it is a mixed mode crack
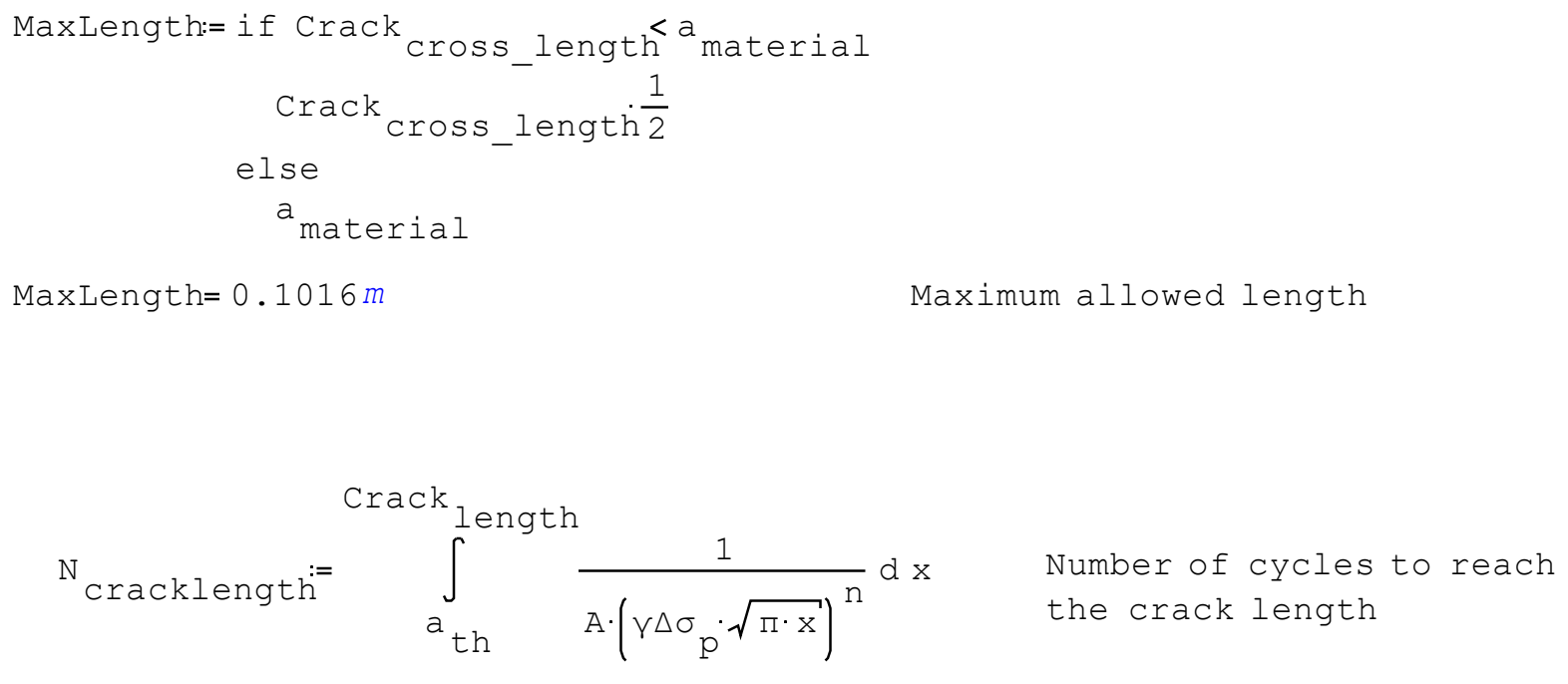


$$
\begin{aligned}
& A:=2 \cdot 3 \cdot 10^{-12} \cdot \frac{\mathrm{mm}}{(\mathrm{MPa} \cdot \sqrt{\mathrm{m}})^{\mathrm{n}}} \\
& \mathrm{n}=3 \\
& \mathrm{\Delta} \sigma_{\mathrm{p}}=66.172 \mathrm{MPa} \\
& \mathrm{a}_{\mathrm{th}}=0.0003 \mathrm{~m}
\end{aligned}
$$$$
\text { MaxLength }=0.1016 \mathrm{~m}
$$$$
N_{\text {maxlength }}:=\int_{a_{t h}^{\text {MaxLength }}}^{A \cdot\left(\gamma \Delta \sigma_{p} \cdot \sqrt{\pi \cdot x}\right)^{n}} d x
$$

Paris Law

Fatigue and fracture factors based on environment and material

Fatigue and fracture factors based on environment and material stress with factors included

Threshold crack length

Maximum allowed crack length
Number of cycles to reach maximum crack length
$\mathrm{N}_{\text {maxlengthnounits }}=\int_{a_{\operatorname{th}}^{\text {MaxLength }}} \frac{1}{2 \cdot 3 \cdot 10^{-12} \cdot(44 \cdot 4 \cdot \sqrt{\Pi \cdot x})^{n}} d x$

Number of cycles to reach the max crack length of $0.3253 \mathrm{~m}$
Number of cycles to reach maximum crack length 
The Tainter Valve sees a significant amount of cycles due to vibrations induced by the water flow. It is difficult to determine a reliable estimate of the cycles without a further FEM analysis. Therefore, to be conservative the rule of thumb should be followed all though the crack is within acceptable FFS and fracture limits.

A good rule of thumb if the crack length, and stress intensity, and FAD are all acceptable is if the crack is less than $3 / 8$ the cross section length then it is safe. If the crack is more than $3 / 8$ of the cross section length then it is best to repair.

State:= if $\frac{\text { Crack }}{\text { Crack }{ }_{\text {length }}}<\frac{3}{8}$
"Safe"
else
"Repair"

State= "Repair"

$\frac{\text { Crack }_{\text {length }}}{\text { Crack }}=0.4375$




\section{Acronyms}

AASHTO The American Association of State Highway and Transportation Officials

ACFM Alternating Current Field Measurement

AFRP Aramid Fiber Reinforced Polymers

AISC American Institute of Steel Construction

ASME American Society of Mechanical Engineers

AWS American Welding Society

BFRP Basalt Fiber Reinforced Polymer

CFRP Carbon Reinforced Polymer

ECA Engineering Critical Assessment

FAD Failure Assessment Diagram

FCM Fracture Critical Members

FEM Finite Element Model

FFS Fitness For Service

FRP Fiber Reinforced Polymers

GFRP Glass Fiber Reinforced Polymers

GTA Gas Tungsten Arc

HSS Hydraulic Steel Structure

LEFM Linear Elastic Fracture Mechanics 


$\begin{array}{ll}\text { LRFD } & \text { Load and Resistance Factor Design } \\ \text { MPI } & \text { Magnetic Particle Inspection } \\ \text { NDT } & \text { Non-Destructive Testing } \\ \text { SMA } & \text { Shape Memory Alloys } \\ \text { SMAW } & \text { Shielded Metal Arc Welding } \\ \text { TR } & \text { Technical Report } \\ \text { USACE } & \text { United States Army Corps of Engineers }\end{array}$




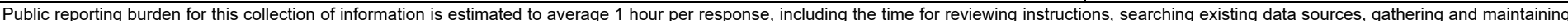

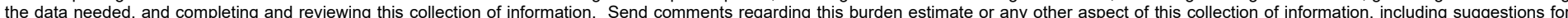

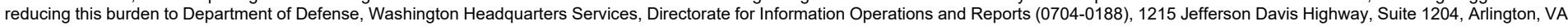

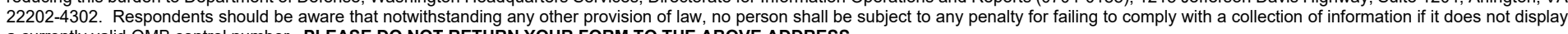
a currently valid OMB control number. PLEASE DO NOT RETURN YOUR FORM TO THE ABOVE ADDRESS.

\begin{tabular}{|l|l|l|} 
1. REPORT DATE (DD-MM-YYYY) & 2. REPORT TYPE & 3. DATES COVERED (FrOm - To)
\end{tabular} April 2021

\section{TITLE AND SUBTITLE} Final

Classical and Innovative Methods of Fatigue and Fracture Repairs in Navigation Steel Structures

5a. CONTRACT NUMBER

5b. GRANT NUMBER

5c. PROGRAM ELEMENT NUMBER

6. AUTHOR(S)

5d. PROJECT NUMBER

Christine M. Lozano and Guillermo A. Riveros

5e. TASK NUMBER

5f. WORK UNIT NUMBER

\section{PERFORMING ORGANIZATION NAME(S) AND ADDRESS(ES)}

Information Technology Laboratory

U.S. Army Engineer Research and Development Center

3909 Halls Ferry Road

Vicksburg, MS 39180-6199

9. SPONSORING / MONITORING AGENCY NAME(S) AND ADDRESS(ES)

U.S. Army Corps of Engineers

Washington, DC 20314-1000

8. PERFORMING ORGANIZATION REPORT NUMBER

ERDC/ITL TR-21-3

Washington, DC $20314-1000$

12. DISTRIBUTION / AVAILABILITY STATEMENT

Approved for public release; distribution is unlimited.

\section{SUPPLEMENTARY NOTES}

\section{ABSTRACT}

Most of the hydraulic steel structures (HSS) in the U.S. have reached or have past their design life, which leads to unsatisfactory performance. Welded connections with low fatigue resistance, poor weld quality, unanticipated structural behavior, or unexpected loading due to the deterioration of the design boundary conditions are the causes of fatigue cracking. The purpose of this report is to identify and evaluate the traditional and new methods used for fatigue and fracture repairs in navigation steel structures to restore their load carrying capacity and fatigue and fracture resistance. The final objective was to generate a guidance report comprising of recommended and more efficient repair methods for the different fatigue limit states observed in navigation steel structures.

\section{SUBJECT TERMS}

Hydraulic structures--Maintenance and repair Service life (Engineering)

\begin{tabular}{|c|c|c|}
\hline \multicolumn{3}{|c|}{ 16. SECURITY CLASSIFICATION OF: } \\
\hline a. REPORT & b. ABSTRACT & c. THIS PAGE \\
\hline Unclassified & Unclassified & Unclassified \\
\hline
\end{tabular}

Steel, Structural--Fatigue

Steel, Structural--Fracture

11. SPONSOR/MONITOR'S REPORT NUMBER(S)

10. SPONSOR/MONITOR'S ACRONYM(S)

17. LIMITATION OF ABSTRACT

SAR
18. NUMBER OF PAGES

132 19a. NAME OF RESPONSIBLE PERSON

19b. TELEPHONE NUMBER (include area code) 
